\title{
WestVirginiaUniversity
}

THE RESEARCH REPOSITORY @ WVU

Graduate Theses, Dissertations, and Problem Reports

2002

\section{Rubber toughening of glass-fiber -reinforced nylon 66}

\author{
Fares D. Alsewailem
}

West Virginia University

Follow this and additional works at: https://researchrepository.wvu.edu/etd

\section{Recommended Citation}

Alsewailem, Fares D., "Rubber toughening of glass-fiber -reinforced nylon 66" (2002). Graduate Theses, Dissertations, and Problem Reports. 2458.

https://researchrepository.wvu.edu/etd/2458

This Dissertation is protected by copyright and/or related rights. It has been brought to you by the The Research Repository @ WVU with permission from the rights-holder(s). You are free to use this Dissertation in any way that is permitted by the copyright and related rights legislation that applies to your use. For other uses you must obtain permission from the rights-holder(s) directly, unless additional rights are indicated by a Creative Commons license in the record and/ or on the work itself. This Dissertation has been accepted for inclusion in WVU Graduate Theses, Dissertations, and Problem Reports collection by an authorized administrator of The Research Repository @ WVU.

For more information, please contact researchrepository@mail.wvu.edu. 


\title{
Rubber Toughening of Glass-Fiber-Reinforced Nylon 66
}

Fares D. Alsewailem

\author{
Dissertation submitted to the \\ College of Engineering and Mineral Resources \\ at West Virginia University \\ in partial fulfillment of the requirements \\ for the degree of
}

\author{
Doctor of Philosophy \\ in \\ Chemical Engineering
}

\author{
Rakesh K. Gupta, Ph.D., Chair \\ John W. Zondlo, Ph.D. \\ Charter D. Stinespring, Ph.D. \\ Hota S. GangaRao, Ph.D. \\ Robert H. Wildi
}

Department of Chemical Engineering

\author{
Morgantown, West Virginia \\ 2002
}

Keywords: Thermoplastic, Nylon 66, Rubber, Toughness, Glass Fiber, Recycling

Copyright 2002 Fares D. Alsewailem 


\title{
Abstract \\ Rubber Toughening of Glass-Fiber-Reinforced Nylon 66
}

\author{
Fares D. Alsewailem
}

Glass fibers are commonly added to thermoplastics by the process of extrusion compounding for a variety of reasons, mainly to enhance their strength and make them dimensionally stable. Since the extruder has to be flushed out each time product composition is changed, a large amount of incompatible polymeric waste is generated. This waste material is usually landfilled even though the polymers contained in it are valuable and worth being recycled. It is the drastic reduction in mechanical properties resulting from polymer incompatibility which restricts their recycling. A good strategy of recycling thermoplastics calls for separating materials from each other before utilizing them. This research deals with characterizing and rubber toughening of a post industrial glass-fiber-reinforced nylon 66 which was separated from other polymers. A virgin glassfiber-reinforced nylon 66 was also used in order to compare its properties with those of the recycled ones.

Rubbers used in this study were Styrene-Ethylene-Butylene-Styrene and Ethylene-Propylene grafted with maleic anhydride; SEBS-g-MA and EP-g-MA. Composites of glass-fiber-reinforced nylon 66 with various rubber contents were prepared by extrusion. The pelletized extrudates were injection molded to different standard specimens for mechanical testing such as impact, tensile, and flexural. Flow properties of the composites were examined by the melt flow index and rotational viscometry. Morphology of the fractured surface of the composites was examined by scanning electron microscopy.

Elongation and impact strength of the composites were found to increase with increasing rubber content while tensile and flexural strength decrease with increasing rubber content. Elongation of the recycled material was slightly less than that of the virgin material. This is probably due to the presence of contaminants within the recycled material. The variation of rubber content with both tensile and flexural strengths was found to obey the rule of mixtures. The morphology of the fractured surfaces showed significant signs of plastic deformation such as shear bands and cavitations as rubber content increased, and this correlates well with mechanical properties which resulted in an increase in toughness of the composites when rubber content was increased. The results of this investigation clearly show the possibility of balancing strength and toughness of the material when adding rubber to a glass-fiber-reinforced nylon 66 . 


\section{Acknowledgments}

I would like to thank my research advisor Dr. Rakesh Gupta for his valuable advising and support during the work on my Ph.D. research and my entire graduate study at West Virginia University. I am also thankful to all members of my research committee for their encouragements to carry out this research. Special thank is extended to Dr. Charter Stinespring for his help with the sputtering machine and for giving me an access for the scanning electron microscope.

My appreciations and thanks are also extended to Mr. Mike Watson from SDR plastics for providing the recycled material and Mr. John F. Lathrop from DuPont for providing the virgin glass-fiber-reinforced nylon 66 and for his technical help regarding the virgin material. I would also like to thank Mr. Kim Ankney from kraton and Mr. Ron Liotta from ExxonMobile chemical company for their generous donations of SEBS-gMA and EP-g-MA rubbers.

The initial portion of this work was funded by an STTR grant from the U.S. Department of Energy to SDR Plastics of Ravenswood, WV in collaboration with Argonne National Laboratory and West Virginia University. 


\section{Table of Contents}

Page \#

Title page

$\begin{array}{lll}\text { Abstract } & \text { ii }\end{array}$

Acknowledgments

Table of contents iv

List of Tables vii

List of Figures viii

\section{Chapter 1}

Introduction

1.1 Background

1.2 Glass-fiber-reinforced thermoplastics 4

1.3 Rubber toughening of thermoplastics 5

1.4 Nylon 66: its properties and applications 9

1.5 Thermoplastics combined with rubber and glass fiber 11

1.6 Research objectives 11

\section{Chapter 2}

Review of fiber-reinforced and rubber-toughened thermoplastics

2.1 Glass-fiber-reinforced thermoplastics $\quad 13$

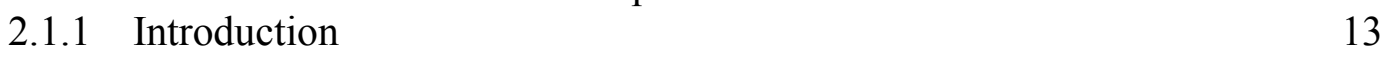

$\begin{array}{ll}\text { 2.1.2 Strength of fiber-reinforced polymers } & 17\end{array}$

$\begin{array}{ll}\text { 2.1.2.1 Stress-strain behavior } & 25\end{array}$

2.1.3 Impact strength of reinforced polymers 26

2.1.4 Effect of fiber surface on morphology of the matrix 30

$\begin{array}{lll}2.1 .5 & \text { Fracture toughness } & 31\end{array}$

2.1.6 Concluding remarks 35

2.2 Rubber toughening of thermoplastics 37

$\begin{array}{lll}2.2 .1 & \text { Introduction } & 37\end{array}$

2.2.2 Deformation mechanisms of polymers 37

$\begin{array}{ll}\text { 2.2.2.1 Shear yielding } & 37\end{array}$

$\begin{array}{ll}2.2 .2 .2 \text { Crazing } & 39\end{array}$

2.2.3 Theories of rubber toughening $\quad 42$ 
2.2.3.1 Multiple crazing theory 43

2.2.3.2 Shear yielding theory $\quad 44$

2.2.3.3 Simultaneous crazing and shear yielding 44

2.2.4 Strength of rubber-toughened polymers 45

2.2.5 Factors affecting the process of toughening 47

2.2.5.1 Effect of rubber phase morphology 51

2.2.5.2 Effect of temperature $\quad 55$

2.2.5.3 Effect of rubber type and its interaction with matrix material $\quad 57$

2.2.6 Review of rubber toughening of nylon $66 \quad 60$

2.2.6.1 Toughening mechanism of nylon $66 \quad 62$

2.2.7 Rubber toughening of glass-fiber-reinforced thermoplastics 64

2.2.7.1 Rubber-toughened glass-fiber-reinforced nylon $66 \quad 73$

$\begin{array}{lll}2.2 .8 \text { Conclusion } & 73\end{array}$

\section{Chapter 3}

Materials and procedure

$\begin{array}{lll}3.1 & \text { Materials used } & 75\end{array}$

$\begin{array}{lll}3.1 .1 & \text { Matrix } & 75\end{array}$

$\begin{array}{lll}3.1 .2 & \text { Rubbers } & 75\end{array}$

3.2 Procedure 76

3.2.1 Intrinsic viscosity of the recycled glass-fiber-reinforced nylon66 76

$\begin{array}{lll}3.2 .2 & \text { Sample preparation } & 79\end{array}$

3.2.3 Mechanical tests $\quad 83$

3.2.3.1 Izod impact strength $\quad 83$

3.2.3.2 Tensile strength $\quad 84$

3.2.3.3 Flexural strength $\quad 85$

3.2.4 Glass fiber length $\quad 86$

3.2.5 Thermal behavior $\quad 86$

3.2.6 Rheology tests $\quad 86$

3.2.6.1 Melt flow index $\quad 86$

$\begin{array}{ll}\text { 3.2.6.2 Shear viscosity and modulus } & 87\end{array}$

$\begin{array}{lll}\text { 3.2.7 Morphology of the fractured surface } & 87\end{array}$

\section{Chapter 4}

\section{Results and discussion}

4. Introduction 89

4.1 Mechanical properties $\quad 89$

$\begin{array}{lll}4.1 .1 & \text { Stress-strain data } & 89\end{array}$

4.1.2 Tensile properties of the composites 92

4.1.2.1 Modulus of elasticity $\quad 92$

4.1.2.2 Tensile strength 93

4.1.2.3 Elongation at break $\quad 100$

$\begin{array}{lll}4.1 .3 & \text { Flexural strength } & 102\end{array}$

$\begin{array}{lll}\text { 4.1.4 Impact strength } & 104\end{array}$ 
4.1.5 Tradeoff relationship between strength and toughness of the composites

4.2 Glass fiber length: its dependence on sample preparation 114

4.3 Morphology of the fracture surface of the composites 117

$\begin{array}{lll}4.4 & \text { Thermal properties } & 130\end{array}$

4.4.1 Thermal expansion 130

4.4.2 Heat of fusion of the composites 131

4.5 Rheology of the composites 134

4.5.1 Melt flow index 135

4.5.2 Viscosity and shear modulus of the composites 138

\section{Chapter 5}

Conclusions and recommendations

5.1 Conclusions 153

5.2 Recommendations 156

$\begin{array}{ll}\text { References } & 158\end{array}$

Appendix A

$\begin{array}{ll}\text { Glossary } & 168\end{array}$

\section{Appendix B}

Fitting the experimental viscosity data to Carreau model 172

\section{Appendix C}

Main mechanical properties data of the composites 


\section{List of Tables}

Page \#

Table 1-1 Effect of modifiers on properties of neat polymers 3

$\begin{array}{ll}\text { Table 1-2 Different grades of glass } & 6\end{array}$

$\begin{array}{lll}\text { Table 3-1 Rubber properties } & 76\end{array}$

Table 3-2 Extrusion composites of recycled and $\begin{array}{ll}\text { virgin nylon } 66 \text { with rubbers } & 81\end{array}$

Table 4-1 Modulus of elasticity of recycled and virgin composites 93

Table 4-2 Effect of material processing on glass fiber length

for recycled glass-fiber-reinforced nylon 66

Table 4-3 Effect of material processing on glass fiber length for virgin glass-fiber-reinforced nylon 66

Table A-1 Definitions of the important terminology used in this research

Table C-1 Tensile strength data for the recycled composites 182

Table C-2 Tensile strength data for the virgin composites 182

Table C-3 Elongation at break data for the recycled composites 183

Table C-4 Elongation at break data for the virgin composites 183

Table C-5 Flexural strength data for the recycled composites 184

Table C-6 Flexural strength data for the virgin composites 184

Table C-7 Impact strength data for the recycled composites 185

Table C-8 Impact strength data for the virgin composites 185 


\section{List of Figures}

Page \#

Figure 1-1 Crack toughening mechanisms in rubber toughened polymers

Figure 1-2 Strain-stress curves for PS and HIPS $\quad 8$

$\begin{array}{lll}\text { Figure 1-3 Nylon products and uses } & 10\end{array}$

Figure 2-1 Critical aspect ratio versus interfacial strength

for E glass, aramid, and C fibers $\quad 15$

Figure 2-2 Glass transition temperature in

glass-fiber-reinforced nylon $66 \quad 16$

Figure 2-3 Heat aging of nylon 66 with $50 \mathrm{wt} \%$ short glass fibers 17

Figure 2-4 Longitudinal tensile stress of

a continuous fiber composite

18

Figure 2-5 Longitudinal tensile stress of

$\begin{array}{ll}\text { a discontinuous fiber composite } & 21\end{array}$

Figure 2-6 Dependence of tensile strength of glass-fiber-reinforced thermoplastics on glass fiber content

Figure 2-7 Strength of glass-fiber reinforced nylon 66

versus fiber phase content

Figure 2-8 Stress-strain relationship for two types

of composite systems

Figure 2-9 Variation of impact strength with fiber volume content at different temperature for fiber-reinforced polypropylene

Figure 2-10 Variation of impact strength against interlayer thickness at various glass transition temperatures for glass fibers coated with latex

Figure 2-11 Optical micrograph for nylon 66 reinforced with Kevlar fibers

Figure 2-12 Schematic of stages in crack growth in a fiber composite 
Figure 2-13 Variation of fiber pull out fracture energy against fiber length $\quad 35$

Figure 2-14 The appearance of shear band 38

Figure 2-15 Shear bands for a blend of HIPS and PPO prepared under strain compression $\quad 39$

Figure 2-16 Craze formation in HIPS 40

Figure 2-17 Schematic of crack plus craze as suggested by Dugdale model $\quad 42$

Figure 2-18 Crazes and shear bands in a HIPS/PPO blend 45

Figure 2-19 Effective area model 46

Figure 2-20 Variation of yield stress with rubber content for ABS 47

Figure 2-21 Stress-strain curves for HIPS/PS/PPO blends at different weight fractions $\quad 48$

Figure 2-22 Rubber particle size versus toughness 49

Figure 2-23 Schematic of variation of shear modulus with temperature 50

Figure 2-24 Izod impact strength as a function of rubber particle size for (20/80) wt\% (SEBS and SEBS-g-MA/nylon 66) 52

Figure 2-25 Inter-particle distance (T) 52

Figure 2-26 Izod impact strength versus ligament thickness $\mathrm{T}$ for rubber/nylon 66 blend system $\quad 53$

Figure 2-27 Izod impact strength versus rubber particle size for nylon 6 and $20 \mathrm{wt} \%$ rubber $\quad 55$

Figure 2-28 Izod impact strength versus temperature for SAN (0 \% rubber) and for a series of ABS containing 6-20\% polybutadiene $\quad 56$

Figure 2-29 Izod impact strength versus temperature for nylon 6 blends with various elastomers (26 vol\%) 
Figure 2-30 Izod impact strength for nylon 6 blended with $20 \%$ (SEBS and SEBS-g-MA)

at various ratios of SEBS/SEBS-g-MA

Figure 2-31 Izod impact strength for nylon 66 blended with (SEBS and SEBS-g-MA) at various ratios of SEBS/SEBS-g-MA

Figure 2-32 Schematic of attachment of nylon to maleic anhydride

Figure 2-33 The interaction between nylon and anhydride

Figure 2-34 Izod impact strength versus temperature for nylon and nylon blended with rubber

Figure 2-35 Stress whitening (sw) on fractured samples of nylon and its blends with rubber

Figure 2-36 Stiffness-toughness trade off for nonreinforced and reinforced nylon 6 toughened with ABS

Figure 2-37 Toughening of reinforced nylon 6 with ABS and EP-g-MA

Figure 2-38 Izod impact strength versus temperature for glass fiber reinforced nylon 66 toughened by EP as a function of fiber volume fraction

Figure 2-39 Stress-strain curves for (nylon 6/EP-g-MA/glass fiber)

Figure 2-40 Izod toughness versus glass fiber content for various blends of SMA and ABS

Figure 2-41 Tensile impact strength versus elastomer concentration for PP composites

Figure 2-42 Shear storage modulus versus elastomer concentration for PP composites

Figure 3-1 Setup used to measure relative viscosity of recycled nylon

Figure 3-2 Sample preparation and molding

Figure 3-3 Procedure of impact strength test 
Figure 3-5 Flexural test procedure

$\begin{array}{lll}\text { Figure 3-6 Torsion test performed by RMS } 800 & 88\end{array}$

Figure 4-1 Stress-strain behavior of virgin glass-fiber-reinforced nylon 66 toughened with EP-g-MA and SEBS-g-MA rubbers at two glass fiber contents: (a) $14.79 \mathrm{wt} \%$, (b) $23.62 \mathrm{wt} \%$

Figure 4-2 Stress-strain behavior of recycled glass-fiber-reinforced nylon 66 toughened with EP-g-MA and SEBS-g-MA rubbers at two glass fiber contents: (a) $14.79 \mathrm{wt} \%$, (b) $23.62 \mathrm{wt} \%$

Figure 4-3 Tensile strength vs. rubber phase concentration for recycled and virgin nylon 66 at two different glass fiber loadings: (a) $14.79 \mathrm{wt} \%$, (b) $23.62 \mathrm{wt} \%$

Figure 4-4 Tensile strength vs. glass fiber content for the virgin composites at $15 \mathrm{wt} \%$ rubber content

Figure 4-5 Comparison of tensile strength of virgin composites with the rule of mixtures

Figure 4-6 Yield strength vs. rubber content for rubber toughened virgin material with $23.62 \mathrm{wt} \%$ glass fiber

Figure 4-7 Elongation at break vs. tensile strength for all composites at two different glass fiber loadings: (a) $14.79 \mathrm{wt} \%$, (b) $23.62 \mathrm{wt} \%$

Figure 4-8 Flexural strength vs. rubber content for recycled and virgin composites at two different glass fiber loadings: (a) $14.79 \mathrm{wt} \%$, (b) $23.62 \mathrm{wt} \%$

Figure 4-9 Comparison of flexural strength of virgin composites with rule of mixtures

Figure 4-10 Izod impact strength vs. rubber weight percent for recycled and virgin nylon 66 at two different glass fiber content: (a) $14.79 \mathrm{wt} \%$, (b) $23.62 \mathrm{wt} \%$

Figure 4-11 Variation of impact strength vs. glass fiber content for the virgin composites at $15 \mathrm{wt} \%$ rubber content

Figure 4-12 Impact strength vs. temperature for fiber-reinforced polypropylene 
Figure 4-13 Effect of temperature on glass fiber reinforced nylon 66 toughened with EP-g-MA at two different glass fiber contents: (a) $14.79 \mathrm{wt} \%$, (b) $23.62 \mathrm{wt} \%$

Figure 4-14 Effect of temperature on glass fiber reinforced nylon 66 toughened with SEBS-g-MA at two different glass fiber contents: (a) $14.79 \mathrm{wt} \%$, (b) $23.62 \mathrm{wt} \%$

Figure 4-15 The tradeoff relationship between toughness and strength of the virgin composites. (a) EP-g-MA, (b) SEBS-g-MA

Figure 4-16 SEM micrographs of the fracture surface of the Izod samples for the recycled composites

Figure 4-17 SEM micrographs of the fracture surface of the Izod samples for the virgin composites with EP-g-MA

Figure 4-18 SEM micrographs of the fracture surface of the Izod samples for the virgin composites with SEBS-g-MA

Figure 4-19 The alignment of glass fibers parallel to flow direction in the injection molding for Izod sample having $23.62 \mathrm{wt} \%$ glass fiber

Figure 4-20 SEM micrographs of the fracture surface of the Izod samples at the notch for the virgin composites with $23.62 \mathrm{wt} \%$ glass fiber and various rubber $\mathrm{wt} \%$

Figure 4-21 SEM micrographs of the fracture surface of the Izod samples ( at $\mathrm{T}=103.5^{\circ} \mathrm{C}$ ) for the virgin composites

Figure 4-22 SEM micrographs of the fracture surface of the tensile samples of the recycled composites with $23.62 \mathrm{wt} \%$ glass fiber and various EP-g-MA wt $\%$

Figure 4-23 SEM micrographs of the fracture surface of the tensile samples of the virgin composites with $23.62 \mathrm{wt} \%$ glass fiber and various EP-g-MA wt\%

Figure 4-24 SEM micrographs of the fracture surface of the flexural samples

Figure 4-25 Coefficient of thermal expansion for the composites: (a) EP-g-MA, (b) SEBS-g-MA 
Figure 4-26 Heat of fusion of the composites at different rubber and glass fiber contents: (a) $14.79 \mathrm{wt} \%$, (b) $23.62 \mathrm{wt} \%$ glass fibers

Figure 4-27 Effect of rubber and glass fiber on crystallinity of nylon 66

Figure 4-28 Melt flow rate for the composites vs. EP-g-MA rubber content at different glass fiber loadings: (a) $14.79 \mathrm{wt} \%$, (b) $23.62 \mathrm{wt} \%$

Figure 4-29 Melt flow rate for the composites vs. SEBS-g-MA rubber content at different glass fiber loadings: (a) $14.79 \mathrm{wt} \%$, (b) $23.62 \mathrm{wt} \%$

Figure 4-30 Flow behavior of the glass fiber reinforced nylon 66 toughened by different weight percent of SEBE-g-MA: (a) Virgin, (b) Recycled

Figure 4-31 Flow behavior of the glass fiber reinforced nylon 66 toughened by different weight percent of EP-g-MA: (a) Virgin, (b) Recycled

Figure 4-32 Variation of zero shear viscosity for the virgin composites against rubber weight fraction at $14.79 \mathrm{wt} \%$ glass fibers with (a) SEBS-g-MA and (b) EP-g-MA

Figure 4-33 Variation of zero shear viscosity for the virgin composites against rubber weight fraction at $23.62 \mathrm{wt} \%$ glass fibers with (a) SEBS-g-MA and (b) EP-g-MA

Figure 4-34 Shear storage modulus for recycled composites at different rubber content: (a) EP-g-MA, (b) SEBS-g-MA

Figure 4-35 Shear storage modulus for virgin composites at different rubber content: (a) EP-g-MA, (b) SEBS-g-MA

Figure 4-36 Shear loss modulus for recycled composites at different rubber content: (a) EP-g-MA, (b) SEBS-g-MA

Figure 4-37 Shear loss modulus for virgin composites at different rubber content: (a) EP-g-MA, (b) SEBS-g-MA

Figure 4-38 Shear storage modulus vs. temperature for virgin composites with $14.79 \mathrm{wt} \%$ glass fiber content and different rubber weight fractions: (a) SEBS-g-MA, (b) EP-g-MA 
Figure 4-39 Shear storage modulus vs. temperature for virgin composites with $23.62 \mathrm{wt} \%$ glass fiber content and different rubber weight fractions: (a) SEBS-g-MA, (b) EP-g-MA

Figure B-1 Fitting viscosity vs. shear rate to Carreau model for the $23.62 \mathrm{wt} \%$ glass fiber toughened with various weight percent of SEBS-g-MA

Figure B-2 Fitting viscosity vs. shear rate to Carreau model for the $23.62 \mathrm{wt} \%$ glass fiber toughened with various weight percent of SEBS-g-MA

Figure B-3 Fitting viscosity vs. shear rate to Carreau model for the $23.62 \mathrm{wt} \%$ glass fiber toughened with $20 \mathrm{wt} \%$ SEBS-g-MA

Figure B-4 Fitting viscosity vs. shear rate to Carreau model for the $23.62 \mathrm{wt} \%$ glass fiber toughened with various weight percent of EP-g-MA

Figure B-5 Fitting viscosity vs. shear rate to Carreau model for the $23.62 \mathrm{wt} \%$ glass fiber toughened with various weight percent of EP-g-MA

Figure B-6 Fitting viscosity vs. shear rate to Carreau model for the $14.79 \mathrm{wt} \%$ glass fiber toughened with various weight percent of EP-g-MA

Figure B-7 Fitting viscosity vs. shear rate to Carreau model for the $14.79 \mathrm{wt} \%$ glass fiber toughened with various weight percent of EP-g-MA

Figure B-8 Fitting viscosity vs. shear rate to Carreau model for the $14.79 \mathrm{wt} \%$ glass fiber toughened with $20 \mathrm{wt} \%$ EP-g-MA

Figure B-9 Fitting viscosity vs. shear rate to Carreau model for the $14.79 \mathrm{wt} \%$ glass fiber toughened with various weight percent of SEBS-g-MA

Figure B-10 Fitting viscosity vs. shear rate to Carreau model for the $14.79 \mathrm{wt} \%$ glass fiber toughened with various weight percent of SEBS-g-MA 


\section{Chapter 1}

\section{Introduction}

\subsection{Background}

Recycling of thermoplastics has a clear effect on preserving the environment by reducing the amount of waste materials that are landfilled. It is estimated that plastics wastes form $20 \%$ by volume of all solid wastes [1]. Thermoplastic resins may be categorized into two groups: engineering thermoplastics and commodity thermoplastics. Engineering thermoplastics are those thermoplastics used for engineering applications due to their excellent properties even at elevated temperatures. Commodity plastics, which usually cost less than $\$ 1$ per pound, refers to those thermoplastics which possess fair properties but which can generally not be used in an elevated temperature environment. From an economic point of view engineering thermoplastics such as nylon, polycarbonate $(\mathrm{PC})$, polyethylene terephthalate $(\mathrm{PET})$, etc are favorable to recycle over commodity plastics such as polyethylene(PE), polystyrene(PS), polypropylene(PP), etc due to their relatively high sale price. Also, the feedstock for recycling comes mainly from two different sources, post consumer and post industrial. Post consumer polymers are materials that are rejected by humans after using them. Examples of post consumer materials are packaging, disposable food and drink containers (e.g. high density polyethylene (HDPE) milk jugs, PET bottles, etc), plastics from used electronics, and obsolete cars. The other source, post industrial, may be divided into two types: first is the waste generated during the processes of shaping and molding of thermoplastics. This waste, called "regrind", is simply the excess of materials being molded and shaped by processing machines such as extruders and injection molding machines. Usually this 
waste "regrind" is re-fed with virgin material and processed again. The second type of post industrial material and the more important one is the waste that accumulates during fabrication and modification of virgin plastics during blending operations. For example, in the manufacture of fiber-reinforced-plastics via extrusion compounding, the extruder must be purged at the end of each run and upon shut down. Mainly, low density polyethylene is used as a purge material. Purging results in a mixture of two plastics. This kind of waste is usually landfilled due to some factors that are discussed below. Often material which needs to be recycled comes in a waste stream where it is associated with other different materials. One could reprocess these materials and use them in applications where superior properties are not important, this is because blending of different polymeric materials results mostly in the formation of immiscible systems which exhibit poor mechanical and physical properties. In applications where excellent properties are required, the recycled material must be separated from other materials in the waste stream. In the second type of post industrial recycling, one may not have a 100 percent pure stream of the targeted material due to melt mixing with purging material. This could lead to poor product performance because of incompatibility. Also when working with glass-reinforced-polymers from different batches, the waste product would vary in glass fiber content. Furthermore, the fact that extrusion is usually done at high temperatures and the fact that quenching of waste polymer is done with water may result in obtaining some degraded and burnt parts. This itself makes clear the importance of characterizing waste material before utilizing it to decide whether it is eligible for recycling into high-value products or not. Perhaps molecular weight measurement is the effective way to know if one is dealing with non-degraded material or not. Once the 
recycled material has been separated and characterized, it is ready to be reused. Here one should realize that properties of the recycled material would generally not match the properties of the virgin material; so the challenge here is to have recycled material with properties close enough to that of virgin material. In particular, properties such as mechanical properties, especially impact and tensile strength, can be altered by adding reinforcing agents such as glass fibers and/or elastomers. When incorporating either rubber which acts as a toughening agent or fibrous reinforcement to the neat polymers some properties may be improved while others may deteriorate or stay unchanged (see Table 1-1).

The present research deals with rubber toughening of a post industrial nylon 66 filled with glass fibers. This waste is generated when glass fibers are compounded with nylon 66. It is therefore important to discuss rubber toughening and glass fiber reinforcing of thermoplastics. More attention will be given to nylon 66 .

Table 1-1 Effect of modifiers on properties of neat polymers [2].

\begin{tabular}{c|c|c}
\hline Property & Tougheners & Glass Fibers \\
\hline Tensile strength & $\downarrow$ & $\uparrow$ \\
Elongation & - & $\downarrow$ \\
Flexural modulus & $\downarrow$ & $\uparrow$ \\
Izod impact & $\uparrow$ & $\uparrow^{*}$ \\
Shear strength & $\downarrow$ & $\uparrow$ \\
Creep deformation under & $\uparrow$ & $\downarrow$ \\
stress with time & $\downarrow$ & $\uparrow$ \\
Heat deflection temperature & $\downarrow$ & $\uparrow$ \\
Hardness & $\downarrow$ & $\downarrow$ \\
Melt flow & &
\end{tabular}

$\downarrow$ Decreased ,-Little or no change, $\uparrow$ Increased

* Not for all polymers (see section 1.2) 


\subsection{Glass fiber reinforced thermoplastics}

Existing neat polymers such as nylon have known physical, mechanical, and thermal properties which depend on molecular weight. There is however always a need to improve properties of thermoplastics to meet some specific applications such as underthe-hood applications where humidity, high temperature, and repeated impact are encountered. One way to alter properties of thermoplastics is to reinforce them with glass fibers. There are several innate characteristics of glass fibers which make them ideal reinforcements [3]

- High tensile strength to weight ratio.

- They are perfect elastic materials (typical glass fibers have a maximum elongation of $5 \%$ at break).

- They are incombustible (typical glass fibers retain approximately $50 \%$ of their strength at $\left.700^{\circ} \mathrm{F}\right)$. Also they have a low thermal expansion coefficient.

- They do not absorb moisture and do not swell, stretch, or undergo chemical change through moisture contact.

- They are dimensionally stable.

- They are corrosion resistant.

Adding up to $40 \%$ by weight of glass fibers to thermoplastics increases strength and rigidity and decreases the coefficient of thermal expansion. In other properties, impact strength and heat distortion temperature, the improvement depends very much on the specific thermoplastics. The most significant effect in thermoplastics is the retention of impact strength down to very low temperatures. The heat distortion temperature is improved most markedly in nylon, but less so in most other thermoplastics [3]. The 
relationship between glass fiber content and impact strength is not always linear. With low modulus thermoplastics, the optimum impact strength may or may not be reached at less than the maximum practical glass content. Normally, room temperature impact strengths of low modulus of elasticity materials such as polypropylene suffer by incorporating glass fibers. With rigid thermoplastics such as polystyrene, notable improvement in room temperature impact strengths usually occur with increasing glass fiber content. In virtually all thermoplastics, impact strengths at low temperatures improve with increasing glass fiber content [3]. There are several grades of glass that are commonly available in fibers (see Table 1-2). Over $90 \%$ of the glass fibers used for reinforcement are of the E-glass type which has good mechanical properties and very good bonding to most thermoplastics since an appropriate coupling agent is employed [4]. Continuous filament glass fibers normally have diameters ranging from 2.54 to 19.05 $\mu \mathrm{m}$. Commercial glass fibers are produced in a variety of forms. These forms include rovings, chopped strands, mats, fabrics, and woven rovings. Chopped glass fiber strands and polymer powder or pellets may be melt blended in a compounding extruder.

\subsection{Rubber toughening of thermoplastics}

Toughness may be defined as the ability to absorb a large amount of energy before failure [5]. Before crack propagation occurs, a material tends to craze if it is brittle such as Polystyrene or shear yield if it is ductile such as nylon. A combination of crazing and shear yielding is possible to observe in some rubber-toughened polymers such as ABS. Crazing usually consists of an array of voids and fibrils which easily break down to form cracks [5]. Figure 1-1 shows different kinds of rubber toughening mechanisms that might take place in a crack. To show an example of toughened material let us 
Table 1-2 Different grades of glass $[3,4]$.

\begin{tabular}{|l|l|l|l|}
\hline Type & Specific gravity & $\mathrm{SiO}_{2}$ content, $\mathrm{wt} \%$ & Description \\
\hline $\mathrm{A}$ & 2.50 & 72 & $\begin{array}{l}\text { Glass of soda-lime composition similar } \\
\text { to bottle glass. Poor thermal and } \\
\text { chemical properties. }\end{array}$ \\
\hline $\mathrm{C}$ & 2.49 & 65 & $\begin{array}{l}\text { Chemically resistant soda-lime- } \\
\text { borosilicate glass used for its high } \\
\text { corrosion and chemical attack } \\
\text { resistance. }\end{array}$ \\
\hline $\mathrm{D}$ & 2.16 & - & $\begin{array}{l}\text { A low-density glass with high electrical } \\
\text { resistance. }\end{array}$ \\
\hline $\mathrm{E}$ & 2.54 & $52-56$ & $\begin{array}{l}\text { Pyrex composition glass Good } \\
\text { electrical properties and good for } \\
\text { general-purpose application when a } \\
\text { combination of good strength and } \\
\text { chemical resistance is observed. }\end{array}$ \\
\hline $\mathrm{S}$ & 2.49 & 65 & $\begin{array}{l}\text { A high-strength, high-modular glass for } \\
\text { specific applications. Higher in cost. }\end{array}$ \\
\hline
\end{tabular}

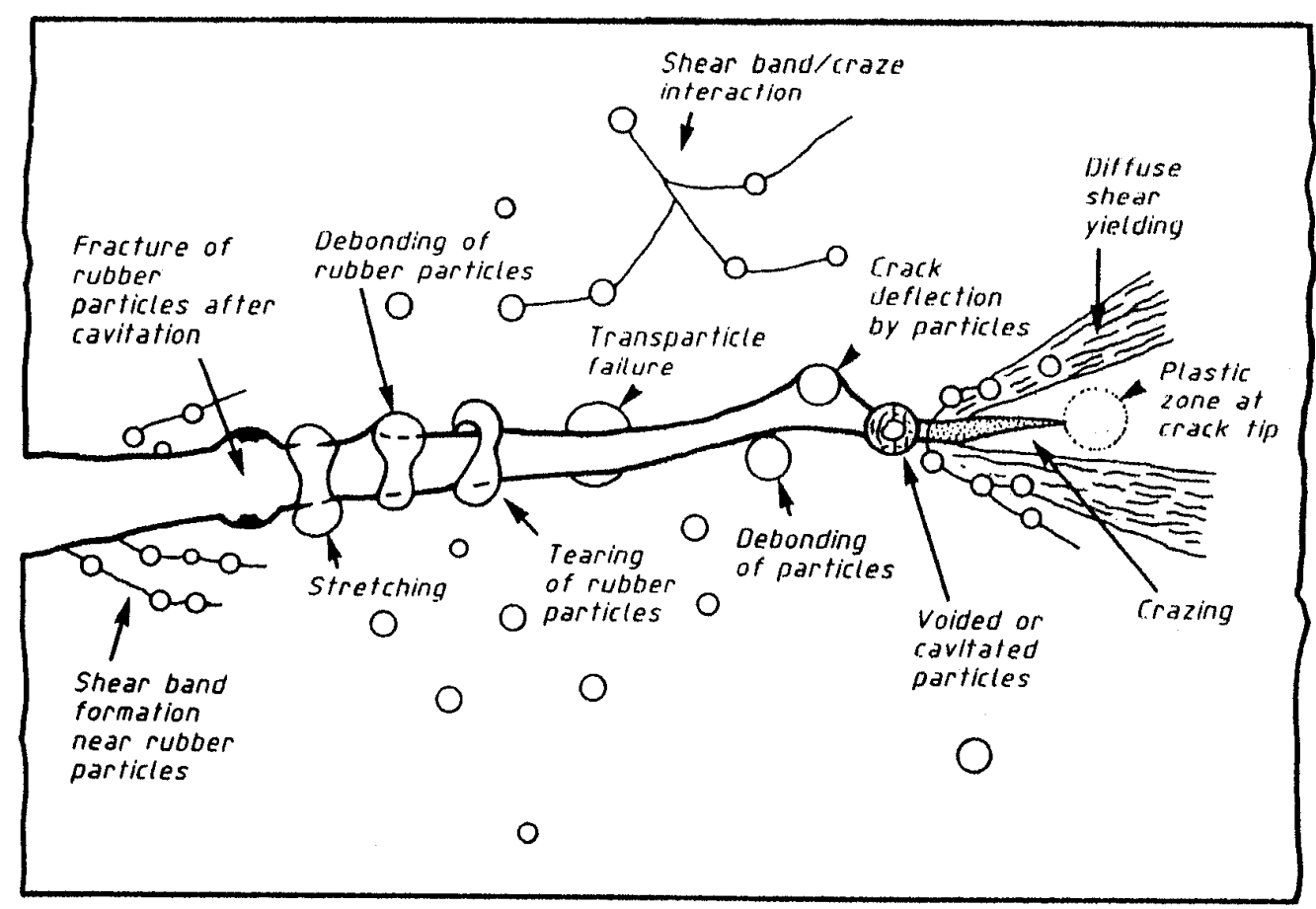

Figure 1-1 Crack toughening mechanisms in rubber-toughened polymers [5]. 
consider polystyrene which is a glassy brittle material that tends to fracture before yielding. Crazing happens before fracture, but not to a great extent. However, when rubber is added to PS to form HighImpactPolystyrene (HIPS) a great amount of crazes are promoted which make fracture occur only at high strains ( see Figure 1-2). The notched Izod impact strength is the common method of measuring toughness; a material having an Izod impact strength of $0.0935 \mathrm{ft}-\mathrm{lb} / \mathrm{in}(5 \mathrm{~J} / \mathrm{m})$ is considered tough while a material with $9.911 \mathrm{ft}-\mathrm{lb} /$ in $(530 \mathrm{~J} / \mathrm{m})$ is designated as super tough [5]. Amorphous thermoplastics such as PS are used in service below their glass transition temperature $\left(\mathrm{T}_{\mathrm{g}}\right)$ where molecules are frozen and when rapid impact leads to sample rupture. However, creep is minimal and they are notch sensitive and brittle at these temperatures. Semicrystalline thermoplastics such as nylon 66 may be used in service above their $T_{g}$; they are tough but molecules are able to move in the amorphous regions which causes them to creep significantly under load. At room temperature, semicrystalline thermoplastics are brittle due to their high $\mathrm{T}_{\mathrm{g}}$ values. The exception to this is $\mathrm{PE}$ whose $\mathrm{T}_{\mathrm{g}}$ is far below room temperature which makes it a tough material at room temperature. Another way to define a tough polymer is by the idea of entanglements via melt rheology. Tough polymers are those which have a high density of entanglements.

Rubber toughened thermoplastics have been classified into two groups. Type I are vinyl polymers which tend to fail by crazing and type II are those that consist of main chain aromatic polymers which fail by shear yielding [7]. Type I polymers are brittle at 10-20 ${ }^{\circ} \mathrm{C}$ below their $\mathrm{T}_{\mathrm{g}}$ [7-10]; and they have low notched and unnotched impact strengths. PS and StyreneAcryloNitrile (SAN) are examples of this group. 


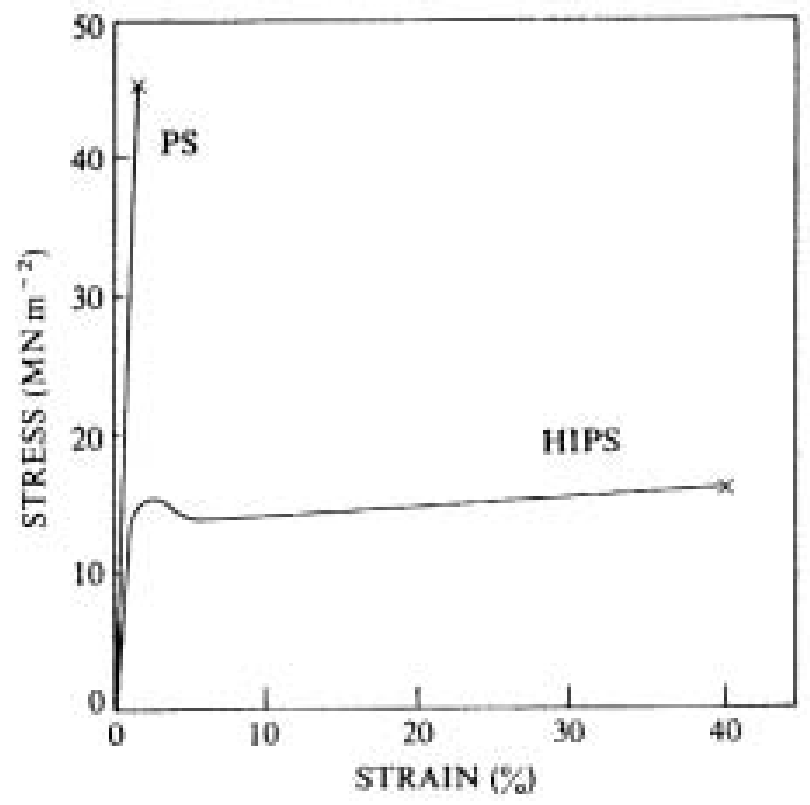

Figure 1-2 Strain-stress curves for PS and HIPS [6].

Type II polymers are brittle under some certain conditions and for this reason they are called pseudo-ductile polymers. Due to their low crack propagation energy, they possess high unnotched impact strength but low notched impact strength. In this class of material, i.e. type II, a brittle to tough temperature or $\mathrm{T}_{\mathrm{bt}}$ is recognized. Nylon, PC, and PET are examples of this group. It should be mentioned here that not all polymers would fall into type I and type II classification. Materials like polyvinylchloride (PVC) which is less ductile than type II and polymethylmethaacrylate (PMMA) which is less brittle than type I are classified as polymers having properties intermediate between type I and type II. 


\subsection{Nylon 66: its properties and applications}

Nylon 66 is synthesized by condensation polymerization of hexamethylenediamine and adipic acid. It is crystalline, and the crystals melt at a high temperature, 255-265 ${ }^{\circ} \mathrm{C}$. This makes it a good candidate for applications where properties such as high strength, excellent chemical and abrasion resistance, and toughness are sought. Molecular weights for nylon 66 range typically from as low as 15,000 for injection molding to values as high as 24,000 for extrusion applications. In spite of its superior properties, nylon 66 is very sensitive to moisture absorption. Indeed, moisture content must be controlled during melt processing of nylon 66. Nylon 66 is considered a tough material (its Izod impact strength $=0.9 \mathrm{ft}-\mathrm{lb} / \mathrm{in}(48.13 \mathrm{~J} / \mathrm{m})$ ) and for this feature it is being used in various applications such as motor housings, gears, etc. Adding glass fibers to nylon 66, e.g. $13 \mathrm{wt} \%$, would enhance its tensile strength from 12 kpsi (82.74 MPa) to about $17.5 \mathrm{kpsi}(120.73 \mathrm{MPa})$; however, the impact strength would not be improved. Figure 1-3 shows possibility of tailoring nylon to meet required properties. One of the products included in Figure 1-3 is Zytel® GRZ which is the source of the recycled material that we have worked with in this project. This is basically nylon 66 reinforced with glass fibers to increase stiffness, strength, dimensional stability and resistance to creep at elevated temperatures in order for use mainly for under-the-hood applications such as radiator endtanks and fans. Indeed, most of nylon 66 applications are in the automotive area. Mineral reinforced nylon 66 grades are also widely used in exterior auto body parts such as mirror housings, wheel covers, and fuel filler doors because they withstand paint oven temperatures, have good dimensional stability, and can withstand the end-use environment. Toughened and glass-fiber-reinforced nylon 66 


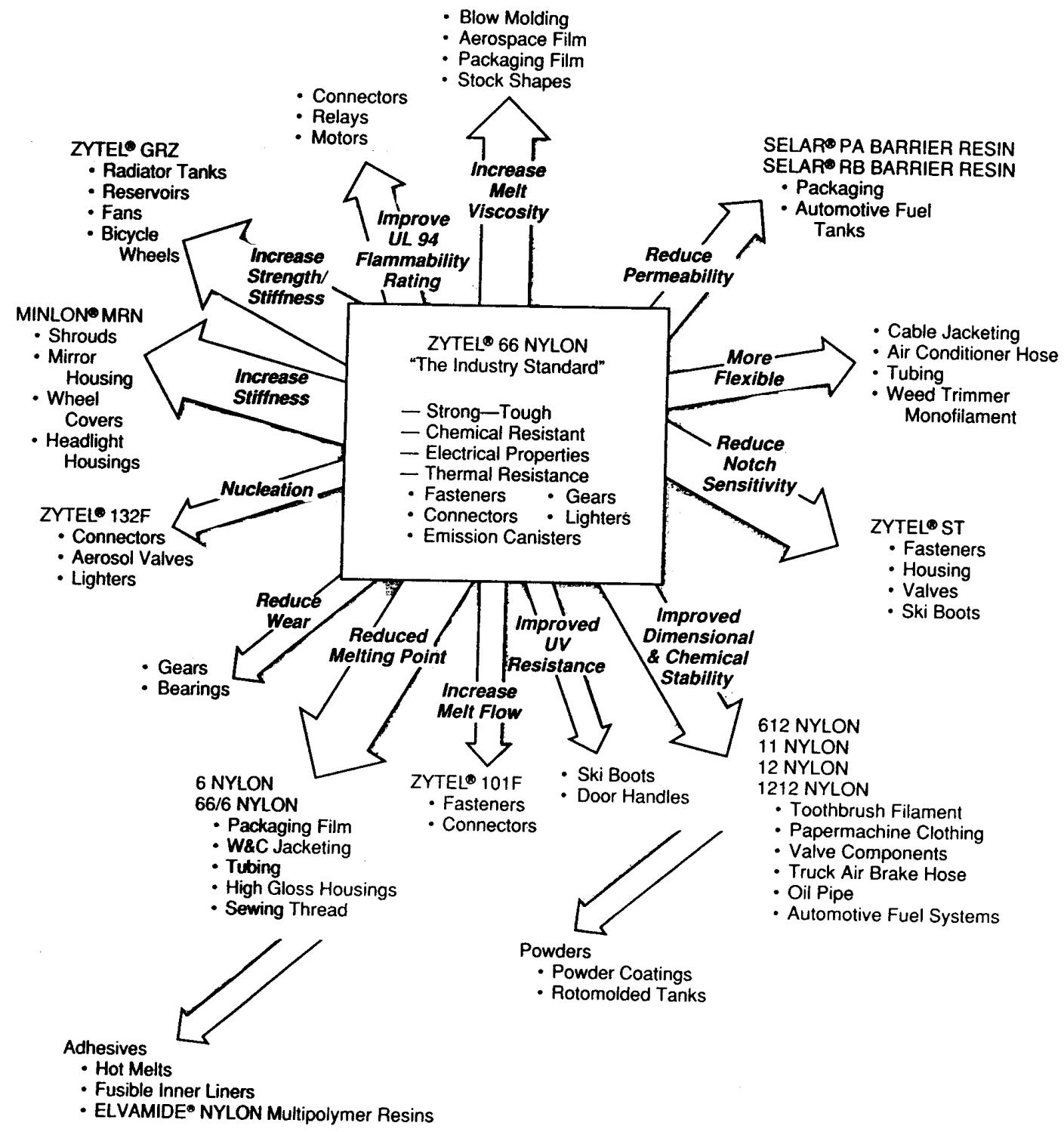

Figure 1-3 Nylon products and uses [2].

grades that are sunlight resistant are used in luggage rack components, door handles, and windshield wiper arms. Plasticized nylon 66 grades are used in automotive air conditioner hose liners, and they reduce refrigerant permeation as compared to nitrile rubber hose. In the interior parts, glass fiber reinforced nylon 66 is used in steering column lock housings, door and window hardware, and pedals used for the accelerator, 
clutch, and brake. Unreinforced nylon 66 is used for fuse boxes and cable binders.

\subsection{Thermoplastics combined with rubber and glass fiber}

The above discussion dealt with blending rubbers or glass fibers with thermoplastics to enhance some desired properties such as toughness and strength. This however, would result in a trade off relationship between these two important properties. For example, tensile strength may be drastically reduced in rubber toughened thermoplastics. Proper adding of glass fibers to rubber toughened thermoplastics could restore tensile strength to some extent. Blending of both glass fibers and rubbers with thermoplastics seems to be a logical way to optimize important properties of thermoplastics. The number of studies conducted, mainly in the last decade, in this field of research is sparse. Among these studies, nylon 66 has received less attention. In fact toughening of glass fiber reinforced nylon 66 with styrene/ethylene/butylene/styrene copolymer and ethylene propylene elastomer grafted with maleic anhydride, SEBS-g-MA and EP-g-MA, has not been investigated. These two rubbers have been recommended as good impact modifiers for nylon [2]. Indeed SEBS-g-MA blended with nylon 66 has resulted in a super tough nylon that has a very high value of Izod impact strength [11-14].

\subsection{Research objectives}

There were two objectives for the current research: technological and scientific. The outlines of these two objectives are the following:

1. Technological objective:

- Characterizing a post industrial nylon 66 (PIN66) reinforced with glass fibers. 
- Modifying impact resistant property of the PIN66 through rubber toughening using SEBS-g-MA and EP-g-MA which are the best tougheners for nylon.

2. Scientific objective:

- Since no data are available for toughening glass-fiber reinforced nylon 66 with SEBS-g-MA and EP-g-MA rubbers, the current research aimed to provide these data.

- Studying the influence of varying rubber content on mechanical and flow properties and the morphology of the virgin glass-fiber-reinforced nylon 66.

- Studying the trade-off relationship between strength and toughness of the composites with both glass fibers and rubber. The goal here was to determine the best combination of rubber and fibers at which high strength and toughness may be achieved. 


\section{Chapter 2}

\section{Review of fiber-reinforced and rubber-toughened thermoplastics}

\subsection{Glass-fiber-reinforced thermoplastics}

\subsubsection{Introduction}

The most significant development in the evolution of continuous fiber composites has been the introduction of thermoplastic matrices which are creep resistant, tough and have a high deflection under load temperature. One of the earliest polymers improved by this technique was polyethersulphone (PES) but, being amorphous, PES is subject to environmental attack under adverse conditions. polyetheretherketone (PEEK) was introduced later and its semicrystalline nature proved advantageous against environmental attack. Many other thermoplastic matrices are now available including polyetherimide (PEI), polyamideimide (PAI), polyphenylenesulphide (PPS), polyetherketone (PEK) and polyphenyleneoxide (PPO) [5].

The high tensile strength of glass fibers is preserved when they are coated immediately after fiber drawing. Thereafter, glass strength is reduced by abrasive contacts. E glass fibers are widely used because of their low cost and good mechanical, chemical and electrical properties. They are available as continuous strands chopped to 3 , 6, or $13 \mathrm{~mm}$ lengths. Chopped glass fibers are available in two standard filament diameters, G-filament at $9.5 \mu \mathrm{m}$ and K-filament at $13 \mu \mathrm{m}$. Basic factors in reinforcement are fiber strength, aspect ratio, coupling to the matrix, orientation and concentration. The rule of mixtures serves as a guide to the effect of reinforcement on properties. The rule of mixtures predicts a linear change in properties with volume fractions of reinforcement 
and is often used as a first estimate for reinforced polymers [15]. It states that the property of the composite is equal to the sum of the products of the volume fraction of each component multiplied by its value for that property. The rule of mixtures applies best to nondirectional properties of composites [16] such as specific volume, specific heat, refractive index, and dielectric constant. Mechanical properties exhibit nonlinearity at higher filler levels and with anisotropic (fiber-reinforced) composites. The tensile strength of injection molded nylon, for example, increases with fiber glass content up to about $45 \mathrm{wt} \%$ and then asymptotically approaches a chopped fiber limit near $60 \mathrm{wt} \%$. Because of elastic interactions between matrix and filler, composite elastic properties differ from those predicted via the rule of mixtures. Physical model predictions require two independent elastic constants (e.g., shear modulus and bulk modulus) for the matrix resin and each additive [2]. Injection molding causes fiber attrition such that molded products have aspect ratios that are typically in the range of 20:1 to 40:1. The strengthening effects of fiber reinforcement increase with aspect ratio asymptotically approaching a limit near L/D of 400:1. The addition of 13 to $50 \mathrm{wt} \%$ glass fibers substantially increases the stiffness, strength, dimensional stability, and resistance to creep at elevated temperatures for nylon. For optimum properties, a silane coupling agent is required to achieve bonding between glass fibers and nylon [2]. Perfect chemical coupling would provide an interface bond strength equal to the matrix shear strength which is about $60 \mathrm{MPa}$ for nylon 66 [17]. A critical aspect ratio (critical fiber length/fiber diameter) can be defined as a function of interfacial bond strength and fiber characteristics [18] as shown in Figure 2-1. By incorporating glass fibers in a thermoplastic matrix, the elongation at break decreases. It has been reported that tensile 
elongation falls rapidly with reinforcement content to about $10 \mathrm{wt} \%$, then decreases slowly with higher levels [2]. For glass fiber reinforced nylon, although its elongation is only a few percent, the elongation at break as measured with an extensometer can be used to evaluate the effectiveness of the compounding technique, coupling agents and effective fiber length. Poor coupling and excessive fiber attrition both lead to low elongations (1\% or less at $30 \mathrm{wt} \%$ glass fiber content) [2]. Flexural strength as measured according to ASTM D790 increases with glass fiber content in a manner similar to tensile strength [2] but tends to be more dependent on sample thickness and fiber orientation. Compressive strength which can be measured according to ASTM D695, increases with fiber content even with low aspect ratio [19]. The shear strength changes slowly from $55 \mathrm{MPa}$ for neat nylon up to $90 \mathrm{MPa}$ for $30 \mathrm{wt} \%$ glass fiber reinforced nylon [2]. Using a computer model fitted to experimental dynamic mechanical data (DMA), Scheetz [2] has shown that the addition of reinforcement to semicrystalline nylons increases the elastic moduli at all temperatures.

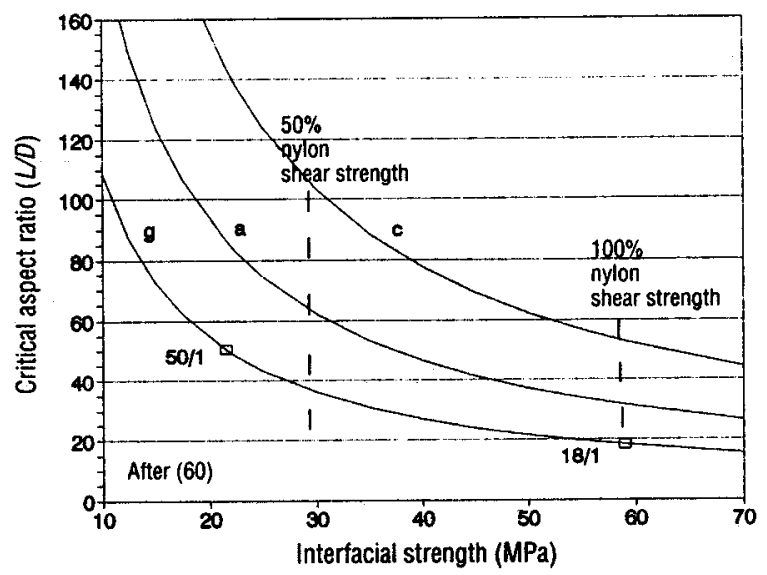

Figure 2-1 Critical aspect ratio versus interfacial strength for E glass (g), aramid (a), and C fibers (c) [18]. 
The percent increase is not constant over temperature because of the viscoelastic characteristics of the polymer. Addition of glass fibers to nylons increases $T_{g}$ by about 1 ${ }^{\circ} \mathrm{C}$ per $5 \mathrm{wt} \%$ glass fibers. This small $\mathrm{T}_{\mathrm{g}}$ shift leads to a family of curves as shown in Figure 2-2. The impact strength goes through a minimum value with increasing filler content and notch sensitivity is also minimized at low contents [2]. Heat deflection temperature increases rapidly with short glass fiber content but approaches an asymptotic limit a few degrees below the melting point [20]. Heat aging, in accordance with ASTM D3045, of reinforced nylons shows a time-dependent decrease in tensile strength [21]. Tensile strength retention decreases rapidly as aging temperatures approach the melt transition as shown in Figure 2-3. Measuring viscosity-shear rate relationships for glassfiber-reinforced thermoplastics is preferably done using a capillary rheometer. At low shear rates, glass fibers cause a significant increase in viscosity. At high shear rates the effect of the fibers becomes very small. The master curve generated for numerous filled nylon compositions is identical to that prepared for the unfilled nylon [2].

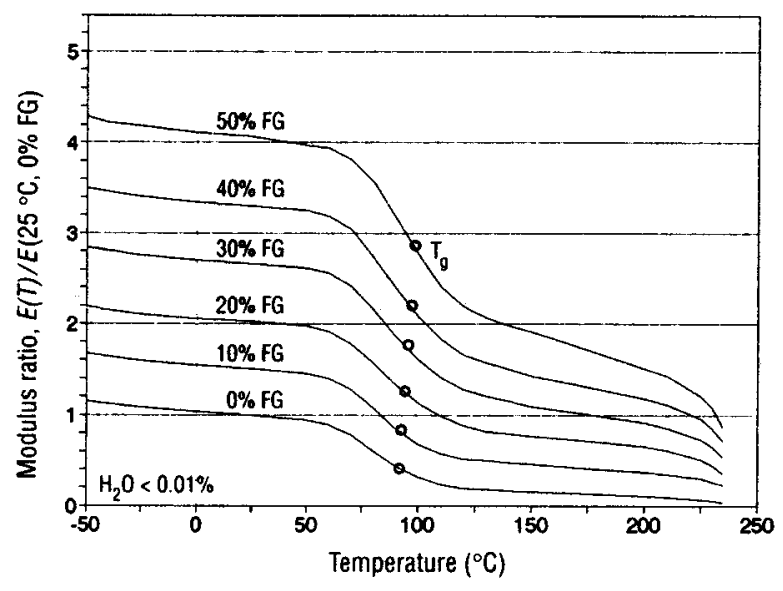

Figure 2-2 Glass transition temperature in glass fiber reinforced nylon 66 [2]. 


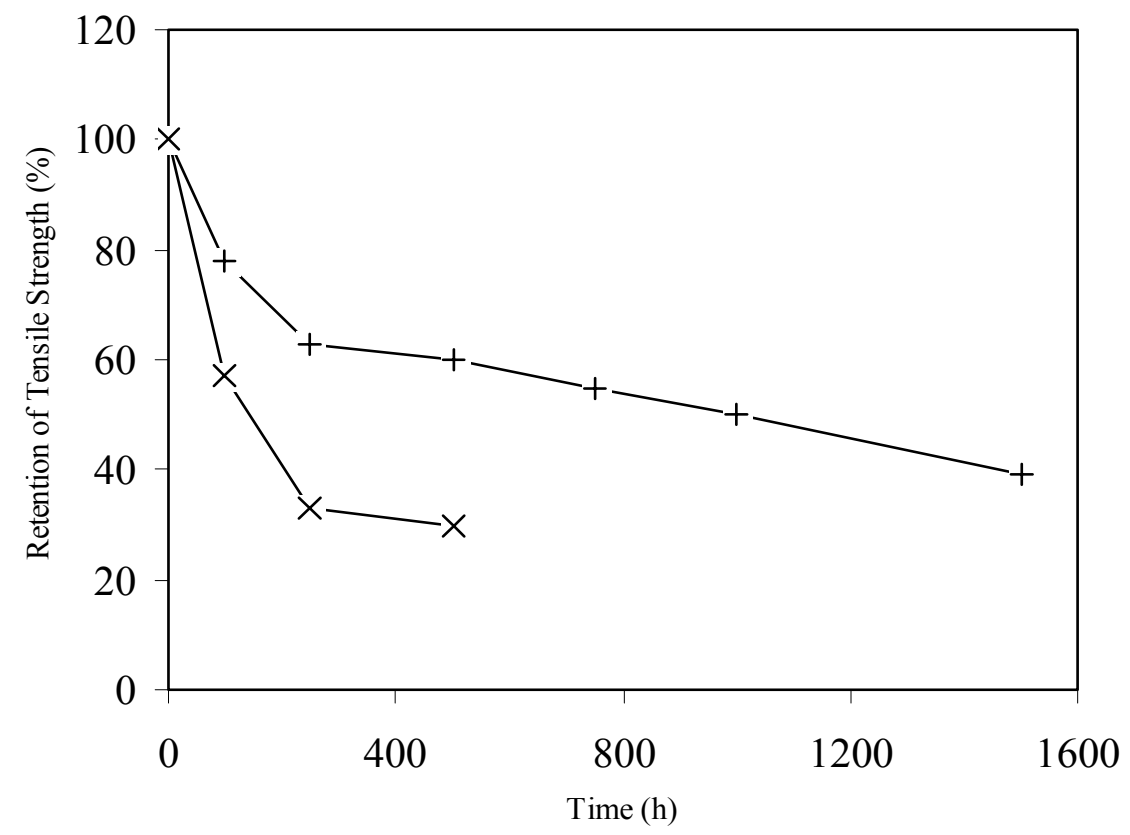

Figure 2-3 Heat aging of nylon 66 with $50 \mathrm{wt} \%$ short glass fibers. $(+)$ at $205{ }^{\circ} \mathrm{C},(\times)$ at $260^{\circ} \mathrm{C}$. Plotted from data in [21]

\subsubsection{Strength of fiber reinforced polymers}

A material reinforced with glass fibers is anisotropic because properties measured along the fiber axis differ from those measured transverse to the fiber axis. A longitudinal force $\mathrm{P}_{\mathfrak{c}}$, applied to a composite containing continuous parallel fibers as shown in Figure $2-4$, would be shared by the fibers and matrix so that [22]

$$
\mathrm{P}_{\mathrm{c}}=\mathrm{P}_{\mathrm{f}}+\mathrm{P}_{\mathrm{m}}
$$


Since load $=$ stress $\times$ area, Eq. 2-1 may be rewritten as

$\sigma_{c}=\sigma_{f}\left(A_{f} / A_{c}\right)+\sigma_{m}\left(A_{m} / A_{c}\right)$

where

$\sigma$

is the tensile stress

A is the cross sectional area and $\left(\mathrm{A}_{\mathrm{c}}=\mathrm{A}_{\mathrm{f}}+\mathrm{A}_{\mathrm{m}}\right)$

c, $\mathrm{f}$, and $\mathrm{m}$ are composite, fiber, and matrix respectively

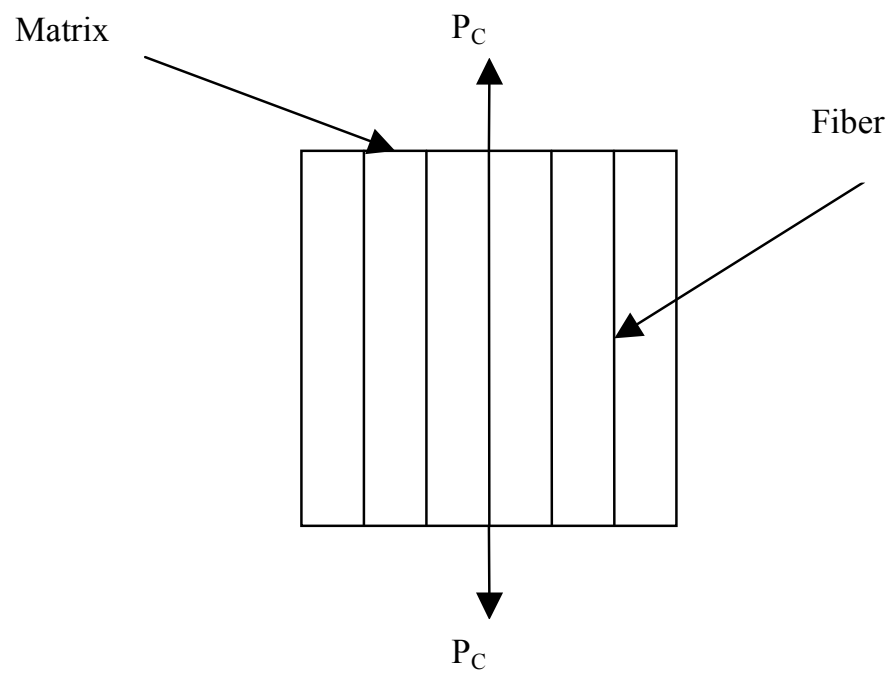

Figure 2-4 Longitudinal tensile stress of a continuous fiber composite. 
Since $\varphi_{\mathrm{f}}=\mathrm{A}_{\mathrm{f}} / \mathrm{A}_{\mathrm{c}}$ and $\varphi_{\mathrm{m}}=\mathrm{A}_{\mathrm{m}} / \mathrm{A}_{\mathrm{c}}$, Eq. 2-2 gives

$\sigma_{\mathrm{c}}=\sigma_{\mathrm{f}} \varphi_{\mathrm{f}}+\sigma_{\mathrm{m}} \varphi_{\mathrm{m}}$

Where

$\varphi \quad$ is the volume fraction

Equation 2-3 is known as the "rule of mixtures". It shows that the composite longitudinal tensile strength is intermediate between the fiber and matrix tensile strengths. The relation given by Eq. 2-3 ignores any interaction between the constituents of the composite. The modified rule of mixtures takes into account the efficiency of fibers as follows [23]:

$$
\sigma_{c}=\sigma_{f} \varphi_{f} e_{I} e_{o}+\sigma_{m} \varphi_{m}
$$

Assuming good bonding between matrix and fibers so that

$\varepsilon_{\mathrm{c}}=\varepsilon_{\mathrm{f}}=\varepsilon_{\mathrm{m}}$

Dividing both sides of Eq. 2-4 by $\varepsilon_{\mathrm{c}}$, the longitudinal modulus of the composite can be written as

$\mathrm{E}_{\mathrm{c}}=\mathrm{E}_{\mathrm{f}} \varphi_{\mathrm{f}} \mathrm{e}_{\mathrm{I}} \mathrm{e}_{\mathrm{o}}+\mathrm{E}_{\mathrm{m}} \varphi_{\mathrm{m}}$ $2-5$ 
Where

$\varepsilon \quad$ is the longitudinal strain

$\mathrm{E} \quad$ is the modulus

e is efficiency factor

I refers to matrix-fiber interaction

o refers to orientation

$\mathrm{e}_{\mathrm{o}} \quad=1$ for unidirectional oriented fibers

0.33 for randomly dispersed fibers [24]

$\mathrm{e}_{\mathrm{I}}$ is difficult to quantify because it is strongly affected by the adhesion between the polymer and fibers. For continuous fibers $\mathrm{e}_{\mathrm{I}}$ is 1 . For discontinuous fibers $\mathrm{e}_{\mathrm{I}}$ is related to the critical aspect ratio of the fibers [25]. The critical aspect ratio occurs when the strength of the interfacial adhesion between the polymer and fiber equals the tensile strength of the fiber. In a discontinuous fiber composite, the applied tensile load is transferred to the fibers by a shearing mechanism between fibers and matrix. If a perfect bond is assumed between fibers and matrix, the difference in longitudinal strains creates a shear stress distribution across the fiber/matrix interface. Ignoring the stress transfer at the fiber end cross sections and the interaction between neighboring fibers, the normal stress distribution in the fibers may be calculated by a simple force balance. A force balance on an infinitesimal length $\mathrm{dx}$ at a distance $\mathrm{x}$ from one end of the fiber, as shown in Figure 2-5, gives [22,25] 
$(\pi / 4) d_{f}^{2}\left(\sigma_{f}+d \sigma_{f}\right)-(\pi / 4) d_{f}^{2} \sigma_{f}-\pi d_{f} d x \tau_{I}=0$

which on simplification gives

$\left(d \sigma_{f} / d x\right)=\left(4 \tau_{i} / d_{f}\right)$

where

$\sigma_{\mathrm{f}} \quad$ is longitudinal stress in the fiber at a distance $\mathrm{x}$ from one of its ends

$\tau_{\mathrm{i}} \quad$ is shear stress at fiber/matrix interface

$\mathrm{d}_{\mathrm{f}} \quad$ is fiber diameter

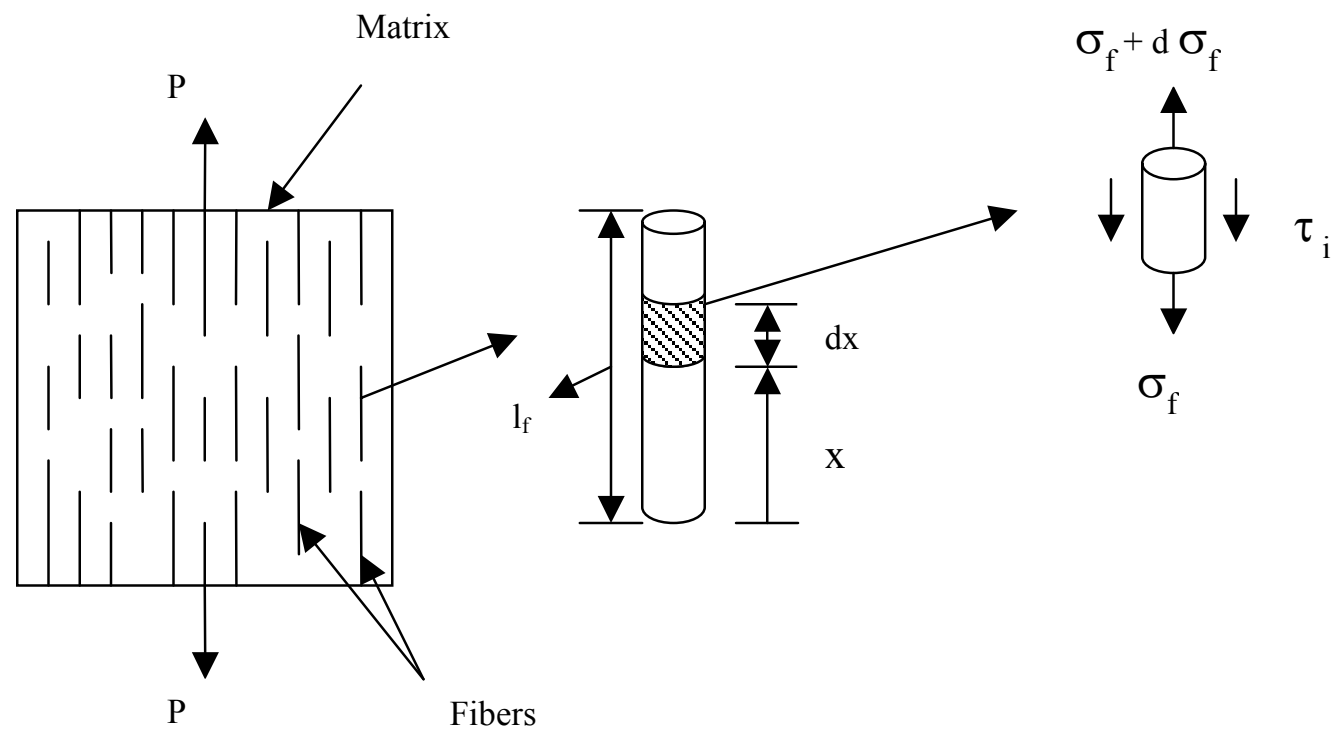

Figure 2-5 Longitudinal tensile stress of a discontinuous fiber composite. 
Assuming no stress transfer at the fiber ends, that is, $\sigma_{\mathrm{f}}=0$ at $\mathrm{x}=0$ and constant shear stress along $\mathrm{x}$, integrating Eq. 2-6 gives

$\sigma_{\mathrm{f}}=\left(4 \tau_{\mathrm{i}} / \mathrm{d}_{\mathrm{f}}\right) \mathrm{x}$

According to Eq. 2-7, the fiber stress is not uniform. It is zero at the ends and builds up linearly to the maximum at the center of the fiber. Therefore, the maximum fiber stress is achieved at $\left(\mathrm{x}=1 / 21_{\mathrm{t}}\right)$

$\left(\sigma_{\mathrm{f}}\right)_{\max }=\left(2 \tau_{\mathrm{i}} / \mathrm{d}_{\mathrm{f}}\right) \mathrm{l}_{\mathrm{t}}$

where

$1_{t} \quad$ is the load transfer length (the minimum fiber length where the maximum fiber stress is obtained

The critical fiber length, $1_{c}$, required for the maximum fiber stress to be equal to the ultimate fiber strength may be obtained by substituting $\sigma_{f u}$ for $\left(\sigma_{f}\right)$ in Eq. 2-8 and rearranging to get $l_{\mathrm{c}}$

$1_{\mathrm{c}}=\left(\sigma_{\mathrm{fu}} / 2 \tau_{\mathrm{i}}\right) \mathrm{d}_{\mathrm{f}}$

where

$\sigma_{\mathrm{fu}} \quad$ is the ultimate fiber strength

$\tau_{\mathrm{i}} \quad$ is the shear strength at fiber/matrix interface or the shear strength of the matrix whichever is less 
The average fiber stress may be obtained by integrating the longitudinal stress over the fiber length as

$\sigma_{\text {avgf }}=\left(1 / 1_{\mathrm{f}}\right) \int_{0}^{1} \mathrm{f} \sigma_{\mathrm{f}} \mathrm{dx}$

Taking into account the contribution of the normal stresses near the two fiber ends, Eq. 210 gives

$\sigma_{\text {avgf }}=\left(\sigma_{\mathrm{f}}\right)_{\max }\left[1-\left(1_{\mathrm{t}} / 21_{\mathrm{f}}\right)\right]$

For a composite system with $1_{\mathrm{f}}>1_{\mathrm{c}}$, the load transfer length is $1_{c}$, whereas $1_{\mathrm{t}}=1_{\mathrm{f}}$ for a system with $1_{\mathrm{f}}<1_{\mathrm{c}}$. When the fiber length is less than the critical length, there is no fiber failure. Instead, the composite fails primarily due to matrix tensile failure [22]. Eq. 2-11 may be rewritten as

$\sigma_{\text {avgf }}=\left(\sigma_{f}\right)_{\max } \mathrm{e}_{\mathrm{I}}$

where

$\mathrm{e}_{\mathrm{I}}=\left[1-\left(1_{\mathrm{c}} / 2 \mathrm{l}_{\mathrm{f}}\right)\right]$

for $1_{\mathrm{f}}>1_{\mathrm{c}}$

$\mathrm{e}_{\mathrm{I}}=1 / 2$

for $1_{\mathrm{f}}<1_{\mathrm{c}}$

Therefore, the longitudinal tensile strength of a discontinuous fiber composite can be obtained by substituting Eq. 2-12 in the rule of mixtures relation, Eq. 2-4 as

$$
\begin{array}{lll}
\sigma_{\mathrm{c}}=\sigma_{\mathrm{f}} \varphi_{\mathrm{f}}\left[1-\left(1_{\mathrm{c}} / 21_{\mathrm{f}}\right)\right] \mathrm{e}_{\mathrm{o}}+\sigma_{\mathrm{m}} \varphi_{\mathrm{m}} & \text { for } 1_{\mathrm{f}}>1_{\mathrm{c}} & 2-13 \\
\sigma_{\mathrm{c}}=\left(\tau_{\mathrm{i}} 1_{\mathrm{f}} / \mathrm{d}_{\mathrm{f}}\right) \varphi_{\mathrm{f}} \mathrm{e}_{\mathrm{o}}+\sigma_{\mathrm{m}} \varphi_{\mathrm{m}} & \text { for } \mathrm{l}_{\mathrm{f}}<1_{\mathrm{c}} & 2-14
\end{array}
$$


The strength of a short glass fiber reinforced thermoplastic depends on many factors that include fiber length, volume fraction of fibers, interfacial shear strength, and fiber orientation. A linear relationship between the strength of the composite and volume fraction of fibers is expected from the rule of mixtures relation. Experimentally, there may be a violation of rule of mixtures prediction [26]. As shown in Figure 2-6, a composite of polyethylene reinforced by glass fibers gives nearly a linear dependence of tensile strength on fiber volume fraction only up to $20 \mathrm{vol} \%$. The deviation from the rule of mixtures prediction at high fiber concentration has been attributed to the interaction between the fibers which can result in massive fiber breakage and loss of strength [27]. Glass-fiber reinforced nylon 66 shows a perfect linear relationship between strength and fiber content as shown in Figure 2-7

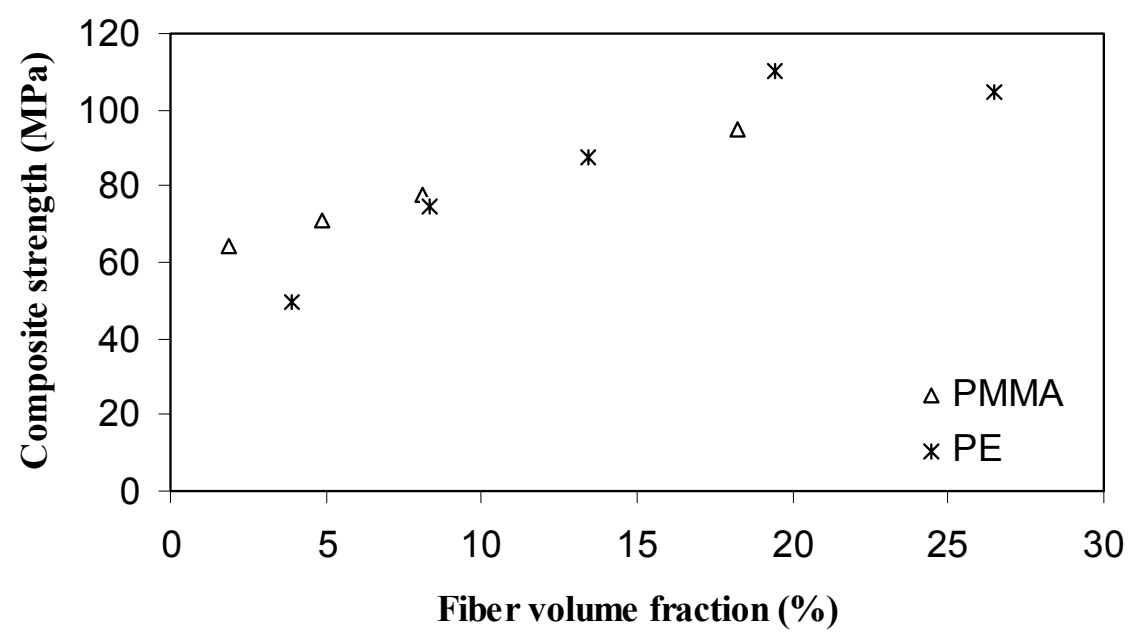

Figure 2-6 Dependence of tensile strength of glass fiber reinforced thermoplastics on glass fiber content. Data taken from [26] 


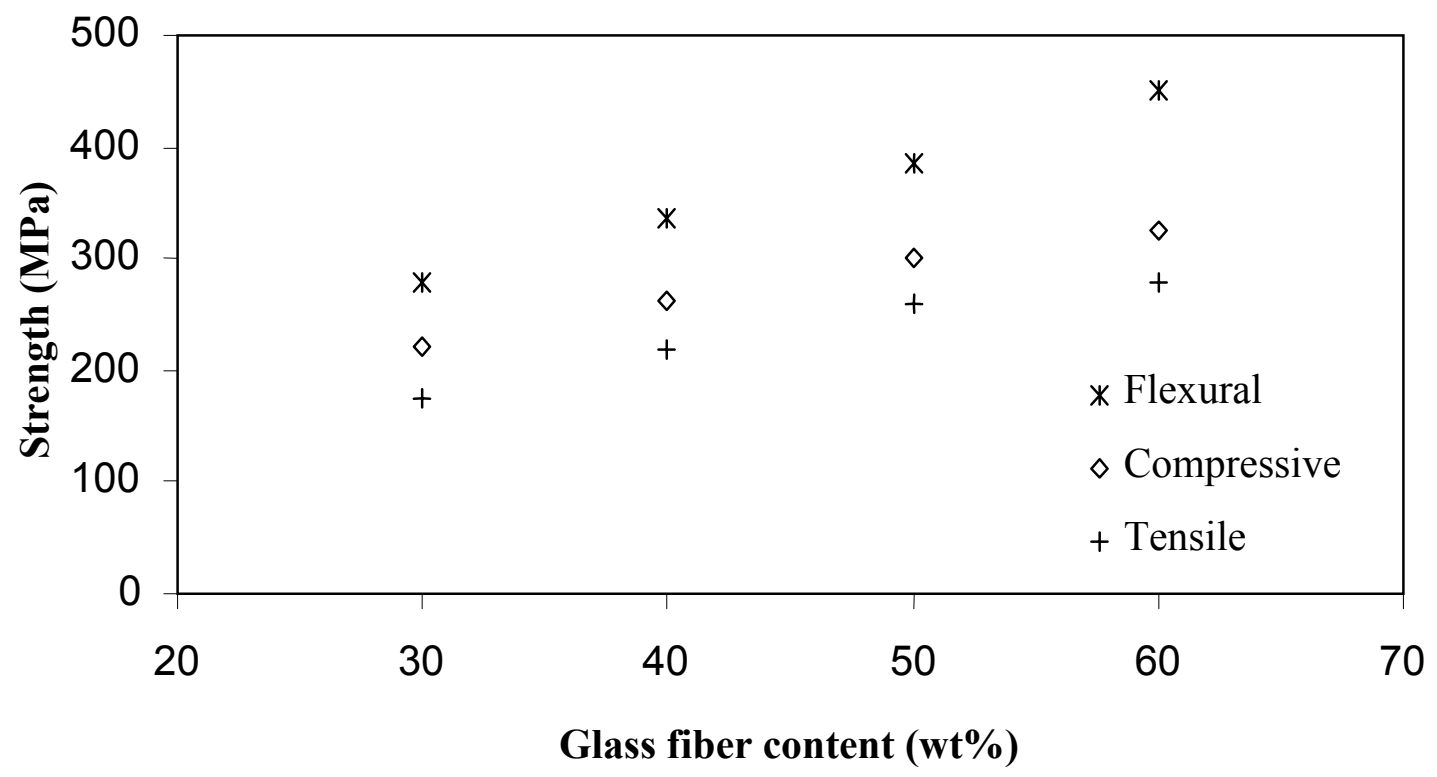

Figure 2-7 Strength of glass-fiber reinforced nylon 66 versus fiber phase content. Extracted from a graph given in [2]

\subsubsection{Stress-strain behavior}

Figure 2-8 shows stress-strain relationships for two different types of composite systems. One composite system involves ductile fibers in a ductile matrix (polyester fibers in polyethylene) as shown by Figure 2-8 a and the other has relatively brittle fibers in a brittle matrix (Kevlar fibers in polymethylmethacrylate) as shown by Figure $2-8 \mathrm{~b}$. As demonstrated in Figure 2-8, addition of fibers for both composites increases stiffness and strength. However, ductile matrix composites reinforced by low modulus fibers show a noticeable reduction in the slope of the stress-strain curves up to $4 \%$ strain. Brittle matrix composites, on the other hand, show nearly elastic behavior to fracture. Although utilizing large volume fractions of fibers significantly increases the stiffness of the composite, the work to fracture decreases drastically due to the increase in fiber concentration. This results in a composite tolerating only small impact energies which 
can not be dissipated in plastic flow processes [23]. The idea of combining different classes of fibers such as carbon and glass in a composite, i.e. hybrid system, has also been suggested to achieve high stiffness and high work of fracture.

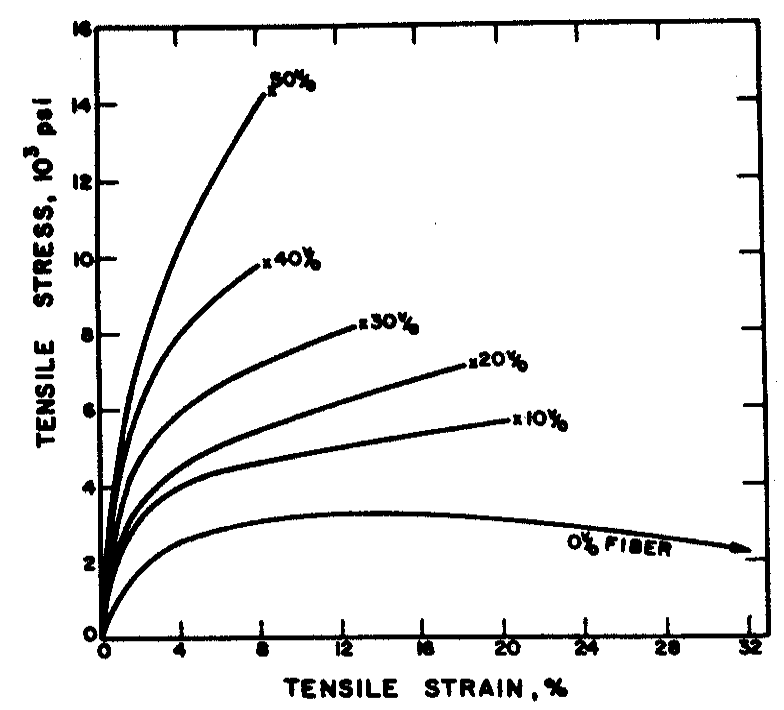

(a)

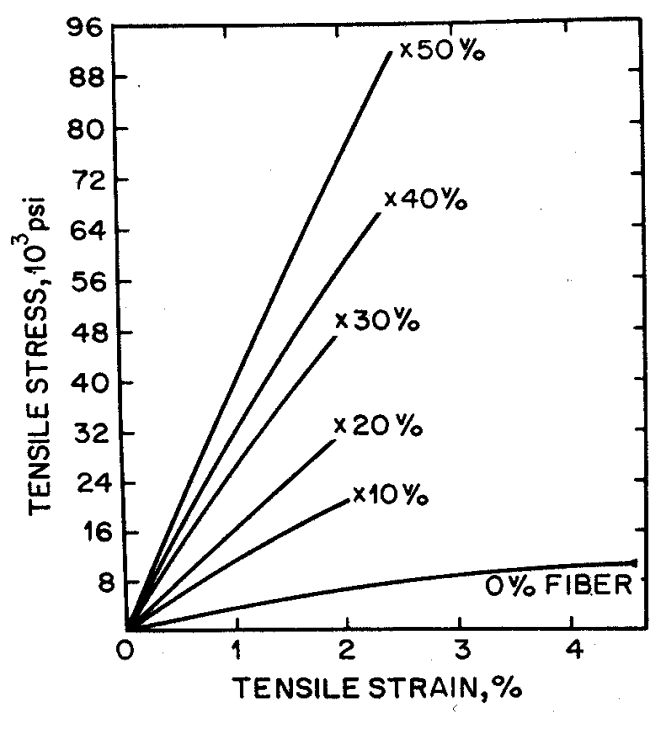

(b)

Figure 2-8 Stress-strain relationship for two types of composite systems: (a)- ductile fibers/ ductile matrix (polyester/polyethylene), (b)- brittle fibers/ brittle matrix (Kevlar/ PMMA) [28].

\subsubsection{Impact strength of reinforced polymers}

Theories capable of predicting the impact-strength of composites are not as well developed as models predicting tensile strength [24]. Impact strength is a measurement of toughness which represents the ability of a material to absorb energy before fracture. Impact strength is not a material property since it changes with several variables such as 
test type (Izod, Charpy, etc.) and sample dimensions. An increase in impact strength results if the increase in energy absorption associated with the increase in strength exceeds the reduction in energy absorption associated with the reduction in the elongation to break [24]. For that reason many tough polymers lose some of their impact resistance when reinforced because the increase in tensile peak strength does not offset the reduction in elongation to break. On the other hand many brittle polymers show an increase in impact strength when reinforced because while the tensile strength increases sharply, the elongation to break is not significantly reduced [24]. By incorporating fibers in a thermoplastic, an increase in stiffness and strength is supposed to be achieved. However, this would produce a material that is very poor in terms of handling impact loading. The area under the stress-strain curve up to the failure point is a measure of the work of fracture. The conditions that lead to high strength and stiffness usually result in low elongation to break, so that the work of fracture may be very low compared to that of the matrix. The work of fracture depends on the existence of a mechanism for energy dissipation. Energy required for fiber pull out is considered for composite impact fracture. The toughness of a composite is maximized when the fiber is at its critical length (see Figure 2-9). Figure 2-9 shows that impact strength of a ductile matrix, i.e. polypropylene, reinforced with glass fibers decreases sharply as fiber volume content increases. However, when ductility of the matrix is suppressed, mainly at low temperature, an increase in impact strength is observed. The difference in impact behavior given by Figure 2-9 may be explained on the basis of elongation to break and work of fracture [23]. When fibers are added to a ductile matrix, elongation to break will 


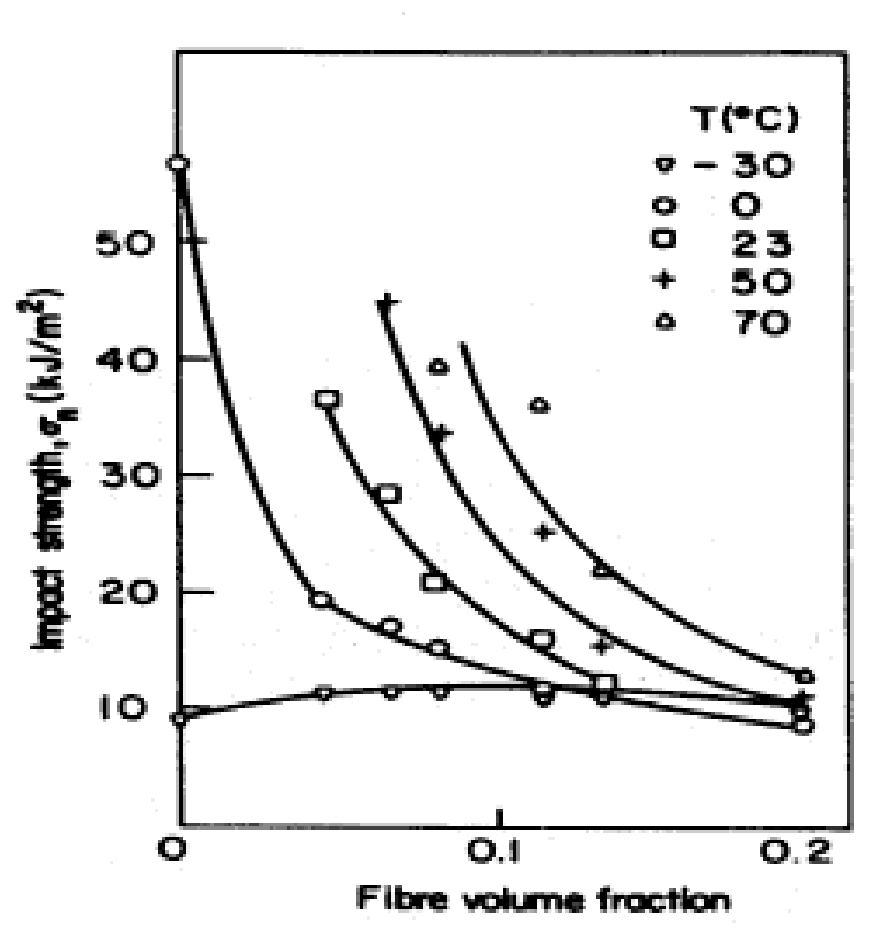

Figure 2-9 Variation of impact strength with fiber volume content at different temperature for fiber-reinforced polypropylene [27].

reduce and at the same time the contribution to the work of fracture resulting from fiber pull out will be very small to offset. At a low temperature when the matrix becomes less ductile and when fiber volume fraction increases, due to the constraining effect of adjacent fibers, these fibers having a length greater less than the critical length will contribute substantially to the fracture work. There is then a tendency for the impact strength to be almost independent of fiber volume content. The fiber-matrix interface has a significant effect on the way that composite handles impact. Local stress concentration, which is responsible for initiation composite failure, may be reduced by applying a thin layer of soft deformable material around the fibers in a composite [29]. For a short fiber composite, the presence of an interlayer between fiber and matrix may affect the critical 
length of fiber at which the energy of fiber pull out is high since the interfacial strength will be reduced. Peiffer [30] has shown that for glass fibers coated with layers of latex of different glass transition temperatures, the impact strength was a function of both the thickness of the interlayer material and $T_{g}$ ( see Figure 2-10). In case of fiber-reinforced thermoplastics, the use of an interlayer to enhance impact property is not as important as in thermoset composites because most of the thermoplastics matrices have some degree of ductility, so that dissipation of crack energy is more significant.

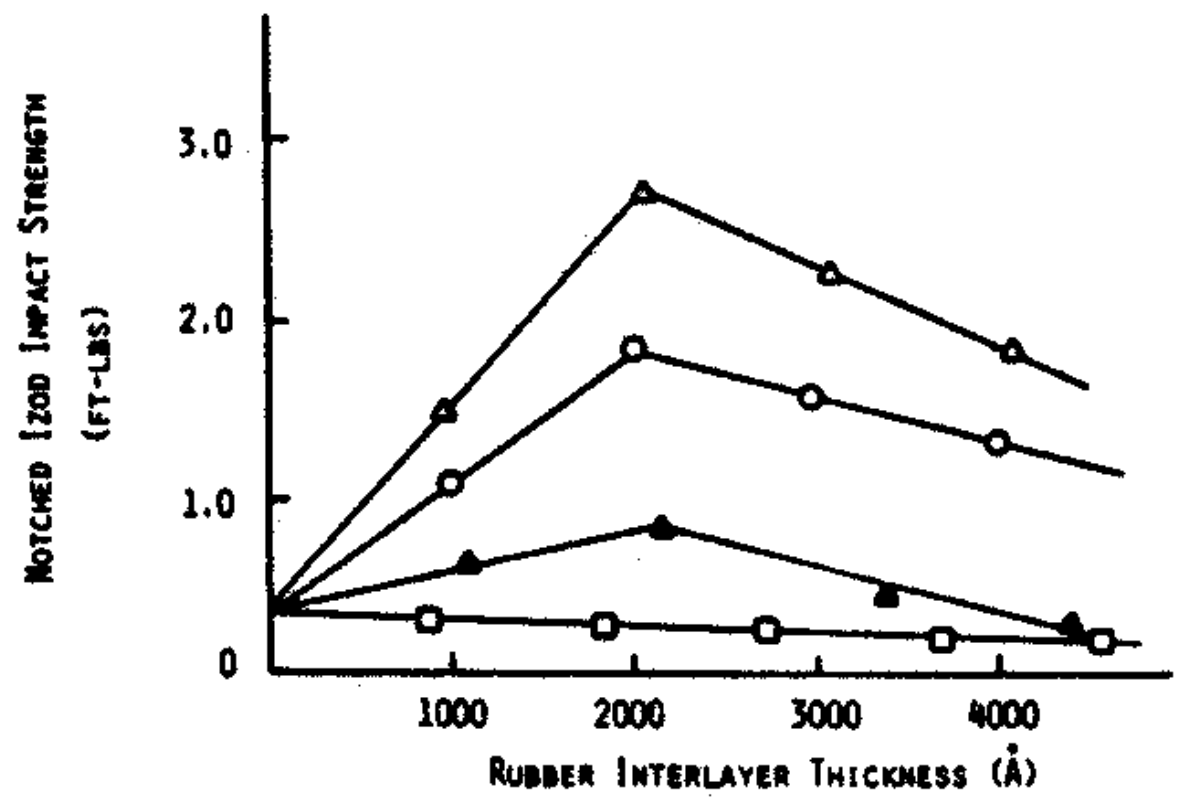

Figure 2-10 Variation of impact strength against interlayer thickness at various glass transition temperatures for glass fibers coated with latex: $(\Delta)-56,(\circ)-14,(\Delta) 10,($, $) 80^{\circ}$ $\mathrm{C}[30]$. 


\subsubsection{Effect of fiber surface on morphology of the matrix}

Bessell and Shortall [31] have studied the crystallization of nylon 66 near surfaces of carbon and glass fibers. They have found that columnar spherulitic growth (transcrystallinity) occurred around the fibers to a distance of one or two fiber diameters. Figure 2-11 shows spherulitic crystals around Kevlar fibers for Kevlar/nylon 66 composite. It was suggested that [31] the presence of transcrystalline material resulted in a weak interface between the columnar structure and around fibers and the main spherulitic structure in the matrix which has led to fiber pull out with sheaths of matrix material.

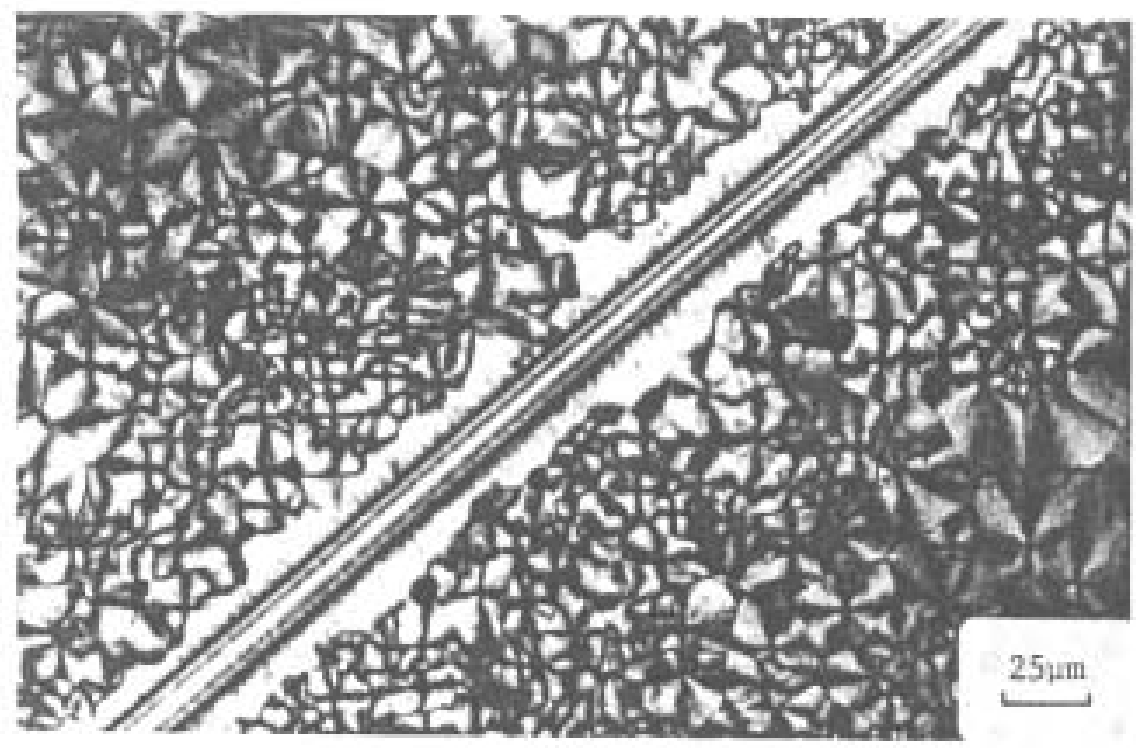

Figure 2-11 Optical micrograph for nylon 66 reinforced with Kevlar fibers [23]. 


\subsubsection{Fracture toughness}

In practice, a composite must be capable of being damaged without undergoing complete failure. For this to happen there must be energy absorbing mechanisms built into the composite. For a composite with glass fibers, a number of methods may be considered [23]:

- The application of a soft coating to the fibers which will act as an inter-layer after the composite is fabricated. This has been shown to reduce significantly the stress concentrating effect of the fibers.

- Utilization of the energy required to debond the fibers from the matrix and then to pull the fibers out of the matrix.

- Use of a weak interface between the fiber and matrix. In this case a triaxial stress system at the tip of an advancing crack causes debonding to occur.

The presence of a weak interface will lead to poor load transfer from the matrix to the fibers and lead to a composite with low strength. However, the presence of poorly dispersed fiber bundles may increase the impact strength of the composite. Since the toughness of the composite is greatest when the length of the fiber is equal to the critical length $1_{c}$, maximum strength and toughness may not be obtained simultaneously. During tensile fracture, reinforced polymer composites can fail in one of two ways [5]

- Fiber breakage

- Fiber pull-out

Folkes [23] points out that, for optimized performance, maximum fiber breakage is necessary. To prevent fiber pull-out, the fiber must be sufficiently long for the frictional 
energy of pull-out to exceed the energy of fiber breakage. The length at which these two energies are equal is called the critical fiber length, $l_{c}$, and it is given by Eq. 2-9. When this critical fiber length is exceeded, then the major fracture mechanism should be the result of fiber fracture. Practically, fiber pull-out still exists at lengths three to four times the critical length [32] owing to anomalies in the bonding of the fiber to the matrix. When the load on the composite is increased, matrix and fiber at the crack tip attempt to deform differently and a relatively large local stress begins to build up in the fiber [5]. This stress may initiate fiber-matrix debonding as shown in Figure 2-12 c. The interfacial shear stress resulting from the fiber-matrix modulus mismatch will then cause extension of the debond along the fiber in both directions away from the crack plane. This will permit further opening of the matrix crack beyond the fiber, and the process will be repeated at the next fiber. An upper limit to the energy of debonding is given by the total elastic energy that will subsequently be stored in the fiber at breaking load, i.e. $\left(\sigma_{f}^{2} / 2 \mathrm{E}_{\mathrm{f}}\right)$ per fiber per unit volume, or with $\mathrm{N}$ fibers bridging the crack [5]

$\mathrm{W}_{\mathrm{d}}=\mathrm{N} \pi \mathrm{r}^{2} \mathrm{y} \sigma_{\mathrm{f}} / 2 \mathrm{E}_{\mathrm{f}}$

Where

$W_{d} \quad$ is the energy of debonding

$\mathrm{N} \quad$ is number of fibers

$\mathrm{r} \quad$ is the radius of fiber

$\mathrm{y} \quad$ is the mean debonding length

$\sigma_{\mathrm{f}} \quad$ is the breaking stress of the fiber

$\mathrm{E}_{\mathrm{f}} \quad$ is the modulus of the fiber 


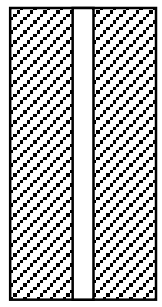

(a)

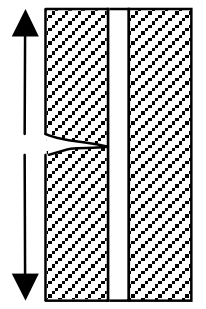

(b)

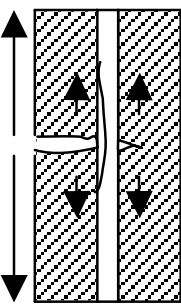

(c)

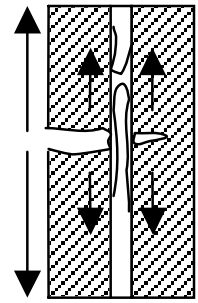

(d)

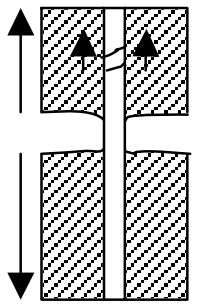

(e)

Figure 2-12 Schematic of stages in crack growth in a fiber composite [5].

After debonding, the fiber and matrix move relative to each other as crack opening continues and work must be done against frictional resistance during the process. Since the extent of the frictional force is not accurately known, this frictional work is difficult to assess. However, if it is assumed that interfacial frictional force, designated as $\lambda$, acts over a distance equal to the fiber extension, then frictional work, $\mathrm{W}_{\mathrm{f}}$, may be estimated as $[5]$

$\mathrm{W}_{\mathrm{f}}=\mathrm{N} \lambda \pi \mathrm{ry}^{2} \varepsilon_{\mathrm{f}}$

Where

$\varepsilon_{\mathrm{f}} \quad$ is the fiber failure strain

After debonding, a continuous fiber is loaded to failure over a gauge length and it may break at any point as shown in Figure 2-12 d. The broken ends then retract and resume their original diameter, and will be held by the matrix. In order to prevent further opening of the crack, which will separate the two parts of the material, these broken ends must be 
pulled out of the matrix (see Figure 2-12 e). Further frictional work is required to achieve this and the resulting fracture surface will often have a brush-like appearance. Work of pull-out, $\mathrm{W}_{\mathrm{p}-\mathrm{o}}$, may be approximately given as [5]

$\mathrm{W}_{\mathrm{p}-\mathrm{o}}=\mathrm{N} \lambda \mathrm{rl}_{\mathrm{c}}^{2} / 6$

Cottrell [33] proposed the following relations for fracture energy arising from fiber pullout:
$\mathrm{U}=\left(\mathrm{v} \tau \mathrm{l}^{2} / 12 \mathrm{~d}\right)$
$1<1 \mathrm{c}$
$2-18$
$\mathrm{U}=\left(\mathrm{v} \tau \mathrm{l}_{\mathrm{c}}^{3} / 12 \mathrm{~d} 1\right)$
$1>1 \mathrm{c}$
2-19

Where

d is the fiber diameter

$\tau \quad$ is the interfacial frictional stress

The energy reaches a maximum at $l=l_{c}$ as shown in Figure $2-13$. It is important to note that the maximum fracture energy is proportional to fiber diameter. The presence of fiber bundles would act as a single large fiber diameter as far as toughness of the composite is concerned. According to Barlow et al. [34] who investigated fiber reinforced PEEK, it has been suggested that energy required for fiber fracture is much higher than that for other fracture types and composites which have good fiber-matrix adhesion are more likely to fail through the matrix. Chai [35] reported that both types of failure, i.e. failure 
through the matrix and fiber pull-out, may occur in the same fracture due to fiber orientations. Fiber bridging has been reported by some researchers [36]. The bridge takes the form of fibers or fiber bundles, bridging the gap between the two halves, tending to retard crack growth and so increasing fracture toughness.

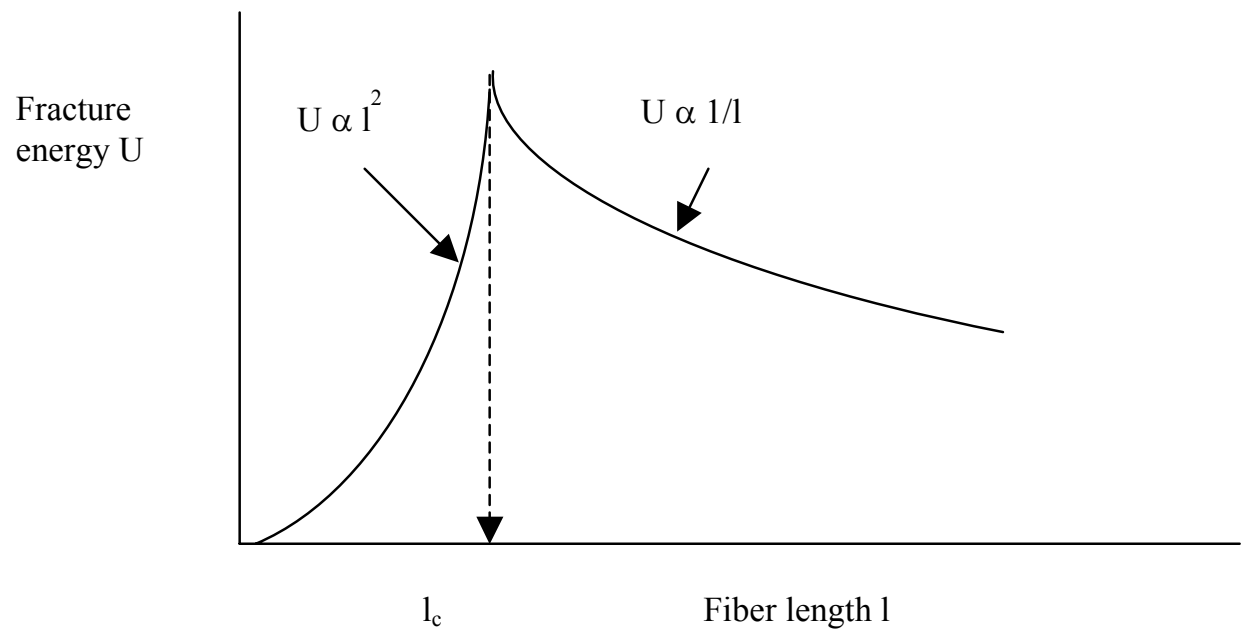

Figure 2-13 Variation of fiber pull out fracture energy against fiber length as proposed by Cottrell [33].

\subsubsection{Concluding remarks}

We have seen that mechanical properties of short glass-fiber-reinforced polymers are affected by several factors such as fiber volume fraction, fiber orientation, interfacial shear strength, and fiber length. Usually, the rule of mixtures predicts a linear relationship between strength and volume fraction of fibers (see Eq. 2-4). For a unidirectional composite system, fiber orientation is obviously fixed. One is then left with two 
important issues: interfacial shear strength and fiber length. The critical fiber length which is defined as the length at which energy for fiber breakage equals energy for fiber pull-out is the determining factor for composite fracture mechanism. This critical fiber length is inversely related to the interfacial shear strength as shown in Eq. 2-9 and illustrated in Figure 2-1. Figure 2-1, shows that the critical aspect ratio of a composite, i.e. (critical fiber length / fiber diameter), tends to decrease upon increasing bonding between fiber and matrix. This implies that for a given fiber diameter and length, the critical fiber length can be changed relative to composite fiber length by increasing or decreasing the interfacial shear strength of the composite. This is important because a composite having fibers whose length is greater than the critical length will be strong and stiff, and failure occurs due to fiber breakage while composite having fiber length less than the critical will be less stronger and stiffer but tough. In the latter case, fiber debonding and pull-out occurs if poor adhesion is encountered. However, at high interfacial shear strength, i.e. good fiber-matrix adhesion, failure occurs in the matrix material. The toughness of a composite is maximum when fiber length equals the critical length which is inversely related to shear strength of the fiber-matrix interface. The use of a thin interlayer between the fiber and matrix is seen to enhance toughness of the composite by influencing critical length for fiber pull-out since shear strength of fibermatrix interface is significantly reduced. 


\subsection{Rubber toughening of thermoplastics}

\subsubsection{Introduction}

Before discussing the aspects of rubber toughening process, it is essential first to understand the deformation mechanisms of the matrix material in which rubber particles are embedded. The rubber exists as a discrete phase in a glassy matrix and cannot contribute alone directly to a large deformation. The matrix must yield or fracture around rubber particles. Rubber phase will act as a stress concentrator, altering the stress distribution within the matrix and producing a change in deformation behavior.

\subsubsection{Deformation mechanisms of polymers}

Bucknall [6] has classified deformation mechanisms in glassy polymers as shear processes and cavitation processes. Shear processes include diffuse shear yielding and localized shear band formation. Those shear processes occur without loss of intermolecular cohesion in the polymer, therefore they result in little or no change in density. Cavitation processes that include crazing, void formation, and fracture are characterized by a local loss of intermolecular cohesion and are characterized by local decreases in density.

\subsubsection{Shear yielding}

Shear deformation consists of a distortion in shape without a significant change in volume. In crystalline polymers, shear yielding occurs by slip on specific slip planes as a result of dislocation glide. Slip occurs on planes of maximum shear stress. In glassy polymers, large strain deformation requires more cooperative movement of molecular 
segments. Therefore, shear yielding is much less localized in glassy polymers compared with that of crystalline polymers. In some polymers, diffuse shear yielding occurs at the stressed region while in other polymers yielding is localized into shear microbands. Strain localization depends on the material nature and geometry [6]. Shear bands (see Figure 2-14 ), thin planar regions of high shear strain, are usually initiated due to internal or surface flaws, or to stress concentrations. The degree of shear bands depends on chemical composition of the polymers, temperature, and thermal history of the sample.

Figure 2-15 shows a micrograph of shear bands for a blend of HIPS and PPO.

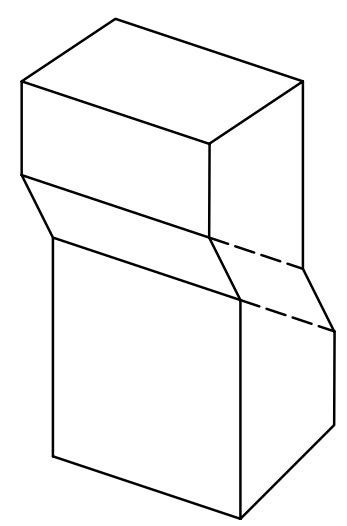

Figure 2-14 The appearance of shear band. 


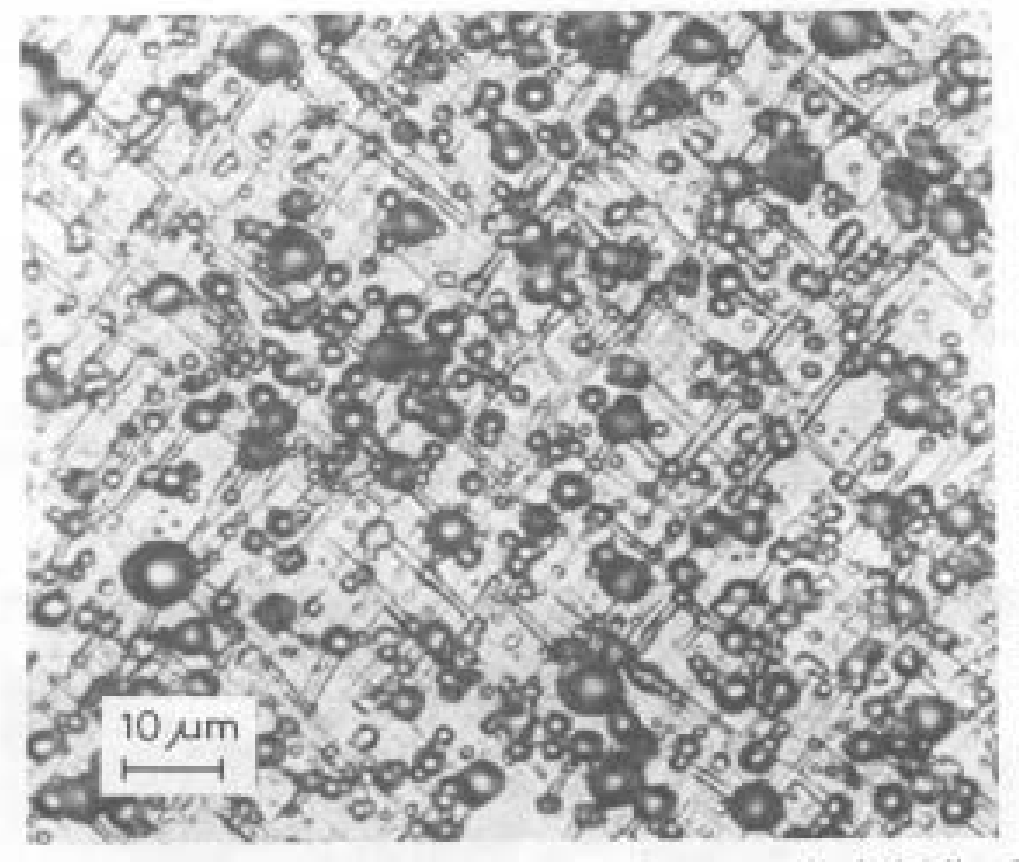

Figure 2-15 Shear bands for a blend of HIPS and PPO prepared under strain compression.[6]

\subsubsection{Crazing}

When a tensile stress is applied to a glassy, mainly brittle, polymer, very small holes form in a plane perpendicular to the stress. These small holes instead of coalescing to form a real crack, become stabilized by fibrils of oriented polymeric material which span the gap and prevent it from becoming wider [6]. The resulting yielded region consisting of a network of voids and fibrils is known as a craze (see Figure 2-16). Crazes usually consist of an open network of polymer fibrils between 10 and $40 \mathrm{~nm}$ in diameter interfused by voids between 10 and $20 \mathrm{~nm}$ in diameter, so that the craze formation may only be visualized by a high magnification microscope such as a transition electron microscope (TEM). 


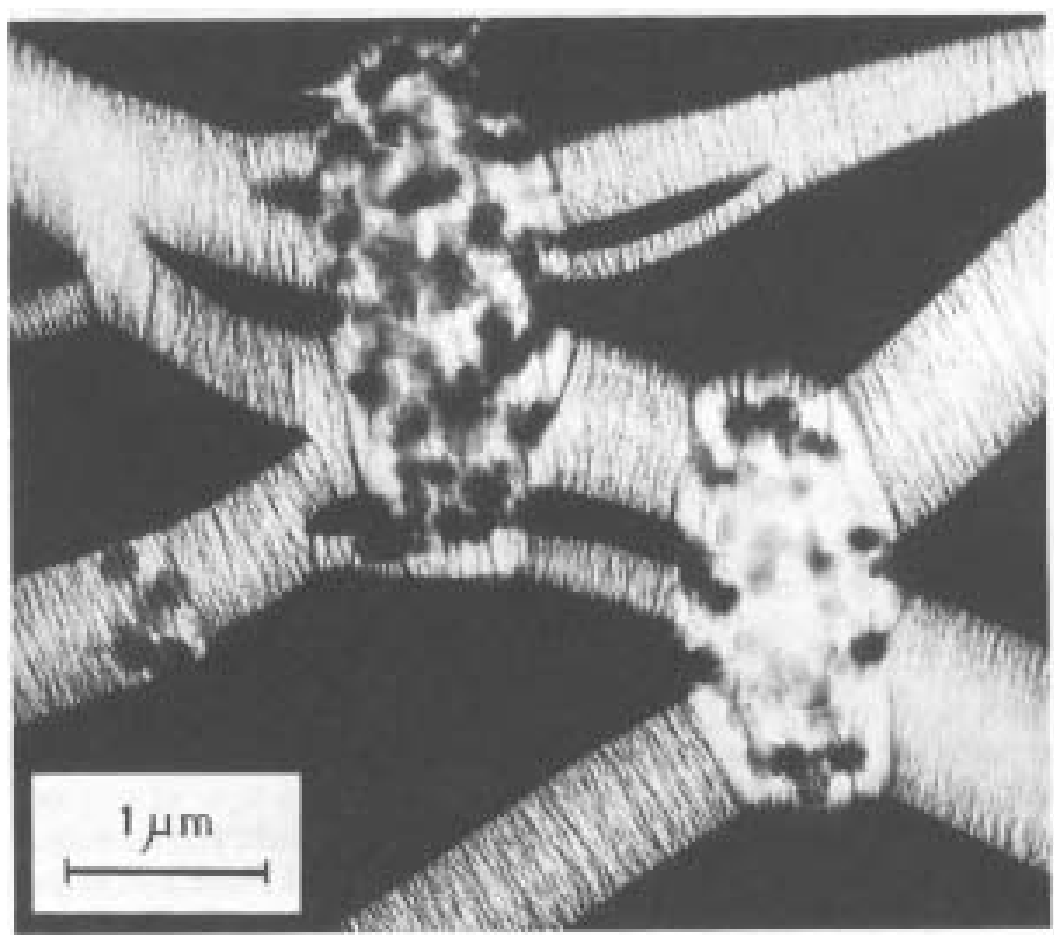

Figure 2-16 Craze formation in HIPS [37].

Crazes grow normal to the tensile stress. They may be millimeters in length and fractions of a millimeter in thickness. However, in toughened materials, they are smaller. They are capable of scattering light due to their structure which gives different refractive index from the surrounding undeformed material. A stressed material with a high density of crazing is said to have " stress whitened " because of its appearance as a result of the scattering. Early work on characterizing crazing focused on stress conditions under which crazes grow. This approach is not fully recommended since crazes may grow at flaws within or at the surface of the material, where stress conditions may not be accurately known. Bowden and Oxborough [38] suggested a criterion in terms of a 
critical tensile strain which depends on the hydrostatic component of the stress tensor. Kramer [39] has suggested the likely steps for craze initiation as:

1. local plastic deformation by shear in the vicinity of a defect which leads to lateral stresses buildup.

2. nucleation of voids to release the triaxial constraints.

3. void growth and strain hardening of the intervening polymer ligaments as molecular orientation proceeds.

A theoretical study of crazing suggests an elliptical crack possessing narrow plastic zones at its tips, with a constant surface stress acting on the boundaries of the zones as shown in Figure 2-17. The stress within the plastic zones is assumed to be uniform, and equal to the yield stress $\sigma_{\mathrm{c}}$ of the material. The elastic stress distributions in the crack are then calculated for a crack of length $2(\mathrm{a}+\mathrm{c})$ in which closing forces $\sigma_{\mathrm{c}}$ are acting over a distance a at each end. Using this model, Dugdale [40] gives the following expression for the length of the plastic zones

$\mathrm{a} / \mathrm{c}=\sec \left(\pi \sigma / 2 \sigma_{\mathrm{c}}\right)$

where

a is length of the plastic zone

c is half length of the crack

$\sigma \quad$ is the applied stress

$\sigma_{\mathrm{c}} \quad$ is the surface stress (constant) 


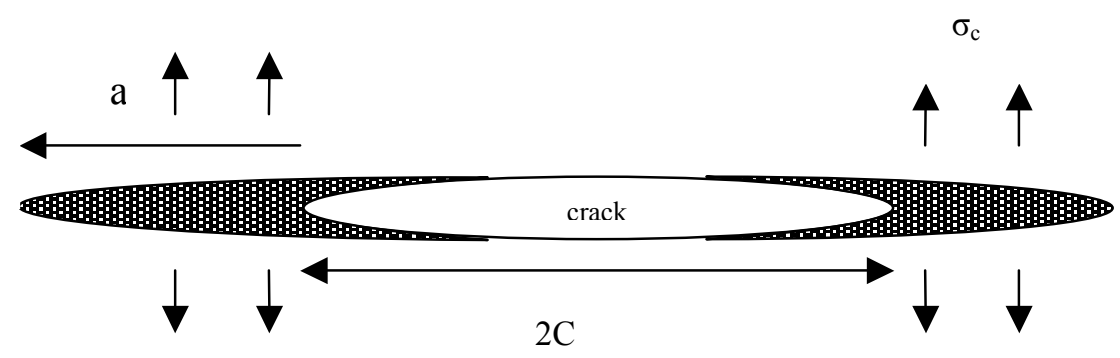

Figure 2-17 Schematic of crack plus craze as suggested by Dugdale model.

\subsubsection{Theories of rubber toughening}

Early theories of rubber toughening suggested that rubber absorbed impact energy by mechanical damping. Damping may explain some of the energy absorption in impact but it does not account for stress-whitening or large strain deformation. Because of this shortcoming of damping theory to fully explain the mechanism of rubber toughening, other theories have been suggested. An early theory of rubber toughening was suggested by Merz et al. [41]. The theory states that rubber particles hold together the opposite faces of a propagating crack, so that the energy absorbed in impact is the sum of the energy to fracture the glassy matrix and the work to break the rubber particles. The theory accounted for some experimental observations. In particular, scattering of light from microcracks explained stress-whitening. Opening of the microcracks provided a mechanism for large strain deformation. A disadvantage of Merz et al. theory referred to as "microcrack theory" is that it ignored the role of the matrix. Fracture behavior of 
toughened PS for example may be completely different from that of toughened PVC [6].

\subsubsection{Multiple crazing theory}

By considering the role of the matrix material in deformation and energy absorption for rubber toughened plastics, the multiple crazing theory, developed by Bucknall and Smith [42], resolved the shortcoming of microcrack theory. The fundamental idea of multiple crazing theory is that rubber particles initiate and control craze growth. Crazes are initiated at points of maximum tensile strain, usually near particle equators, and propagate outwards following planes of maximum tensile strain. The growth of crazing is terminated when the stress concentration at the tip falls below the critical level for propagation, or when a large rubber particle is encountered. The result then is a large number of small crazes (see Figure 2-16) in contrast to the small number of large crazes formed in the matrix material in the absence of rubber particles. Consequently, the toughened polymer can reach a very high strain energy density before fracture. Dense crazing throughout a large volume of the toughened-polymer accounts for high energy absorption in tensile and impact tests. The multiple crazing theory is well founded on experimental evidence and successfully explains the impact and tensile properties of HIPS including stress-whitening, decrease in density and elongation without lateral contraction. However, the theory, i.e. multiple crazing, may not be used to explain the behavior of some toughened polymers such as toughened PVC which exhibits marked necking under tensile yielding without detectable stress-whitening [6]. The shear yielding theory which is discussed next may explain such behavior. 


\subsubsection{Shear yielding theory}

Newman and Strella [43] were the first to suggest that rubber toughening may be due to shear yielding in the matrix. They tested the distortion of rubber particles in ABS tensile samples. They attributed the deformation to a local reduction in $T_{g}$ of rubber phase as a result of triaxial tension. However, triaxial tension promotes crazing rather than shear yielding and shear deformation takes place below $\mathrm{T}_{\mathrm{g}}$ even in a non-dilatational stress field. Rubber particles initiate shear deformation by producing a local increase in the octahedral shear stress rather than by modifying the relaxation behavior of the matrix [6]. Another shortcoming of shear yielding theory is that it cannot explain many phenomena of rubber toughening such as stress-whitening, density change, and elongation without necking. It appears that crazing is the principal mechanism of toughening and shear yielding may contribute to toughening process mainly in ductile polymers where interaction between crazes and shear bands is taking place.

\subsubsection{Simultaneous crazing and shear yielding}

The differences in tensile behavior of HIPS and ABS may be explained on the basis of the contribution of crazing and shear yielding mechanisms to the overall deformation. In ABS, both crazing and shear yielding occur, so that a sample exhibits stress-whitening and necking. In HIPS, crazing is dominant. Figure 2-18 shows the interaction between crazes and shear bands in a rubber toughened polymer. Crazes as seen from the micrograph mostly run from rubber particles. The shear bands seems to run between rubber particles. This is an indication that both crazes and shear bands initiate at stress concentrations produced by rubber particles. The orientation within a 
shear band is parallel to the applied tensile stress and normal to the plane of crazes; therefore shear bands are expected to act as obstacles to craze propagation.

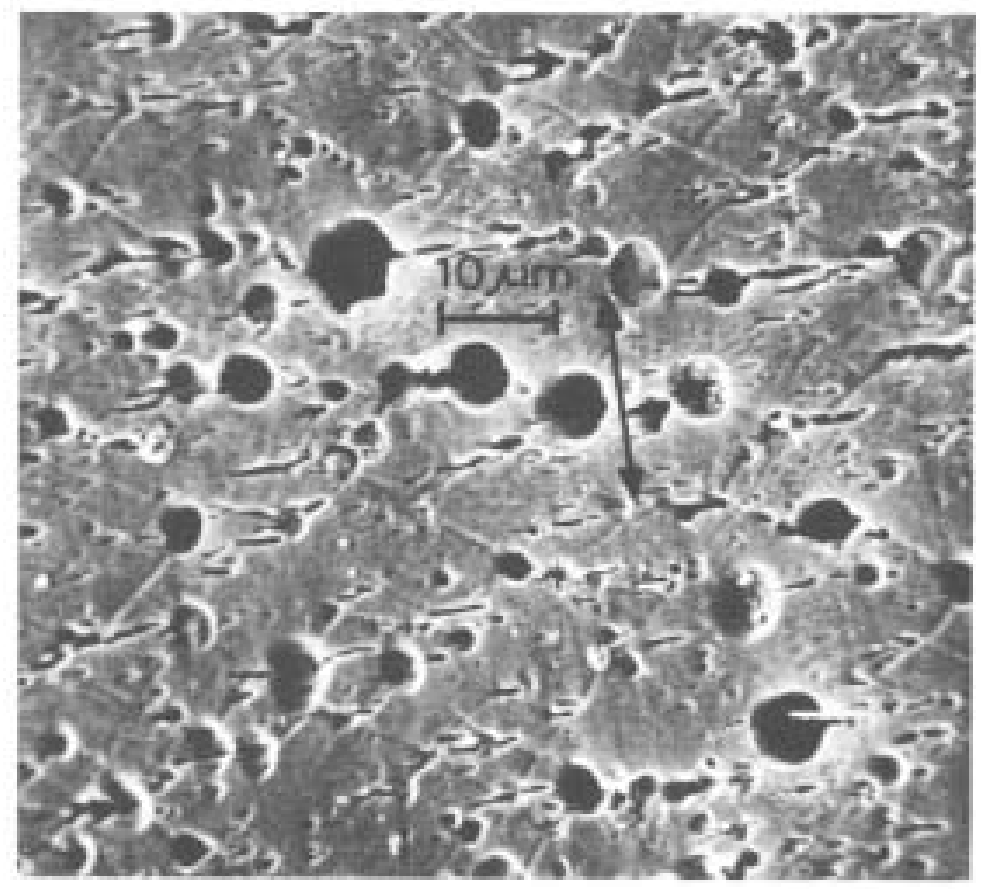

Figure 2-18 Crazes and shear bands in a HIPS/PPO blend. The arrow indicates the direction of tensile strain [6].

\subsubsection{Strength of rubber-toughened polymers}

The rubber phase acts as a stress concentrator, forcing material to yield at a lower applied stress. The yield strength of rubber-toughened polymers may be predicted by Ishai and Cohen equation [44]

$\sigma_{\mathrm{b}}=\sigma_{\mathrm{m}}\left(1-1.21 \varphi_{\mathrm{r}}^{2 / 3}\right)$ 
Where

$\sigma_{\mathrm{b}} \quad$ is yield strength of the blend

$\sigma_{\mathrm{m}} \quad$ is yield strength of the matrix

$\varphi_{\mathrm{r}} \quad$ is rubber phase volume fraction

Equation 2-21 is based on a calculation of the reduced cross section area at b-b section, as shown in Figure 2-19, assuming uniform spherical voids [44]. The maximum stress acts at section $b-b$, where yielding sets in when the maximum effective stress exceeds the yield limit which is a property of the matrix. The shortcoming of Eq. 2-21 is that rubber particles are considered voids. This may lead to over or underestimation of yield stress for rubber toughened plastics depending on type of yield stress test (compression or tensile) [45]. The data on yield stress versus rubber content for $\mathrm{ABS}$ were found to correlate very well with the Ishai and Cohen model as shown in Figure 2-20.

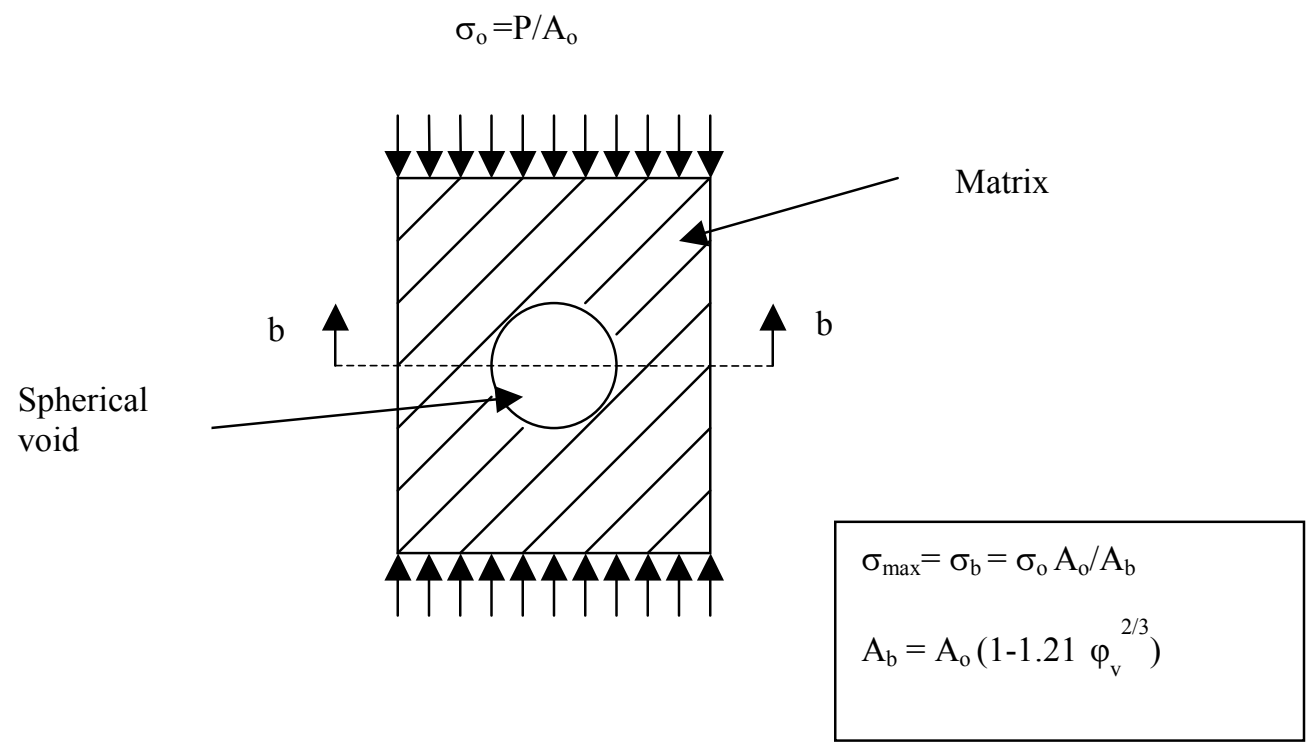

Figure 2-19 Effective area model [44]. 


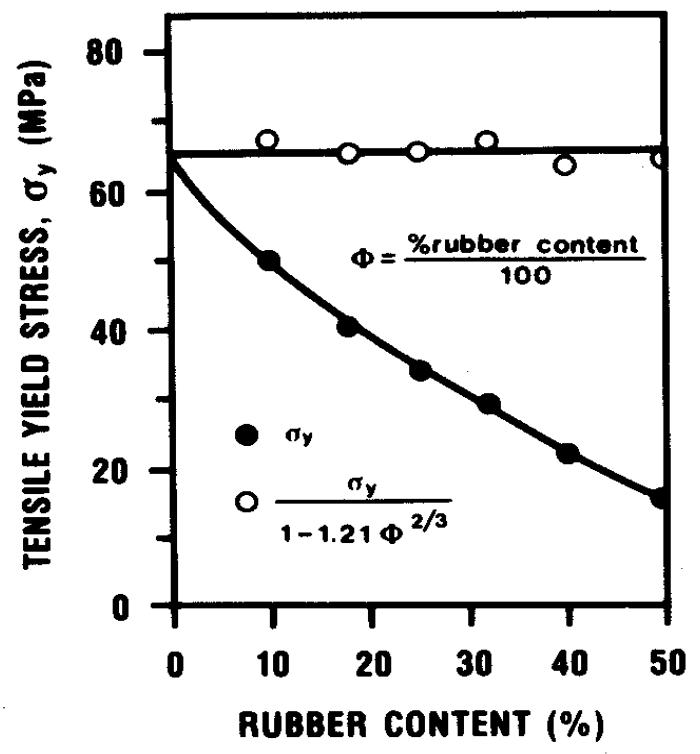

Figure 2-20 Variation of yield stress with rubber content for ABS [46].

Figure 2-21 shows stress-strain curves for blends of HIPS/PS/PPO. As PPO content increases, yield stress increases and elongation at break increases too. The reason for this behavior is that as shear bands form they tend to hinder crazing. Higher stresses are needed to produce a high rate of crazing so shorter crazes are formed, and fracture occurs at higher strain energy [6].

\subsubsection{Factors affecting the process of toughening}

A number of factors can contribute to the failure of toughened polymer when impact occurs. Failure mechanism (crazing and shear yielding), temperature, and notch may affect the toughening process. Microstructure of blends of rubber toughened polymers on the other hand seems to play a crucial role in toughening development. The 


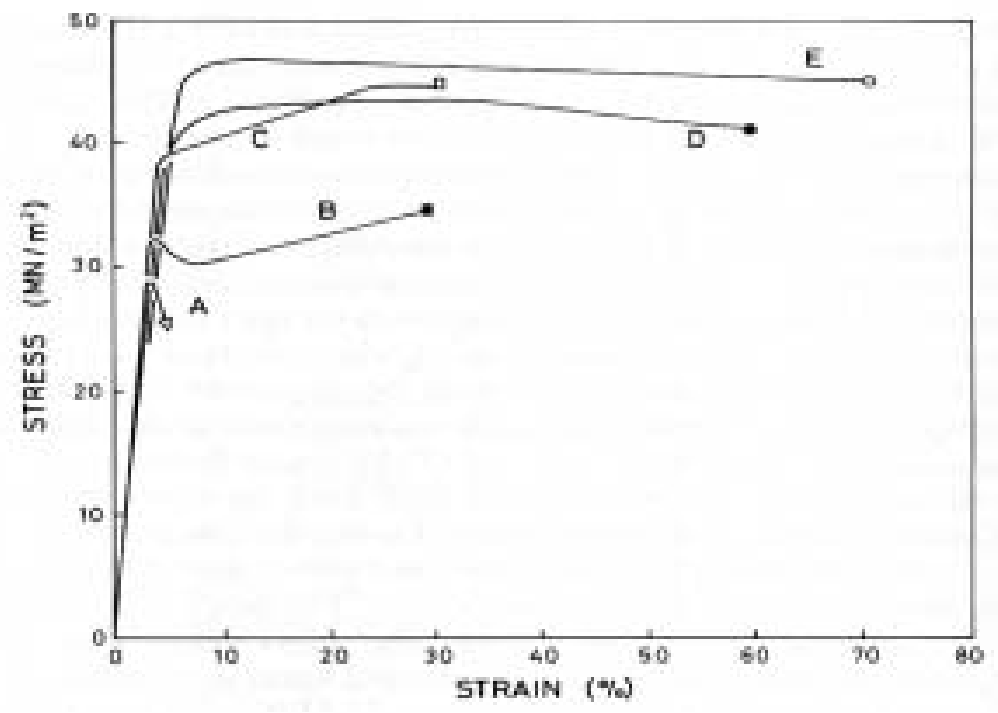

Figure 2-21 Stress-strain curves for HIPS/PS/PPO blends at different weight fractions: $\mathrm{A}(50 / 50 / 0) ; \mathrm{B}(50 / 37.5 / 12.5) ; \mathrm{C}(50 / 25 / 25) ; \mathrm{D}(50 / 12.5 / 37.5) ; \mathrm{E}(50 / 0 / 50)[6]$.

process of rubber toughening of thermoplastics is usually done through melt blending which can be influenced by various parameters such as dispersed particle size and size distribution, and type of rubber used and its reactivity with the matrix material. Rubber usually represents the minor component $(<20 \mathrm{wt} \%)$ in the blend system. As rubber concentration increases, modulus and tensile strength of the blend decrease. Miscibility between polymer matrix and rubber phase has to be very good in order to have a system which is thermodynamically stable. For both brittle and pseudo-ductile polymers, the maximum toughness can be achieved at an optimum rubber phase size (see Figure 2-22). A good distribution of the rubber phase in the polymer matrix is important to have 


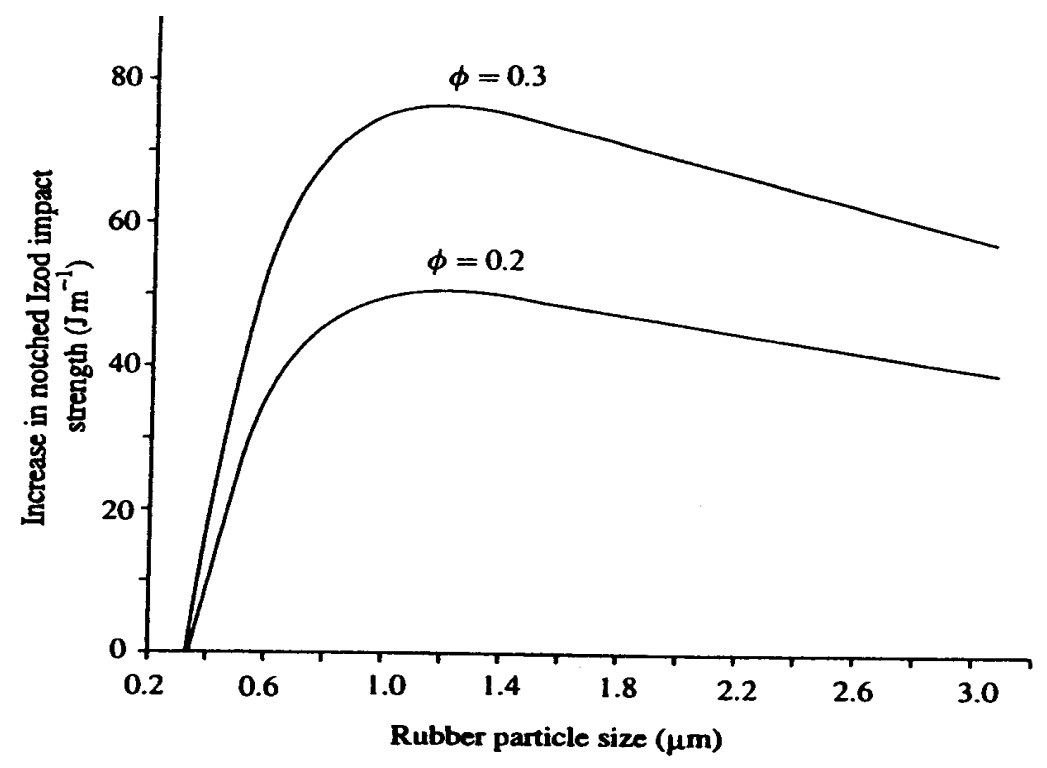

(a)

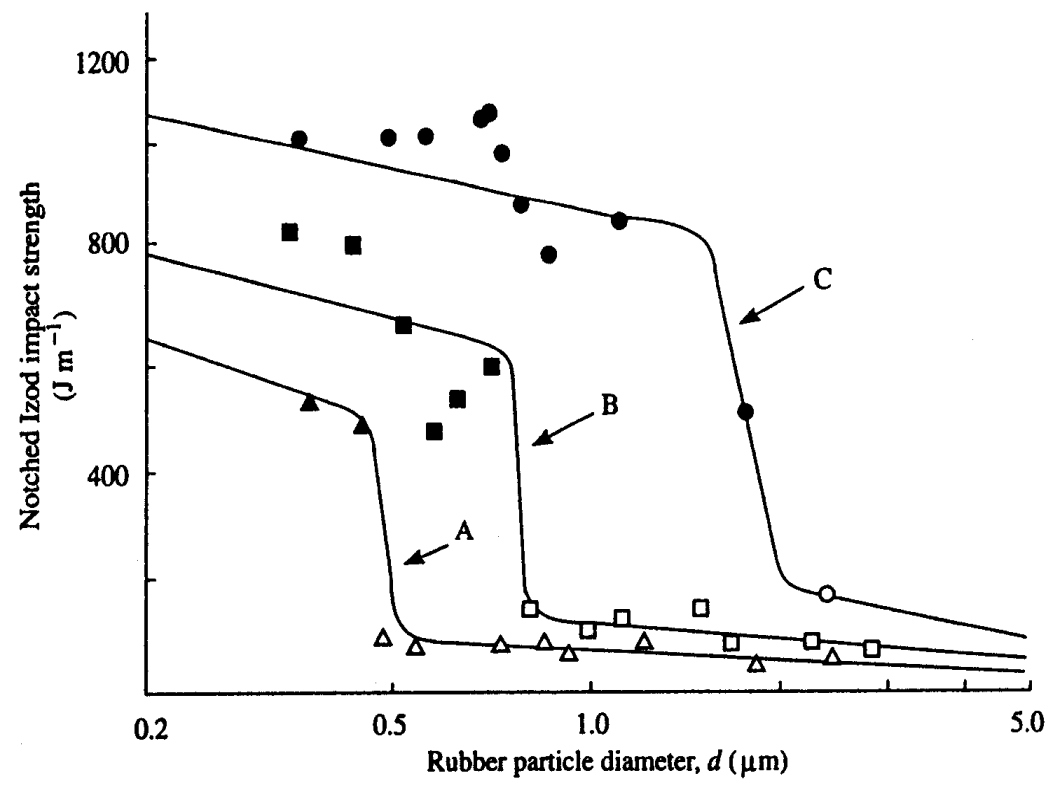

(b)

Figure 2-22 Rubber particle size versus toughness. (a) Brittle [47], (b) Pseudoductile[10]: rubber concentrations are $\mathrm{A}(10 \mathrm{wt} \%), \mathrm{B}(15 \mathrm{wt} \%), \mathrm{C}(25 \mathrm{wt} \%)$. 
effective stress concentrations which lead to enhancement in both crazing and shear yielding in the polymer matrix. The degree of entanglement that a material shows may be taken as an indication of its toughness. For a polymeric material, variation of storage shear modulus $\mathrm{G}^{\prime}$ which represents the ability of material to store energy in elastic form with temperature gives different behavior depending on nature of material. For example, an amorphous polymer exhibits a sharp drop in $G^{\prime}$ at the $T_{g}$ while a semicrystalline material does not (see Figure 2-23).

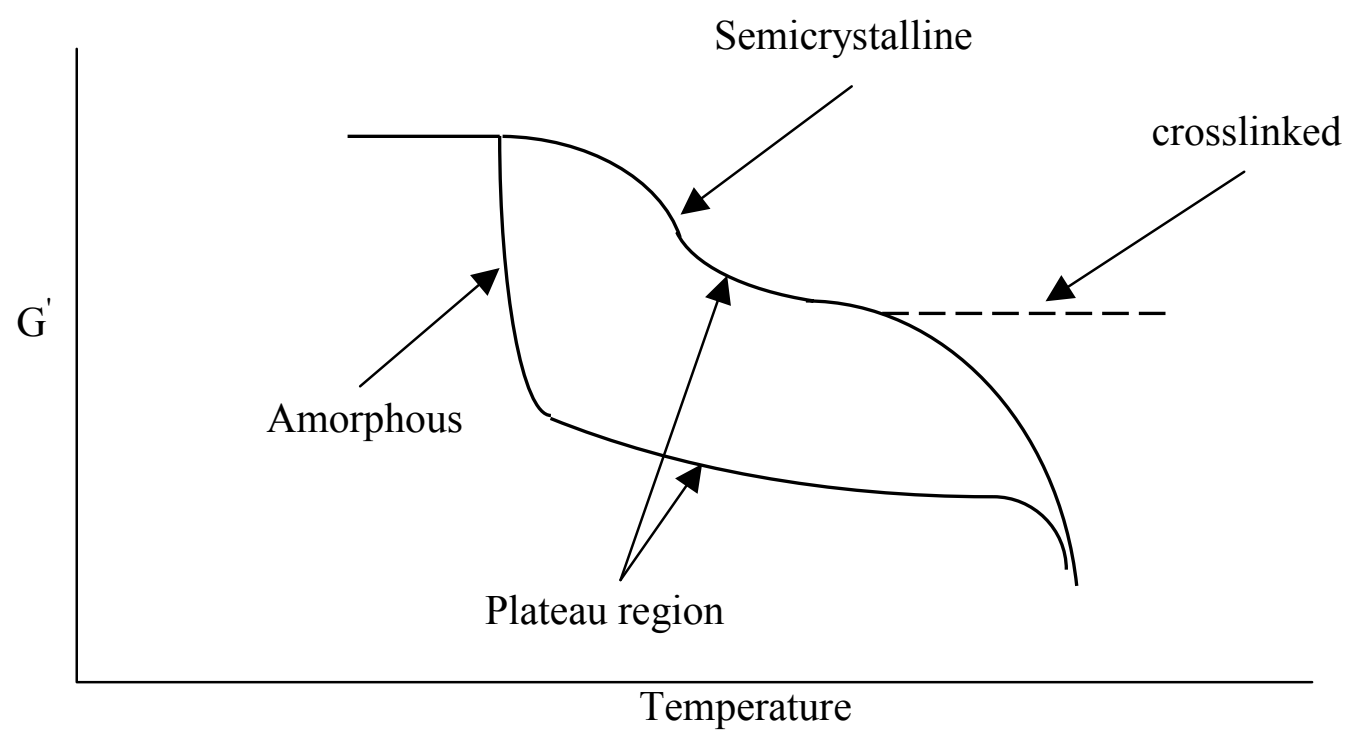

Figure 2-23 Schematic of variation of shear modulus with temperature. 
For a rubber the shear modulus in the plateau region above $T_{g}$ is related to the molecular weight between crosslinks, $M_{c}$ by [5]

$$
\mathrm{G}=\rho \mathrm{RT} / \mathrm{M}_{\mathrm{c}}
$$

\author{
Where \\ $\rho \quad$ is density \\ $\mathrm{R} \quad$ is gas constant \\ $\mathrm{T} \quad$ is the temperature
}

Similar expressions are used to relate shear modulus in the plateau region of an uncrosslinked polymer to the molecular weight between entanglements, $M_{e}[5]$.

\title{
2.2.5.1 Effect of rubber phase morphology
}

$\mathrm{Wu}[10]$ examined toughening of nylon 66 with different types of reactive and non reactive rubbers. He has shown that a sharp transition from tough to brittle mode occurs at a critical rubber particle size at constant volume fraction of rubber as indicated in Figure 2-22 b. A similar finding has been reported by Oshinski et al. [11] who studied toughening of nylon 66 by SEBS and SEBS-g-MA rubber type (see Figure 2-24). Wu [10] further investigated the role of rubber particle size in the toughening process and defined a term called ligament thickness $\mathrm{T}$ as the surface to surface inter-particle distance as shown in Figure 2-25. The significance of this term, ligament thickness $T$, is presented in Figure 2-26 which indicates that tough to brittle transition occurs at a critical ligament 


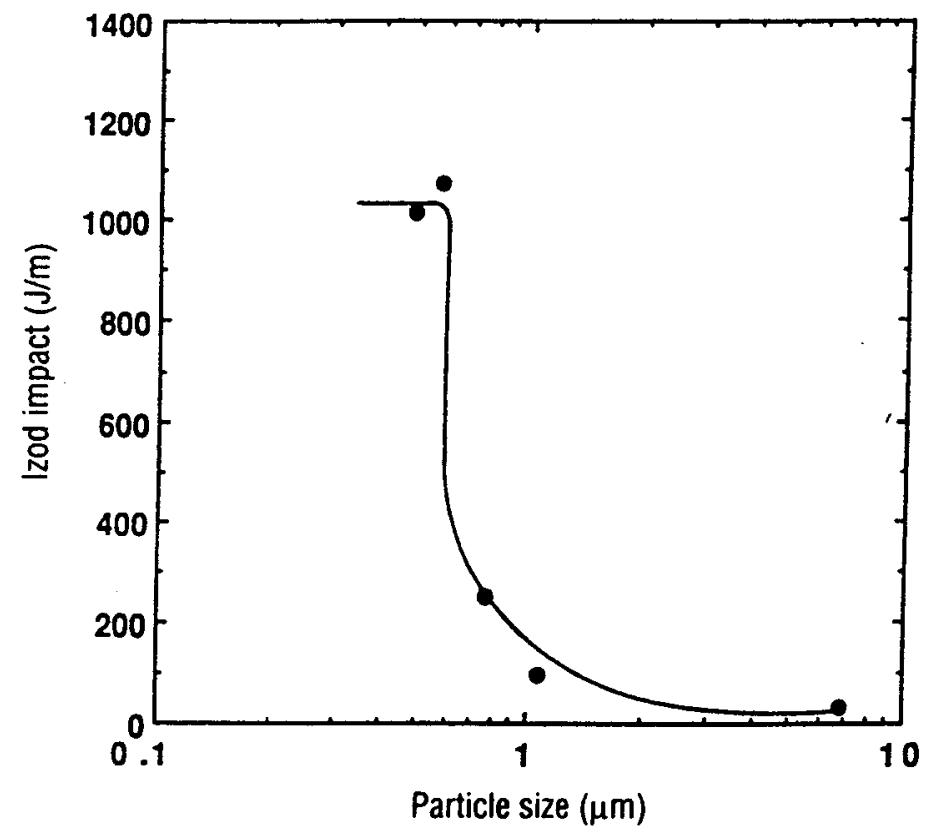

Figure 2-24 Izod impact strength as a function of rubber particle size for $(20 / 80) \mathrm{wt} \%$ (SEBS and SEBS-g-MA/nylon 66) [11].

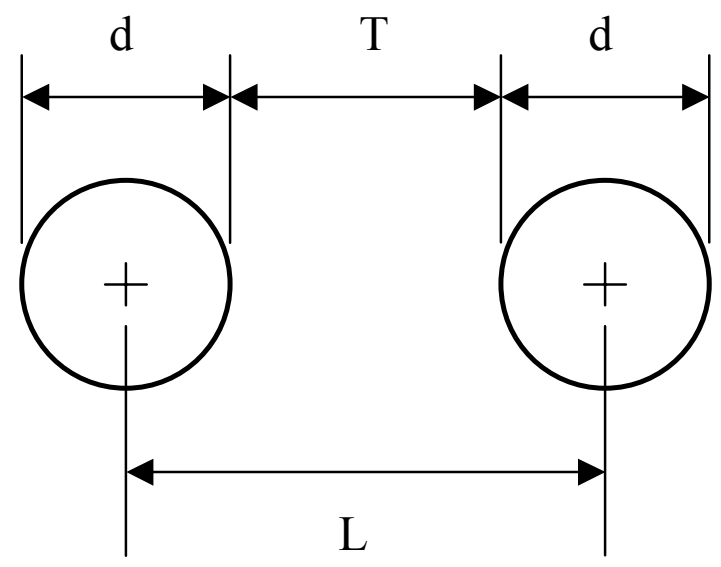

Figure 2-25 Inter-particle distance $(\mathrm{T}), \mathrm{d}$ is rubber particle diameter and $\mathrm{L}$ is center to center particle separation [10]. 


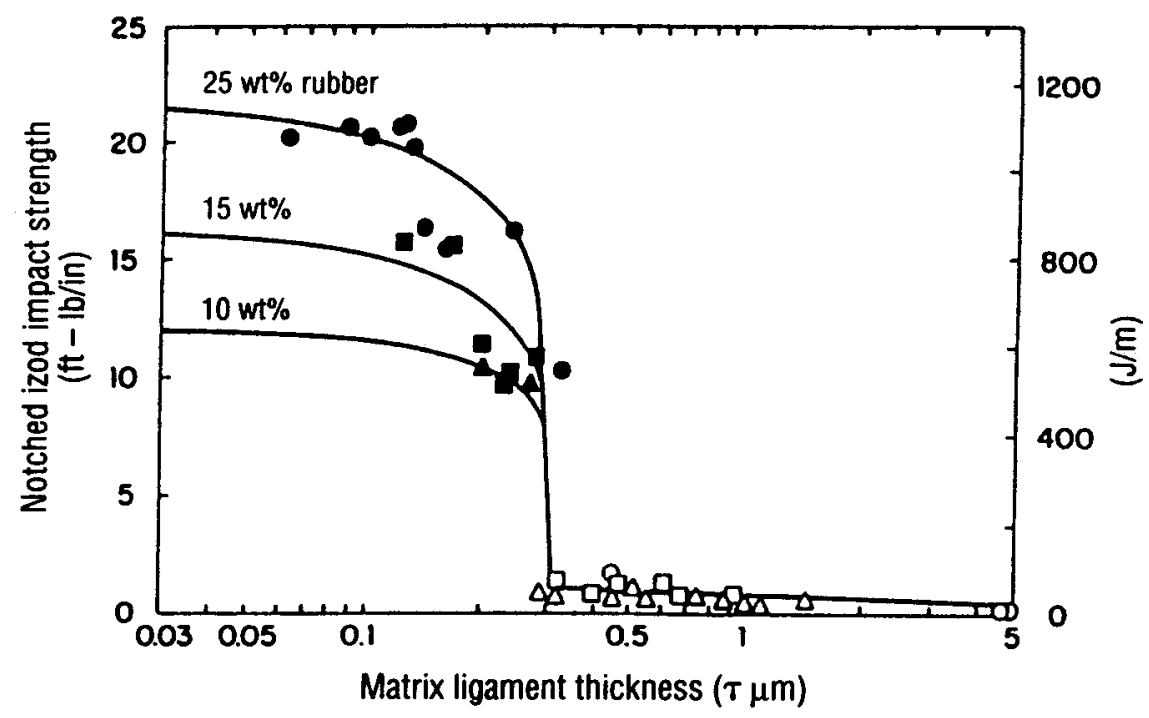

Figure 2-26 Izod impact strength versus ligament thickness T for rubber/nylon 66 blend system [10].

thickness $T_{c}$. Unlike the critical rubber particle diameter shown in Figure 2-22 $b$, the critical ligament thickness is independent of rubber volume fraction and is a material property of the matrix $[10,48]$. The critical rubber particle size is related to the critical ligament thickness by the following formula assuming uniform dispersion of spherical particles in a cubic lattice $[10,48-50]$ :

$\mathrm{d}_{\mathrm{c}}=\mathrm{T}_{\mathrm{c}} /\left[\left(\pi /\left(6 \varphi_{\mathrm{r}}\right)\right)^{1 / 3}-1\right]$

Where

$\mathrm{d}_{\mathrm{c}} \quad$ is the critical rubber particle diameter

$\mathrm{T}_{\mathrm{c}} \quad$ is the critical ligament thickness

$\varphi_{\mathrm{r}} \quad$ is rubber volume fraction 
It has been further suggested that even if the rubber phase is chemically adhered to the matrix, the blend will not be tough unless the inter-particle distance is smaller than the critical value $[10,48-49]$. The mechanism of rubber toughening of nylon 66 suggested by Wu et al. $[48,49]$ was explained in terms of matrix ligament thickness. They suggested that when the matrix ligament thickness is smaller than the critical value $T_{c}$, a transition of plane strain to plane stress occurs and the ligament tends to shear yield; consequently, the blend is tough, but when the ligament thickness is greater than the critical value $T_{c}$, the strain to stress transition is not likely to occur and the ligament fails in brittle mode. The rubber particle distribution is also an important factor in determining the toughening mechanism. When particles are flocculated, the ligaments are thin within one group of flocculated particles but the ligaments between one group of particles and another are thick which would make it hard for ligament yielding to propagate and the blend is considered brittle [48]. Dijkstra et al. [51] have examined the toughening of nylon 6 by ethylene/propylene rubber grafted with maleic anhydride, EP-g-MA. They have shown that for a blend of nylon 6 and EP-g-MA at constant rubber volume fraction, reducing rubber particle size below a critical value resulted in significant reduction in Izod impact strength as illustrated in Figure 2-27. This finding suggests that there is a minimum rubber particle size that is not effective in initiating appropriate energy absorbing mechanism. It seems there is a contradiction between the toughening mechanism of nylon 66 as described by $\mathrm{Wu}$ et al. [10,48-50] and that of nylon 6 which as described by Dijkstra et al. [51]. 


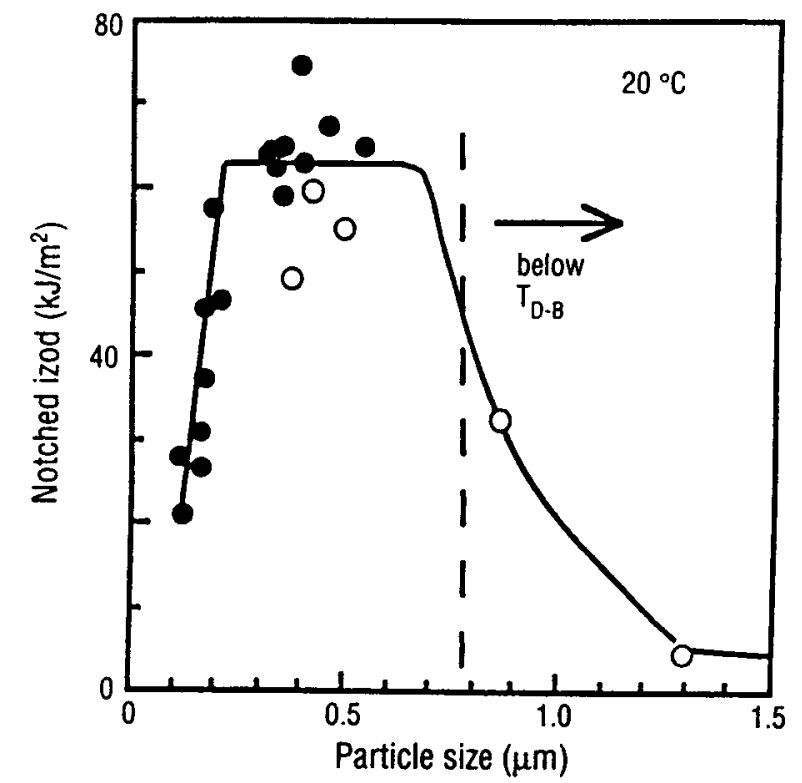

Figure 2-27 Izod impact strength versus rubber particle size for nylon 6 and $20 \mathrm{wt} \%$ rubber:(๑) Modified rubber (EP-g-MA); (O) Unmodified rubber [51].

\subsubsection{Effect of temperature}

At temperatures below the rubber glass transition $T_{g}$, toughness of a blend of polymer and rubber cannot be increased due to the brittleness of rubber phase. When temperature increases above $\mathrm{T}_{\mathrm{g}}$, the rubber phase starts to act as a good stress concentrator and toughness as measured by Izod impact strength is expected to increase. As temperature increases further, a sharp increase in toughness is more likely to take place. The temperature at which the transition in Izod impact strength occurs is commonly called tough to brittle temperature or $\mathrm{T}_{\mathrm{tb}}$. Bucknall [6] has investigated the effect of temperature on toughness of acrylonitrile-butadaiene-styrene (ABS) polymers. He noticed that a big transition in Izod impact strength occurred at high temperatures and rubber contents of $20 \%$. However, no transition was observed for $6 \%$ of rubber content 
(see Figure 2-28). The sharp transition occurs at high temperatures and high rubber content because the energy required for crack propagation is greater than the energy stored elastically in the specimen when the crack is initiated. Therefore additional energy is taken from the pendulum during the propagation stage. At lower temperatures, the crack propagation energy is smaller and there is sufficient elastic energy stored to complete the fracture of the specimens [6]. In case of nylon, similar behavior of temperature toughness relationship has been reported by Dijkstra [51] as illustrated by Figure 2-29.

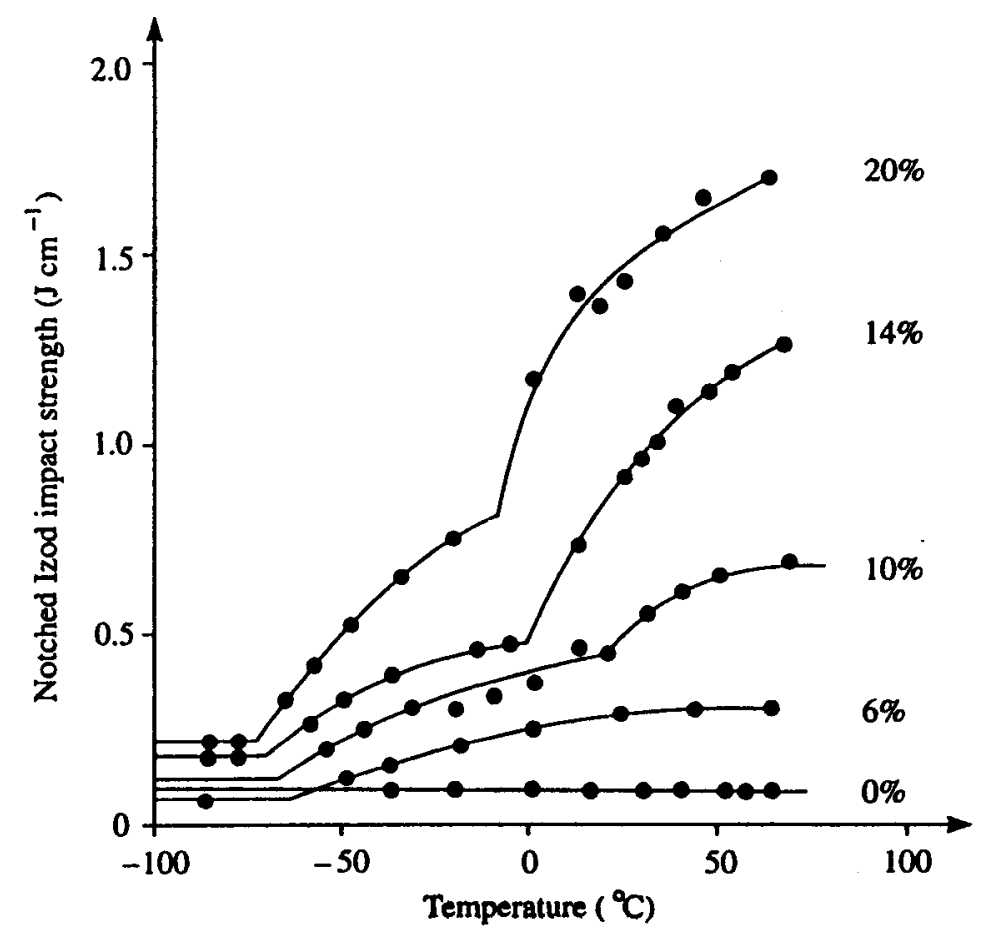

Figure 2-28 Izod impact strength versus temperature for SAN ( $0 \%$ rubber) and for a series of ABS containing 6-20\% Polybutadiene (PB) [6]. 


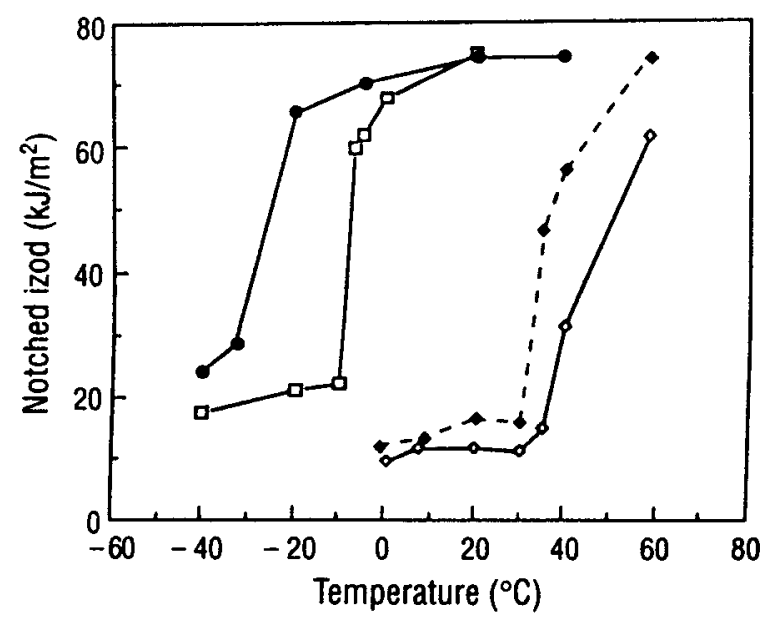

Figure 2-29 Izod impact strength versus temperature for nylon 6 blends with various elastomers (26 vol\%): (•) Butyl rubber; ( $\square$ ) EPDM; $(\bullet)$ LDPE (20\% tensile strain before testing); $(\diamond)$ LDPE ( $0 \%$ tensile strain before testing) [51].

\subsubsection{Effect of rubber type and its interaction with matrix material}

Nylon can be effectively toughened by ethylene/propylene (EP) and styrene/ethylene/butylenes/styrene (SEBS) grafted with maleic anhydride [2]. Oshinski et al. [52] have shown that combining reactive and non reactive rubbers is an effective way to toughen nylon 6 (see Figure 2-30). They have concluded that combining both reactive and non reactive rubbers may control rubber particle size which is the key factor in toughening process. This conclusion indeed has been reached and reported by some earlier studies [12-13,53-56]. In case of nylon 66 the story appears to be different. Figure 2-31 shows that SEBS-g-MA is the more effective toughener for nylon 66 at room temperature than a combination of SEBS-g-MA and SEBS [11]. In terms of its reactivity with maleic anhydride, nylon 66 is considered difunctional while nylon 6 is monofunctional. Unlike nylon 6, nylon 66 chains may have all amine or all acid groups 


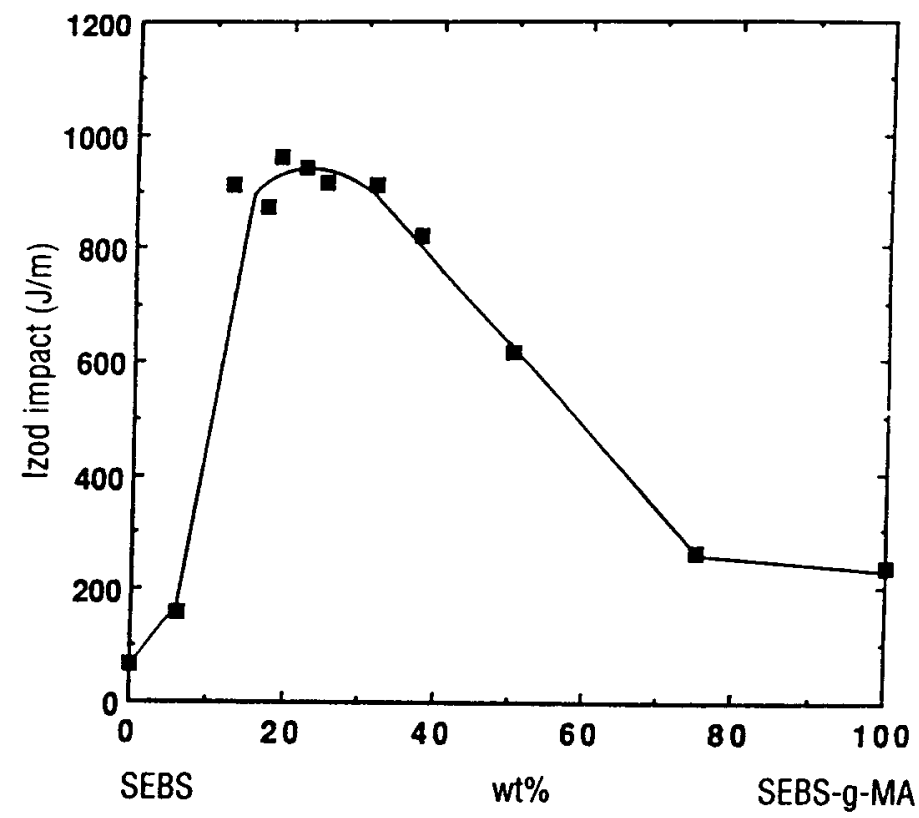

Figure 2-30 Izod impact strength for nylon 6 blended with 20\% (SEBS and SEBS-g-MA) at various ratios of SEBS/SEBS-g-MA [52].

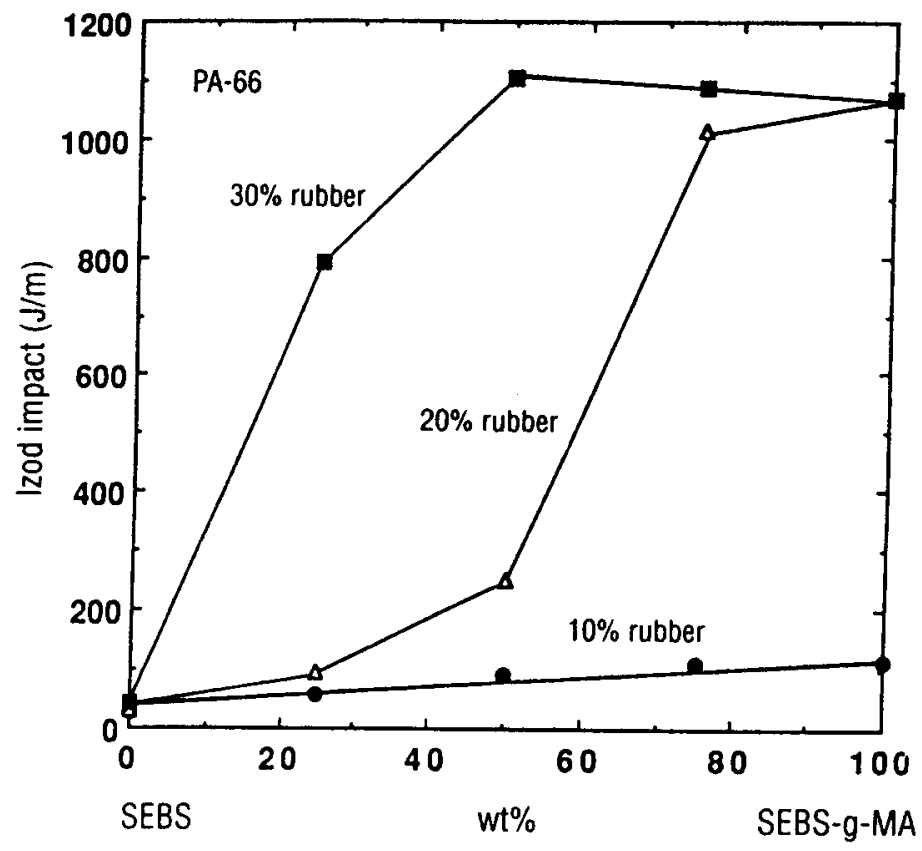

Figure 2-31 Izod impact strength for nylon 66 blended with (SEBS and SEBS-g-MA) at various ratios of SEBS/SEBS-g-MA [11]. 
or one of each. This difunctional nature of nylon 66 allows it to strongly attach to the rubber phase by forming crosslinks with rubber particles or looping within a particle as shown in Figure 2-32. Some studies have shown that the morphology of EP-g-MA blends with nylons depends strongly on the blending conditions such as shear rate and temperature [57,58] however, blends of SEBS-g-MA rubber type and nylon 6 are less affected by the blending conditions due to the ability of forming very fine morphology even at mild conditions [52].

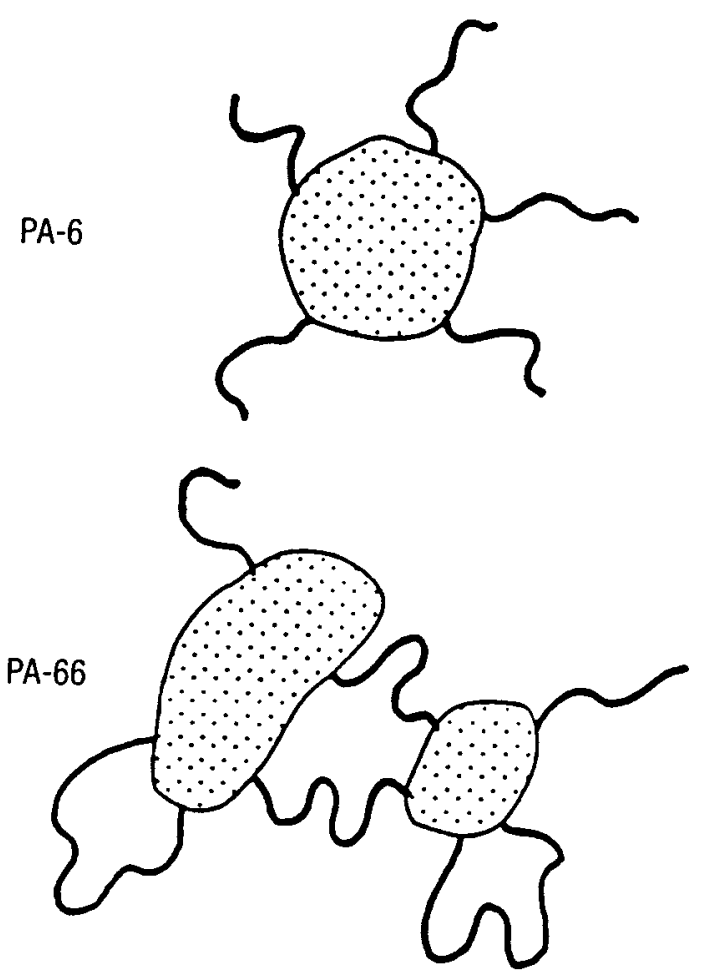

Figure 2-32 Schematic of attachment of nylon to maleic anhydride [11]. 


\subsubsection{Review of rubber toughening of nylon 66}

Although nylon 66 is considered to be a tough material, there has been a great demand for further increasing its toughness and that is due to its notch sensitivity and brittleness at low temperatures which make its resistance to crack propagation very poor. The incorporation of rubber phase into nylon via melt blending is an effective way to obtain very tough nylon. Typically, acid-functional elastomers at percentages ranging from 5 to $20 \mathrm{wt} \%$ are extrusion blended with nylon to enhance its toughness [2]. Maleic anhydride ethylene/propylene elastomers (EP-g-MA and EPDM-g-MA), styrene/ethylene/butylene/styrene block copolymers (SEBS-g-MA), and core-shell rubbers are considered important examples of rubbers that serve as impact modifiers for nylon [2]. Anhydride and other functional groups in the elastomers can react with nylon during melt extrusion through the amine groups or through routes that involve the amide linkage to produce nylon grafted with the elastomer as shown in Figure 2-33. This process of grafting would reduce the interfacial tension between nylon and the rubber phase and hence enhance the dispersion of rubber particles in the nylon phase. Commercial core-shell impact modifiers which are typically made of a rubbery core (e.g. crosslinked butadiene copolymer) and a hard shell (e.g. methyl methacrylate copolymer), are not effective for toughening nylon due to lack of interaction between nylon and the shell part which leads to poor dispersion. In order to have a core-shell rubber that could be used for nylon toughening, one of the following criteria should be met [2]

1-The shell should be modified so that it contains functional groups that can react with nylon.

2- Adding another polymer that is miscible with the shell and can react with nylon. 
Notch sensitivity of nylon was first observed by Bragow [59] in 1956 when he conducted a series of tensile impact tests on nylon. This has led to a number of patents dealing with ways to improve nylon ductility. During the 1960 's, one of the approaches to toughen nylon was by incorporation of ethylene/acrylic(and methacrylic) acid copolymers [60]. This approach [60] required that the rubber phase size to be in the range of 2-4 $\mu \mathrm{m}$. By measuring the blend melt viscosity, an increase was noticed. However toughness, measured by notched Izod impact strength, was little improved. Seddon et al. [61] noticed an improvement in impact strength as measured by charpy test when a rubber type of

\section{(a) Grafting}

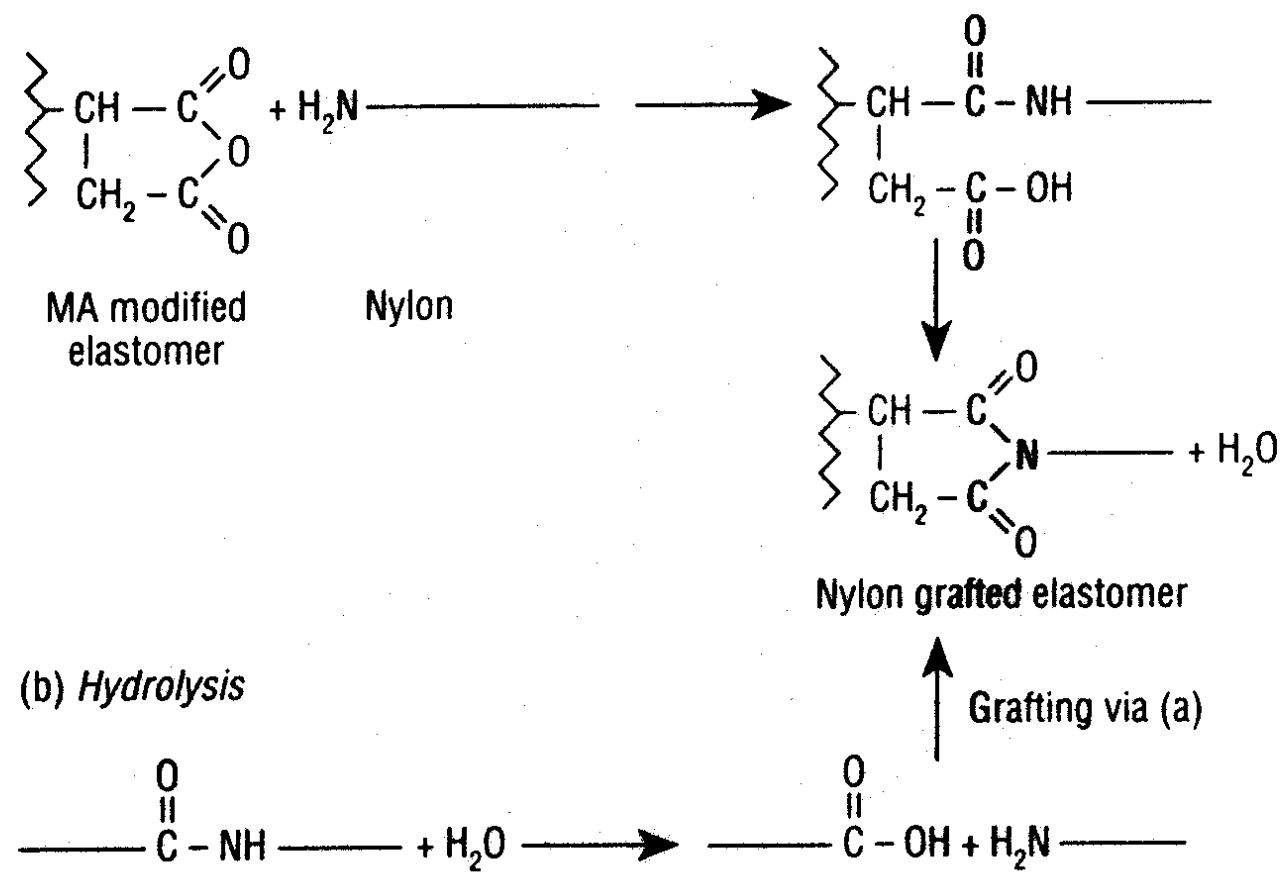

(c) Amide-anhydride reaction

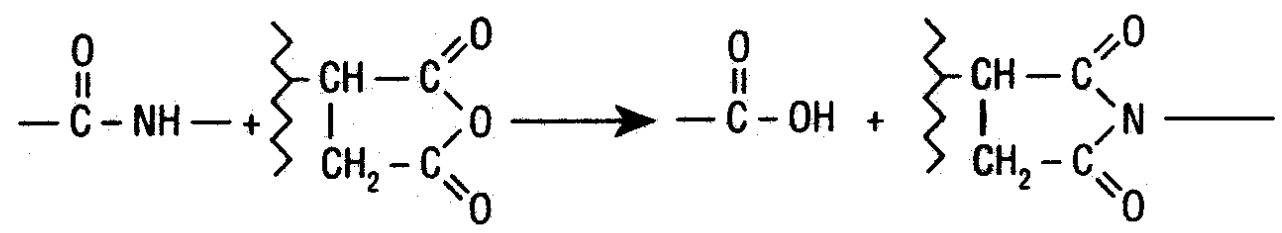

Figure 2-33 The interaction between nylon and anhydride [2]. 
ethylene terpolymers containing hydroxyl or epoxy groups was blended with nylon. Other approaches for nylon toughening that have been reported during the 1960's and early 1970's where tougheners such as nylon-ethylene/ethyl acrylate graft copolymers [62], grafts of carboxylic acid containing copolymers onto an emulsion made elastomer rubber [63], and acid and anhydride containing elastomers [64]. One of the important tougheners for nylon which will be used in the present study is ethylene propylene copolymer grafted with maleic anhydride. The introduction of ethylene propylene copolymer to nylon toughening was proposed by Roura [65]. Rubber toughening of nylon 66 has been extensively investigated by Wu et al. [8-10,48-50,57].

\subsubsection{Toughening mechanism of nylon 66}

The primary deformation mechanisms in rubber toughened nylon are shear yielding and cavitations in rubber particles or the matrix [58,66-69]. Crazing has also been reported [9,70-72] as well as fibrillation within nylons [48]. Typically, when the craze initiation stress is lower than the shear initiation stress, the deformation is due to crazing and the opposite is true [2]. In a model developed by Margolina and Wu [49], a mechanism for rubber toughened nylon 66 was suggested. Inter-particle distance or matrix ligament thickness was the key to determining if the blend was likely to be tough. According to the model, if the thin ligament can interconnect or percolate throughout the matrix then yielding can propagate through the entire deformation zone leading to tough behavior. Gaymans and Borggreve $[73,74]$ have shown that rubber toughened nylon has a brittle to tough transition in the intermediate temperature range between the $T_{g}$ of the nylon and that of the rubber as shown in Figure 2-34. In the brittle region B, only the 
fracture surface near the notch is stress-whitened while the rest of the fracture surface is smooth. The energy absorption is mainly due to deformation during crack initiation and crack propagation appears to be unstable (see Figure 2-35 a). In region $\mathrm{C}$, where transition from brittle to tough occurs, the whole fracture surface area is stress-whitened and the crack propagation is stable (see Figure 2-35 b) [75]. Borggreve et al. [76,77] have suggested that cavitation within rubber

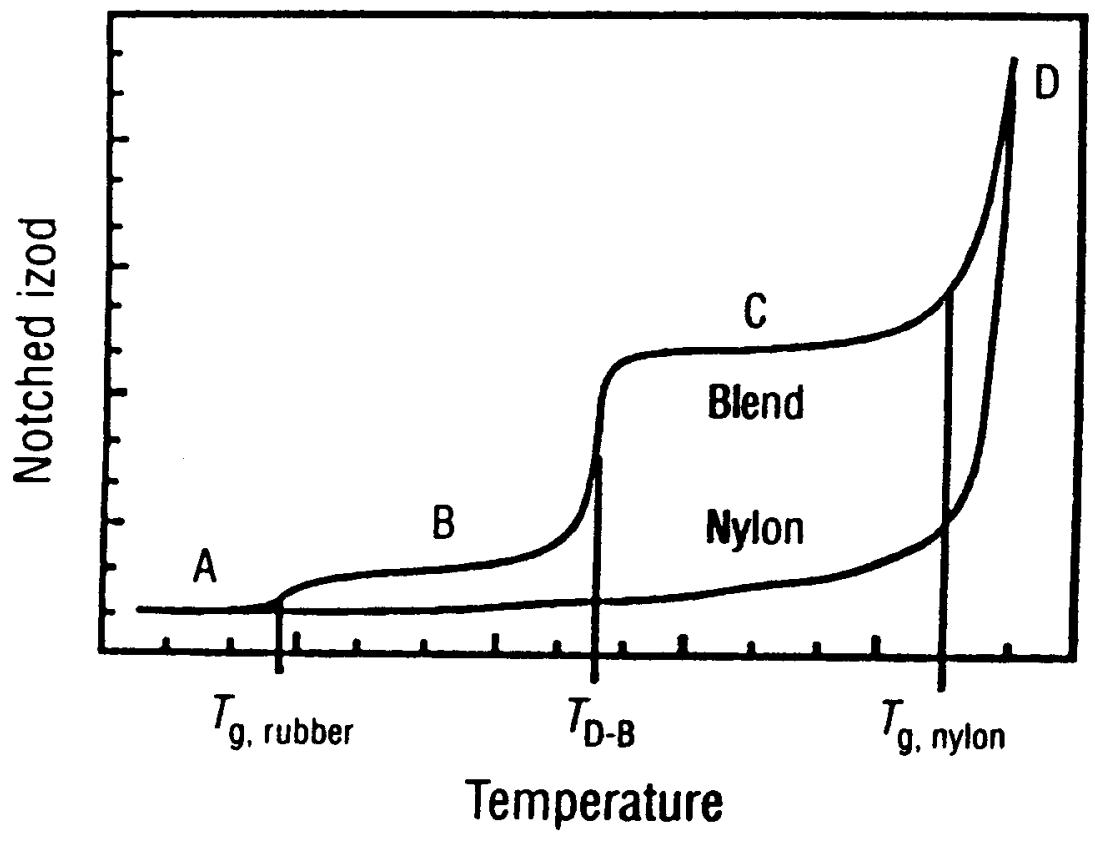

Figure 2-34 Izod impact strength versus temperature for nylon and nylon blended with rubber [74]. 


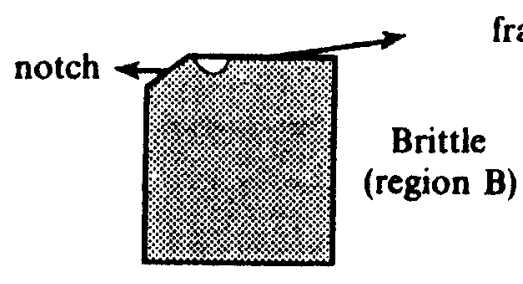

(a)

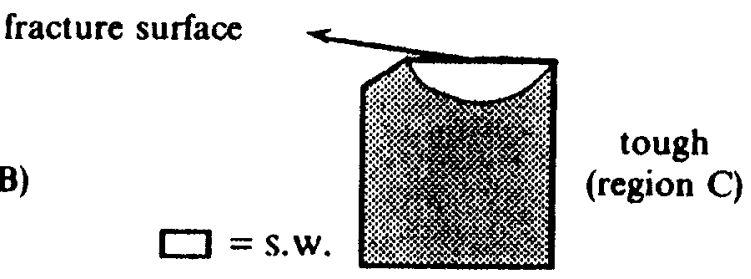

(b)

Figure 2-35 Stress whitening (sw) on fractured samples of nylon and its blends with rubber [75].

particles may play an important role in the process of nylon toughening. They have found that brittle to tough transition temperature increases with increasing cohesive strength of the rubber. Bucknall et al. [78] have reported on formation of highly drawn filaments in the nylon. Cavitations of rubber particles or hole formation within the matrix appears to be responsible for this kind of behavior $[69,78]$.

\subsubsection{Rubber toughening of glass fiber reinforced thermoplastics}

Thermoplastics are routinely blended with rubbery materials to enhance their toughness as we have already discussed in the previous sections. Reinforcement materials on the other hand such as glass fibers are added to polymeric materials in order to make them strong and stiff. It is logical to postulate that there is a trade off between stiffness and toughness for a blend system consisting of a polymer and either rubber or reinforcement agent. Investigating triple composites consisting of neat polymer, reinforcement agent, and rubber has been of great interest to some researchers in recent years, however these studies seem to be fewer in number [79-92]. Composites with a superior balance of strength, stiffness, toughness, and ductility may be achieved by the proper combination of glass fibers and rubber toughening [79]. 
In a recent study, Cho and Paul [79] have investigated the morphology and mechanical properties of glass fiber reinforced nylon 6 toughened with ABS and EP-gMA. They have shown by mechanical testing that the balance of toughness and stiffness can be improved by proper incorporation of glass fibers into rubber toughened nylon 6 . Figure 2-36 shows the trade off between toughness and stiffness for both reinforced and nonreinforced nylon 6 toughened by ABS. Since ABS is incompatible with nylon 6 the Izod impact strength values for composites of glass fiber reinforced nylon 6 and ABS were less as compared to nylon 6 toughened by EP-g-MA (see Figure 2-37).

Nylon 6/GF/ABS/IA (100-x-y-z)/y/x/z

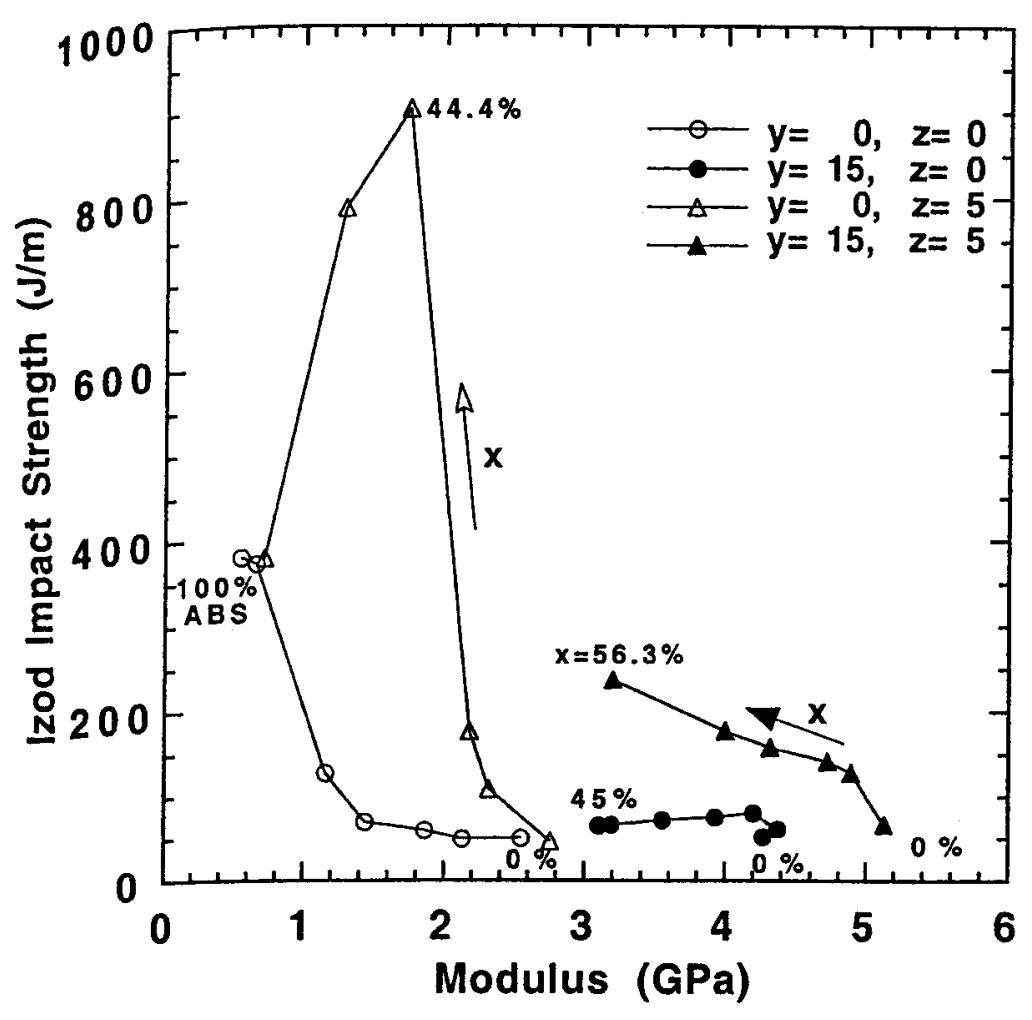

Figure 2-36 Stiffness-toughness trade off for nonreinforced and reinforced nylon 6 toughened with ABS [79]. 
In a series of publications Nair et al. [80-83] investigated the fracture resistance of glass fiber reinforced nylon 66 toughened by styrene acrylonitrile (SAN) with butadiene and ethylene propylene diene monomer (EPDM) type of rubbers. They found that EPDM rubber was not as effective a toughening agent as was the butadiene rubber in ABS and this was because of the weakness at the rubber/nylon 66 or SAN interface [83]. This interfacial weakness is due to the incompatibility of EPDM with either nylon 66 or SAN phases which leads to unstable morphology. As far as the interaction between rubber particles and glass fibers is concerned, it has been suggested that the extent of rubber toughening is larger when fibers are present than when fibers are absent, provided the fiber-matrix interface is strong [83].

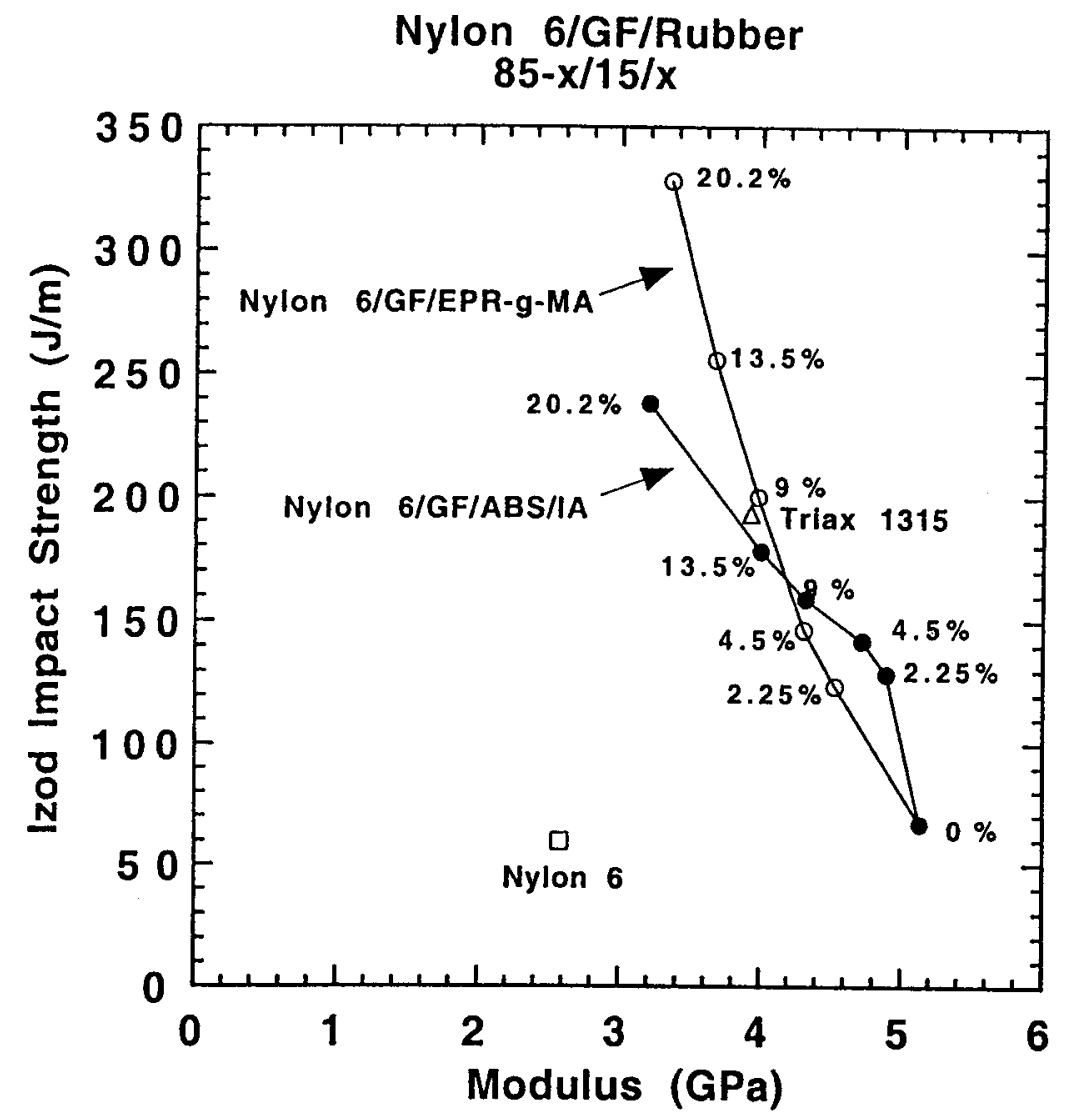

Figure 2-37 Toughening of reinforced nylon 6 with ABS and EP-g-MA, Triax is a commercial $15 \%$ glass fiber reinforced nylon 6 toughened with ABS [79]. 
It is necessary to mention here that although compatibility between rubber and matrix seem to be a necessity to have better toughening as suggested by the above studies [7983], $\mathrm{Wu}[10]$, who studied rubber toughening of nylon 66 with no glass fiber reinforcement, has suggested that chemical adhesion between rubber and thermoplastic is not a necessary condition for toughening and the determining factor is the rubber interparticle distance.

Some researchers have reported that for nylon 6 toughened by $20 \mathrm{wt} \%$ EP-g-MA, adding a small amount of glass fibers (i.e. $<5 \mathrm{wt} \%$ ) enhanced blend tensile modulus but at the same time caused a $50 \%$ reduction in room temperature Izod impact strength [85]. This finding points to the importance of the balance between toughness and strength when combining both glass fibers and rubbers in a blend with a thermoplastic. The behavior of low temperature toughness of rubber toughened reinforced nylon 6 appears to be different from that of rubber toughened unreinforced nylon 6 . Toughened nylon 6 with no glass fibers exhibits a sharp transition in notched Izod impact strength; introducing a relatively high glass fiber content (i.e. $>5 \mathrm{wt} \%$ ) eliminates this sharp transition in toughness and results in a gradual decrease in toughness as temperature decreases [85]. A similar finding has been reported by Dijkstra et al. [51]. They noticed an absence of transition in impact strength of nylon 6 toughened with EP when glass fiber volume fraction was $>5 \%$ (see Figure 2-38). The stress-strain behavior of glass fiber reinforced nylon 66 toughened by EP-g-MA as reported by Laura et al. [85] emphasized the idea of optimizing stiffness and toughness of thermoplastics. Figure 2-39 shows that as rubber content is increased to $20 \mathrm{wt} \%$ the modulus and yield strength are decreased relative to the unmodified material. Contrary to this, the modulus and yield strength are improved 


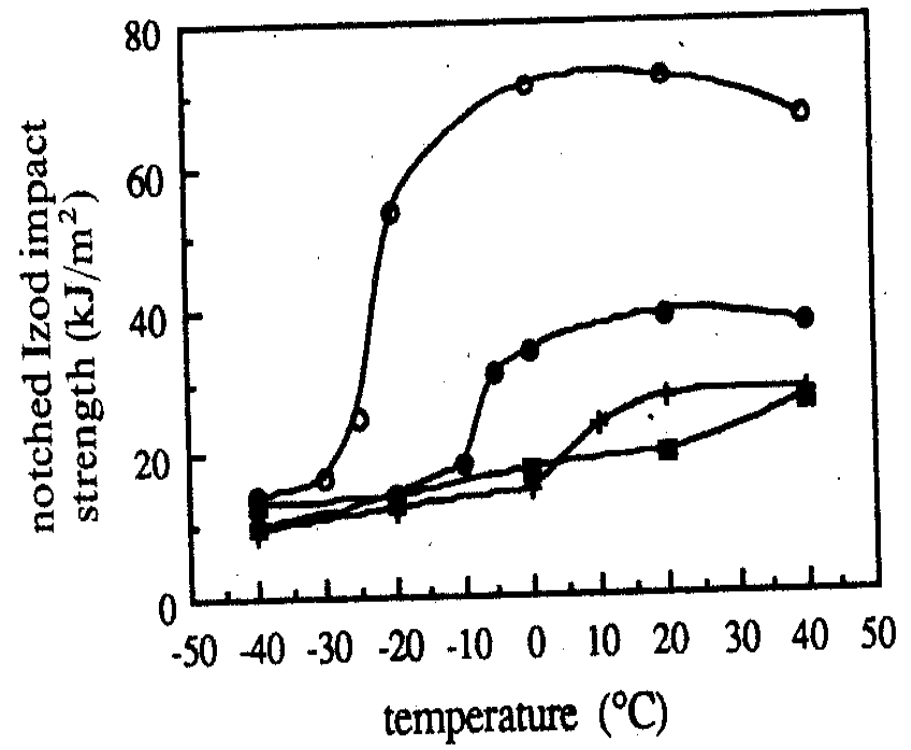

Figure 2-38 Izod impact strength versus temperature for glass fiber reinforced nylon 6 toughened by EP as a function of fiber volume fraction: (o) $0 ;(\bullet) 0.2 ;(+) 1 ;(\boldsymbol{\square}) 5[51]$.

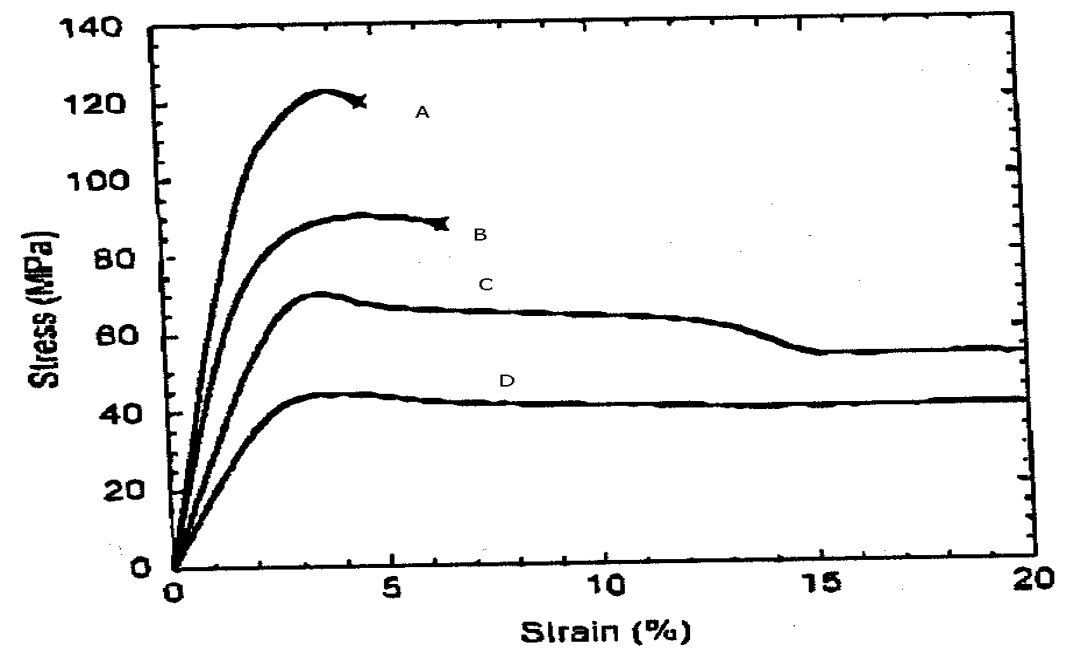

Figure 2-39 Stress-strain curves for (nylon 6/EP-g-MA/glass fiber): $\mathrm{A}(80 / 0 / 20)$; B(80/20/20); C(100/0/0); D(80/20/0) [85]. 
when $20 \mathrm{wt} \%$ glass fiber is added. When $20 \mathrm{wt} \%$ glass fiber is used to reinforce the blend containing $20 \mathrm{wt} \%$ rubber the yield strength and modulus are significantly higher than the corresponding values for neat nylon 6.

Azari and Boss [87] have conducted a comparative study on long and short glass fiber reinforced impact modified nylons, i.e. nylon 6 and nylon 66 . They have found that at a relatively high temperature (i.e. $121^{\circ} \mathrm{C}$ ), the impact modified long glass fiber nylons have about $50 \%$ more tensile and flexural strength than the impact modified short glass fiber nylons.

On the subject of the interaction between glass fibers and rubber particles, it has been suggested that glass fibers inhibit crazing at rubber particles and rubber particles tend to promote crazing at fiber-matrix interface and also void initiation at fiber ends [88]. Figure 2-40 shows Izod impact strength versus glass fiber content for blends of ABS and styrene maleic anhydride (SMA) reinforced by glass fibers. For up to $10 \%$ of glass content, toughness of rubber toughened materials decreases while increase in toughness is seen for untoughened materials, which include very low rubber content and/or small particle sizes since smaller rubber particles are less efficient in toughening under high strain rate [88]. The decrease in toughness of the rubber toughened material is believed to be due to inhibition of crazing at rubber particles caused by the presence of glass fibers and the promotion of void formation at the ends of fibers by rubber particles and since void formation at fiber ends can be suppressed because it is a time dependent process the decrease in toughness was not large (see Figure 2-40) [88]. Glass fibers contribute to propagation toughness by fiber bridging of the matrix crack and by fiber pull out, this along with craze formation at the glass fiber-matrix interface which is 


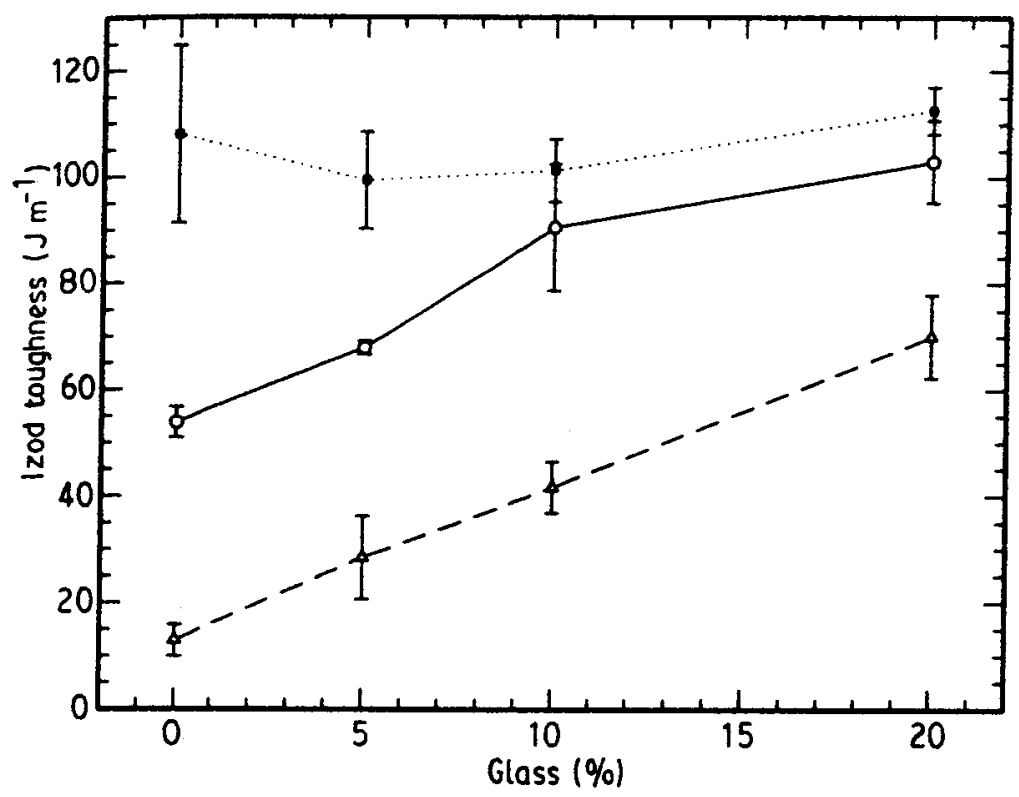

Figure 2-40 Izod toughness versus glass fiber content for various blends of SMA and ABS : (ם) $9.5 \mathrm{wt} \%$ rubber and large particle size; (O) $9.5 \mathrm{wt} \%$ rubber and moderate particle size; $(\Delta) 2 \mathrm{wt} \%$ rubber and small particle size [88].

promoted by rubber particles explain the increase of toughness at high glass content (i.e. beyond $10 \mathrm{wt} \%$ of glass content) [88]. This study [88] suggested some roles of the fibermatrix interface in toughening process, but no conclusive interpretations have been made in terms of interface properties.

Although interfacial chemical bonding between matrix and rubber particles is not necessary for toughening as suggested by $\mathrm{Wu}$ [10] who claimed that Van der Waals attraction, typically $1 / 8$ of the chemical adhesion, provides enough adhesion for toughening, in case of glass fiber reinforced thermoplastics the adhesion between matrix material and glass fibers seems to play a major role in the toughening process. For very short glass fibers the fracture energy is given by Eqs 2-18 and 2-19. It is clear to realize 
that, as given in Eqs 2-18 and 2-19, by increasing shear strength at the interface the energy of fracture would increase, however this is not quite the case when an elastomer phase is introduced between matrix and fibers. The role of fiber-matrix interface in rubber toughened fiber reinforced thermoplastics is not fully understood and controversial [88,89]. Kelnar [89] studied the effect of polypropylene and ethylene propylene rubber grafted with acrylic acid (AcPP and AcEPR) on properties of polypropylene toughened by ethylene propylene rubber (EPR) and reinforced by short glass fibers. He concluded that adding AcPP and AcEPR to the composite caused a strong adhesion at fiber interface which has led to fiber pull out with material layer containing AcEPR and/or PP. However, this strong adhesion between glass fibers and either AcPP or AcEPR does not favor toughness of the composite. Figure 2-41 shows that the unfunctionalized composite (i.e. PP/EPR/glass fibers) has a higher value of toughness even though adhesion with fiber interface is poor. One should notice that as Figure 2-41 indicates that brittle-ductile transition is observed only for the $\mathrm{PP}+\mathrm{AcPP} / \mathrm{EPR} / \mathrm{glass}$ fibers composite, despite the fact that no data have been reported on the effect of rubber phase size on toughness which would have seemed to be crucial, the author [89] attributed this transition in impact strength to the change in the phase structure as shown in Figure 2-42. The distance between fiber ends appears to be an important factor governing toughness of thermoplastics. The fracture toughness as measured by plane-strain fracture toughness $\mathrm{K}_{1 \mathrm{c}}$ of fiber reinforced nylon 66 was found to increase significantly when the mean fiber end spacing is less than six times the fiber diameter [91]. This is an analogy to rubber toughening of nylon 66 reported by $\mathrm{Wu}[10]$ who has shown that rubber toughening of nylon 66 is significantly influenced by rubber particle to particle distance. Note here that 
Wu used Izod impact strength to report for toughness.

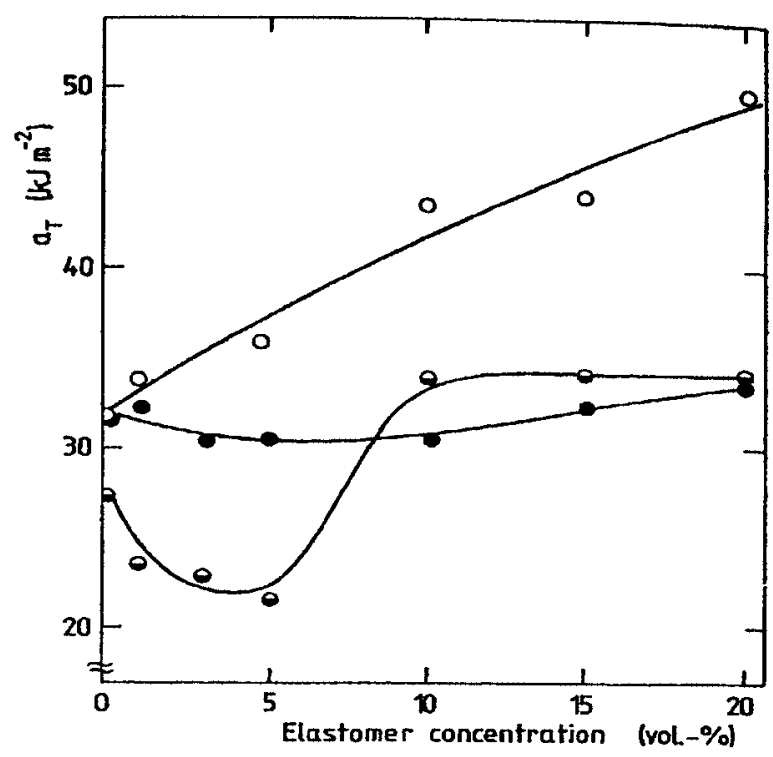

Figure 2-41 Tensile impact strength versus elastomer concentration for PP composites: (O) EPR; (•) AcEPR; (O)AcPP/EPR [89].

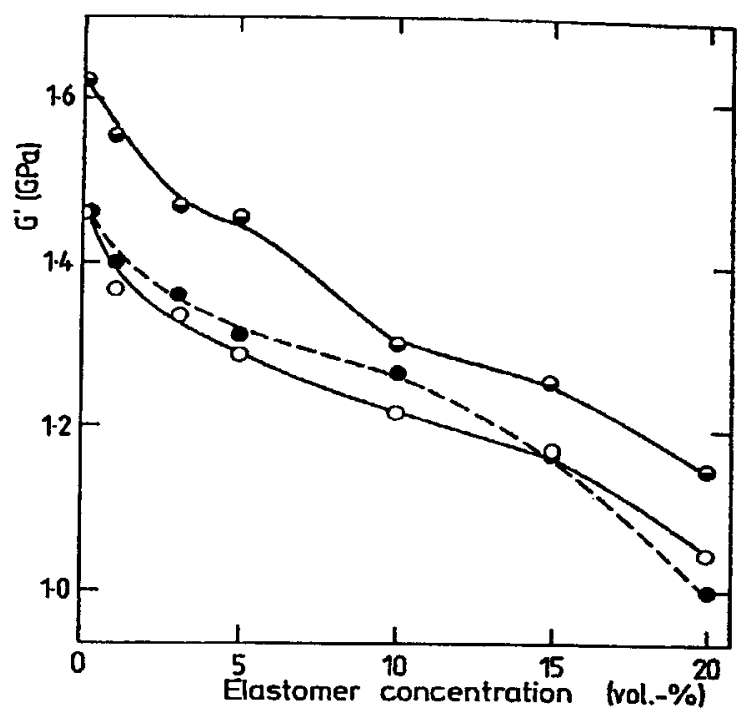

Figure 2-42 Storage shear modulus versus elastomer concentration for PP composites: (O) EPR; (•) AcEPR; (O)AcPP/EPR [89]. 


\subsubsection{Rubber-toughened glass-fiber-reinforced nylon 66}

Although rubber toughening of neat nylon 66 has been extensively investigated as discussed before [8-10,48-50,57], a few studies are available on rubber toughening of glass-fiber-reinforced nylon 66. In these studies, different kinds of elastomers have been utilized. Also the order of mixing, i.e. blending rubber-toughened nylon 66 with glass fibers or glass-fiber-reinforced nylon 66 with rubber, has not been the same. A system consisting of SAN and either butadiene or EPDM rubbers, which showed incompatibility with nylon 66 phase, have been used as tougheners [80-83]. Nair et al. [80] have found that the tensile strength of fiber-reinforced nylon 66 toughened with ABS tends to increases with increasing rubber, i.e. ABS, content in the composite up to (20/80) wt\% (nylon 66/ABS). This is a positive deviation from the rule of mixtures which predicts a linear decrease in the strength of the composites upon increasing rubber content. Contrary to the behavior observed with tensile strength data, elongation at break of the glass-fiberreinforced nylon 66 toughened with ABS has shown a negative deviation from the rule of mixtures. The elongation at break of the fiber-reinforced nylon 66 was found to decrease with increasing rubber, i.e. ABS, content in the range from (20/80) wt\% (ABS/nylon 66) to $100 \mathrm{wt} \%$ ABS [80]. Other studies [86,92] have used a DuPont product Zytel ST801, known as super tough nylon 66, as their base material. This rubber toughened nylon 66, Zytel ST801, is Zytel 101 blended with EPDM rubber.

\subsubsection{Conclusion}

Based on a survey of the literature, it can be concluded that ABS and EPDM rubber have been the only ones used when compounding with glass-fiber-reinforced 
nylon 66. On the other hand, other rubbers such as SEBS-g-MA have proven to be good impact modifiers for nylon 66 [11-14]. It has been shown by others that blending nylon 66 with $20 \mathrm{wt} \%$ of SEBS-g-MA results in a super tough nylon 66 that has an Izod impact strength of about 20 times that of neat nylon 66 [11]. While there is enough data about toughening of unreinforced nylon 66 by SEBS-g-MA and EP-g-MA, toughening of glass fiber reinforced nylon 66, for example DuPont's GRZ 70, with SEBS-g-MA and EP-gMA has not been investigated yet. Therefore, the main aim of the current research is to carry out the above mentioned task. 


\section{Chapter 3}

\section{Materials and procedure}

\subsection{Materials used}

\subsubsection{Matrix}

At the early stages of this research, the motivation was to characterize, modify, and utilize a recycled nylon 66 reinforced by glass fibers. This glass-fiber reinforced nylon 66 was obtained from SDR Plastics. It was a waste generated during compounding operations and it contained other thermoplastics such as PE and PC. Argonne National Lab separated the nylon 66 from PE\&PC. The separated nylon was shipped to West Virginia University as lot A\&B products. The difference between these two products was that they had different glass fiber contents, and this showed up as a difference in the specific gravities. When it was decided to study rubber toughening of nylon 66 it was decided to work on both recycled and virgin glass-reinforced nylon 66 .

DuPont supplied the virgin glass reinforced nylon 66 with two different glass contents, i.e. 13 and $33 \mathrm{wt} \%$. Working with virgin material would enable a comparison of its properties with those of the recycled one. According to the manufacturer, the tensile and Izod impact strengths of the virgin material are $17.5 \mathrm{kpsi}(120.67 \mathrm{MPa})$ and $0.9 \mathrm{ft}-$ $\mathrm{lb} / \mathrm{in}(48.13 \mathrm{~J} / \mathrm{m})$ at $13 \mathrm{wt} \%$ of glass fiber and $27 \mathrm{kpsi}(186.16 \mathrm{MPa})$ and $2.2 \mathrm{ft}-\mathrm{lb} / \mathrm{in}$ $(117.65 \mathrm{~J} / \mathrm{m})$ at $33 \mathrm{wt} \%$ of glass fiber respectively.

\subsubsection{Rubbers}

Rubbers used in this study are EP-g-MA (Exxelor VA 1801) and SEBS-g-MA (KRATON FG1901X). They were supplied by ExxonMobil and KRATON polymers respectively. These two rubbers are semicrystalline and have been produced by maleic 
anhydride grafting process. As mentioned in Chapter 1, the maleic anhydride group is expected to react with the amine group in nylon 66 which would promote the miscibility of the blend during melt extrusion. Table 3-1 gives some of the properties of these two rubbers.

Table 3-1 Rubber properties*.

\begin{tabular}{|l|c|c|}
\hline \multicolumn{1}{|c|}{ Property } & EP-g-MA & SEBS-g-MA \\
\hline $\begin{array}{l}\text { Maleic Anhydride content } \\
(\mathrm{wt} \%)\end{array}$ & $0.45-0.75$ & $1.4-2.0$ \\
\hline Polystyrene content $(\mathrm{wt} \%)$ & - & 30 \\
\hline Specific gravity & 0.87 & $<1$ \\
\hline Melt flow index $(\mathrm{g} / 10 \mathrm{~min})$ & 9 & 21.2 \\
& $\left(10 \mathrm{~kg} / 230^{\circ} \mathrm{C}\right)$ & $\left(5 \mathrm{~kg} / 230^{\circ} \mathrm{C}\right)$ \\
\hline $\mathrm{T}_{\mathrm{g}}\left({ }^{\circ} \mathrm{C}\right)$ & -42 & - \\
\hline
\end{tabular}

* Provided by the suppliers.

\subsection{Procedure}

\subsubsection{Intrinsic viscosity of the recycled glass-fiber reinforced nylon 66}

Intrinsic viscosity (IV) is a reasonable method to estimate molecular weight of a polymer. Estimating molecular weight provides helpful information regarding the degradation that occurs during the extrusion process. Reduction in molecular weight is an indication of chain scission. IV can be calculated by the following formula

$[\eta]=\left(\eta_{\mathrm{sp}} / \mathrm{c}\right)_{\mathrm{c} \rightarrow 0}$

where

c is concentration in $\mathrm{g} / 100 \mathrm{ml}$

$\eta_{\mathrm{sp}} \quad$ is the specific viscosity which is given by Eq 3-2 


$$
\eta_{\mathrm{sp}}=\eta_{\mathrm{r}}-1
$$

Molecular weight can be related to intrinsic viscosity by the Mark-Houwink equation as

$[\eta]=\mathrm{k} \mathrm{M}^{\mathrm{a}}$

where $\mathrm{a}$ and $\mathrm{k}$ are constants which depend on temperature and solvent used $\mathrm{a}=0.786, \mathrm{k}$

$=3.53 \times 10^{-4}$ ) [15]. Note that the molecular weight given in Eq. 3-3 is the viscosity average molecular weight $\left(\mathrm{M}_{\mathrm{v}}=1.78 \mathrm{M}_{\mathrm{n}}\right)$ [15]. Relative viscosity, $\eta_{\mathrm{r}}$, is the key property for calculations for IV. $\eta_{\mathrm{r}}$ is the viscosity ratio of solution to solvent, and it is simplified by ASTM D2857 as the ratio of efflux time of solution to solvent; a $100 \mathrm{ml}$ CannonFenske viscometer was used to determine the efflux time for solution and solvent [15]. $0.5 \mathrm{~g}$ of recycled nylon 66 (excluding glass fiber weight) was dissolved in $100 \mathrm{ml}$ of 90 $\%$ formic acid. The mixture was allowed to come to equilibrium overnight, and the flask was subjected to shaking frequently in order to have complete dissolution. The solution was then filtered using a filtering flask to separate nylon from glass fibers. This step of filtration was repeated several times to assure that no traces of glass fibers were contained in the nylon sample. The set up for measuring efflux times for both solvent and solution consists of the viscometer, a constant temperature water bath, thermometer, and a stop watch to measure time (Figure 3-1). After placing the viscometer in the water bath , 7.5 $\mathrm{ml}$ of pure formic acid was charged into it and then the temperature was let to equilibrate 


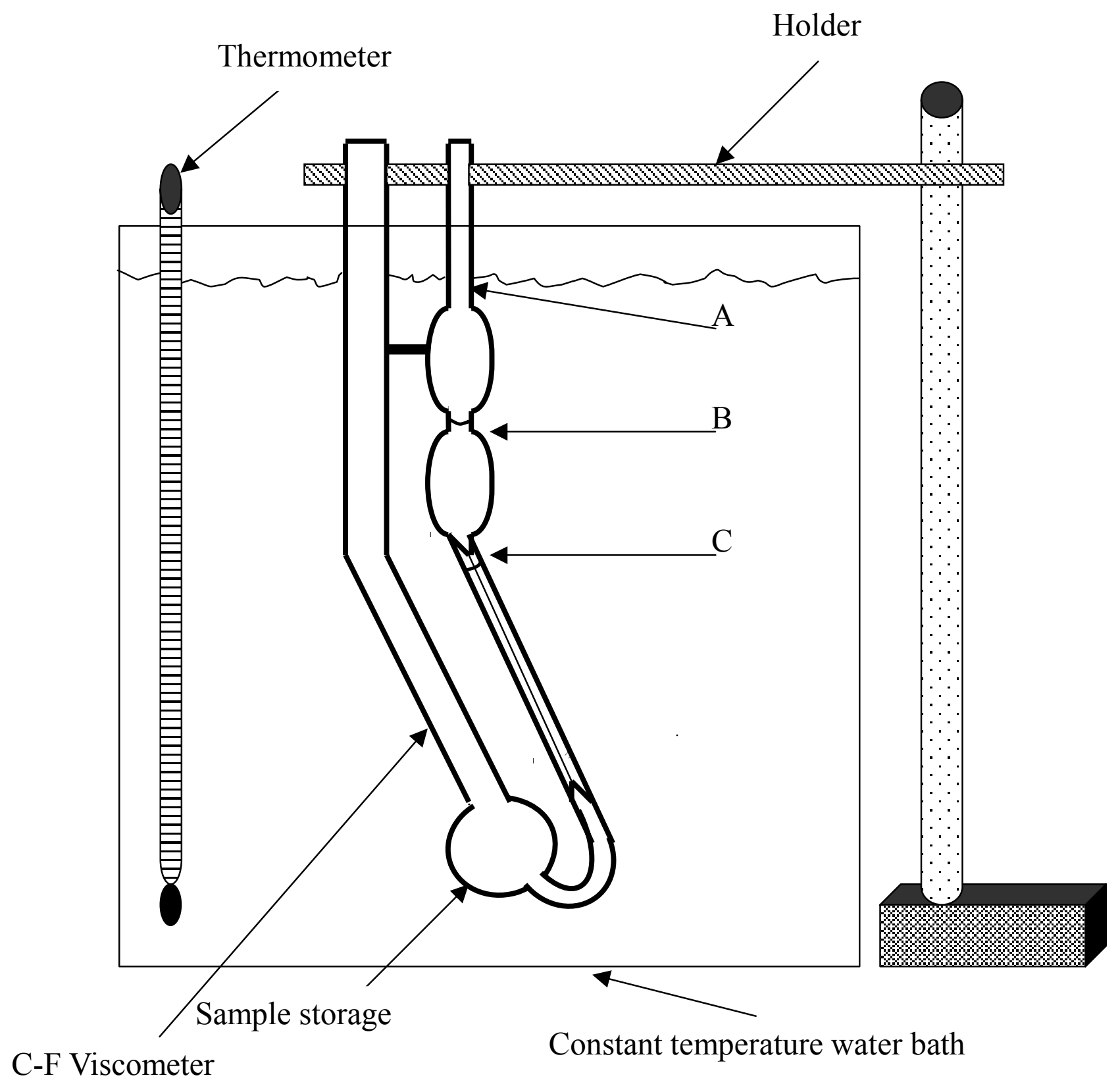

Figure 3-1 Setup used to measure relative viscosity of recycled nylon. 
at $25^{\circ} \mathrm{C}$. When the temperature had stabilized, a sample was drawn slightly above point B by applying suction to tube A then the sample was allowed to flow freely. Efflux time for solvent, $t_{s}$, was recorded when the meniscus traveled from point $\mathrm{B}$ to point $\mathrm{C}$. The efflux time was recorded when three consecutive readings agreed to within $0.1 \mathrm{sec}$. After measuring the efflux time for the pure solvent, the viscometer was cleaned by removing the solvent sample and purging the instrument with some solution sample. The same steps for measuring efflux time for pure solvent were repeated to measure the efflux time for the solution, t. Finally, relative viscosity was calculated as:

$\eta_{\mathrm{r}}=\mathrm{t} / \mathrm{t}_{\mathrm{s}}$

\subsubsection{Sample preparation}

Samples of nylon and rubber were melt blended in a twin screw extruder. A C.W. Brabender continuous intermeshing counter rotating twin screw extruder with $42 \mathrm{~mm}$ diameter screws and $8 \mathrm{lb} / \mathrm{h}$ maximum flow rate was used. One may dry mix materials and directly injection mold them without pre-blending them in an extruder. However this can result in moldings having composition variations. The injection molding machine screw is not intended to perform mixing, but instead it is used as a metering device. For this reason, it is important to have good blended samples that represent all constituents involved prior to the injection molding step. Blending rubbers and nylon using the twin screw extruder would result in reduction in glass fiber lengths that exist in nylon; however this factor may be ignored since all samples were prepared using the same conditions of temperatures and screw speeds (rpm). In order to minimize fiber attrition in the extruder, a moderate screw speed, $40 \mathrm{rpm}$, was used. The extrusion temperature used 
was $275^{\circ}$ C. Glass fiber content in the samples was determined by ash test (ASTM D2584). This was done by burning a pre-weighed sample at $650^{\circ} \mathrm{C}$ and measuring the ash weight. Before each extrusion run, samples were dried overnight at $82^{\circ} \mathrm{C}$, and , when performing extrusion, the hopper was purged by argon gas to prevent degradation. The extrudates were then drawn into long strands in a water bath and then pelletized using a Brabender strand pelletizer. Since virgin materials have glass fiber contents different from those of recycled materials, combining of the two virgin materials was done in order to match the glass fiber content of the recycled materials. 5,10,15, and $20 \mathrm{wt} \%$ of both rubbers were dry mixed and melt blended with the two recycled and virgin glass fiber reinforced nylon 66 samples. In order to mold test samples, i.e. Izod bars and dog-bone shapes, by injection molding, at least $3 \mathrm{lb}$ of material was produced during each extrusion run. Pellets of glass fiber reinforced nylon blended with SEBS-g-MA and EP-g-MA rubbers prepared by extrusion were injection molded using a Unilog B4 injection molding machine manufactured by Battenfeld. After injection molding, samples were immediately put in doubled sealed plastic bags and stored in a sealed container containing silica gel adsorbent in order to prevent moisture pickup by nylon. The samples were taken out of the container only at the time of the test. Therefore all tests were conducted at "dry as molded" condition. Table 3-2 gives the details of preparation of all the samples. Glass fiber contents of lot A and lot B are $23.62 \mathrm{wt} \%$ and $14.79 \mathrm{wt} \%$ respectively. The steps of preparation of samples from extrusion to injection molding are shown in Figure 3-2. 
Table 3-2 Extrusion composites of recycled and virgin nylon 66 with rubber.

\begin{tabular}{|c|c|c|c|c|c|c|}
\hline \multirow[b]{2}{*}{$\begin{array}{c}\text { Composite } \\
\#\end{array}$} & \multicolumn{6}{|c|}{ Composition (wt\%) } \\
\hline & $\begin{array}{l}\text { Recycled } \\
23.62 \mathrm{wt} \% \\
\text { glass }\end{array}$ & $\begin{array}{l}\text { Recycled } \\
14.79 \mathrm{wt} \% \\
\text { glass }\end{array}$ & $\begin{array}{l}\text { Virgin } \\
23.62 \mathrm{wt} \% \\
\text { glass }\end{array}$ & $\begin{array}{l}\text { Virgin } \\
14.79 \mathrm{wt} \% \\
\text { glass }\end{array}$ & EP-g-MA & $\begin{array}{l}\text { SEBS-g- } \\
\text { MA }\end{array}$ \\
\hline 1 & 100 & 0 & 0 & 0 & 0 & 0 \\
\hline 2 & 95 & 0 & 0 & 0 & 5 & 0 \\
\hline 3 & 90 & 0 & 0 & 0 & 10 & 0 \\
\hline 4 & 85 & 0 & 0 & 0 & 15 & 0 \\
\hline 5 & 80 & 0 & 0 & 0 & 20 & 0 \\
\hline 6 & 0 & 80 & 0 & 0 & 20 & 0 \\
\hline 7 & 0 & 85 & 0 & 0 & 15 & 0 \\
\hline 8 & 0 & 90 & 0 & 0 & 10 & 0 \\
\hline 9 & 0 & 95 & 0 & 0 & 5 & 0 \\
\hline \multicolumn{7}{|c|}{ Cleaning extruder } \\
\hline 10 & 0 & 100 & 0 & 0 & 0 & 0 \\
\hline 11 & 0 & 95 & 0 & 0 & 0 & 5 \\
\hline 12 & 0 & 90 & 0 & 0 & 0 & 10 \\
\hline 13 & 0 & 85 & 0 & 0 & 0 & 15 \\
\hline 14 & 0 & 80 & 0 & 0 & 0 & 20 \\
\hline 15 & 80 & 0 & 0 & 0 & 0 & 20 \\
\hline 16 & 85 & 0 & 0 & 0 & 0 & 15 \\
\hline 17 & 90 & 0 & 0 & 0 & 0 & 10 \\
\hline 18 & 95 & 0 & 0 & 0 & 0 & 5 \\
\hline \multicolumn{7}{|c|}{ Cleaning extruder } \\
\hline 19 & 0 & 0 & 100 & 0 & 0 & 0 \\
\hline 20 & 0 & 0 & 95 & 0 & 0 & 5 \\
\hline 21 & 0 & 0 & 90 & 0 & 0 & 10 \\
\hline 22 & 0 & 0 & 85 & 0 & 0 & 15 \\
\hline 23 & 0 & 0 & 80 & 0 & 0 & 20 \\
\hline 24 & 0 & 0 & 0 & 80 & 0 & 20 \\
\hline 25 & 0 & 0 & 0 & 85 & 0 & 15 \\
\hline 26 & 0 & 0 & 0 & 90 & 0 & 10 \\
\hline 27 & 0 & 0 & 0 & 95 & 0 & 5 \\
\hline \multicolumn{7}{|c|}{ Cleaning extruder } \\
\hline 28 & 0 & 0 & 0 & 100 & 0 & 0 \\
\hline 29 & 0 & 0 & 0 & 95 & 5 & 0 \\
\hline 30 & 0 & 0 & 0 & 90 & 10 & 0 \\
\hline 31 & 0 & 0 & 0 & 85 & 15 & 0 \\
\hline 32 & 0 & 0 & 0 & 80 & 20 & 0 \\
\hline 33 & 0 & 0 & 80 & 0 & 20 & 0 \\
\hline 34 & 0 & 0 & 85 & 0 & 15 & 0 \\
\hline 35 & 0 & 0 & 90 & 0 & 10 & 0 \\
\hline 36 & 0 & 0 & 95 & 0 & 5 & 0 \\
\hline
\end{tabular}


Dried Pellets of Nylon and Rubber

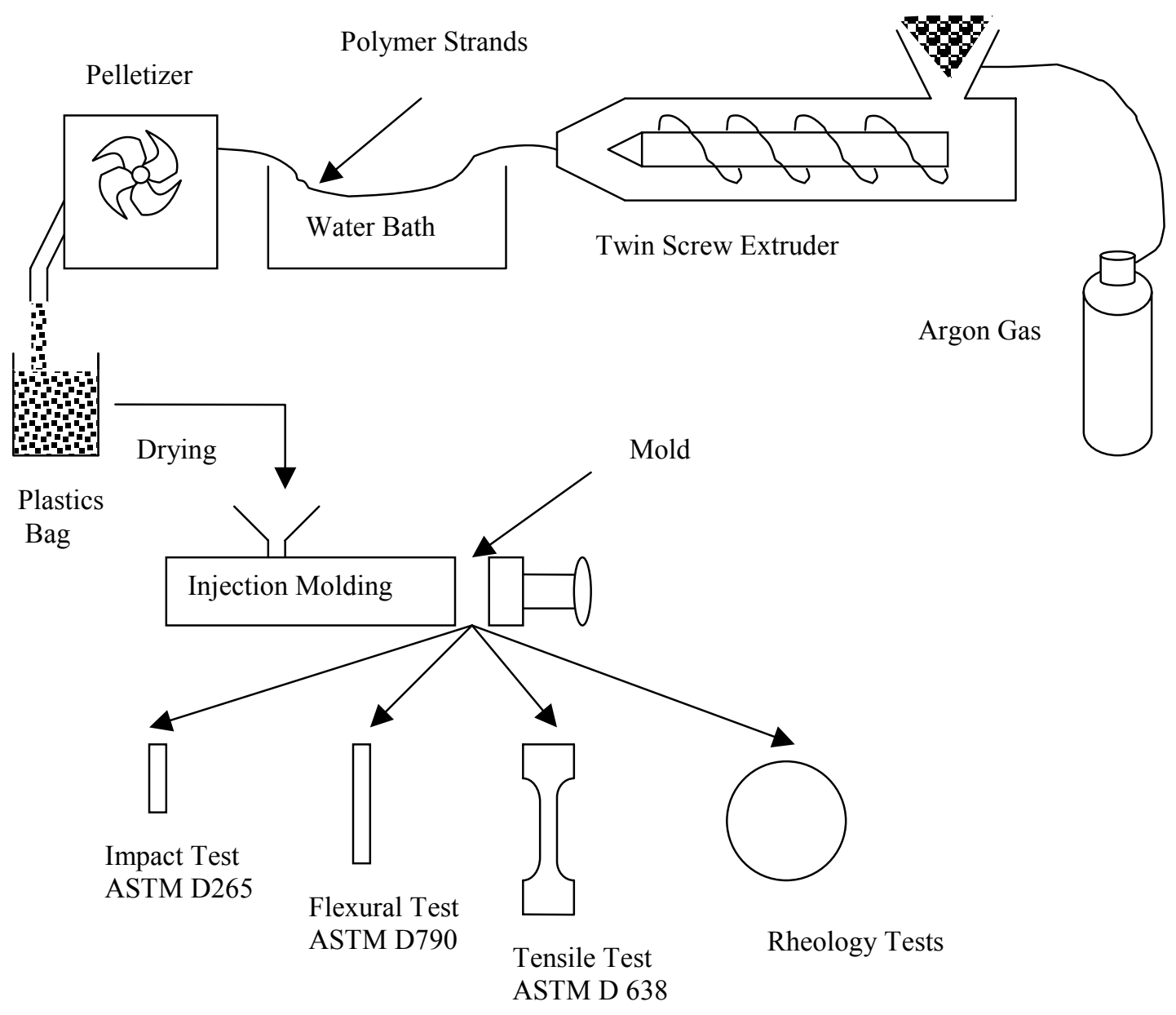

Figure 3-2 Sample preparation of rubber-toughened glass-fiber-reinforced nylon 66. 


\subsubsection{Mechanical tests}

\subsubsection{Izod impact strength}

Izod impact strength was measured according to ASTM D 256. The test was done employing an impact testing machine (Instron model BLI) with pendulum capacity of 2 $\mathrm{ft}-\mathrm{lb}$ at room temperature. A manual Notchvis manufactured by Ceast was used to make notched samples. The energy in $\mathrm{ft}-\mathrm{lb}$ required to fracture the sample was measured from the reading dial. The correction due to wind friction was made and the actual energy was then divided by the thickness of the sample at the notch. The test procedure is illustrated in Figure 3-3. The measurements were conducted over five specimens for each test and the average was reported.

Fracture energy indicator

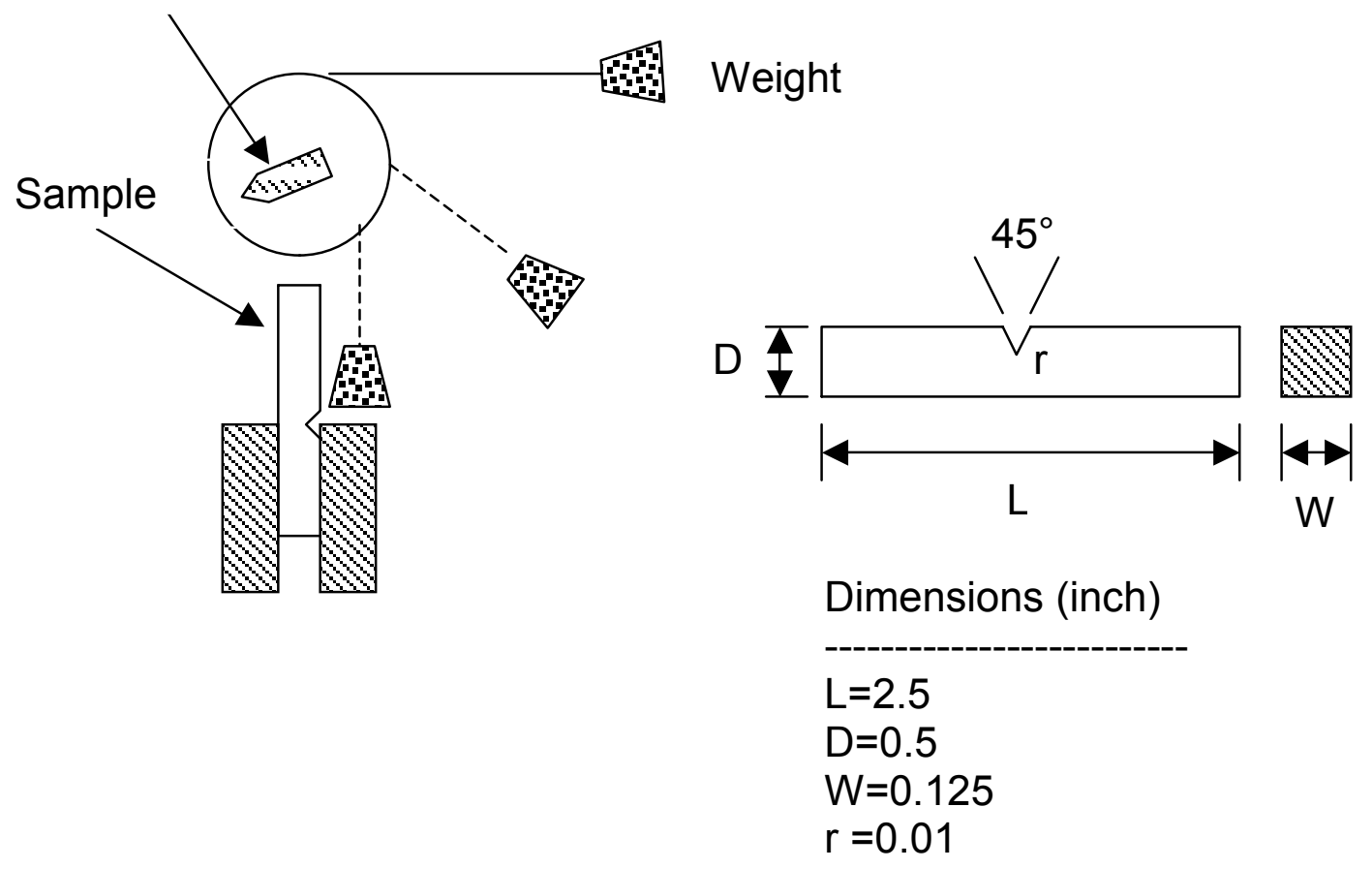

Figure 3-3 Procedure of impact strength test. 
Izod impact strength was also measured at temperatures above room temperature. A heating chamber was used at three different temperatures $56.7,73.6$, and $103.5^{\circ} \mathrm{C}$ as measured by a surface probe digital thermometer.

\subsubsection{Tensile strength}

Tensile strength was measured according to ASTM D 638 using Instron machine model 8501 at an extension rate of $0.2 \mathrm{in} / \mathrm{min}$. Elongation at break was measured by the help of an extensiometer. Five samples were tested for each composition, and the average was reported. A schematic of tensile test procedure is given in Figure 3-4.

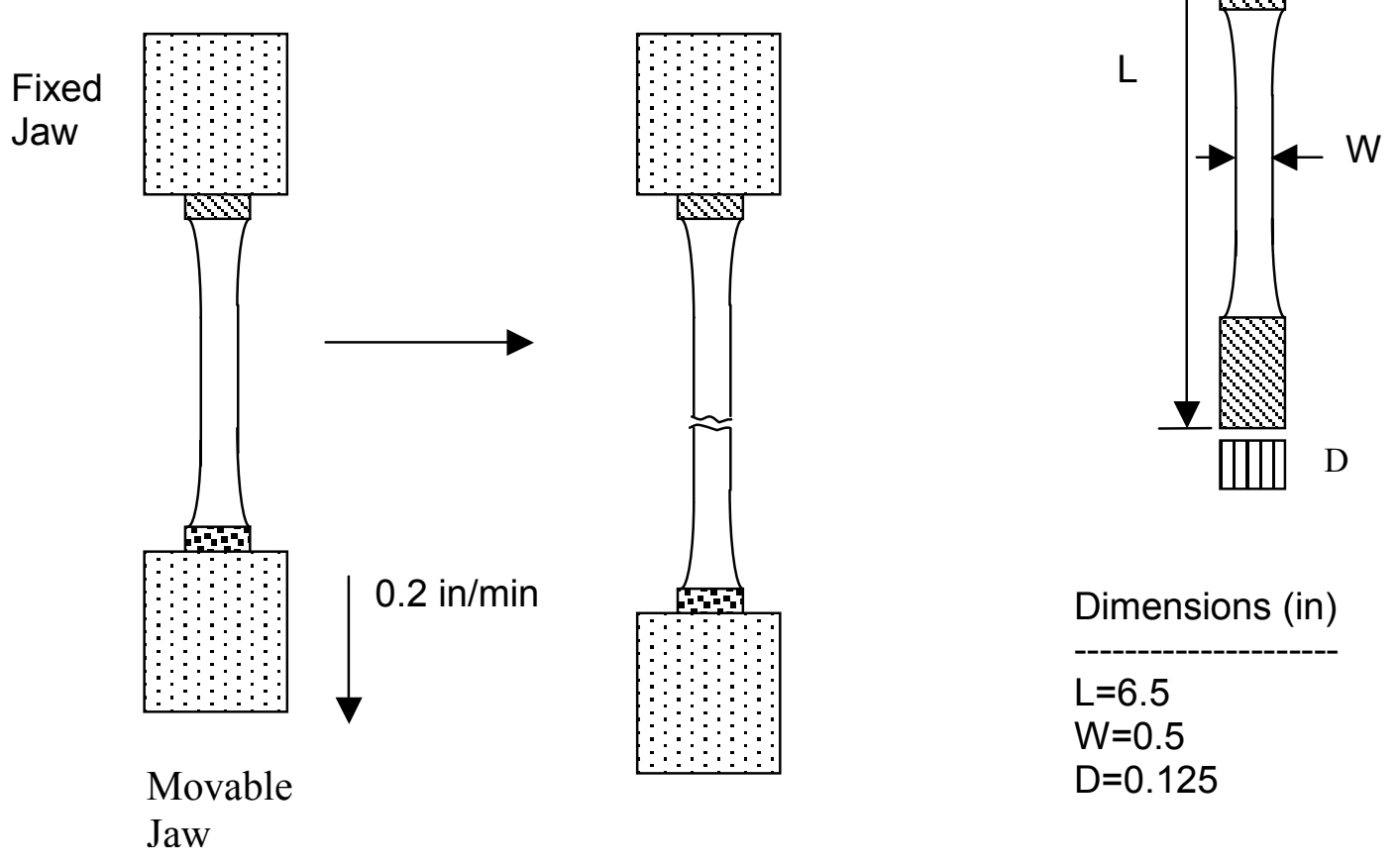

Figure 3-4 Tensile strength test. 


\subsubsection{Flexural strength}

Flexural strength was measured according to ASTM D 790.The fixture used is shown in Figure 3-5, and it is attached to the Instron 8501. After loading the sample, the lower part was allowed to move at a rate of $0.053 \mathrm{in} / \mathrm{min}$ while the upper part was kept stationary. The flexural strength was calculated as

Flexural strength $=\left(3 \mathrm{PS} / 2 \mathrm{Wd}^{2}\right)$

where

$\begin{array}{ll}\text { P } & \text { is the load } \\ \text { S } & \text { is support span } \\ \text { W } & \text { is sample width } \\ \text { D } & \text { is sample depth }\end{array}$

Dimensions (in)

$\mathrm{d}=0.125$

$\mathrm{W}=0.5$

$\mathrm{S} / \mathrm{d}=16$ (Acc. to ASTM D790)

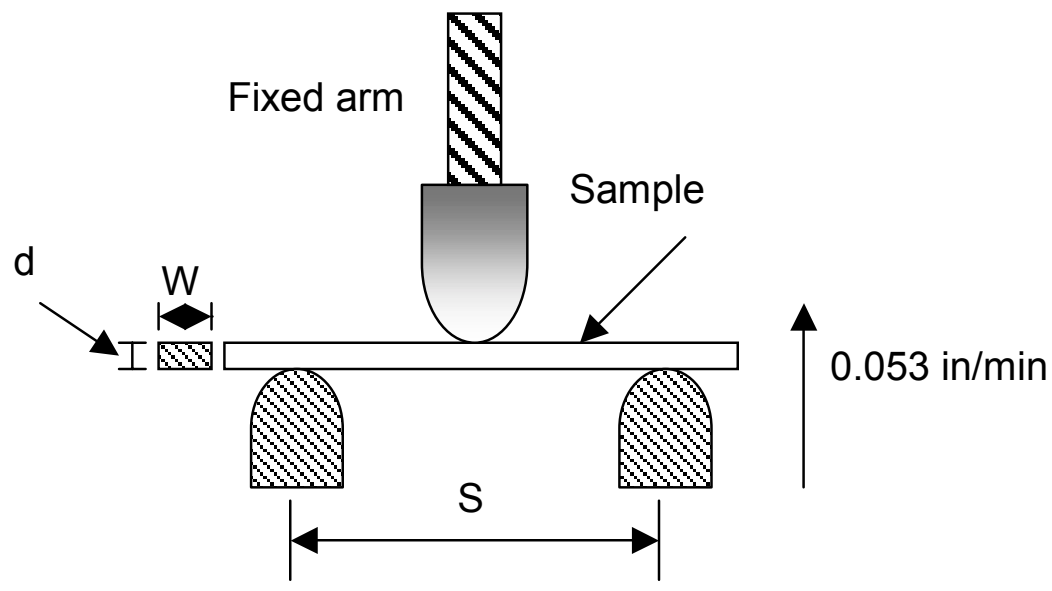

Figure 3-5 Flexural test procedure. 


\subsubsection{Glass fiber length}

In order to assess any reduction in glass fiber length due to extrusion and injection molding processes, glass fiber diameter and length in samples as received, after extrusion, and after injection molding were measured by optical microscopy technique. The procedure involved burning the sample and spreading the remaining fibers on a microscopy glass gently by a drop of silicone oil. The fibers then were viewed under a microscope with a digital camera attached to a computer. Fiber lengths were measured by an image analysis program. Fiber diameter was measured manually from pictures $(=13$ $\mu \mathrm{m})$. the fiber length was computed from the area calculated by the program. At least 200 fiber lengths were measured and the average was reported.

\subsubsection{Thermal behavior}

A differential scanning calorimetery (DSC) was used to measure the heat of fusion of the blends. This test was done to observe the effect of the presence of both glass fibers and rubber on the crystallinity of nylon 66. Samples ranging in weight from 10.28 $\mathrm{mg}$ to $19.42 \mathrm{mg}$ were heated twice at a scan rate of $10^{\circ} \mathrm{C} / \mathrm{min}$ from room temperature to $300^{\circ} \mathrm{C}$. Area under the melting peak was measured.

\subsubsection{Rheology tests}

\subsubsection{Melt flow index}

Melt Flow Index (MFI) in g/10min was measured by a Dynisco LMI 4000 melt indexer at $275^{\circ} \mathrm{C}$ and $5 \mathrm{~kg}$ temperature and load respectively. MFI of samples after extrusion and injection molding was measured. Also MFI of pure nylon 66 (Zytel 101 L) 
was also measured in order to compare its fluidity with that of samples that contained glass fibers and rubber.

\subsubsection{Shear viscosity and modulus}

A Rheometric Scientific Mechanical Spectrometer (RMS 800) was used to measure shear viscosity and modulus of rubber toughened glass fiber reinforced nylon 66. A parallel plate fixture with a diameter of $25 \mathrm{~mm}$ and $1 \mathrm{~mm}$ gap was used. Discs of $1 \mathrm{~mm}$ thickness were prepared from the circular injection molded samples (see Figure 32). Since these injection molding samples have thicknesses greater than $1 \mathrm{~mm}$ they were reduced to $1 \mathrm{~mm}$ thickness sheets by the means of a hot press; then disks with a diameter of $25 \mathrm{~mm}$ were cut out of those sheets. Frequency sweep tests were conducted for all samples at strain sweep of $10 \%$ and $275^{\circ} \mathrm{C}$. This strain amplitude, i.e. $10 \%$, was within the viscoelastic region as seen from the strain sweep tests conducted for all blends. Viscosity and storage $\left(G^{\prime}\right)$ and loss $\left(G^{\prime \prime}\right)$ moduli were measured versus frequency. The variation of storage modulus against temperature was measured by the torsion test. In this test, the flexural test molded bars after adjusting their lengths were used as the rectangular bars as shown in Figure 3-6. The bar was mounted between the clamps of the fixture and a sinusoidal torsion at $1 \mathrm{rad} / \mathrm{sec}$ frequency and $0.1 \%$ strain rate was applied to the bar.

\subsubsection{Morphology of the fractured surface}

The fracture surface of the samples, mainly the Izod samples and some of the tensile and flexural samples, was sputter coated with gold by an SPI sputtering machine. 
The coated samples were then tested for the morphology of the fracture surface using AMR model 1000 scanning electron microscope at a voltage of $10 \mathrm{kv}$. When performing temperature sweep on a rectangular torsion test by the Rheometrics Mechanical Spectrometer (RMS 800), the coefficient of thermal expansion (CTE) may be calculated automatically by the RMS 800 . Coefficient of thermal expansion, $\alpha$, gives the fractional change in length of a material for a unit change in temperature

$$
\alpha=(\Delta \mathrm{L} / \Delta \mathrm{T})\left(1 / \mathrm{L}_{\mathrm{O}}\right)
$$

Where

$\Delta \mathrm{L} \quad$ is change in length of the specimen

$\Delta \mathrm{T} \quad$ is change in temperature

$\mathrm{L}_{\mathrm{O}} \quad$ is original length of the specimen

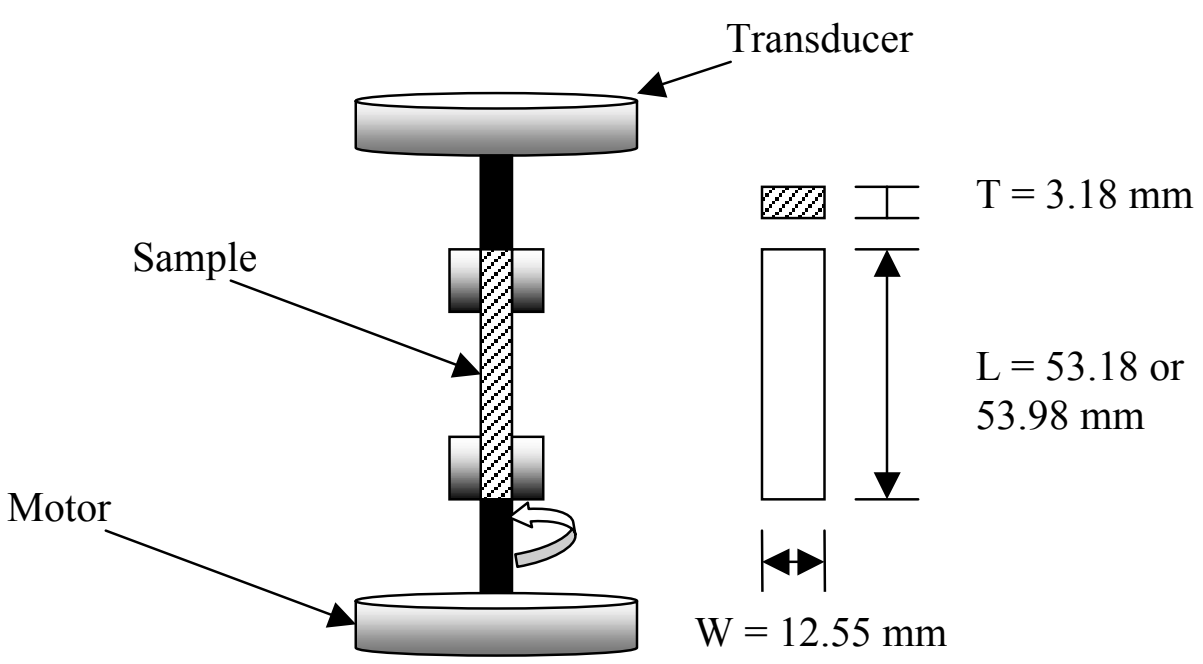

Figure 3-6 Torsion test performed by RMS 800 . 


\section{Chapter 4}

\section{Results and Discussion}

\section{Introduction}

This chapter presents the current research results. The main results include mechanical, thermal, and flow properties. Tensile, impact, and flexural strengths are discussed. Heat of fusion of the composites (glass-fiber-reinforced nylon 66 blended with rubbers) is also presented and discussed. Results of rheology of the composites presented include melt flow index, shear viscosity, and shear loss and storage moduli. Morphology of the fractured surfaces as examined by a scanning electron microscope is presented and discussed. Unless otherwise specified, in all results presented in this chapter, glass fiber weight percent is based on nylon 66 and glass while rubber weight percent is based on total sample weight.

\subsection{Mechanical properties}

\subsubsection{Stress-strain data}

The stress-strain curves of both recycled and virgin glass-fiber-reinforced nylon 66 blended with EP-g-MA and SEBS-g-MA rubbers are given by Figures 4-1 and 4-2. As seen from the stress-strain curves, while glass fiber reinforced nylon 66 shows a high degree of strength and stiffness to fracture, addition of up to $20 \mathrm{wt} \%$ of rubber reduces both strength and stiffness. This can be seen in the form of (i) reduction in the slope of the linear portion of the stress-strain curves which represents the stiffness or modulus of the material, and (ii) reduction in tensile stress. However, the elongation at break increases with increasing rubber content. Composites with SEBS-g-MA type of rubber 


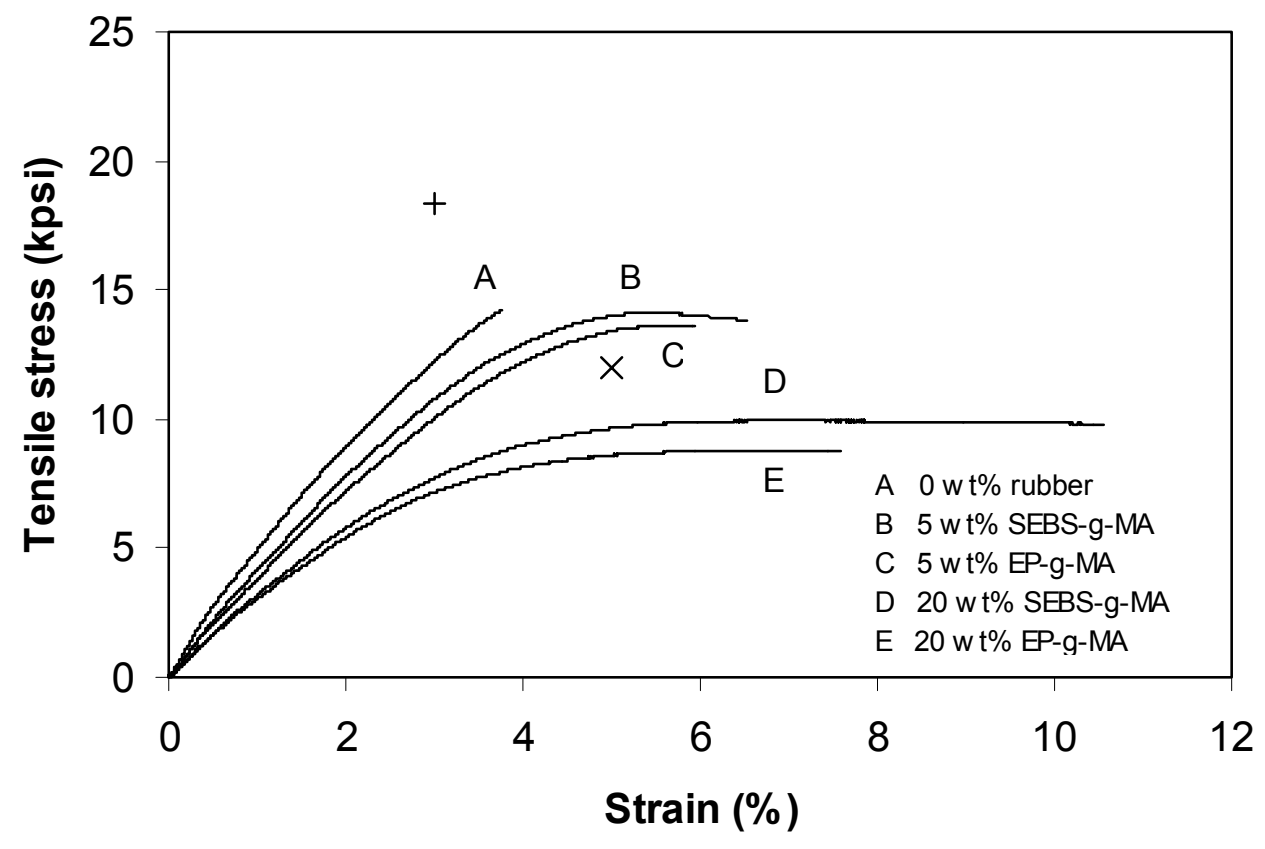

(a)

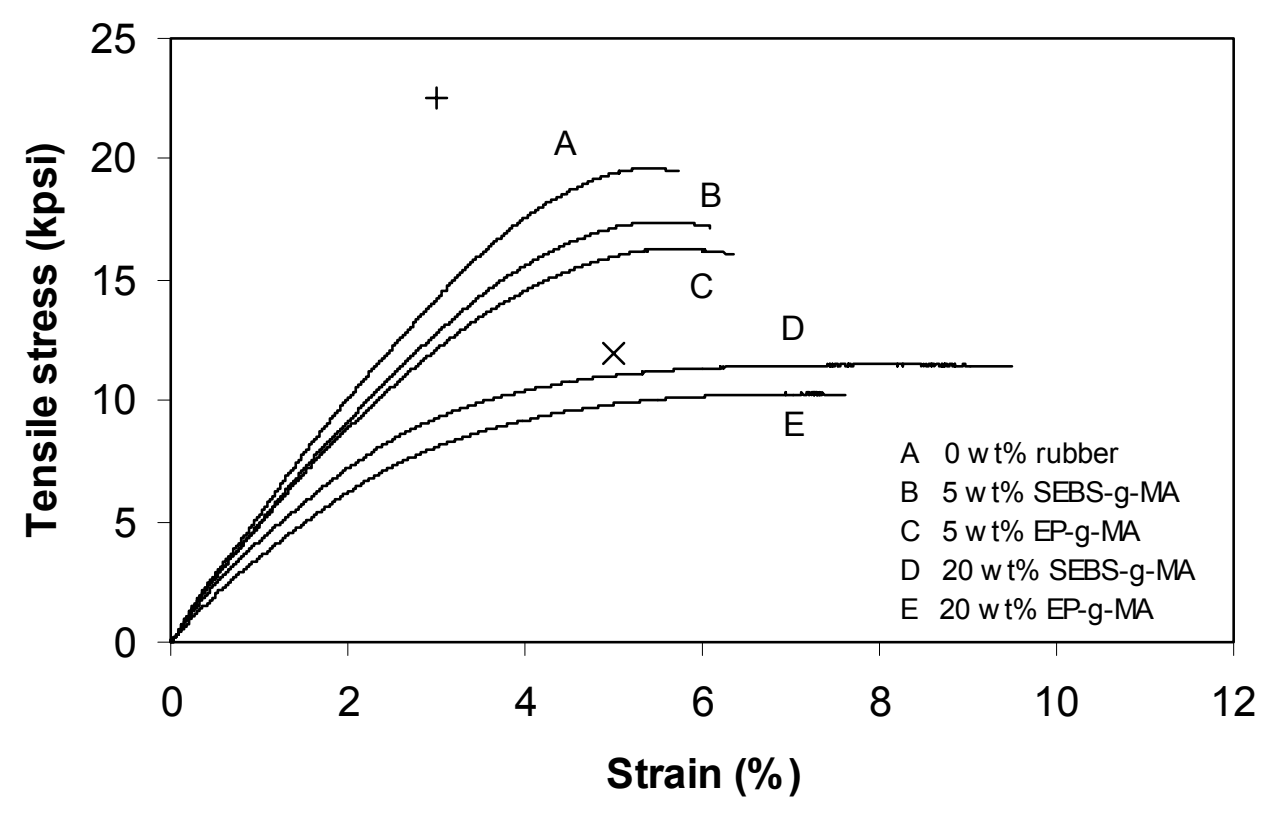

(b)

Figure 4-1 Stress-strain behavior of virgin glass-fiber-reinforced nylon 66 toughened with EP-g-MA and SEBS-g-MA rubbers at two glass fiber contents: (a) $14.79 \mathrm{wt} \%$, (b) 23.62 wt $\%$. [ $(\times)$ yield strength of nylon 66 (Zytel $101 \mathrm{~L})$, and $(+)$ fracture strength of nylon 66 with $14.79 \mathrm{wt} \%$ in (a) and $23.62 \mathrm{wt} \%$ in (b) glass fiber (DuPont data)] 


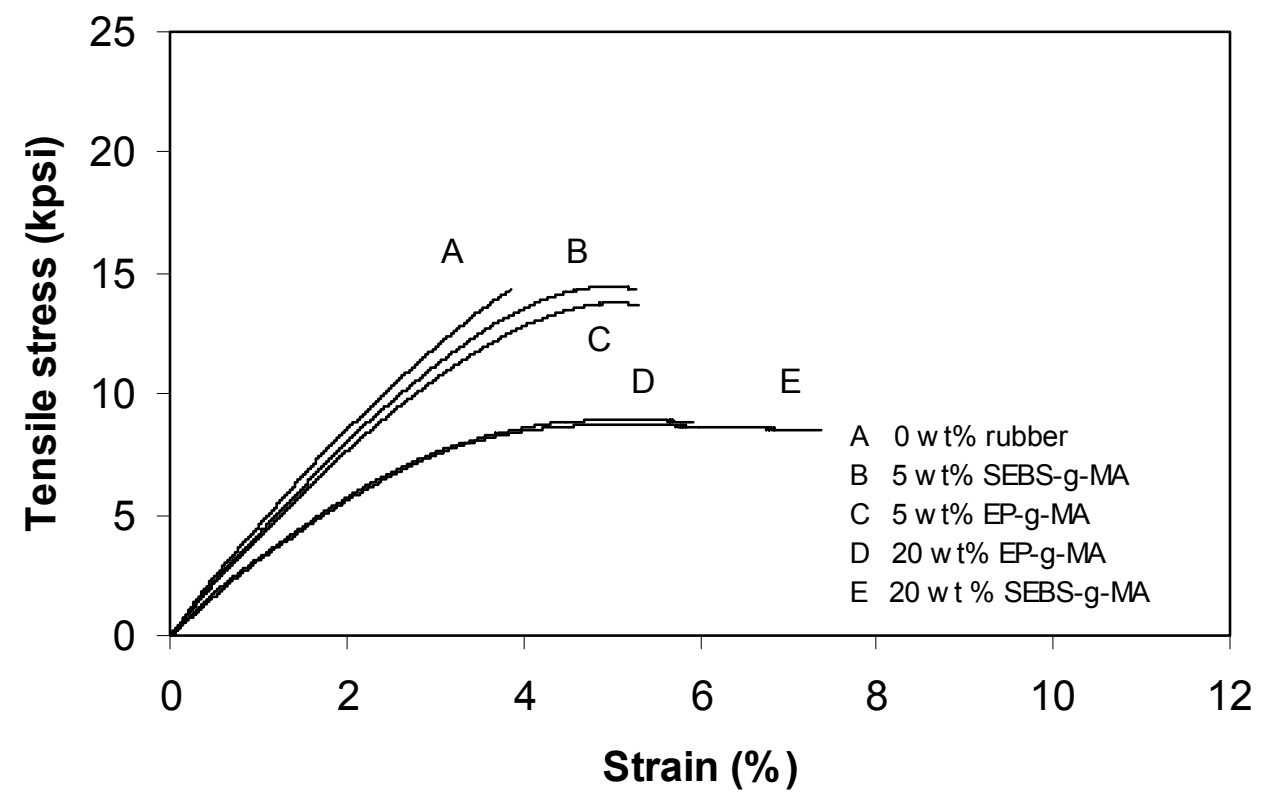

(a)

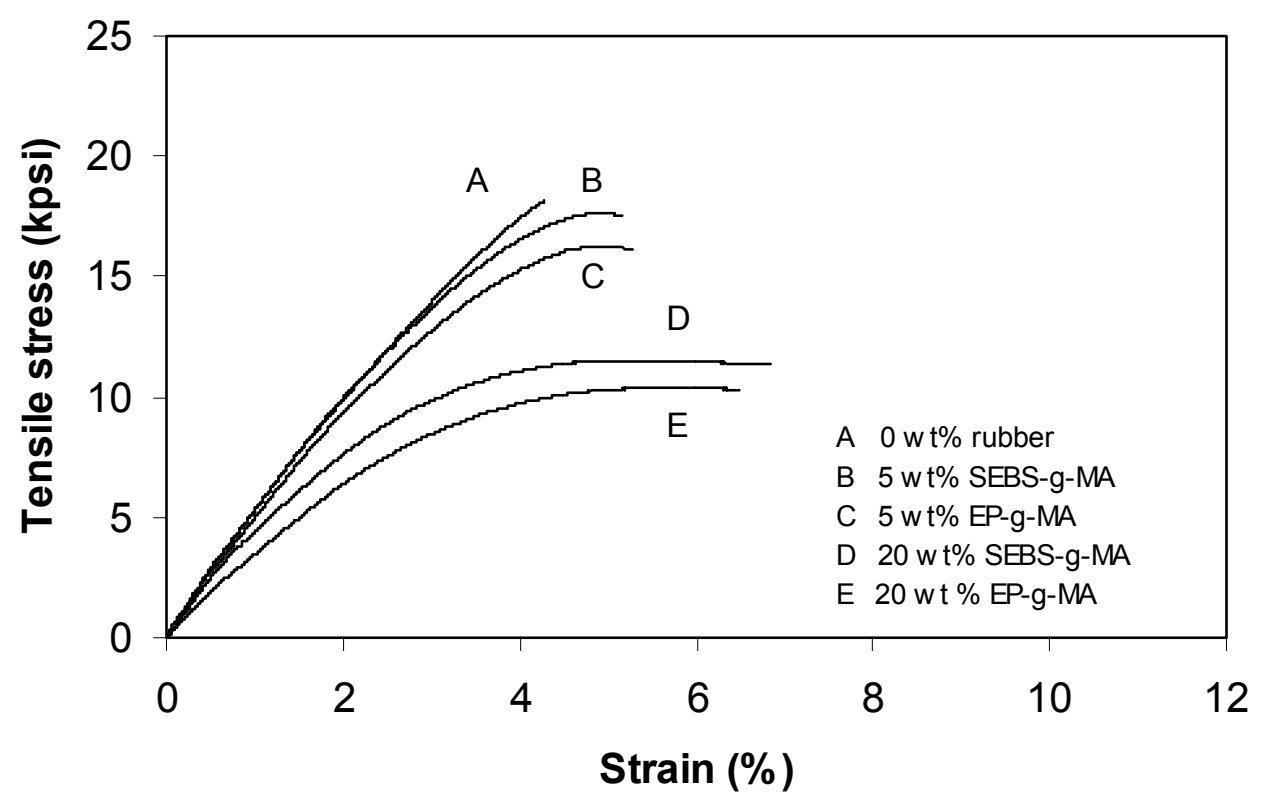

(b)

Figure 4-2 Stress-strain behavior of recycled glass fiber reinforced nylon 66 toughened with EP-g-MA and SEBS-g-MA rubbers at two glass fiber contents: (a) $14.79 \mathrm{wt} \%$, (b) $23.62 \mathrm{wt} \%$. 
show higher elongation at break especially at high rubber content (i.e. $20 \mathrm{wt} \%$ ) in comparison with that of composites with EP-g-MA rubber. Recycled composites have less elongation at break in comparison with that of the virgin composites. A possible reason for the reduction in elongation at break for the recycled composites will be discussed when presenting elongation at break data in the following section. Figure 4-1 shows that the unprocessed glass-fiber-reinforced nylon 66, as taken from DuPont data, has higher tensile strength but less elongation at break than that of similar composites prepared and tested by current study. A reason for this difference may be the massive reduction in glass fiber length during processing by extrusion and injection molding.

\subsubsection{Tensile properties of the composites}

\subsubsection{Modulus of elasticity}

Modulus of elasticity of both recycled and virgin composites is given in Table 41. The values of modulus were calculated from the slope of the linear portion of stressstrain curves given previously in Figures 4-1 and 4-2. From Table 4-1, it can be clearly seen that addition of rubber to glass-fiber-reinforced nylon 66 reduces its modulus. This is expected since rubber, which has a low value of modulus, tends to force the material to yield at lower value of stress as it acts as a stress concentrator. The recycled composites show good values of modulus in comparison with the virgin ones especially at low glass

fiber content. Composites containing SEBS-g-MA rubber show better modulus than that of composites with EP-g-MA rubber. 
Table 4-1 Modulus of elasticity of recycled and virgin composites.

\begin{tabular}{|c|c|c|c|c|c|c|c|c|}
\hline \multirow{4}{*}{$\begin{array}{l}\text { Rubber } \\
\text { content } \\
(w t \%)\end{array}$} & \multicolumn{8}{|c|}{ Modulus (kpsi) } \\
\hline & \multicolumn{4}{|c|}{ Recycled } & \multicolumn{4}{|c|}{ Virgin } \\
\hline & \multicolumn{2}{|c|}{$\begin{array}{l}14.79 \mathrm{wt} \% \text { glass } \\
\text { fiber }\end{array}$} & \multicolumn{2}{|c|}{$\begin{array}{l}23.62 \mathrm{wt} \% \\
\text { glass fiber }\end{array}$} & \multicolumn{2}{|c|}{$\begin{array}{l}14.79 \mathrm{wt} \% \\
\text { glass fiber }\end{array}$} & \multicolumn{2}{|c|}{$\begin{array}{l}23.62 \mathrm{wt} \% \\
\text { glass fiber }\end{array}$} \\
\hline & $\begin{array}{l}\text { EP-g- } \\
\text { MA }\end{array}$ & $\begin{array}{l}\text { SEBS- } \\
\text { g-MA }\end{array}$ & $\begin{array}{l}\text { EP-g- } \\
\text { MA }\end{array}$ & $\begin{array}{l}\text { SEBS- } \\
\text { g-MA }\end{array}$ & $\begin{array}{l}\text { EP-g- } \\
\text { MA }\end{array}$ & $\begin{array}{l}\text { SEBS- } \\
\text { g-MA }\end{array}$ & $\begin{array}{l}\text { EP-g- } \\
\text { MA }\end{array}$ & $\begin{array}{l}\text { SEBS- } \\
\text { g-MA }\end{array}$ \\
\hline $\mathbf{0}$ & 4.033 & 4.033 & 4.599 & 4.599 & 4.014 & 4.014 & 4.731 & 4.731 \\
\hline 5 & 3.606 & 3.800 & 4.216 & 4.579 & 3.341 & 3.622 & 3.990 & 4.298 \\
\hline 20 & 2.867 & 2.853 & 3.135 & 3.741 & 2.669 & 2.884 & 3.107 & 3.599 \\
\hline
\end{tabular}

\subsubsection{Tensile strength}

The tensile strength of the various composites is plotted against weight $\%$ of rubber at the two glass fiber loadings in Figure 4-3. The tensile strength of virgin nylon 66 (Zytel 101 L) and glass-fiber-reinforced nylon 66 is also plotted in Figure 4-3 for the sake of comparison. The glass-fiber-reinforced nylon 66 prepared and tested by the current study has less tensile strength than that of the virgin material as reported by DuPont. The reduction in fiber length upon extrusion and injection molding is believed to cause this difference. The difference between tensile strength values of recycled and virgin blends seems to be minute. This is expected and is due to the fact that the strength of the composite is dominated by the strength of the glass fibers. In an experiment to further validate this finding, a tensile test was conducted for a mixture consisting of 50 $\mathrm{wt} \%$ of the recycled nylon 66 containing $23.62 \mathrm{wt} \%$ glass fibers and $50 \mathrm{wt} \%$ of virgin 


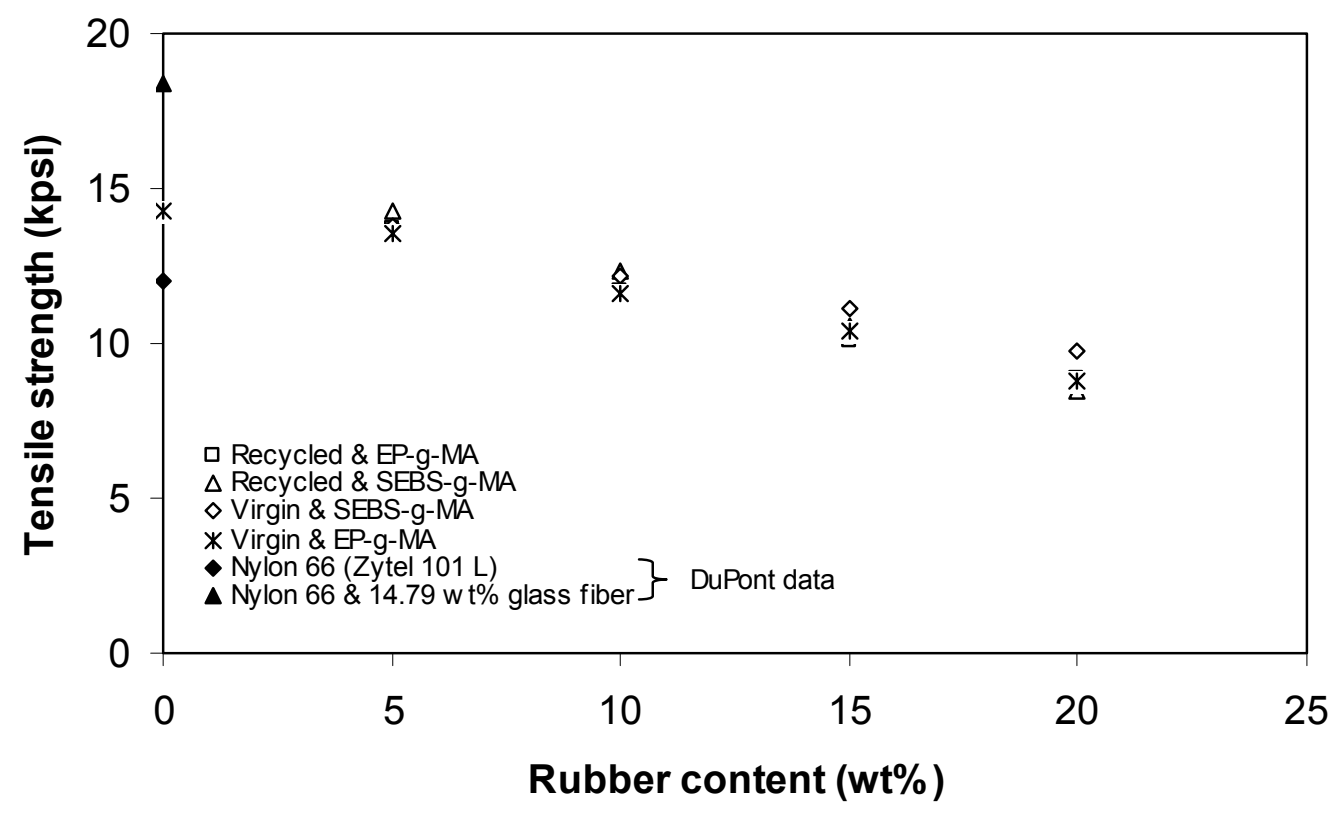

(a)

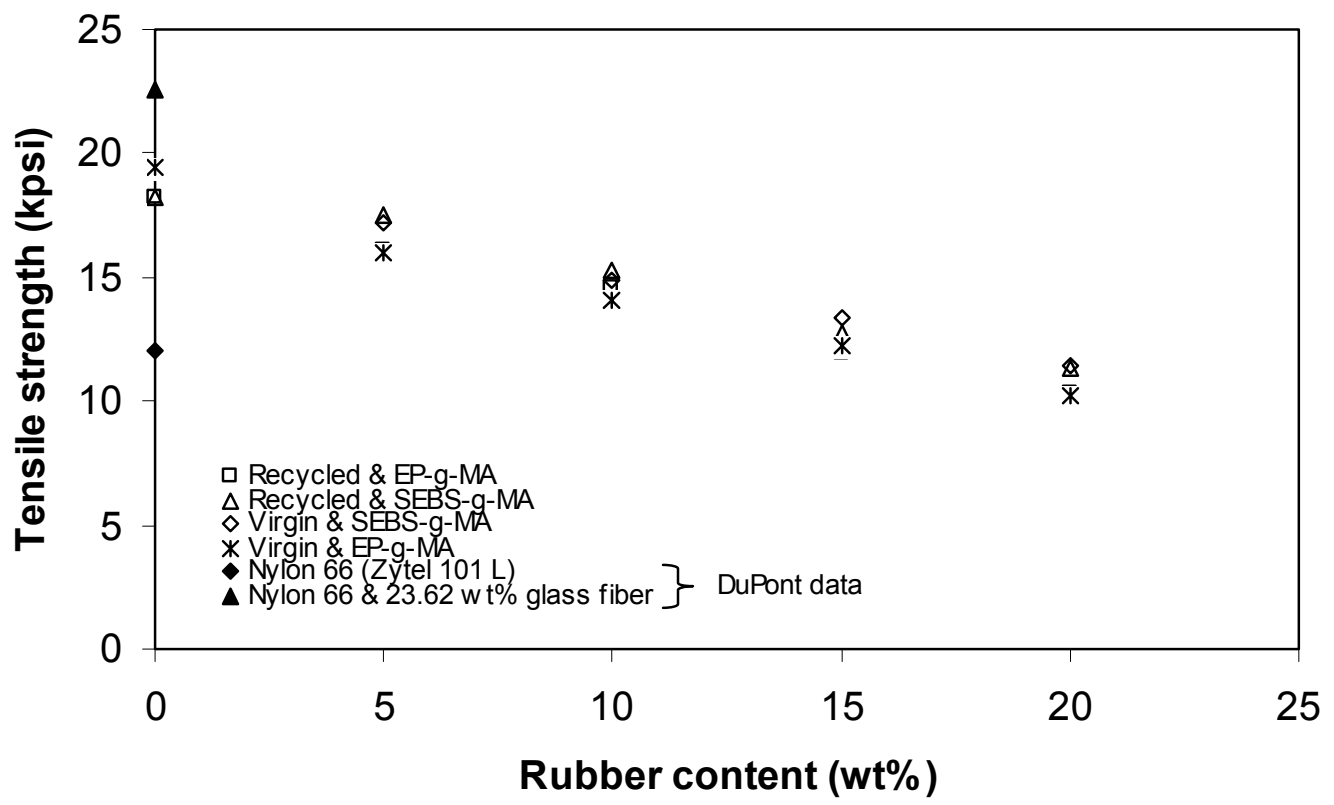

(b)

Figure 4-3 Tensile strength vs. rubber phase concentration for recycled and virgin nylon 66 at two different glass fiber loadings: (a) $14.79 \mathrm{wt} \%$, (b) $23.62 \mathrm{wt} \%$. 
nylon 66 (Zytel $101 \mathrm{~L}$ ) with no glass fibers. The glass fiber content of this mixture was $11.81 \mathrm{wt} \%$. The measured value of tensile strength of this composite was $13.33 \mathrm{kpsi}$ (91.91 MPa). When the tensile strength of the recycled material was extrapolated to 11.81 wt $\%$ glass fiber content assuming a linear additive relationship [2], it gave a value of $13.55 \mathrm{kpsi}(93.42 \mathrm{MPa})$ which is slightly higher than the value of tensile strength for the blend where $50 \%$ by weight of the recycled material was replaced by virgin nylon 66 (Zytel $101 \mathrm{~L}$ ). This indicates that the recycled nylon had a reasonable molecular weight since replacing half of the recycled material by the virgin non reinforced nylon $66 \mathrm{did}$ not enhance the tensile property. Note that most of the important mechanical properties of neat polymers such as tensile strength depend strongly on molecular weight. Indeed, the intrinsic viscosity of the recycled nylon 66 was found to be $1.004 \mathrm{dl} / \mathrm{g}$ which gives a molecular weight of greater than 15,000 which is a typical value for molecular weight of injection molding nylon 66 grade. As expected, Figure 4-3 shows that addition of rubber to both virgin and recycled glass-fiber-reinforced nylon 66 tends to lower their strength. This is because the rubber phase acts as a stress concentrator forcing material to yield at lower values of stress. These same data are replotted in Figure 4-4 as tensile strength versus fiber content at a fixed rubber content of $15 \mathrm{wt} \%$. It is seen that as glass fiber content increases, composites with SEBS-g-MA give better tensile strength than composites with EP-g-MA rubber. The results of tensile strength, given by Figure 4-5, show that strength varies fairly linearly with rubber content according to the rule of mixtures which generally predicts a linear relationship between composite strength and volume fraction of the constituents as discussed previously in Chapter 2. This contrasts with the tensile strength versus rubber content behavior of a glass-fiber-reinforced nylon 


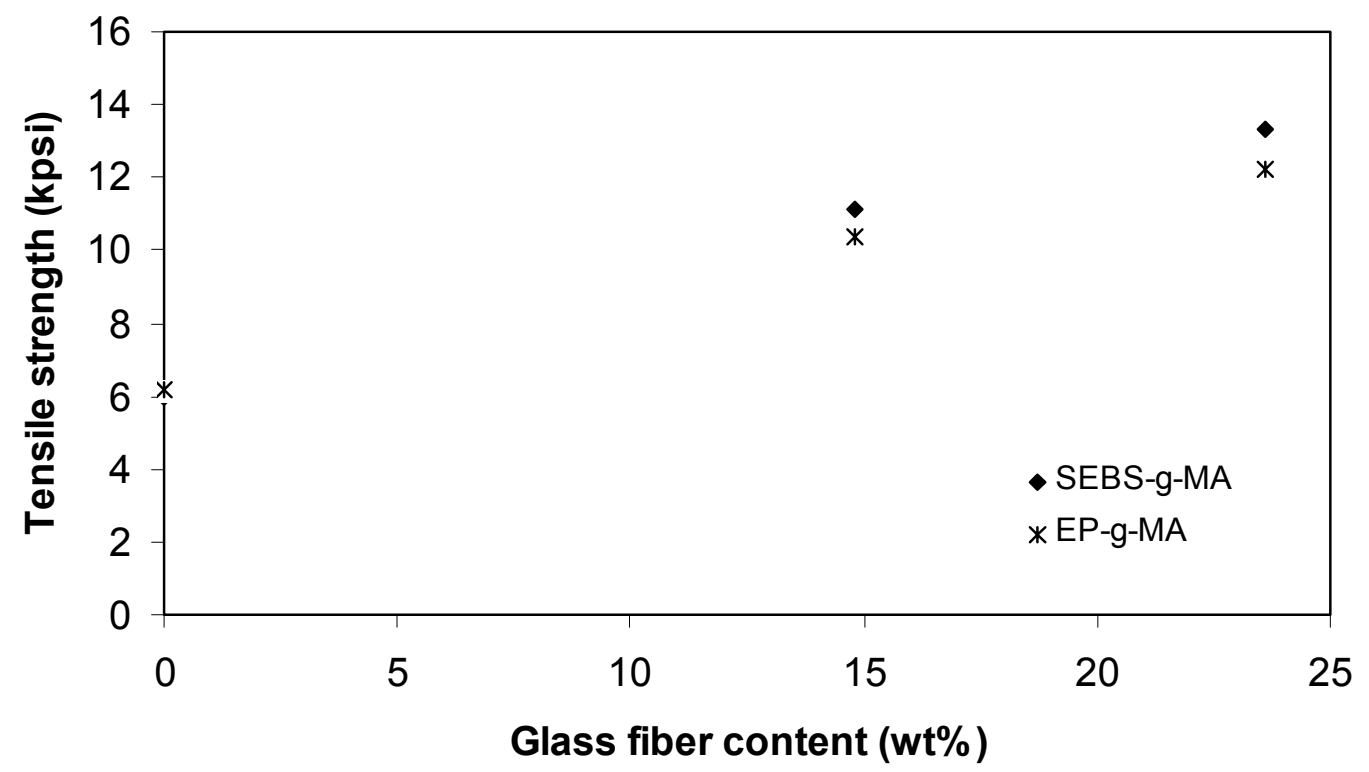

Figure 4-4 Tensile strength versus glass fiber content for the virgin composites at $15 \mathrm{wt} \%$ rubber content.

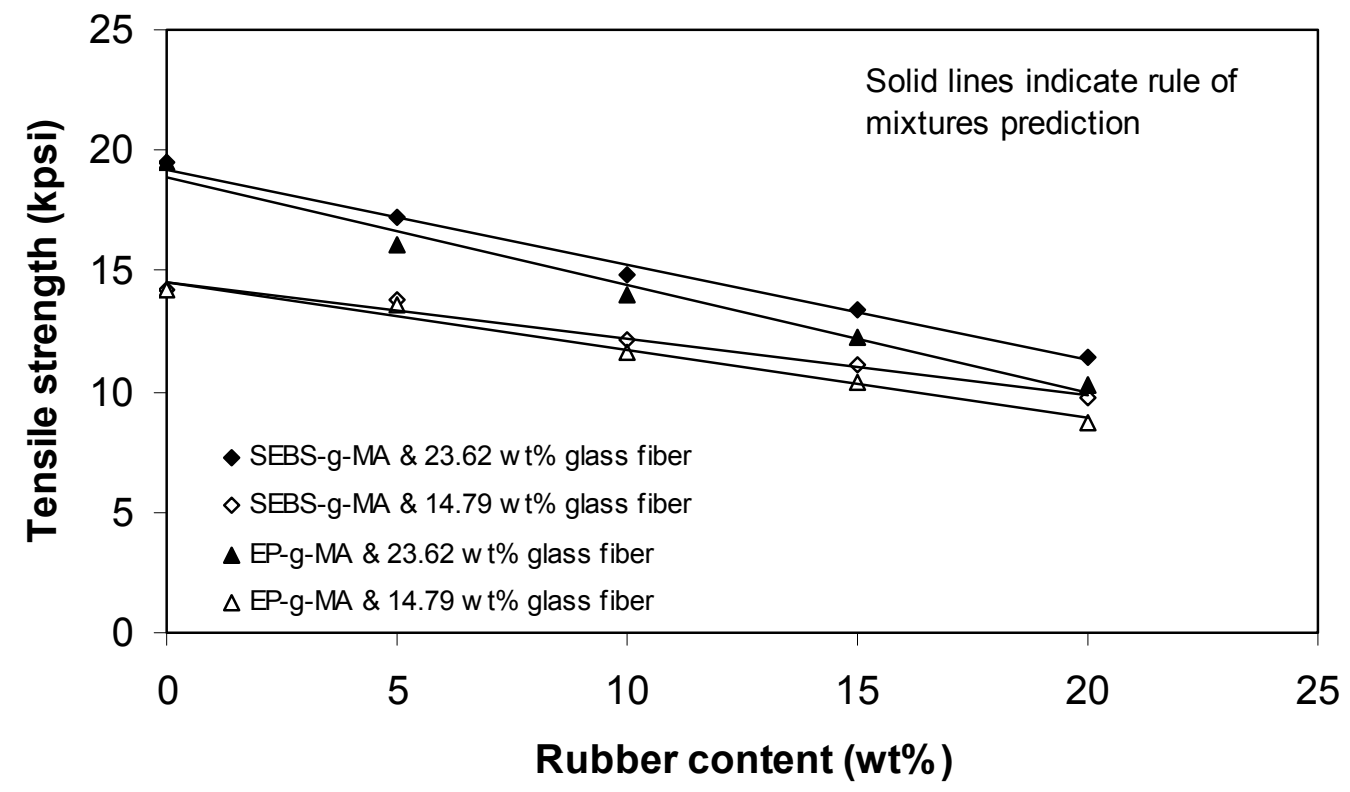

Figure 4-5 Comparison of tensile strength of virgin composites with the rule of mixtures. 
66 toughened with ABS as reported by others [80]. The tensile strength of the reinforced nylon 66 increased upon increasing ABS content until around $50 \mathrm{wt} \%$ based on total weight of nylon 66 and ABS [80]. The increase in tensile strength upon increasing rubber content indicates a lack of toughness which is the major role of rubber phase. A possible reason for the lack of toughness may be due to the incompatibility of nylon 66/ABS blend although a compatibilizer has been used [80]. For the present study, both rubbers used have maleic anhydride group which can react with the amine group in nylon 66 and make a miscible blend. All composites showed a decrease in tensile strength upon increasing both SEBS-g-MA and EP-g-MA rubber content.

As discussed in Chapter 2, the yield stress dependence on rubber volume fraction in rubber toughened polymers may be predicted theoretically by use of the effective area model developed by Ishai \& Cohen [44]. However, for the current research, one expects that Ishai \& Cohen equation will underestimate the yield stress data since both rubber and glass fibers are present in the nylon. Glass fibers, which act as reinforcement agents, tend to increase yield stress of the composite material. Ishai and Cohen have also proposed a relation for calculating yield stress for reinforced polymers in the absence of rubber as

$\sigma_{\mathrm{c}}=\mathrm{A}+\mathrm{B} \log \varepsilon+\mathrm{C} \varphi_{\mathrm{f}}$

Where

$\sigma_{\mathrm{c}} \quad$ is composite yield stress

$\varepsilon \quad$ is strain rate which is defined as extensional rate applied on specimen divided by the original length of the specimen

$\varphi_{\mathrm{f}} \quad$ is volume fraction of the reinforcement 

$\mathrm{A}, \mathrm{B}$, and $\mathrm{C}$
are constants

Ishai and Cohen have proposed the above relation, Eq. 4-1, based on the fact that strain rate and reinforcement content influence yield stress independently. At a fixed strain rate, yield stress of the reinforced polymer was found to increase linearly with increasing reinforcement content. Similarly, at a fixed content of the reinforcement, yield stress of the composite was found to increase linearly with increasing strain rate [44]. The slopes of these lines, i.e. $\mathrm{B}$, and $\mathrm{C}$, are independent of both strain rate and reinforcement volume content [44]. The constants A, B, and C depend on the matrix material used. Ishai \& Cohen have mentioned that the equation is valid for up to $50 \mathrm{vol} \%$ reinforcement. Also, the range of strain rate that they used was from $0.0027 \mathrm{~min}^{-1}$ to $1.35 \mathrm{~min}^{-1}$. Conceptually, one may argue that since the current study deals with incorporation of rubber to a glassfiber-reinforced matrix, combining both equations, i.e. Eq. 4-1 and Ishai \& Cohen model ( the effective area model) given by Eq. 2-21, would account for the presence of both the rubber and glass reinforcement. Indeed we can combine Eqs 2-21 and 4-1 as follows:

$$
\sigma_{\mathrm{c}}=\mathrm{C} \varphi_{\mathrm{f}}+\sigma_{\mathrm{m}}\left(1-1.21 \varphi_{\mathrm{r}}^{2 / 3}\right)
$$

Where

$\varphi_{\mathrm{f}}$ and $\varphi_{\mathrm{r}}$ are volume fraction of glass fiber and rubber respectively based on total weight of sample 
Note that the first two terms in Eq. 4-1, i.e. A + B $\log \varepsilon$, are not included in Eq. 4-2 due to the fact that they represent the yield strength of the matrix at a fixed strain rate which is already included in Eq. 2-21 as $\sigma_{\mathrm{m}}$. By examining Eq. 4-2, it is easy to notice that when no rubber is present, i.e. $\varphi_{\mathrm{r}}=0$, and Eq. 4-2 reduces to Eq. 4-1 which is the yield stress relation for the reinforced material. On the other hand, at zero percent of reinforcements (glass fibers), Eq. 4-2 will reduce to the Ishai \& Cohen equation, Eq. 2-21. Figure 4-6 shows a comparison between yield stress predictions and data for rubber-toughened nylon 66 at the higher glass fiber content (23.62 wt\%). Figure 4-6 clearly shows that while the Ishai \& Cohen model given by Eq. 2-21 underestimates the actual experimental data since it does not account for the effect of the reinforcement, Eq. 4-2 does a good job of predicting the experimental data.

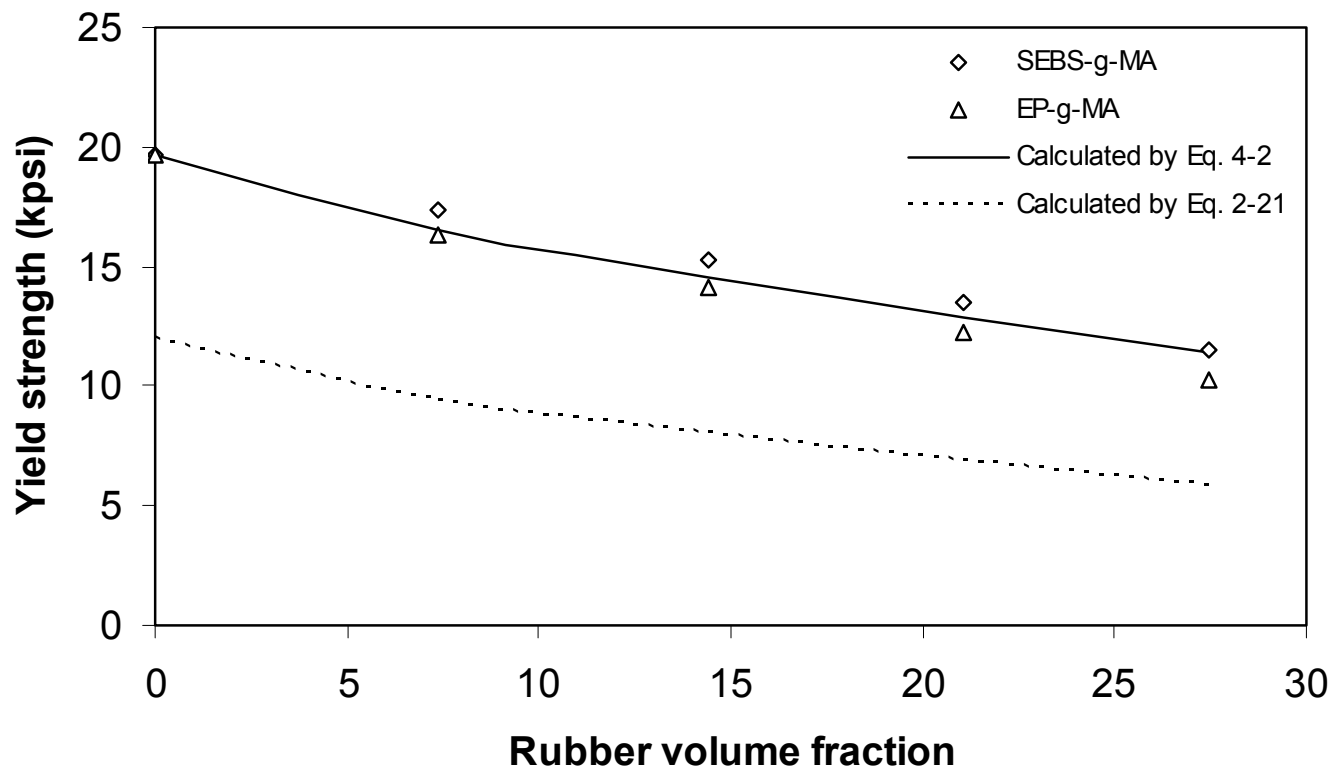

Figure 4-6 Yield strength vs. rubber content for rubber toughened virgin material with $23.62 \mathrm{wt} \%$ glass fiber. 


\subsubsection{Elongation at break}

In Figure 4-7, the elongation at break of both recycled and virgin composites is plotted against rubber content. Also plotted in Figure 4-7 is the elongation at break of unprocessed virgin glass-fiber-reinforced nylon 66 and the elongation at yield for nylon 66 (Zytel 101 L). it is seen from Figure 4-7 that the elongation of the glass-fiberreinforced nylon 66 that was processed by the current study is slightly higher than that of the values reported by DuPont. This is attributed to the reduction in fiber length upon processing by extrusion and injection molding. Increasing the amount of rubber in the composites of fiber reinforced nylon 66 is seen to increase the elongation at break.

Overall, the elongation at break is small and going from lower to higher glass fiber loading does not seem to change the elongation much. In general, though, the recycled materials have lower elongations compared to those of virgin materials. This reduction in the elongation is due to the presence of impurities and may also be related to the reduction in toughness of the recycled composites as discussed in section 2.1.3 of Chapter 2. In the experiments carried out to measure the intrinsic viscosity of recycled nylon 66 , it was found that $3 \mathrm{wt} \%$ of the sample tested did not dissolve in formic acid but disappeared upon burning the remaining glass fibers at high temperature (i.e. $650^{\circ} \mathrm{C}$ ). This suggested that some impurities may be contained in the recycled material. This contamination may be from some incompatible material such as polyethylene which was used as a purge material in extruder. The presence of incompatible material with recycled glass-fiberreinforced nylon 66 is believed to make it fracture at lower elongation. The additional processing history which may have led to some molecular weight reduction may also have contributed to the reduction in elongation. Composites with SEBS-g-MA have 


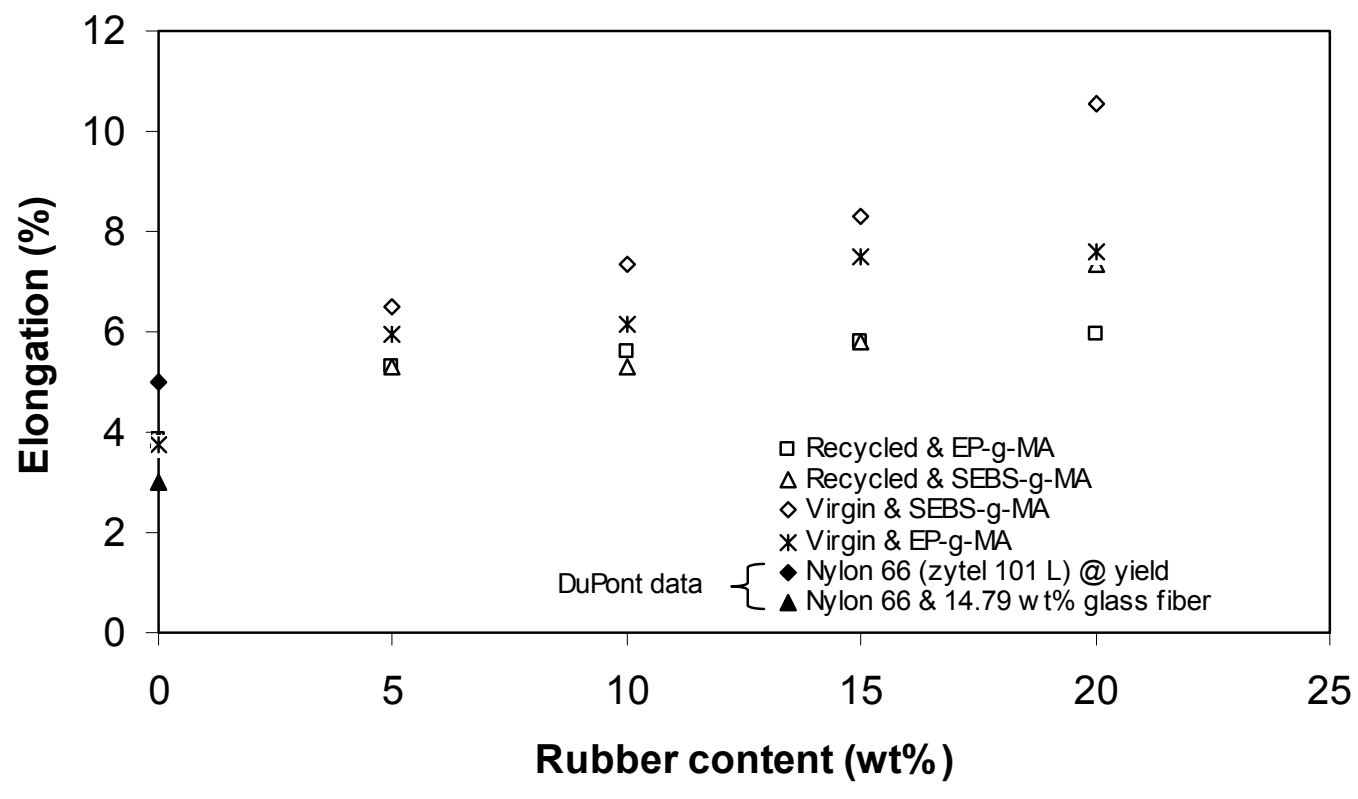

(a)

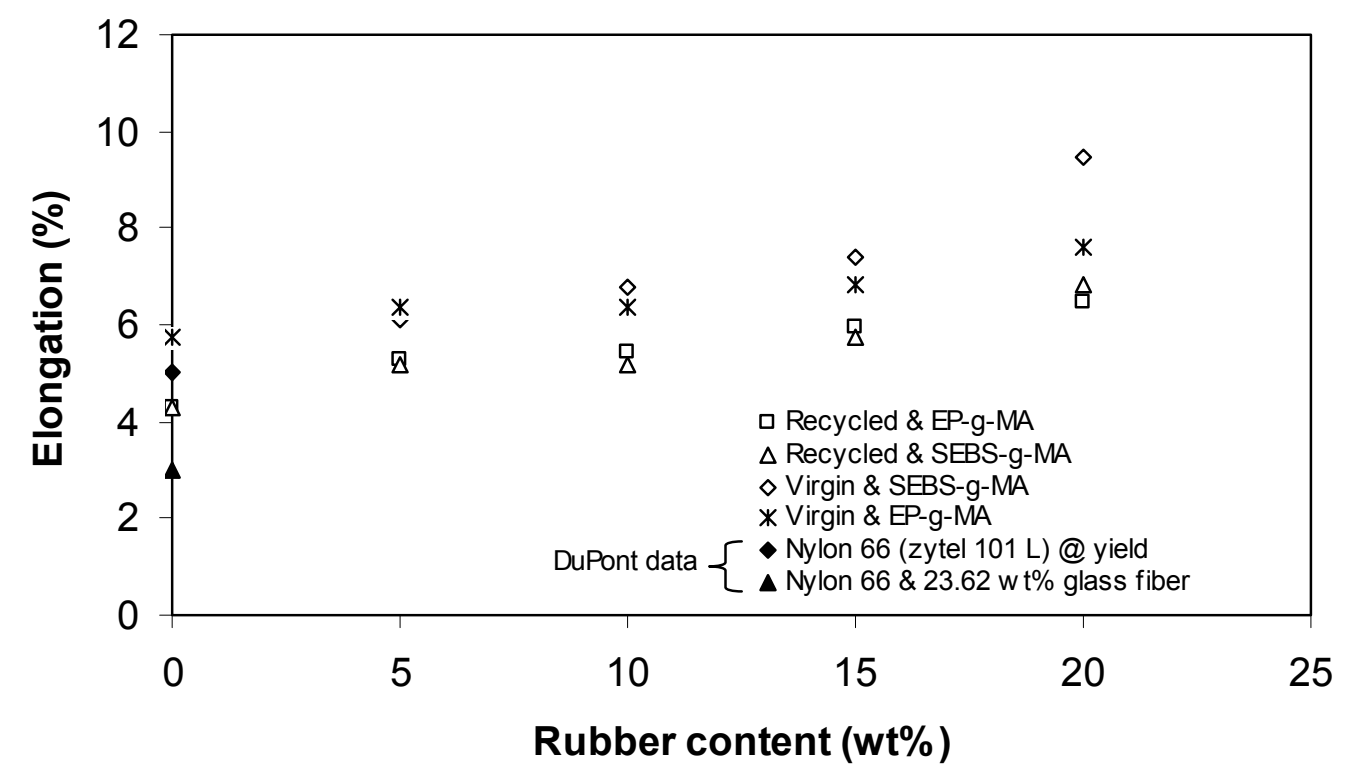

(b)

Figure 4-7 Elongation at break vs. tensile strength for all composites at two different glass fiber loadings: (a) $14.79 \mathrm{wt} \%$, (b) $23.62 \mathrm{wt} \%$. 
higher elongation at break than those with EP-g-MA rubber. This implies that SEBS-gMA is more ductile than EP-g-MA. However, both rubbers, i.e. SEBS-g-MA and EP-gMA, are seen to increase elongation of the composites as rubber content is increased. This is in contrast with the behavior of glass-reinforced nylon 66 toughened by ABS where elongation at break increased upon increasing rubber content [80].

\subsubsection{Flexural strength}

Flexural strength of the composites is given in Figure 4-8. The flexural strength of virgin glass-fiber-reinforced nylon 66 as reported by DuPont seems to be higher than that of same material which was prepared and tested by the current study (see Figure 4-8). The difference in flexural strength of the virgin composites in comparison with DuPont's data is attributed to the reduction in glass fiber length as mentioned in the discussion above. Adding EP-g-MA and SEBS-g-MA rubbers to both recycled and virgin glassfiber-reinforced nylon 66 tends to decrease flexural strength, and this mirrors the same trend seen in tensile strength data. However, composites with SEBS-g-MA rubber showed relatively higher values of flexural strength. Recycled composites showed good flexural property when compared with virgin blends. All composites did not break within the strain on the outer surface of the fibers, i.e. 5\%, as specified in ASTM D 790. This is not an unusual observation since composites become more ductile upon incorporating the rubber phase. In case of recycled composites with $0 \mathrm{wt} \%$ rubber, the breaking of sample within the $5 \%$ strain may be attributed to glass fiber length or aspect ratio. As seen with the result of tensile strength, the variation of flexural strength of the composites with rubber content is seen to comply with the rule of mixtures as indicated in Figure 4-9. 


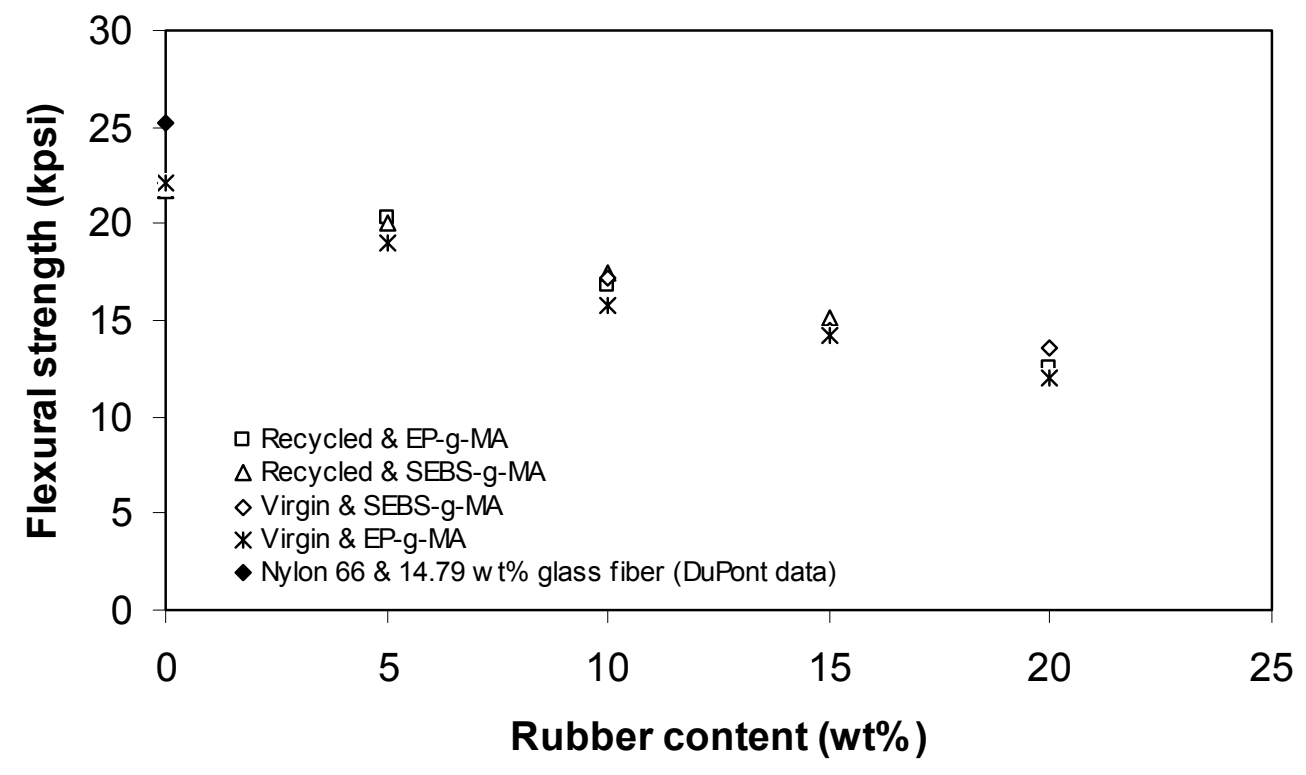

(a)

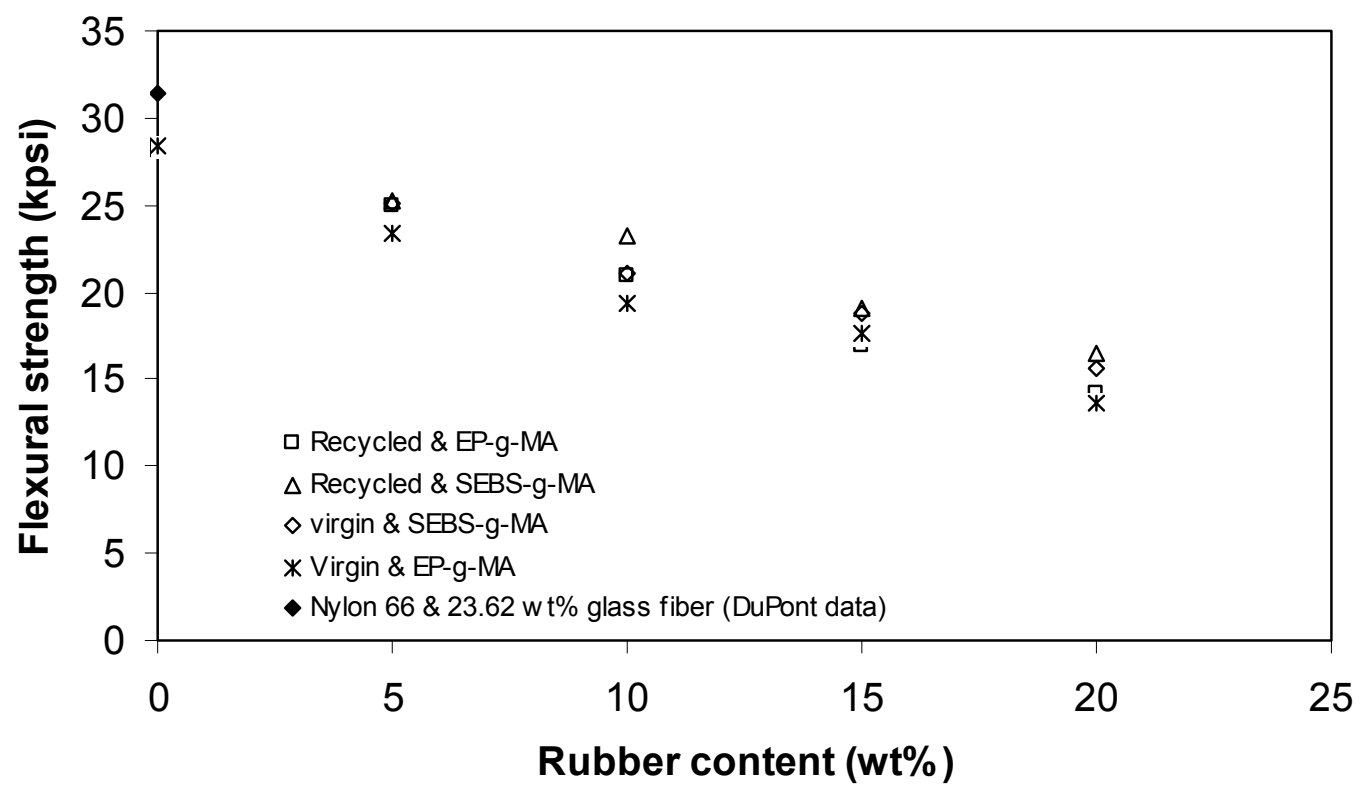

(b)

Figure 4-8 Flexural strength vs. rubber content for recycled and virgin composites at two different glass fiber loadings: (a) $14.79 \mathrm{wt} \%$, (b) $23.62 \mathrm{wt} \%$. 


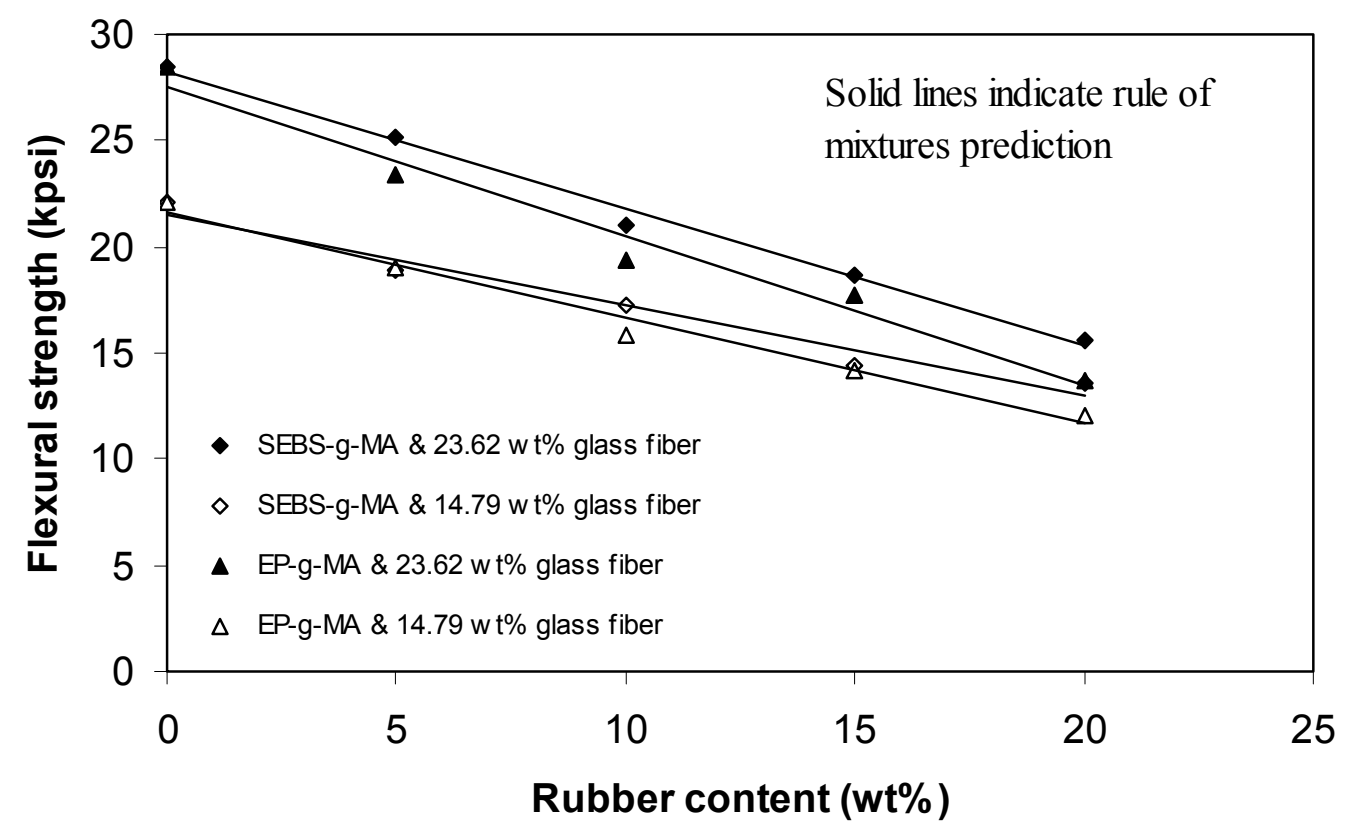

Figure 4-9 Comparison of flexural strength of virgin composites with rule of mixtures.

\subsubsection{Impact strength}

Figure 4-10 gives Izod impact strength data for recycled and virgin glass-fiberreinforced nylon 66. Figure 4-10 clearly shows that the addition of 5-20 wt\% of EP-gMA or SEBS-g-MA to both recycled and virgin glass-fiber-reinforced nylon 66 increases toughness significantly. The two rubbers seem to be equally effective at toughening the reinforced nylon at the lower fiber content, but at the higher fiber content, EP-g-MA appears to be superior. Also, the virgin polymer has a higher impact strength compared to the recycled nylon. The reported Izod impact strength for un-reinforced nylon 66 toughened by SEBS-g-MA at weight ratio of (20/80) (SEBS-g-MA/nylon 66) [11] is about $20 \mathrm{ft}-\mathrm{lb} /$ in $(1070 \mathrm{~J} / \mathrm{m})$. Needless to say, the cause of the lower Izod impact strength in the present study is due to glass fiber presence in the matrix. 
The two rubbers that were employed in this study were carefully selected for the purpose of toughening the recycled and virgin glass-fiber-reinforced nylon 66 since they were expected to form miscible blends with nylon 66. In order to examine the effectiveness of these two rubbers for toughening nylon 66 , blends containing $15 \mathrm{wt} \%$ of both rubbers, i.e. SEBS-g-MA and EP-g-MA, were formulated with nylon 66 (Zytel $101 \mathrm{~L}$ ), but with no glass fibers. The blends were prepared by extrusion and injection molding using the same conditions as used with the reinforced composites. The measured Izod impact strength for $(15 / 85) \mathrm{wt} \%$ of (EP-g-MA/nylon 66) and (SEBS-g-MA/nylon 66) were 3.11 and $5.40 \mathrm{ft}-$ lb/in respectively. This indicates that both rubbers are effective in toughening nylon 66 . While the reinforced blends having $15 \mathrm{wt} \%$ of SEBS-g-MA and $23.62 \mathrm{wt} \%$ glass fiber suffers $\sim 40 \%$ reduction in toughness, the blend consisting of $23.62 \mathrm{wt} \%$ glass fibers and $15 \mathrm{wt} \%$ EP-g-MA has slightly increased toughness if compared to the un-reinforced blend (see Figure 4-11). This may imply that composites with EP-g-MA have some brittleness which would lead to some increase in toughness upon reinforcing with glass fibers. Note here that incorporating $33 \mathrm{wt} \%$ glass fiber into nylon 66 which is semiductile at room temperature increases its toughness by a factor of 2.2. The increase in impact strength when a material is reinforced may be related to the elongation. The elongation at break data given in Figure 4-7 clearly indicate that reinforced nylon containing EP-g-MA has less elongation than in the case of SEBS-g-MA. It seems that the extent of reaction between EP-g-MA and nylon 66 up to the weight percent of rubber specified in this study made the rubber phase not sufficient enough for super toughness. A similar observation has been reported by others [11]. 


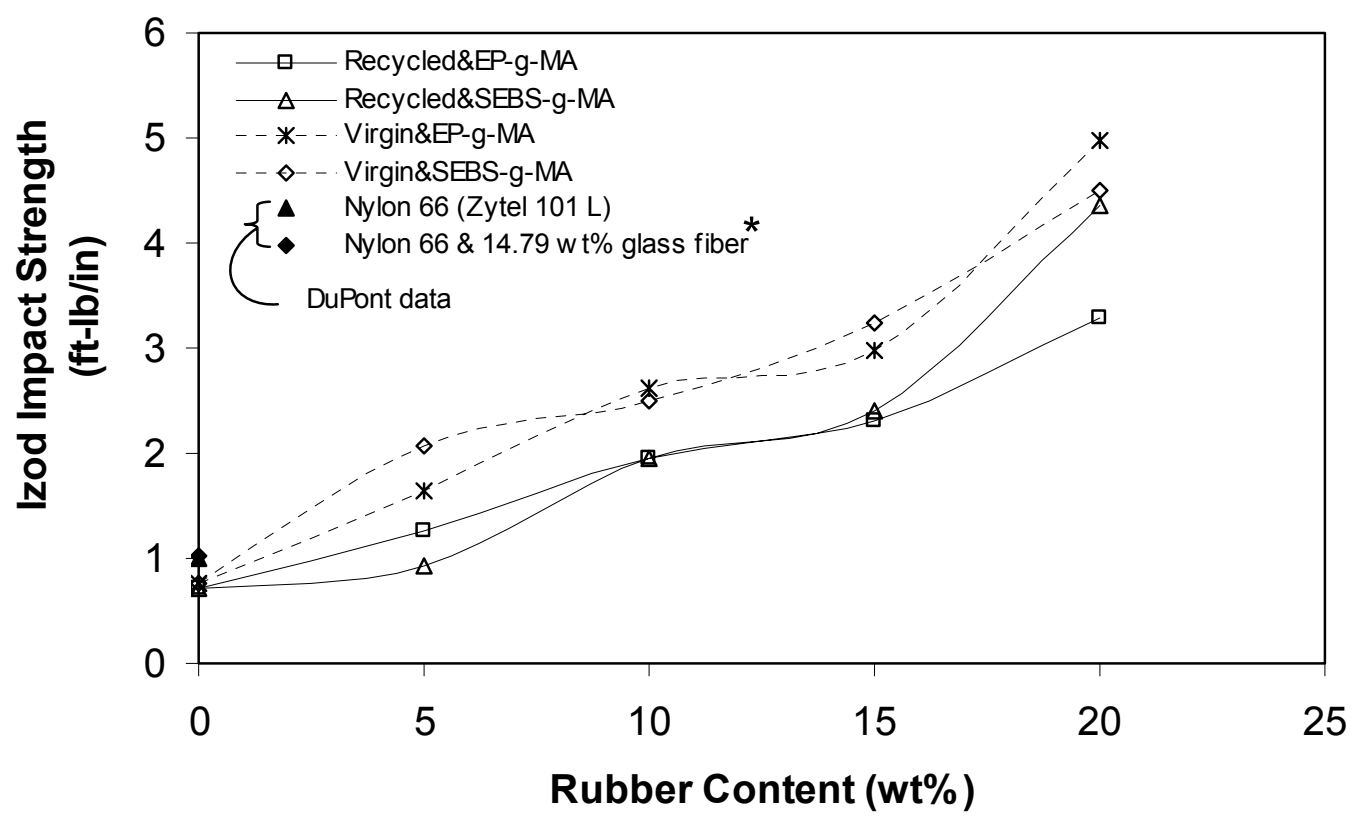

(a)

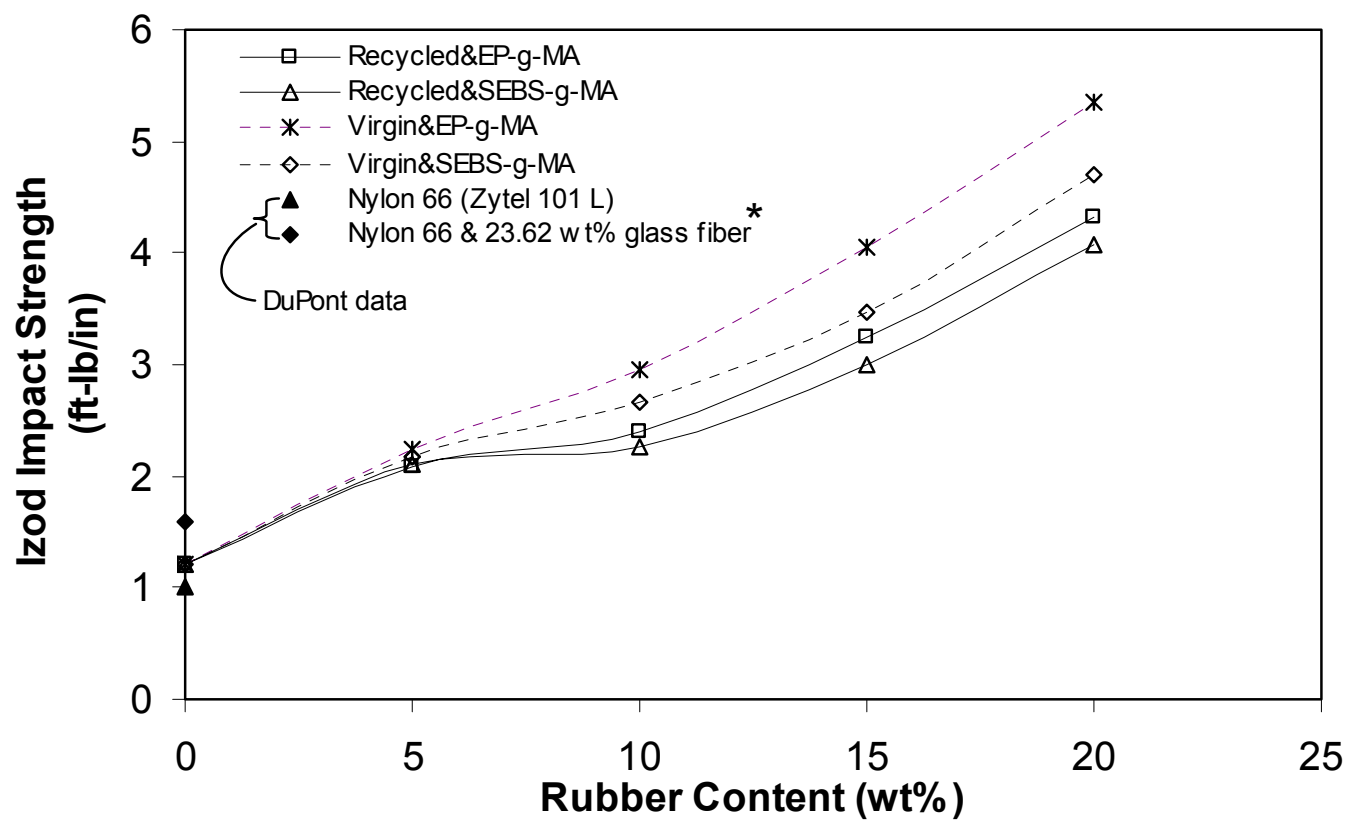

(b)

Figure 4-10 Izod impact strength vs. rubber weight percent for recycled and virgin nylon 66 at two different glass fiber contents: (a) $14.79 \mathrm{wt} \%$, (b) $23.62 \mathrm{wt} \%$. * data were interpolated assuming linear relation between impact strength and glass content. 


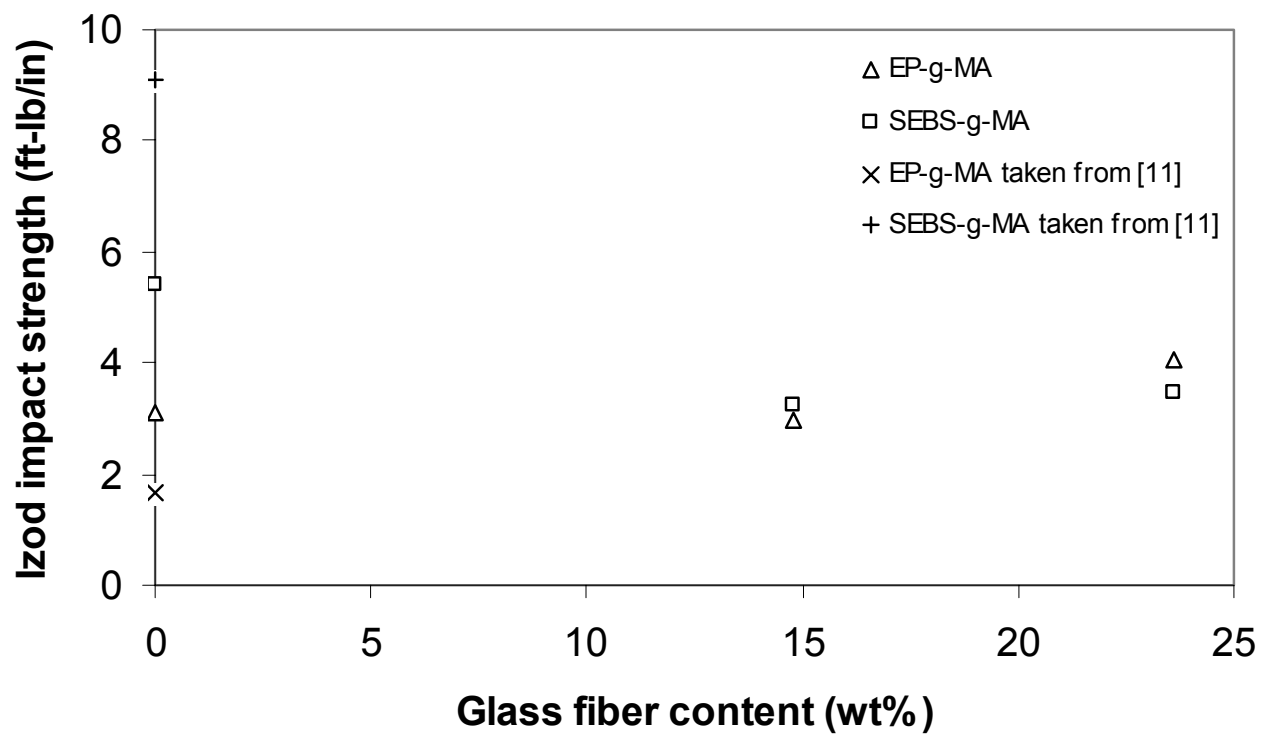

Figure 4-11 Variation of impact strength versus glass fiber content for the virgin composites having $15 \mathrm{wt} \%$ rubber.

Since one of the important uses of glass fiber reinforced nylon 66 is under-thehood applications in automobiles where the temperature may be high, it is important to know the impact strength behavior of the reinforced nylon 66 when toughened with rubber at high temperatures. Since the current research deals with incorporating both rubber and glass fibers in nylon 66 , it is helpful to discuss the behavior of impact strength against temperature for rubber-toughened nylon 66 with no glass fibers. It appears that there is no data available in impact strength versus temperature for rubber-toughened nylon 66. It has been shown in Chapter 2 that a noticeable brittle to tough transition is observed when Polybutadiene is added to SAN in case of ABS [6] (see Figures 2-28), and when EPDM rubber is added to nylon 6 [51] (see Figure 2-29). The transition in 
impact strength seems to be sharp at higher rubber content and the brittle-tough temperature is seen to be dependent on rubber content and type of rubber used. In case of nylon 6 toughened with $\mathrm{EP}$, it has been shown that increasing glass fiber content in the composite tends to drastically reduce the transition in impact strength versus temperature as shown in Figure 2-38. The behavior of impact strength against temperature for a reinforced polypropylene is shown in Figure 4-12. Figure 4-12 clearly shows that in the absence of rubber phase, and as fiber content increases the impact strength decreases with no transition from brittle to ductile upon increasing temperature. For the present study, Figures 4-13 and 4-14 show Izod impact strength for virgin composites as a function of temperature. The impact strength increases as temperature increases at all rubber contents except for those composites that contain $20 \mathrm{wt} \%$ of EP-g-MA rubber where the impact strength at temperatures grater than $50^{\circ} \mathrm{C}$ remains almost unchanged. The transition from brittle to tough upon increasing temperature is not seen to be large. The presence of glass fibers seems to suppress the transition from brittle to tough in impact strength versus temperature relationship for reinforced nylon 66 toughened by EP-g-MA and SEBS-g-MA rubbers. At a temperature below the $\mathrm{T}_{\mathrm{g}}$, nylon 66 is considered semi ductile material because the amorphous part is below the $T_{g}$ where chains are frozen. Therefore, the nylon phase in the composite will probably not contribute to enhancement in elongation of the blend so that the presence of glass fiber in the composite will not affect elongation significantly and impact strength increases. In this case, increasing glass fiber content is seen to increase impact strength. Beyond the $T_{g}$ the chains that occupy the amorphous part start to move and become rubbery and when impact occurs they act as a stress concentrators which leads to absorption of energy before failure. However, the 
presence of glass fibers will drastically reduce the elongation and as a result of that impact strength does not change especially at higher rubber content ( $>5 \mathrm{wt} \%)$. Here, increasing glass fiber content does not change impact strength regardless of the content of rubber phase in the composite.

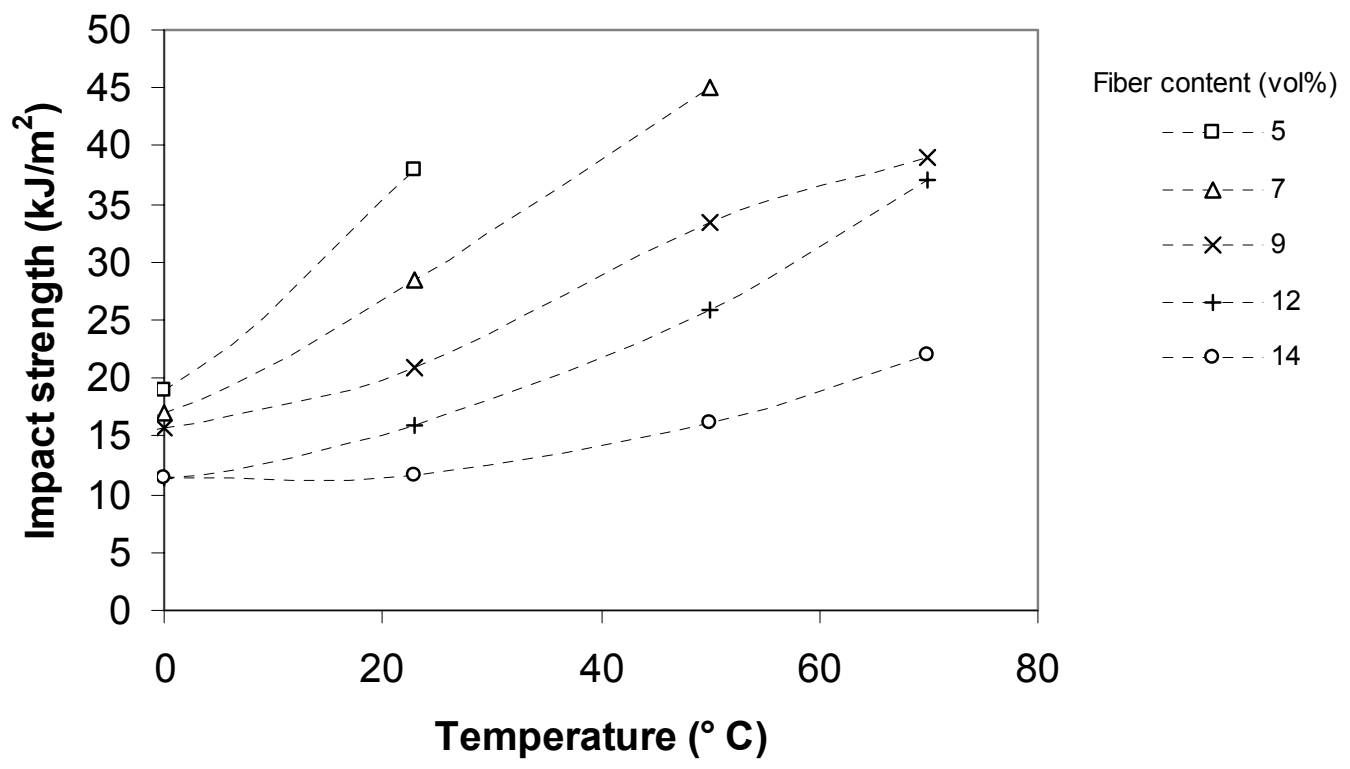

Figure 4-12 Impact strength versus temperature for fiber-reinforced polypropylene. Replotted from [27] 


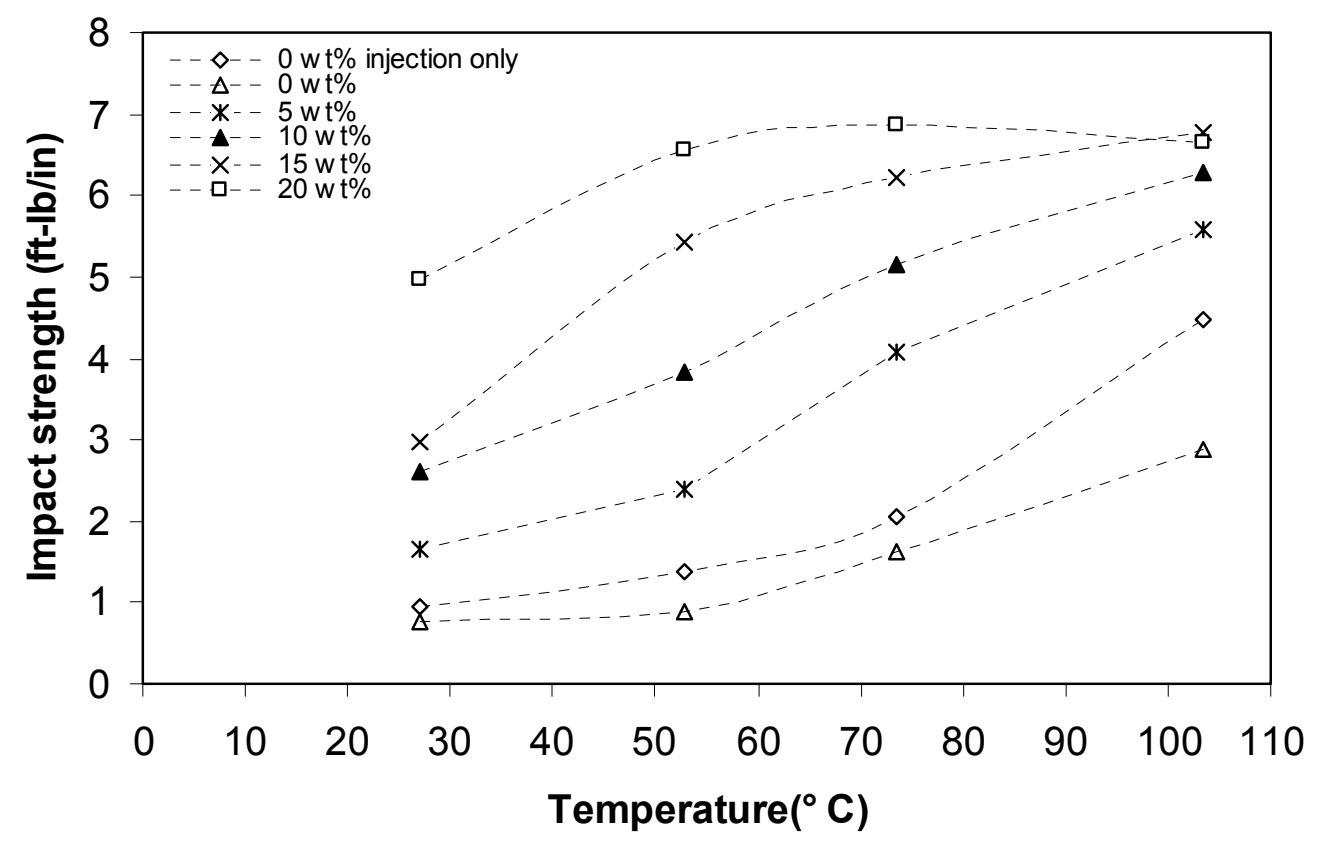

(a)

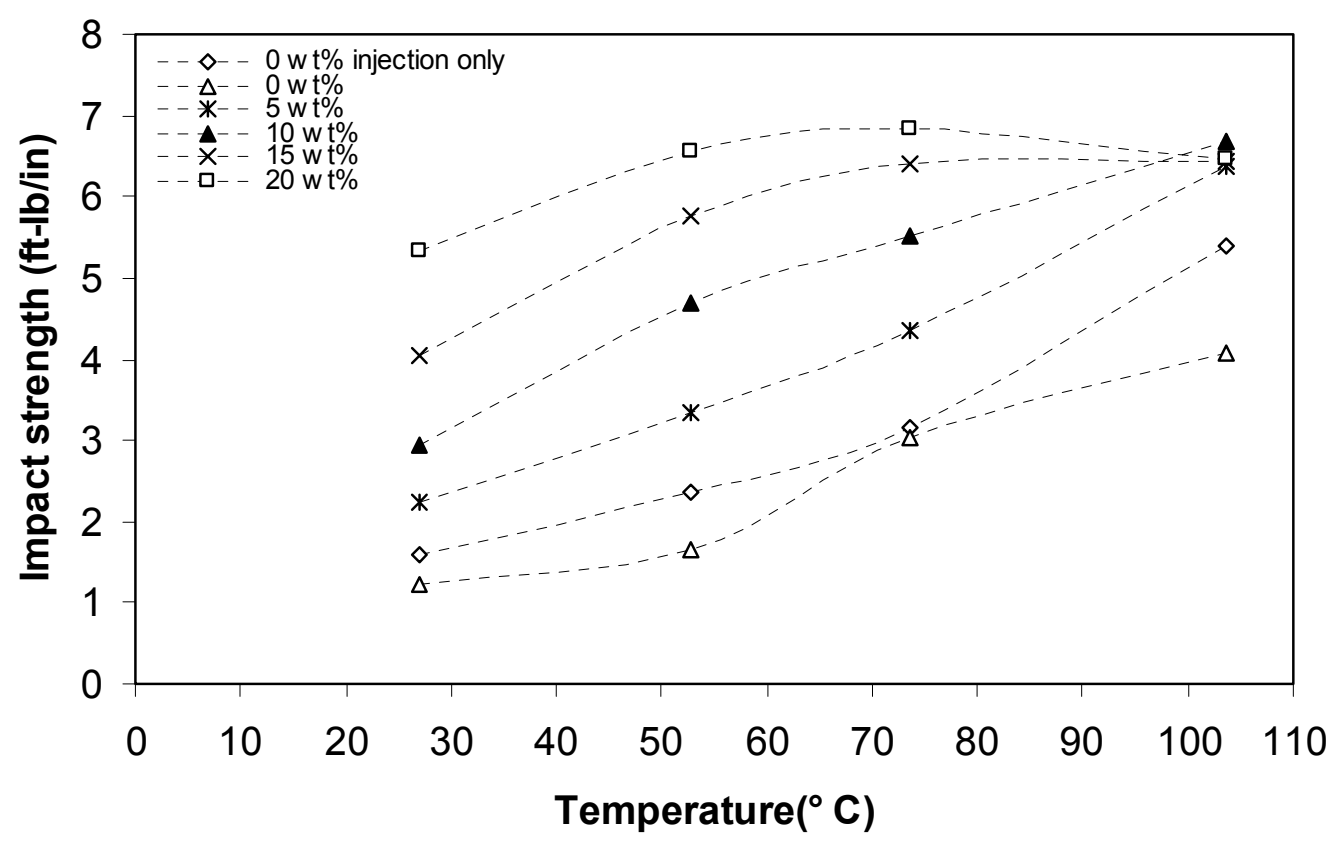

(b)

Figure 4-13 Effect of temperature on glass-fiber-reinforced nylon 66 toughened with EPg-MA at two different glass fiber contents: (a) $14.79 \mathrm{wt} \%$, (b) $23.62 \mathrm{wt} \%$. 


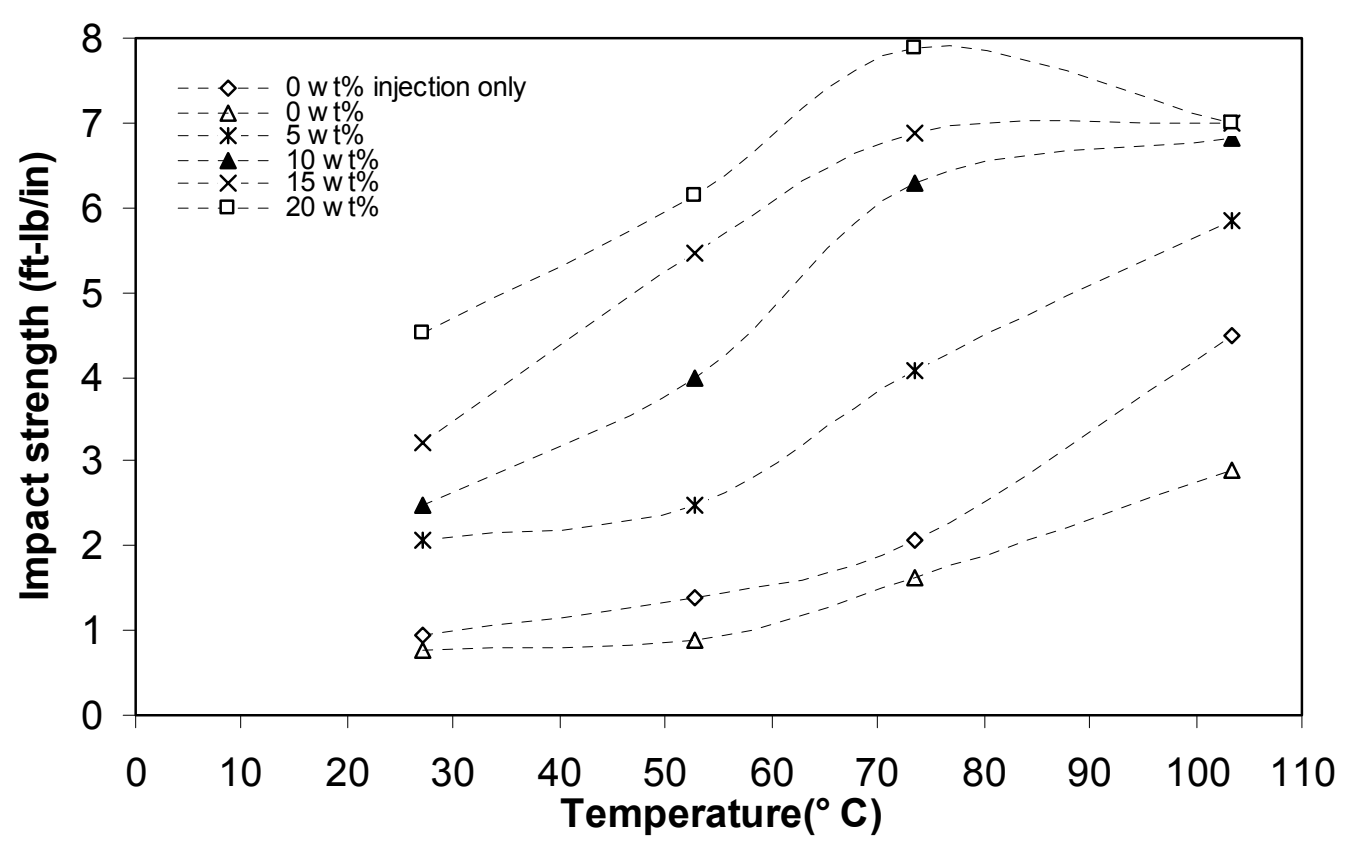

(a)

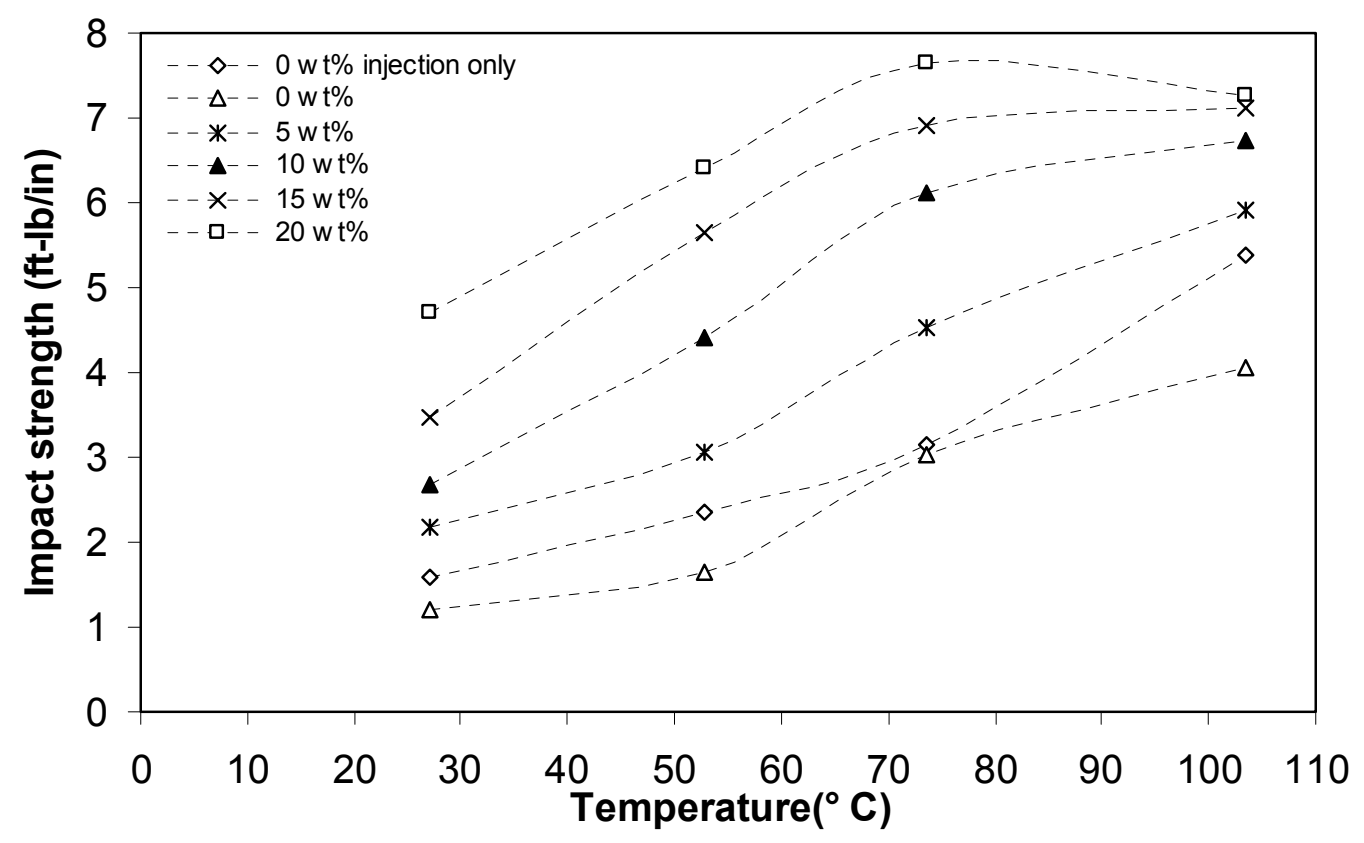

(b)

Figure 4-14 Effect of temperature on glass-fiber-reinforced nylon 66 toughened with SEBS-g-MA at two different glass fiber contents: (a) $14.79 \mathrm{wt} \%$, (b) $23.62 \mathrm{wt} \%$. 
Figures 4-13 and 4-14 also show that for un toughened composites (i.e. composites having $0 \mathrm{wt} \%$ rubber) the transition in impact strength occurs at temperature above $70{ }^{\circ} \mathrm{C}$ while when rubber is introduced the transition occurs at temperature below $70^{\circ} \mathrm{C}$. Note here that a typical $\mathrm{T}_{\mathrm{g}}$ for nylon is between 70 and $80^{\circ} \mathrm{C}$. It seems that addition of reacted rubber to glass-fiber-reinforced nylon 66 may have resulted in a reduction in $\mathrm{T}_{\mathrm{g}}$.

\subsubsection{Tradeoff relationship between strength and toughness of the composites}

Generally, toughness of thermoplastics tends to drastically reduce or remain unchanged upon glass fiber incorporation. At the same time important properties such as strength, stiffness and dimensional stability are improved. On the other hand, the addition of rubber can improve toughness, but there is a reduction in the strength and stiffness. By combining both glass fibers and rubber to thermoplastics, one may optimize the mechanical properties of the polymer. Figure 4-15 shows this tradeoff relationship between toughness and strength of nylon 66 at different glass fiber and rubber contents used in this study. As shown in Figure 4-15, increasing rubber content leads to increase in impact strength, but, at the same time, tensile strength decreases. This clearly shows the possibility of balancing strength and toughness by adding appropriate amounts of rubber and glass fibers to the polymer. For example, tensile and impact strengths of nylon 66 may increase by $28.3 \%$ and $167 \%$ respectively upon incorporating $23.62 \mathrm{wt} \%$ and 10 $\mathrm{wt} \%$ of glass fiber and SEBS-g-MA rubber respectively (see Figure 4-15). It is interesting to note that the tensile strength-impact strength relationship, given by Figure 4-15, for the current research is linear. The linear equations that govern the experimental data are: 


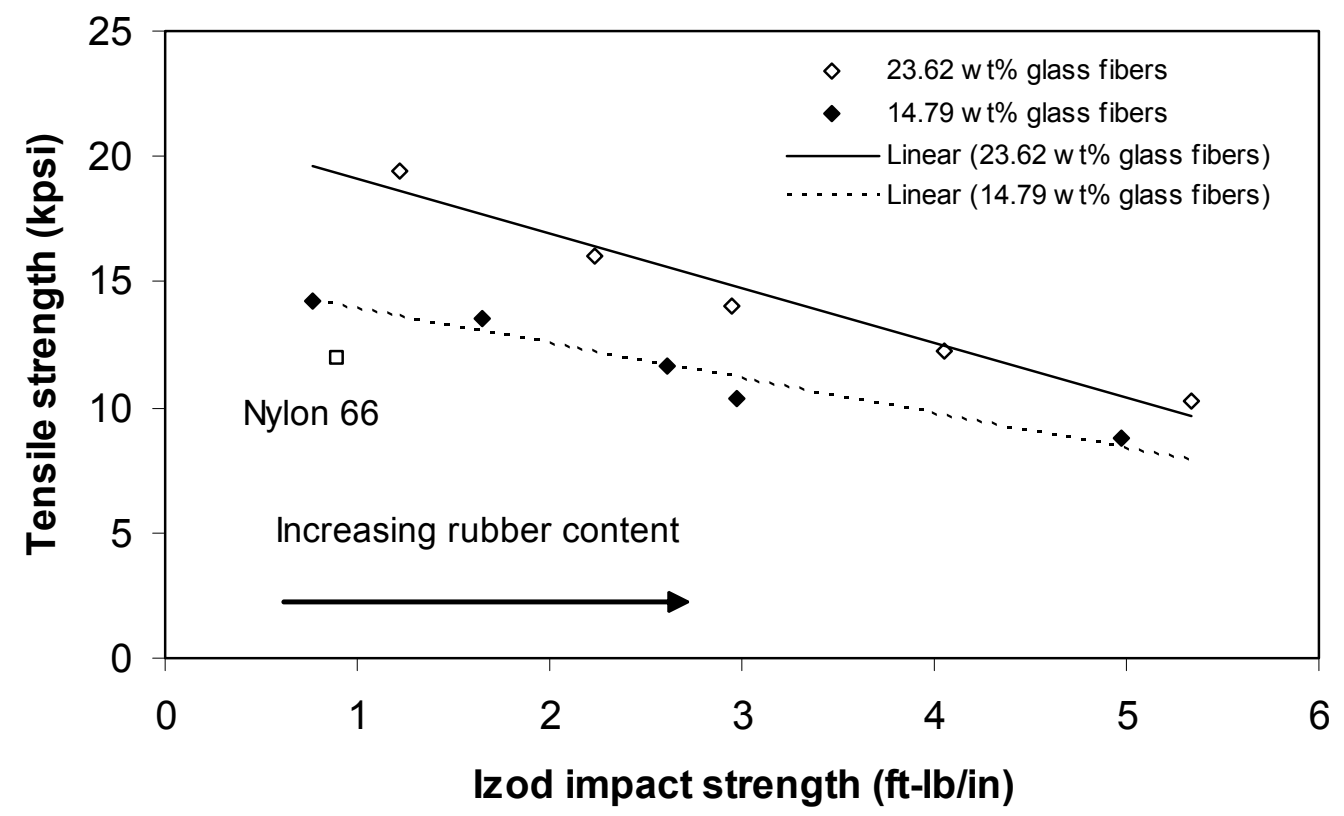

(a)

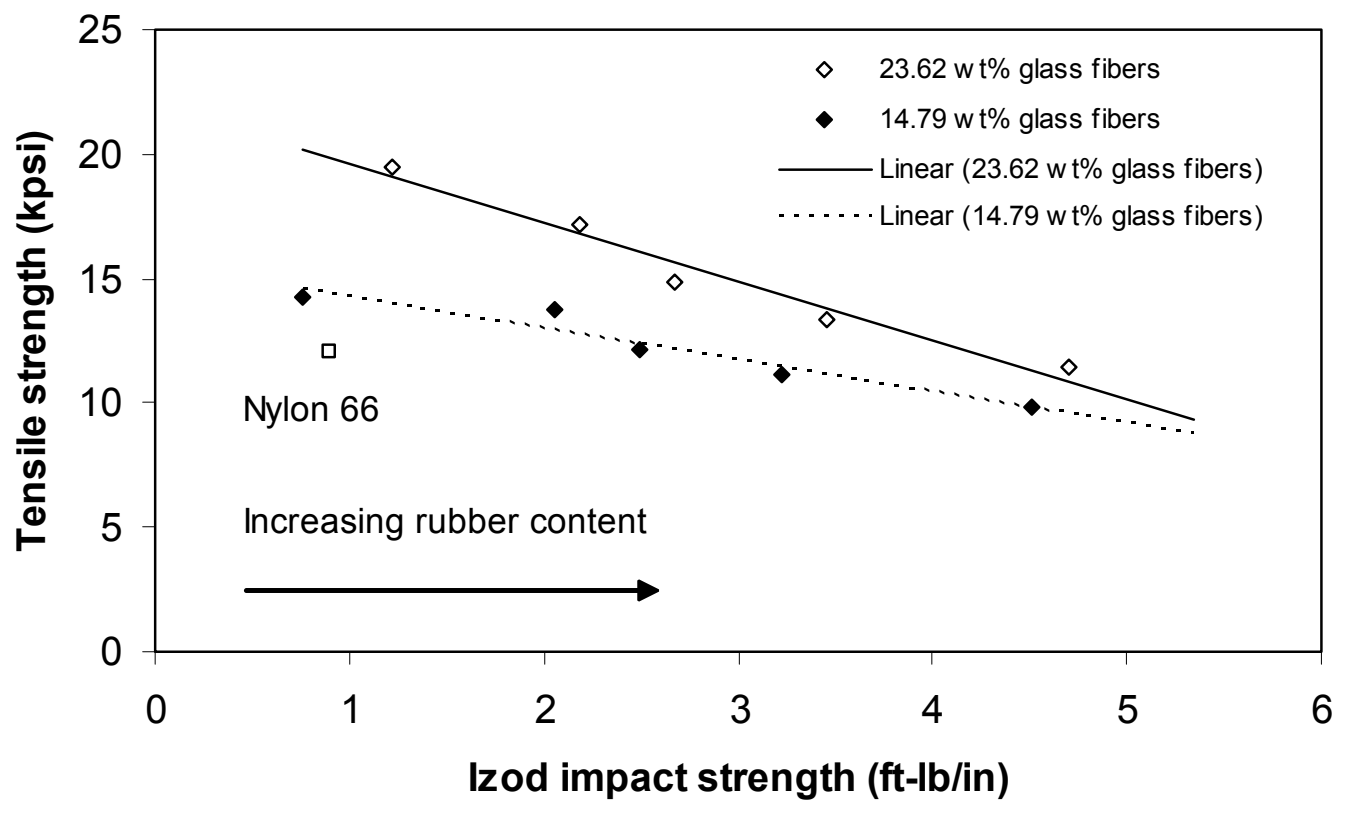

(b)

Figure 4-15 The tradeoff relationship between toughness and strength of the virgin composites. (a) EP-g-MA, (b) SEBS-g-MA. 
For the composites having $23.62 \mathrm{wt} \%$ glass, the relation is given by

$$
\begin{array}{lrr}
(\mathrm{TS}) & =21.268-2.172(\mathrm{IS}) \quad \text { EP-g-MA } \\
(\mathrm{TS}) & =21.959-2.355(\mathrm{IS}) \quad \text { SEBS-g-MA }
\end{array}
$$

and for the composites containing $14.79 \mathrm{wt} \%$ glass fiber, the relation is

$$
\begin{aligned}
& (\mathrm{TS})=15.322-1.389(\mathrm{IS}) \quad \text { EP-g-MA } \\
& (\mathrm{TS})=15.577-1.284(\mathrm{IS}) \quad \text { SEBS-g-MA }
\end{aligned}
$$

where

TS refers to tensile strength, while IS to impact strength

This says that for nylon 66 toughened with the rubbers employed in this study, i.e. EP-gMA and SEBS-g-MA, and reinforced with short glass fibers, at given glass fiber and rubber contents, it is possible to predict the tensile strength when knowing the value of the impact strength and vise versa.

\subsection{Glass fiber length: its dependence on sample preparation}

It is known that during plastic fabrication by injection molding, fiber breakage (attrition) is likely to occur. This may lead to a large population of fibers in the molded article that have lengths that are very small to be effective in ensuring good mechanical properties such as strength and stiffness. For the current study, the average glass fiber length for both recycled and virgin nylon 66 was determined for the following six cases: 
I- As received.

II- After extrusion.

III- After injection molding.

IV- Extrusion followed by injection molding.

V- After extrusion with $20 \mathrm{wt} \%$ rubber.

VI- Extrusion followed by injection molding with $20 \mathrm{wt} \%$ rubber.

The situations listed above arise in practice, and it is necessary to asses the change in fiber length when the material is subjected to different processes such as injection molding and extrusion. The results of fiber length analysis are presented in Tables 4-2 and 4-3. As can be seen from Tables 4-2 and 4-3, a drastic reduction in fiber length occurs when material is processed by extrusion followed by injection molding. In general, material that has been processed by direct injection molding has a smaller fiber length than material that has only been extruded. This is probably due to the mild shear conditions chosen for extrusion (i.e. low screw speed $=40 \mathrm{rpm}$ ). In the injection molding machine a high shear rate is expected to be applied to the material which would cause massive fiber breakage. Incorporating rubber into glass-fiber- reinforced nylon 66 leads to further fiber length reduction. During blending in the extruder, the rubber phase tends to disperse in nylon. This interaction between rubber and nylon and glass fibers may result in fiber breakage. Recycled material initially has a larger fiber length as compared to the virgin material. This may explain the good tensile and flexural results obtained for the recycled material. Taking a typical value for fiber strength as $2470 \mathrm{MPa}$ [84] and assuming good matrix-fiber adhesion so that shear strength of the material may be taken 
as shear strength of nylon 66 (typically $66.2 \mathrm{MPa}$ ), the critical fiber length in the present case may be calculated by Eq. 2-9. After introducing the numbers, the critical fiber length is found to be $\sim 234 \mu \mathrm{m}$. The typical critical fiber length for glass fiber-nylon 66 system is about $230 \mu \mathrm{m}$ [23]. The fiber lengths of the specimens tested morphologically are less than the critical length (see method IV and VI in Tables 4-2 and 4-3). This implies that the fracture mechanism of the composites will be dominated by fiber pull-out and this is indeed what the morphology of the fracture surfaces reveled as discussed in the next section. Also since fiber length is less than the critical length, the failure is expected to be due to matrix fracture or fiber-matrix debonding if the adhesion is poor.

Table 4-2 Effect of material processing on glass fiber length for recycled glass-fiber reinforced nylon 66 .

\begin{tabular}{|c|c|c|c|c|c|c|c|c|}
\hline & & & & Ilass fiber & Content ( & $v t \%)$ & & \\
\hline & & & 79 & & & & 3.62 & \\
\hline & Fiber & $\mathrm{Mec}$ & nical pre & perties & Fiber & Me & anical prot & erties \\
\hline Method & $\begin{array}{l}\text { length } \\
(\mu \mathrm{m})\end{array}$ & $\begin{array}{l}\text { Tensile } \\
\text { (kpsi) }\end{array}$ & $\begin{array}{l}\text { Impact } \\
(f t- \\
\text { lb/in) }\end{array}$ & $\begin{array}{l}\text { Flexural } \\
\text { (kpsi) }\end{array}$ & $\begin{array}{l}\text { length } \\
(\mu \mathrm{m})\end{array}$ & $\begin{array}{l}\text { Tensile } \\
\text { (kpsi) }\end{array}$ & $\begin{array}{l}\text { Impact } \\
(f t-l b / i n)\end{array}$ & $\begin{array}{l}\text { Flexural } \\
\text { (kpsi) }\end{array}$ \\
\hline$I$ & 417.6 & - & - & - & 417.6 & - & - & - \\
\hline II & 262.6 & - & - & - & 258 & - & - & - \\
\hline III & 291.5 & 13.96 & 0.87 & 22.84 & 253.5 & 19.87 & 1.35 & 29.82 \\
\hline$I V$ & 252.6 & 14.31 & 0.71 & 21.77 & 235.55 & 18.19 & 1.20 & 28.31 \\
\hline$V$ & 232.8 & - & - & - & 255.44 & - & - & - \\
\hline$V I$ & 225.5 & 8.49 & 4.36 & 11.92 & 217.45 & 11.32 & 4.07 & 16.47 \\
\hline
\end{tabular}


Table 4-3 Effect of material processing on glass fiber length for virgin glass-fiber reinforced nylon 66 .

\begin{tabular}{|c|c|c|c|c|c|c|c|c|}
\hline \multirow{4}{*}{ Method } & \multicolumn{8}{|c|}{ Glass fiber Content (wt\%) } \\
\hline & \multicolumn{4}{|c|}{14.79} & \multicolumn{4}{|c|}{23.62} \\
\hline & $\begin{array}{l}\text { Fiber } \\
\text { length }\end{array}$ & \multicolumn{3}{|c|}{ Mechanical property } & $\begin{array}{l}\text { Fiber } \\
\text { length }\end{array}$ & \multicolumn{3}{|c|}{ Mechanical property } \\
\hline & $\begin{array}{l}\text { length } \\
(\mu \mathrm{m})\end{array}$ & $\begin{array}{l}\text { Tensile } \\
\text { (kpsi) }\end{array}$ & $\begin{array}{l}\text { Impact } \\
(f t- \\
\text { lb/in) }\end{array}$ & $\begin{array}{l}\text { Flexural } \\
\text { (kpsi) }\end{array}$ & $\begin{array}{l}\text { length } \\
(\mu \mathrm{m})\end{array}$ & $\begin{array}{l}\text { Tensile } \\
\text { (kpsi) }\end{array}$ & $\begin{array}{l}\text { Impact } \\
\text { (ft- } \\
\text { lb/in) }\end{array}$ & $\begin{array}{l}\text { Flexural } \\
\text { (kpsi) }\end{array}$ \\
\hline$I$ & 305.08 & - & - & - & 305.08 & - & - & - \\
\hline II & 285.86 & - & - & - & 277.99 & - & - & - \\
\hline III & 243.04 & 16.27 & 0.95 & 23.02 & 230.39 & 20.98 & 1.60 & 29.77 \\
\hline$I V$ & 222.47 & 14.26 & 0.76 & 22.13 & 201.64 & 19.46 & 1.22 & 28.41 \\
\hline $\boldsymbol{V}$ & 228.14 & - & - & - & 259.06 & - & - & - \\
\hline$V I$ & 223.27 & 9.79 & 4.51 & 13.61 & 195.81 & 11.42 & 4.70 & 15.60 \\
\hline
\end{tabular}

\subsection{Morphology of the fracture surface of the composites}

Studying the fracture surface of the samples is a useful way to assess different aspects of the toughening process. Electron microscopy allows one to actually see fibers upon fracture. Whether fibers are pulled out from the matrix or are broken and the degree of adhesion with the matrix may be easily visualized. Also one can see the degree of alignment of fibers in the sample. In principle, fibers tend to align themselves in the direction of flow during injection molding. Toughening with rubber usually results in an increase in plastic deformation of the matrix. Shear bands, crazing, and cavitations are 
usually expected to be seen when examining the fracture surface of rubber-toughened thermoplastics as signs for the mechanism of rubber toughening.

For the current research we examined the fracture surface of rubber toughened glass-fiber reinforced nylon 66 at two extremes of strain rate: Izod samples which represent a high strain rate (impact speed $\sim 10 \mathrm{ft} / \mathrm{sec}$ ) and tensile and flexural samples which represents a low strain rate. Figures 4-16 through 4-18 show the morphology of the fracture surface of some Izod samples of both recycled and virgin composites. The test was done at room temperature which implies that the matrix, i.e. nylon 66, was semibrittle since its $T_{g}$ is above room temperature. Therefore, in the absence of rubber phase nylon 66 is not expected to absorb much energy before fracture. As is clearly evident from the fracture surfaces, fiber pull-out is great with the blends with $0 \mathrm{wt} \%$ rubber. When rubber is introduced to the glass-fiber reinforced nylon 66 , the extent of fiber pull-out is reduced considerably (see Figures 4-16 (c) and (f) and 4-18 (c) and (e)). As discussed in Chapter 2 under the subject of fracture toughness of reinforced polymers, a maximum toughness is achieved at fiber critical length. Here the morphology of the fracture surface of the Izod samples shows that the addition of rubber to glass-fiberreinforced nylon 66 reduces fiber pull-out. Indeed fiber breakage was observed with some of the blends (see Figures 4-16 (e) and 4-17 (b)). This morphology correlates with mechanical properties, i.e. an increase in impact strength of the composites. The rubber phase increases ductility of the composites resulting in large deformations which increase the energy absorption before fracture. While composites with no rubber have less deformation and clean surface of fibers being pulled out, those composites with a high rubber content have a great degree of plastic deformation and fibers that are surrounded 


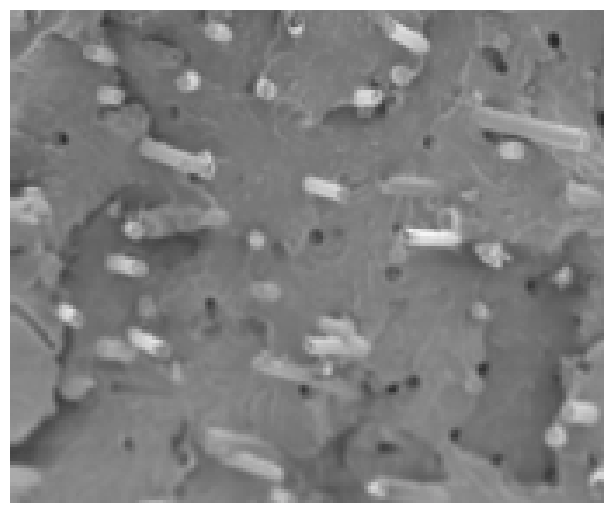

(a)

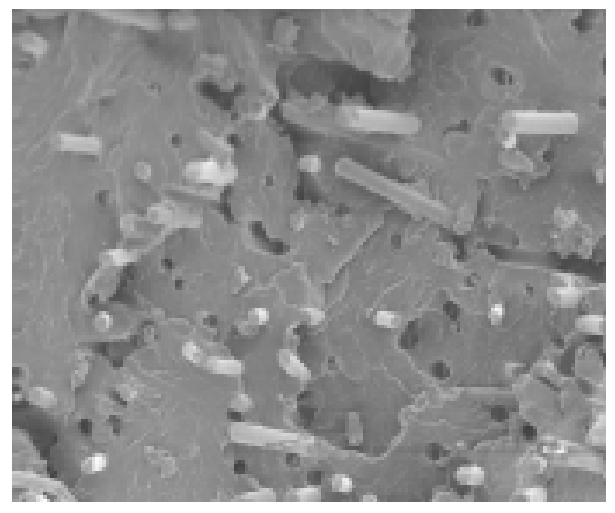

(c)

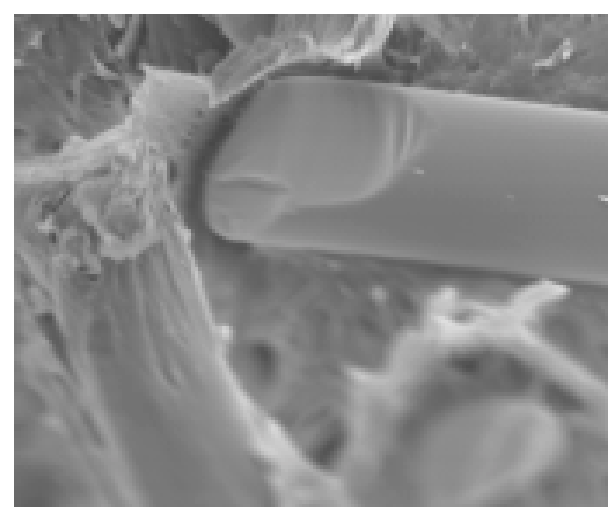

(e)

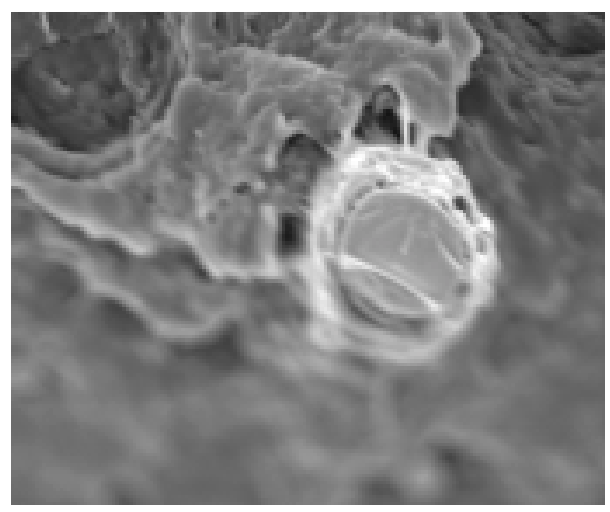

(b)

$\times 2.2 \mathrm{k}$

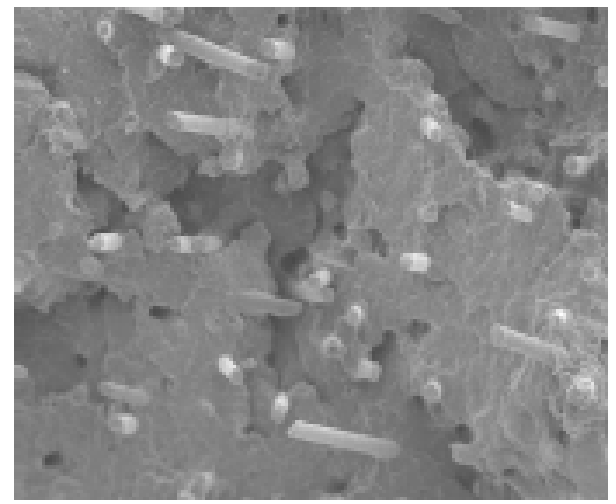

(d)

$\times 220$

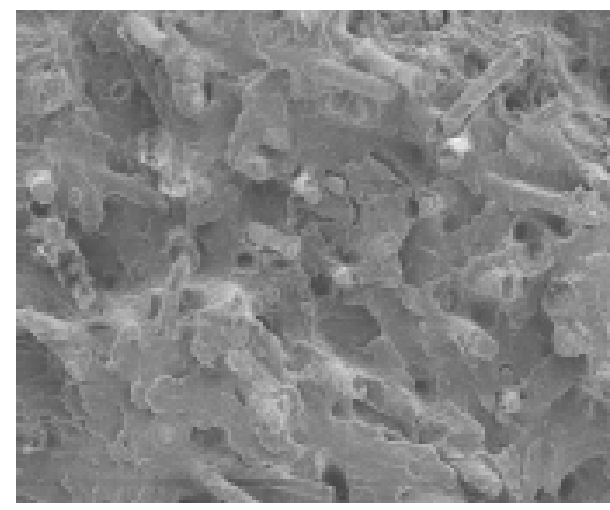

(f)

$\times 220$

Figure 4-16 SEM micrographs of the fracture surface of Izod samples for the recycled composites: (a) and (b) $14.79 \mathrm{wt} \%$ glass fiber and 0 and $20 \mathrm{wt} \%$ EP-g-MA respectively; (c)-(f) $23.62 \mathrm{wt} \%$ glass fiber and 0, 5, 5, and $20 \mathrm{wt} \%$ EP-g-MA. 


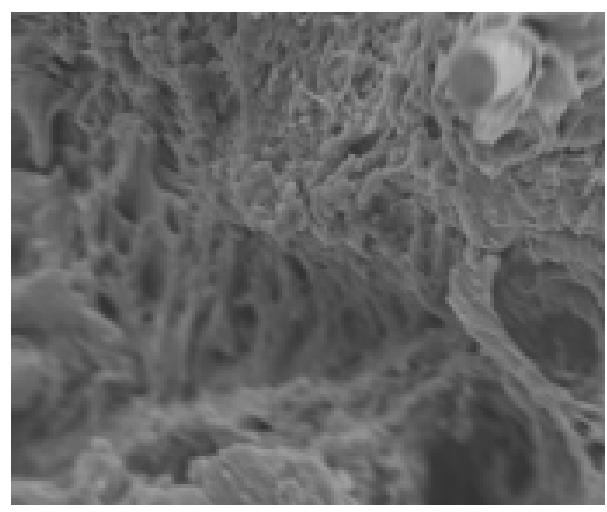

(a)

$\times 1.2 \mathrm{k}$

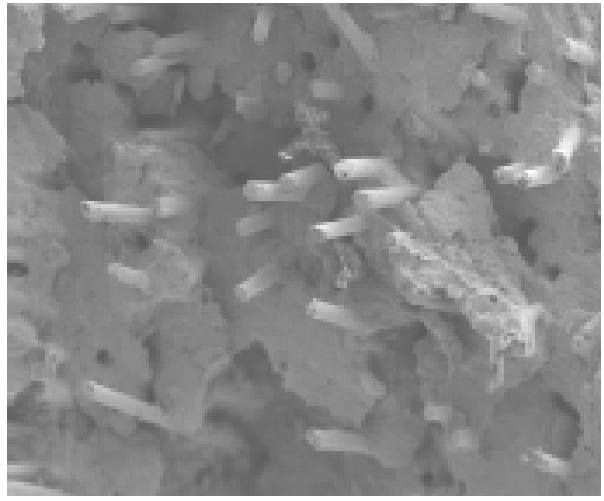

(c)

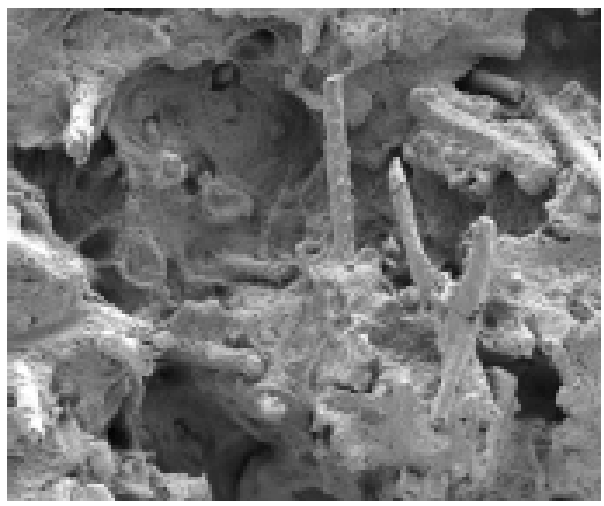

(e)

$\times 220$

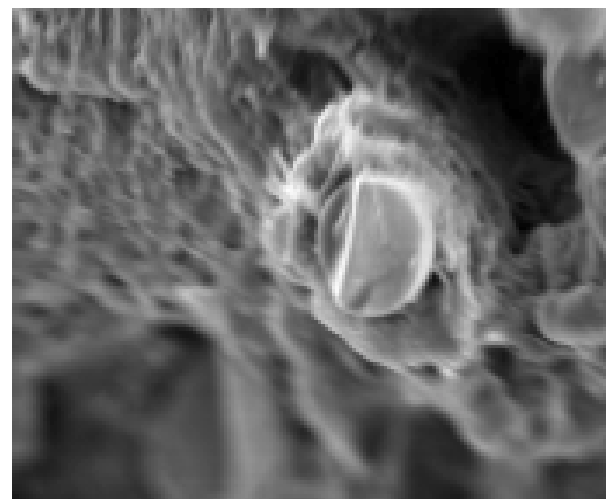

(b)

$\times 2.2 \mathrm{k}$

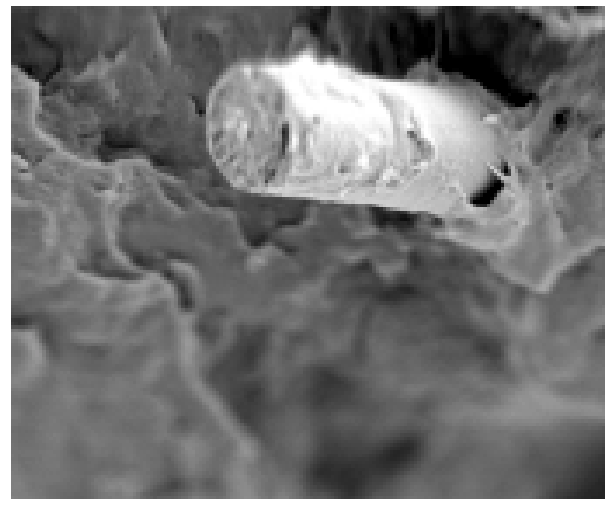

(d)

$\times 2.2 \mathrm{k}$

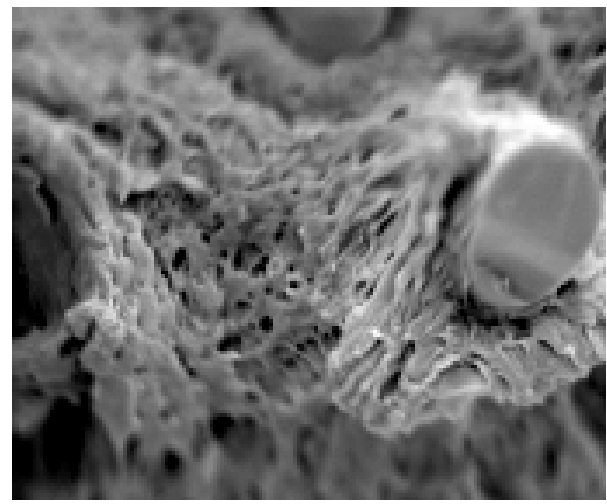

(f)

Figure 4-17 SEM micrographs of the fracture surface of Izod samples for the virgin composites with EP-g-MA: (a) and (b) $14.79 \mathrm{wt} \%$ glass fibers and $20 \mathrm{wt} \%$ rubber; (c)-(f) $23.62 \mathrm{wt} \%$ glass fiber and 5,5,20,20 wt $\%$ rubber. 


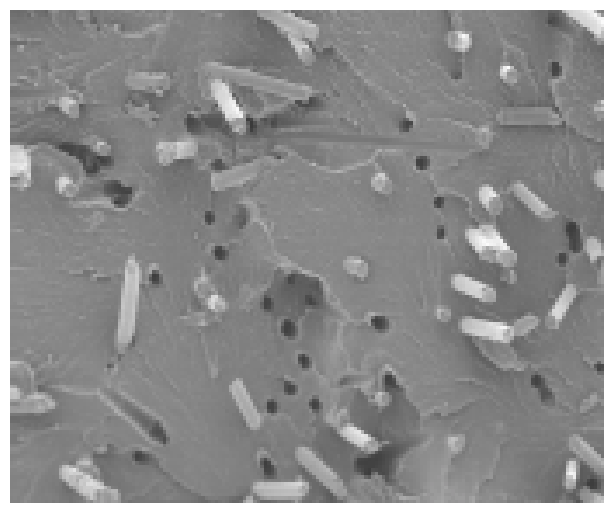

(a)

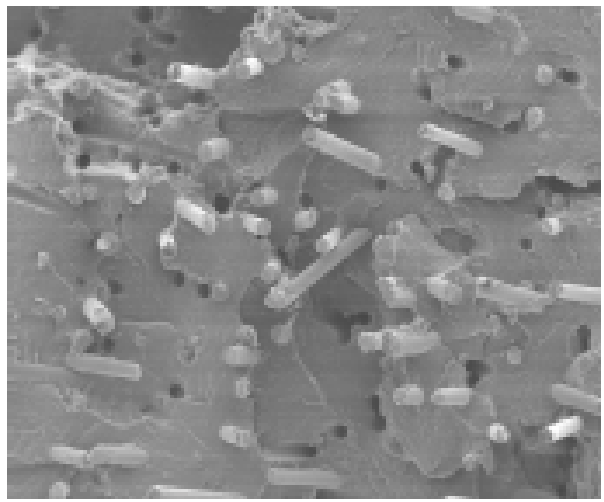

(c)

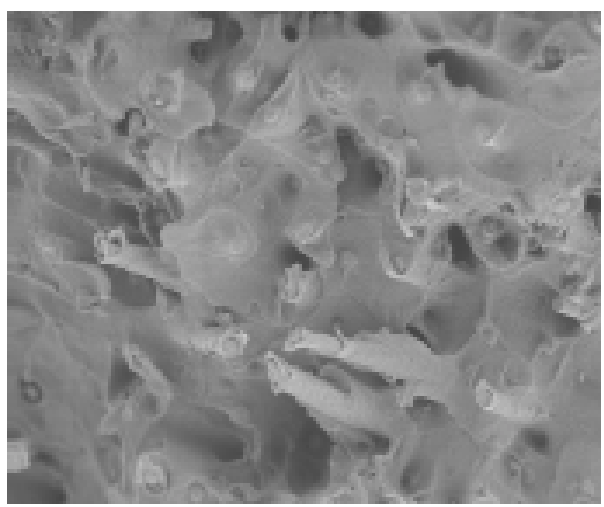

(e)

$\times 220$

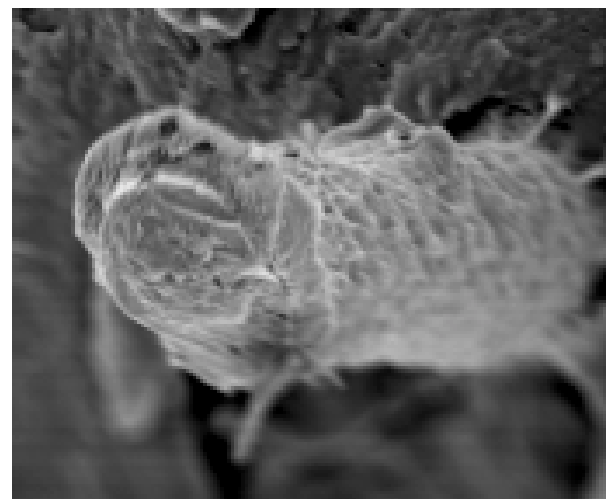

(b)

$\times 2.2 \mathrm{k}$

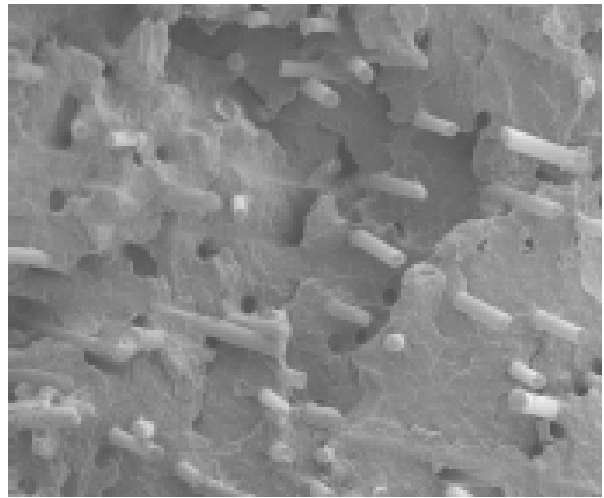

(d)

$\times 220$

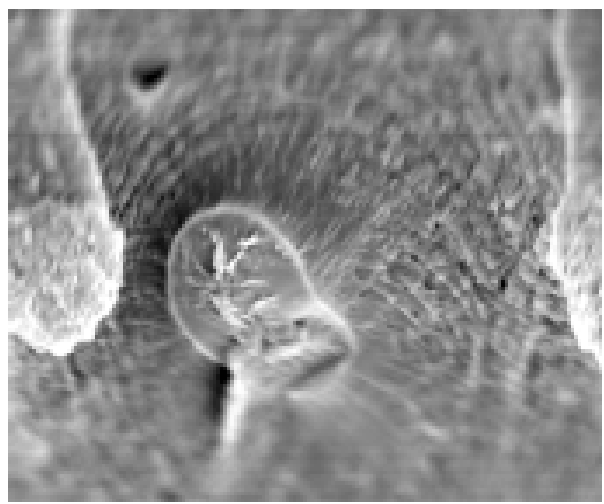

(f)

$\times 2.2 \mathrm{k}$

Figure 4-18 SEM micrographs of the fracture surface of Izod samples for the virgin composites with SEBS-g-MA: (a) and (b) $14.79 \mathrm{wt} \%$ glass fibers and 0 and $20 \mathrm{wt} \%$ rubber respectively; (c)-(f) $23.62 \mathrm{wt} \%$ glass fiber and 0,5,20,20 wt $\%$ rubber. 
by a great amount of matrix material. In other words, there is good adhesion between matrix and fibers (see Figures 4-17 (a)-(e) and 4-18 (b),(c), and (e)). As noted by Nair et al. [83], a strong fiber-matrix interface is essential for polymer toughening.

The morphology of the fracture surface of the Izod samples also shows evidence of shear yielding and cavitation. Shear yielding and cavitation are believed to be the main mechanisms for rubber toughening in nylon 66. Figure 4-18 (f) clearly shows that shear bands were formed around a fiber in circular pattern. Also, cavitation around the fiber is seen in Figure 4-17 (f). Since the properties of the glass-fiber-reinforced composite are greatly dependent of the orientation of fibers in the molded samples, one needs to examine this important parameter. As mentioned previously, fibers are expected to align in the flow direction in processes such as injection molding. For the current research, Izod bars were cut in a direction parallel to the flow direction and examined by SEM. Figure 4-19 shows that, in general, fibers were aligned in the flow direction as expected. In a fractured Izod sample plane stress fracture region is located near the notch while plane strain fracture region is a way from the notch. Wu et al. $[48,49]$ have stated that plane strain to plane stress transition has to occur in order for the material to increase in toughness. For the current study, as revealed by Figure $4-20$ which gives the fracture surface morphology of the Izod samples at the notch, no significant difference in the morphology is noted in comparison with the morphology of the surface a way from the notch (see Figures 4-17 and 4-18). 


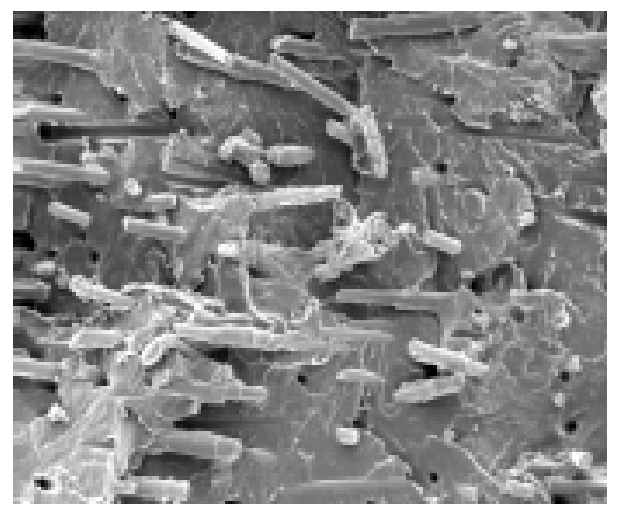

$\times 220$

Figure 4-19 The alignment of glass fibers parallel to flow direction in the injection molding for Izod sample having $23.62 \mathrm{wt} \%$ glass fiber.

The morphology of fractured Izod samples tested at a temperature of $103.5^{\circ} \mathrm{C}$ was examined and is shown in Figure 4-21. At this temperature, the matrix material, i.e. nylon 66 is at temperature above its $\mathrm{T}_{\mathrm{g}}$ which will make nylon 66 act in a ductile fashion. Consequently, shear deformation is very likely to take place as a mechanism of absorbing the energy of impact. Figure 4-21 in fact demonstrates that deformation has been increased in comparison with Izod samples tested at room temperature as given in Figures 4-17 and 4-18. Unlike the fracture surface of the Izod sample which has $23.62 \mathrm{wt} \%$ glass fiber with no rubber (tested at room temperature) as given in Figure 4-18 (c), here nylon 66 looks more deformed and the glass fibers that are pulled out from the matrix have some matrix material sticking on them (see Figure 4-21 (a)). This observation becomes more clear when rubber content increases as demonstrated by Figure 4-21 (b)-(f). However, when rubber content is increased, the extent of fiber pull-out is diminished. 


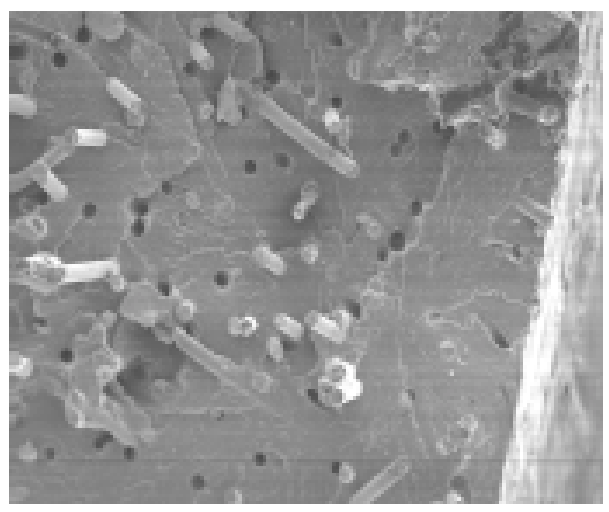

(a)

$\times 220$
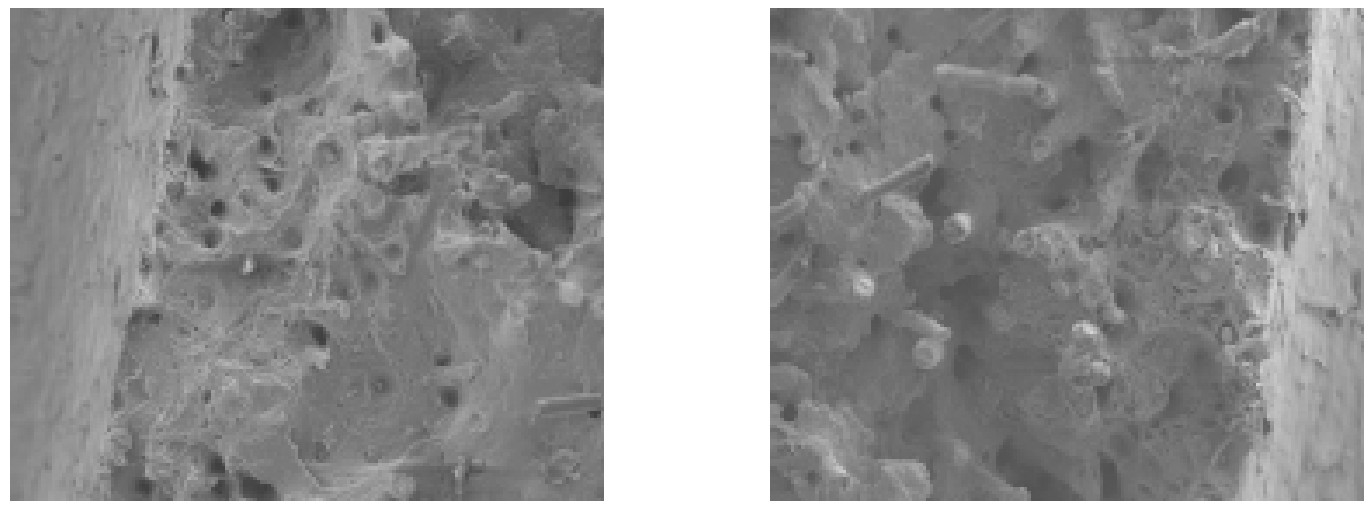

(b)

$\times 220$

(c)

$\times 220$

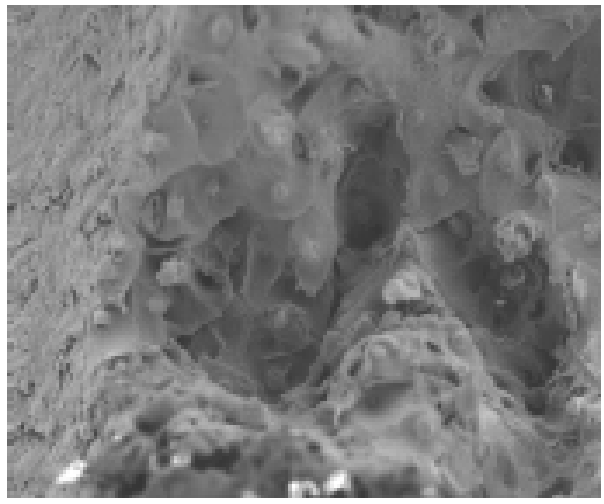

(d)

$\times 220$

(e)

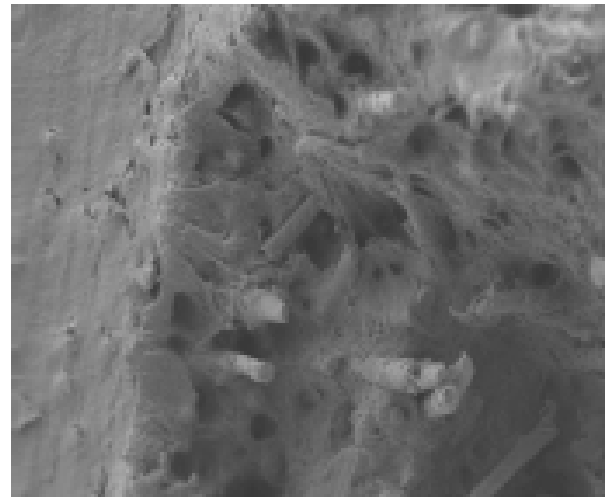

$\times 220$

Figure 4-20 SEM micrographs of the fracture surface of the Izod samples at the notch for the virgin composites with $23.62 \mathrm{wt} \%$ glass fiber and various rubber $\mathrm{wt}^{\mathrm{t}} \%$ : (a) $0 \%$; (b) 5 $\%$ SEBS-g-MA; (c) $5 \%$ EP-g-MA; (d) $20 \%$ SEBS-g-MA; (e) $20 \%$ EP-g-MA. 


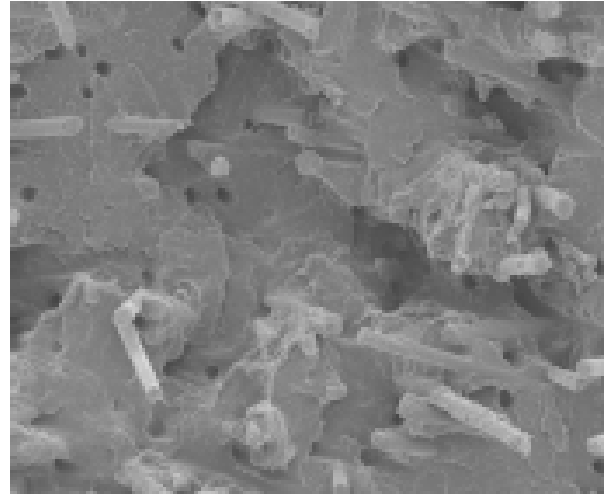

(a)

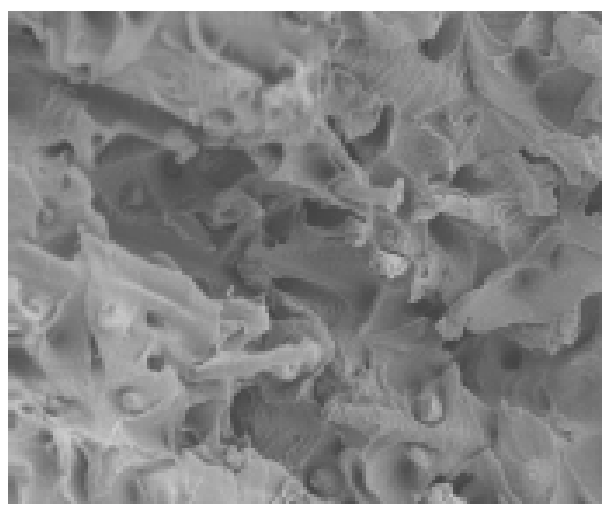

(c)

$\times 220$

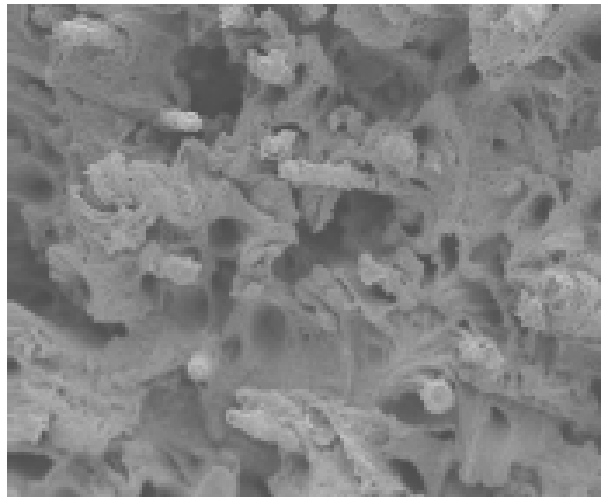

(e)

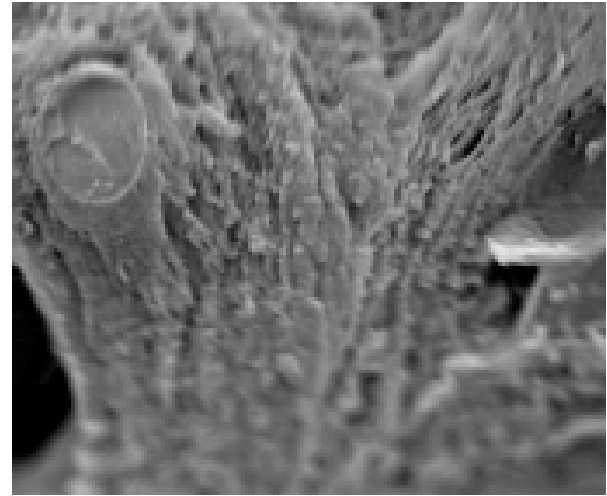

(b)

$\times 2.2 \mathrm{k}$

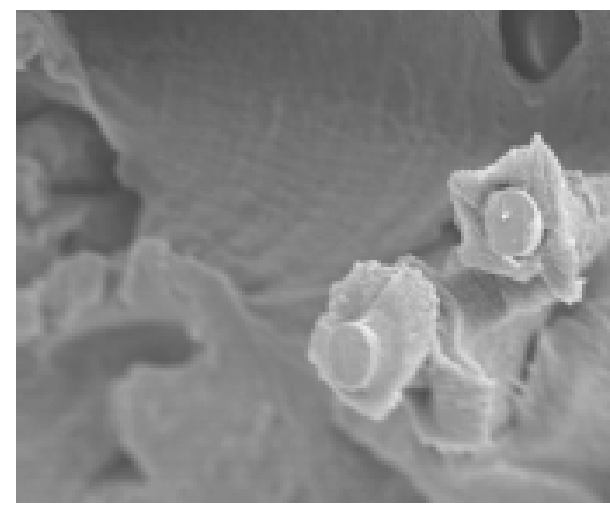

(d)

$\times 1.1 \mathrm{k}$

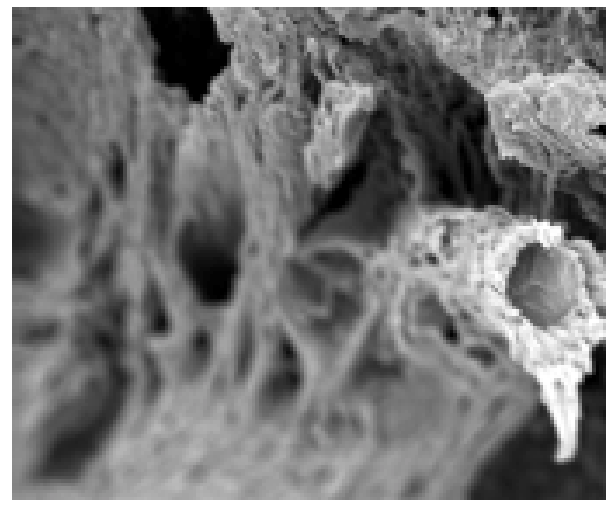

(f)

$\times 1.2 \mathrm{k}$

Figure 4-21 SEM micrographs of the fracture surface of the Izod samples ( at $\mathrm{T}=103.5^{\circ}$ C) for the virgin composites: (a) and (c)-(f) $23.62 \mathrm{wt} \%$ glass fiber and 0 and 20, $20 \mathrm{wt} \%$ SEBS-g-MA, 20,20 wt\% EP-g-MA respectively; (b) $14.79 \mathrm{wt} \%$ glass fiber and $20 \mathrm{wt} \%$ SEBS-g-MA. 
The fracture surfaces of various tensile samples for recycled and virgin composites are shown in Figures 4-22 and 4-23. A tensile test is done at much lower strain rate than in an Izod test $(0.2 \mathrm{in} / \mathrm{min}$ or $0.00028 \mathrm{ft} / \mathrm{sec})$. The morphology of the fracture surface of the tensile samples reveals similar behavior as seen with Izod fracture surface. Increasing rubber content is seen to enhance the adhesion between matrix and fiber and cause nylon 66 to deform more (see Figures 4-22 (a), (c), and (d) and 4-23 (b), (e), and (d)). Samples that were broken during the three point bending test (flexural) within or slightly above the $5 \%$ strain that is specified by ASTM D790 were also examined by the SEM. A flexural test is done at much lower strain rate than both Izod and tensile tests $(0.053 \mathrm{in} / \mathrm{min}$ or $0.000074 \mathrm{ft} / \mathrm{sec})$. Figure $4-24$ shows the fracture surface of the flexural samples. In general, morphology of the flexural samples was similar to that of Izod and tensile samples except for some different morphologies presented by Figure 4-24 (a)-(e). Similar to what was observed with Izod and tensile fractured surfaces, addition of rubber to glass-fiber-reinforced nylon 66 increases the amount of nylon 66 around the fiber during fiber pull-out as demonstrated by Figure 4-24 (f). Figure 4-24 (a) also shows a noticeable crack. This crack has been observed with composite having the lower glass content, i.e. $14.79 \mathrm{wt} \%$, and $0 \mathrm{wt} \%$ rubber. In the absence of rubber phase, crack initiation and propagation are expected to be large. Multiple fiber breakage was seen with the recycled material (see Figure 4-24 (e)). At the edge of the sample where the upper load in the three point bending test is applied, an area was observed which was highly deformed. The size of this area increased with increasing rubber content (see Figure 4-24 (b)-(d)). This kind of behavior associated with only flexural sample fracture surface may be attributed to the nature of the test. 


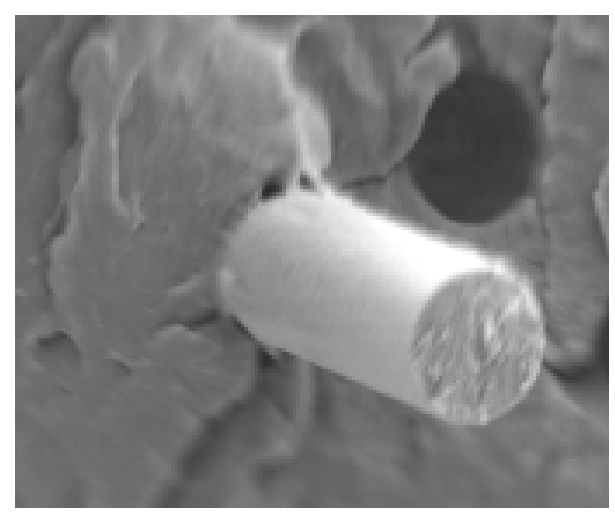

(a) $\quad \times 2.4 \mathrm{k}$

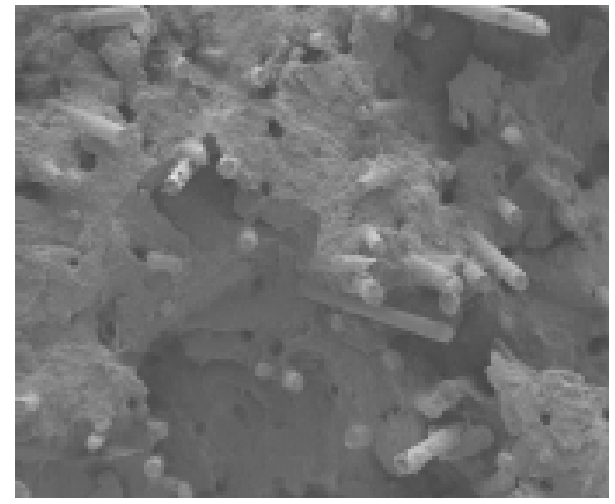

(b)

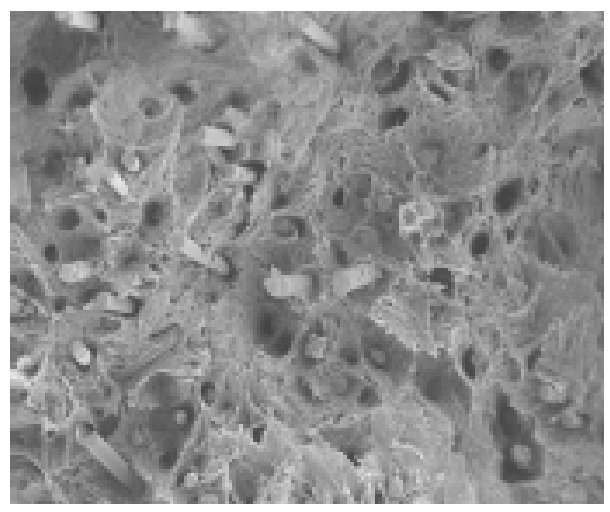

(d)

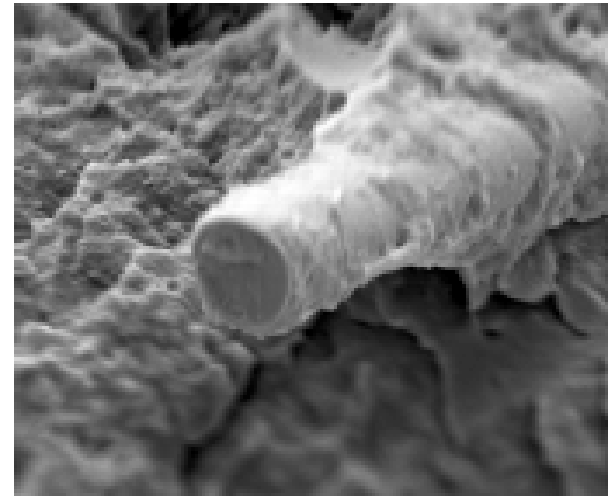

(c)

$\times 2.2 \mathrm{k}$

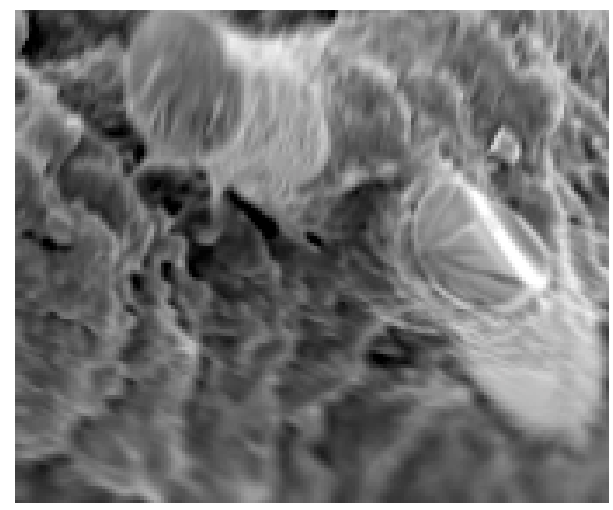

(e)

Figure 4-22 SEM micrographs of the fracture surface of the tensile samples of the recycled composites with $23.62 \mathrm{wt} \%$ glass fiber and various EP-g-MA wt $\%$ : (a) $0 \%$; (b) and (c) $5 \%$; (d) and (e) $20 \%$. 


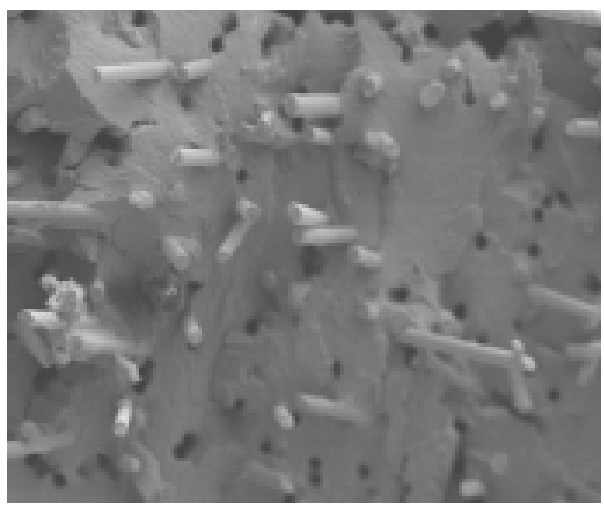

(a)

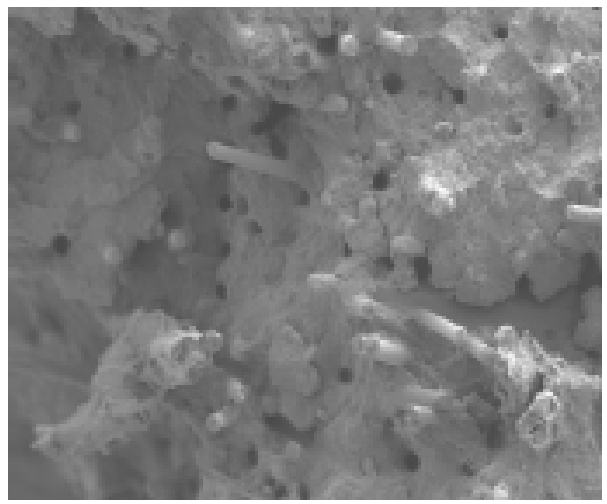

(c) $\times 220$

$\times 220$

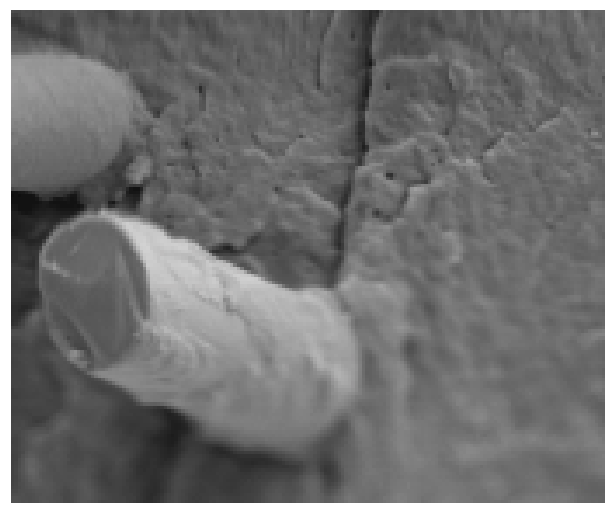

(b)

$\times 2.2 \mathrm{k}$

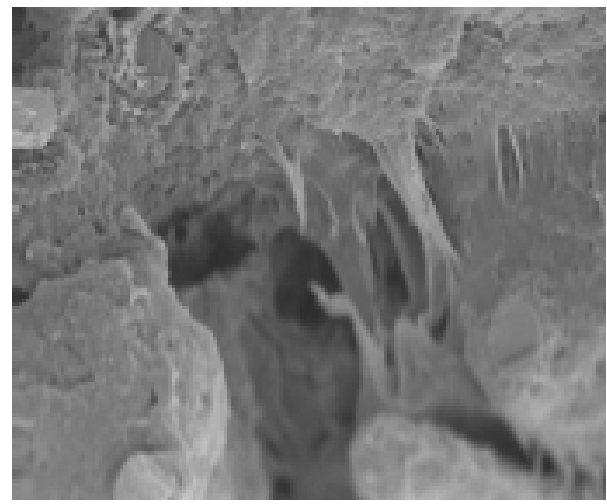

(d)

$\times 1.1 \mathrm{k}$

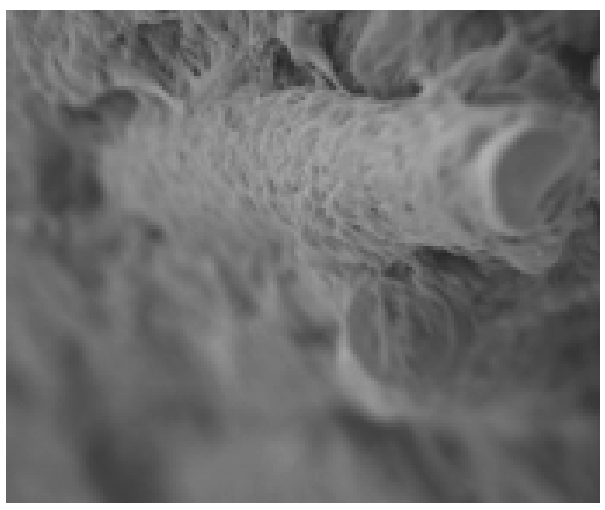

(e)

$\times 2.2 \mathrm{k}$

Figure 4-23 SEM micrographs of the fracture surface of the tensile samples of the virgin composites with $23.62 \mathrm{wt} \%$ glass fiber and various EP-g-MA wt\%: (a) and (b) $0 \%$; (c) 5 $\%$; (d) and (e) $20 \%$. 


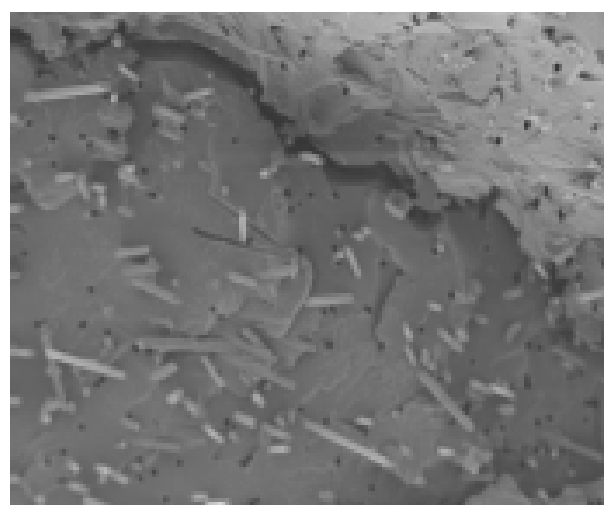

(a)

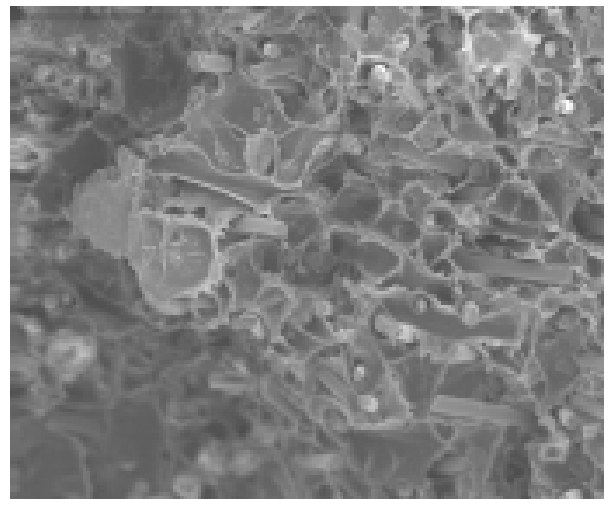

(c)

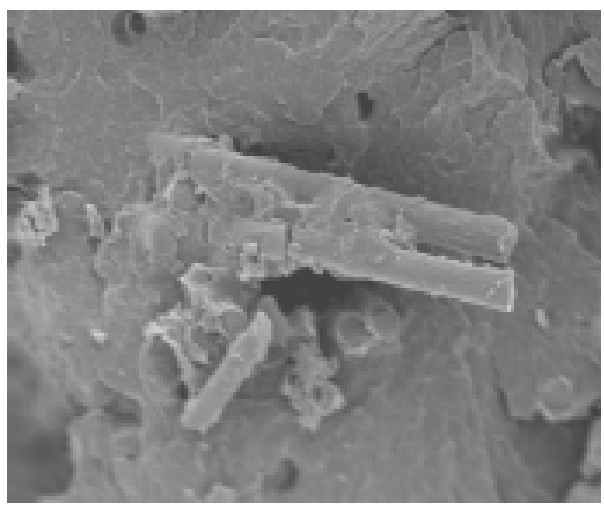

(e)

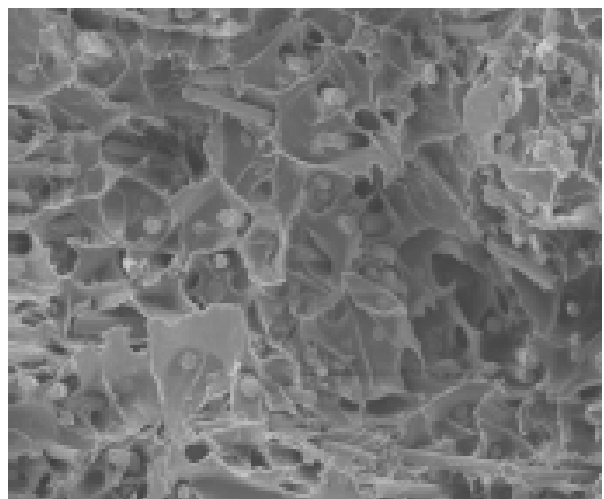

(b)

$\times 220$

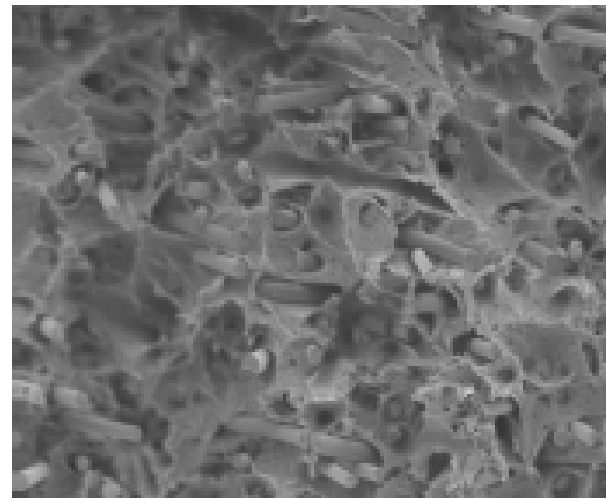

(d)

$\times 220$

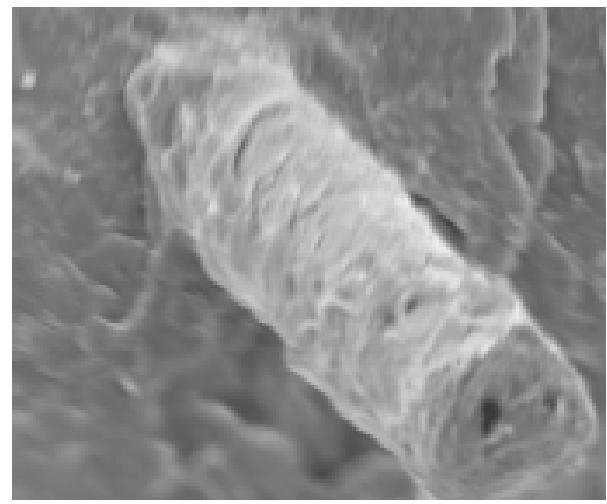

(f)

$\times 2.3 \mathrm{k}$

Figure 4-24 SEM micrographs of the fracture surface of the flexural samples: (a) and (b) virgin with 14.79 and $23.62 \mathrm{wt} \%$ glass fiber respectively and $0 \mathrm{wt} \%$ rubber; (c)-(f) recycled with $23.62 \mathrm{wt} \%$ glass fiber and 0,5,5,5 wt $\%$ EP-g-MA. 
Since flexural test is done at very low rate of strain, material has enough time to deform before fracture. In case of Izod test for instance, material is suddenly hit by the weight and immediately fractured.

In conclusion, it was shown that, as observed by fracture surface of the samples, composites of reinforced nylon 66 exhibit brittle fracture surface with great extent of fiber pull-out. These fibers come out of the matrix material with clean surface showing no sign of good adhesion between matrix and fibers. However, when rubber was introduced, material exhibited great amount of deformation and fibers were surrounded with considerable amounts of matrix material which is a sign of good adhesion between fiber and matrix. Shear bands and cavitations were observed with composites with SEBS-gMA rubber (see Figure 4-18 (f)) and only cavitations were observed with composites with EP-g-MA rubber (see Figure 4-17 (f)). The morphology of the fractured surface seems to correlate well with mechanical properties of the composites. At higher rubber content, matrix deformation and good adhesion between fiber and matrix were observed which led to an increase in impact strength of the composites.

\subsection{Thermal properties}

\subsubsection{Thermal expansion}

The coefficient of thermal expansion (CTE) may be used as an indication of the dimensional stability of composites. Glass fibers are known for their low CTE, but when these are combined with thermoplastics, the CTE is greatly affected by the orientation of fibers. For example, the CTE in the flow direction of 30\% to $33 \%$ glass fiber reinforced nylon 66 is about one third the CTE in the transverse direction [2]. 
Figure 4-25 shows the variation of the thermal expansion coefficient as a function of temperature for rubber-toughened glass-fiber-reinforced nylon 66 used in this study. As expected, Figure 4-25 indicates that composites with high rubber content and low glass fiber content have the higher values of CTE.

\subsubsection{Heat of fusion of the composites}

The heat of fusion of rubber-toughened glass-fiber-reinforced nylon 66 is plotted against rubber weight percent in Figure 4-26. The samples were taken from the injection molding bars. The first heating scan in the DSC was discarded since it represents the thermal history of the material. Since all samples tested were extruded twice by extrusion followed by injection molding, a sample of virgin nylon 66 (Zytel 101 L) was extruded twice and tested in the DSC to measure its heat of fusion value. This was done to compare heat of fusion data of the rubber-toughened glass-fiber- reinforced nylon 66 with that of neat nylon 66 that has neither rubber nor glass fiber to asses any change in crystallinty of nylon 66 when both rubber and glass fiber are incorporated. The value of heat of fusion for the $100 \mathrm{wt} \%$ nylon 66 was found to be $\sim 62.94 \mathrm{~J} / \mathrm{g}$. This value was used to calculate heat of fusion of nylon 66 in the composites as indicated by the solid and dashed lines in Figure 4-27. Figure 4-27 shows that heat of fusion values of the composites are essentially the same as those of nylon 66 with the exception of the composites at $14.79 \mathrm{wt} \%$ glass fiber with EP-g-MA rubber where the crystallinty of the composites seems to be suppressed. The thermal behavior of the rest of the composites suggests that the presence of both glass fibers and rubber in the composites has little effect on the crystallinity of nylon 66. It is interesting to mention here that for 


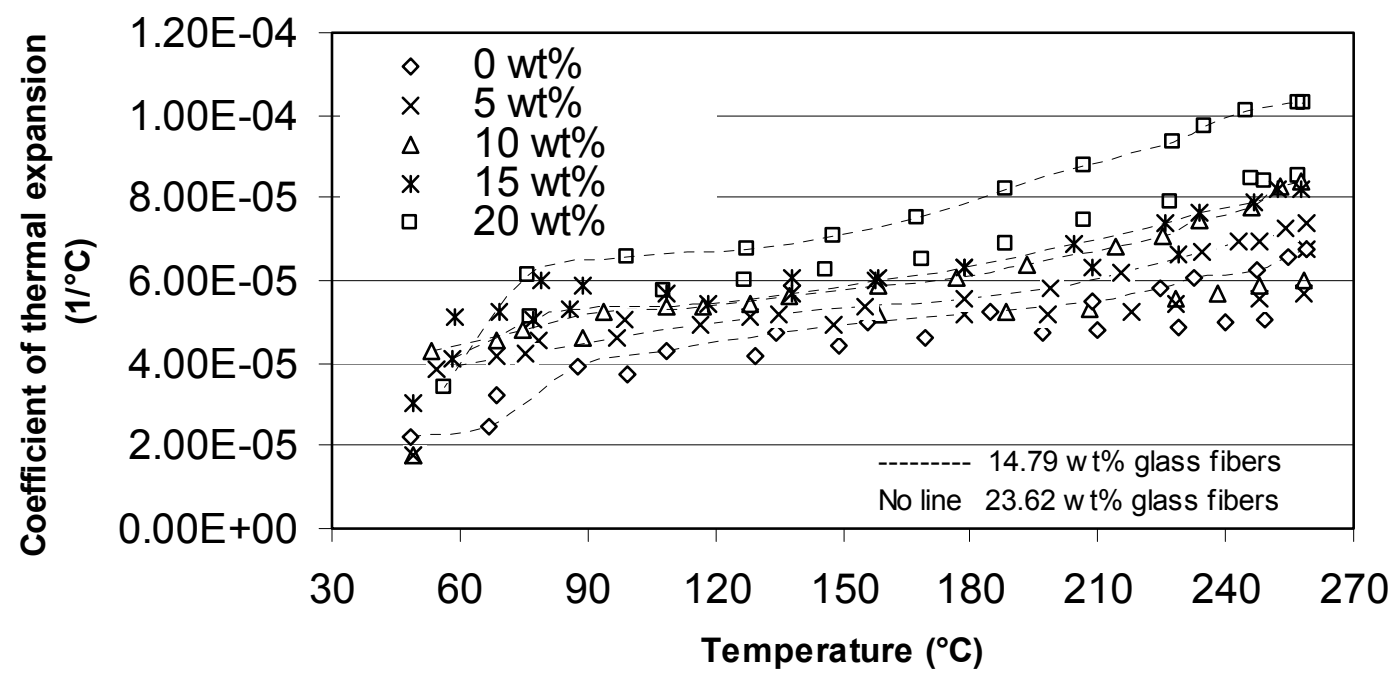

(a)

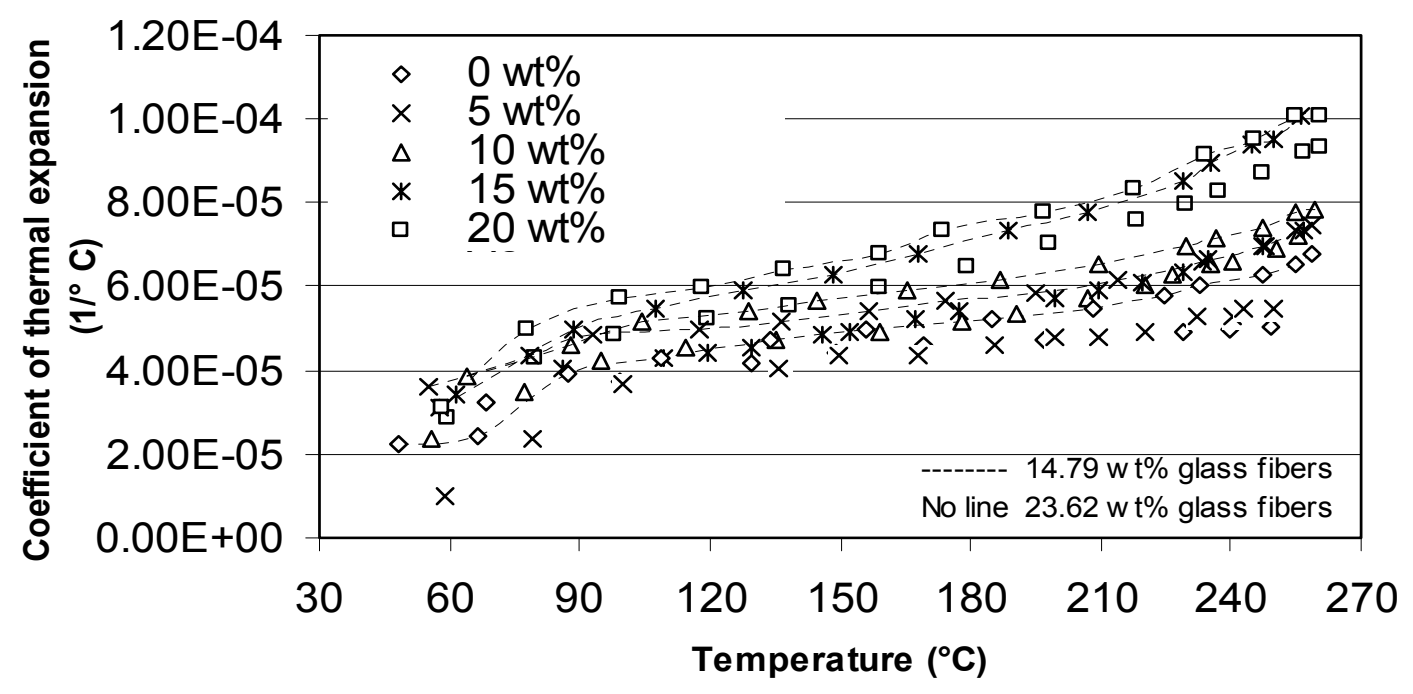

(b)

Figure 4-25 Coefficient of thermal expansion for various composites: (a) EP-g-MA, (b) SEBS-g-MA. 


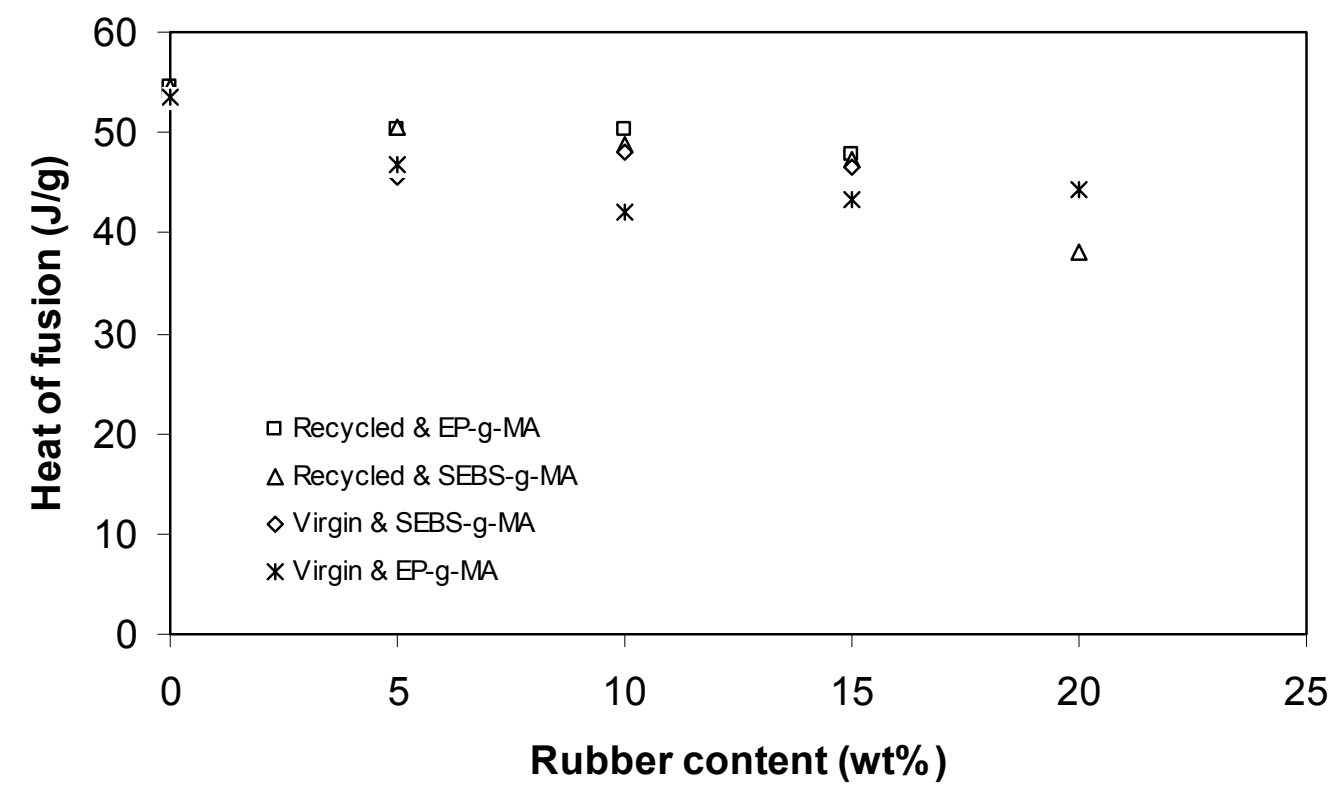

(a)

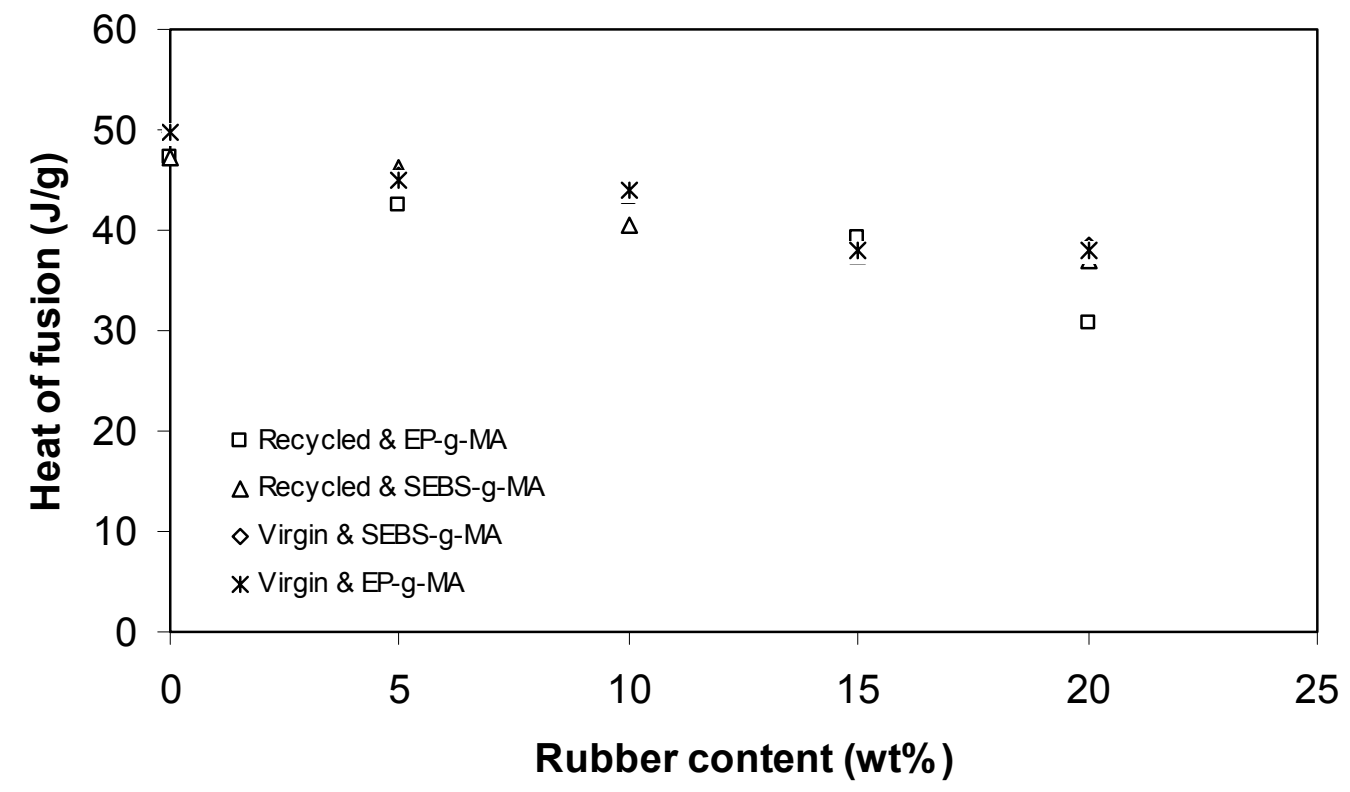

(b)

Figure 4-26 Heat of fusion of the composites at different rubber and glass fiber contents: (a) $14.79 \mathrm{wt} \%$, (b) $23.62 \mathrm{wt} \%$ glass fibers. 


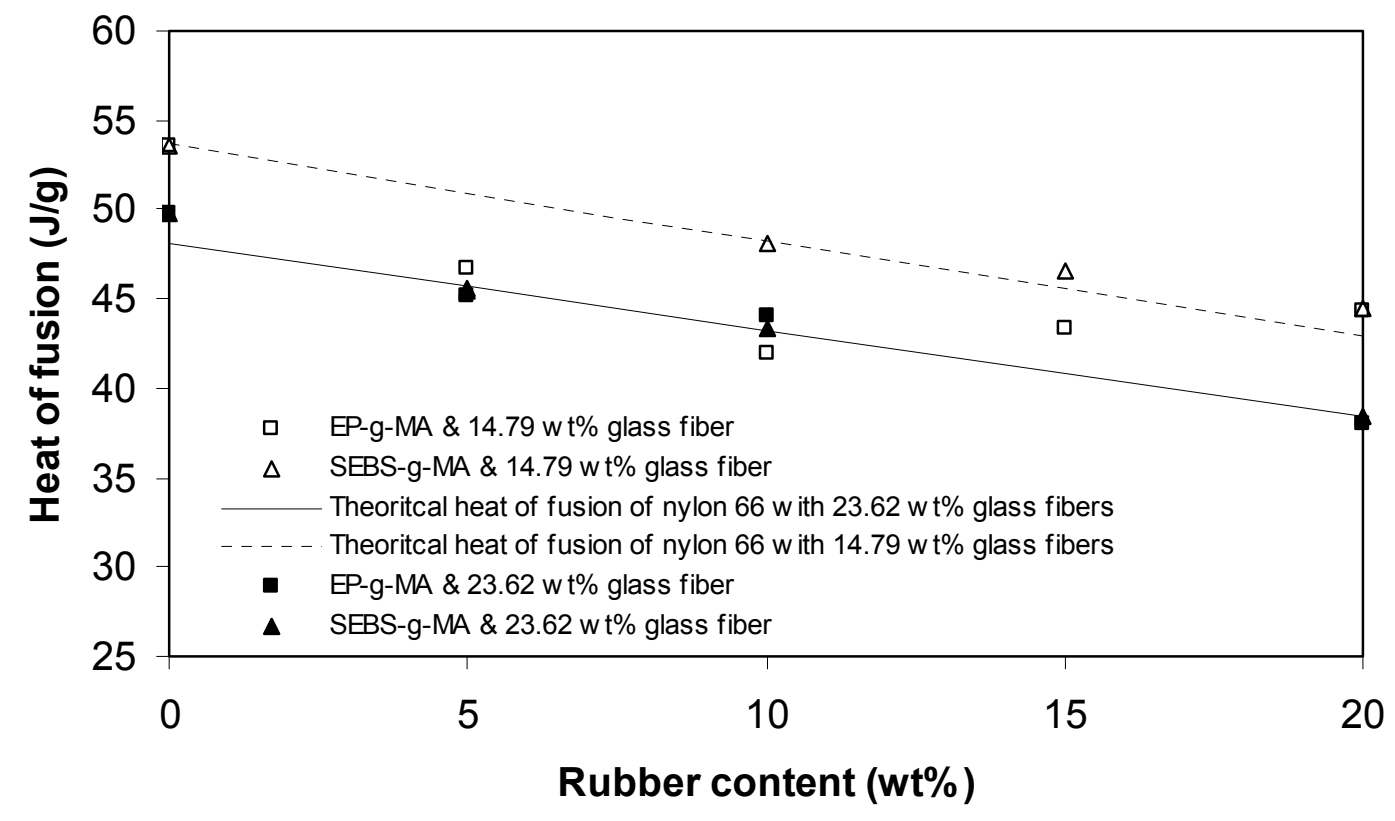

Figure 4-27 Effect of rubber and glass fiber on crystallinity of nylon 66.

unreinforced nylon 66 toughened by SEBS-g-MA, it has been reported that addition of 20 wt $\%$ of SEBS-g-MA to nylon 66 does not affect crystallinity of nylon 66 much [11]. In the case of fiber reinforced thermoplastics, as reported in Chapter 2, although Kevlar fibers have been found to increase crystallinity of nylon 66 by providing nucleating agents for crystal growth, glass fibers have no effect on the crystallinity of nylon 66 [23].

\subsection{Rheology of the composites}

Due to glass fiber content, polymer flow in both extruder and melt flow indexer was irregular. The surface of the strands was very rough and melt fracture was observed with some extrudates which exhibited a notable degree of brittleness. When examining the melt flow rate in the melt flow indexer, material did not flow even at $264^{\circ} \mathrm{C}$ and 8.06 $\mathrm{kg}$. However, at a temperature greater than $275^{\circ} \mathrm{C}$ the flow was smooth. In contrast with 
extrusion and melt flow index runs, samples made for tensile and impact tests by injection molding did not appear to have any defects. Instead, they possessed good ductility and surface smoothness.

\subsubsection{Melt flow index}

Melt flow index (MFI) is a measure of fluidity of a thermoplastic. MFI is usually reported as grams of polymer extruded through a die in 10 min at specified load and temperature conditions. In principle, MFI is inversely related to both viscosity and molecular weight of a polymeric material. Material would have high molecular weight if its MFI is low and vice versa. To reduce errors associated with measuring MFI and to see how much reduction in MFI would occur when incorporating rubber to glass fiber reinforced nylon 66, ratio of MFI of the composites to that of nylon 66 (Zytel 101L) is shown in Figures 4-28 and 4-29. The temperature used to measure MFI of the composites is $275^{\circ} \mathrm{C}$ which is same temperature used during extrusion and injection molding. It can be seen from Figures 4-28 and 4-29 that rubber-toughened recycled glass-fiber-reinforced nylon 66 has greater MFI than that of the virgin composites. It is also clear that there is a drastic reduction in MFI when rubber content increases at fixed glass fiber loading. At high glass fiber and rubber contents the difference in MFI between recycled and virgin composites becomes smaller. Also a difference has been noticed, at lower rubber contents, between the MFI of the only extruded composites and that for composites prepared by extrusion followed by injection molding as indicated by Figures 4-28 and 429. This difference in MFI may be attributed to fiber length attrition caused by extrusion and injection molding. composites prepared by extrusion followed by injection molding 


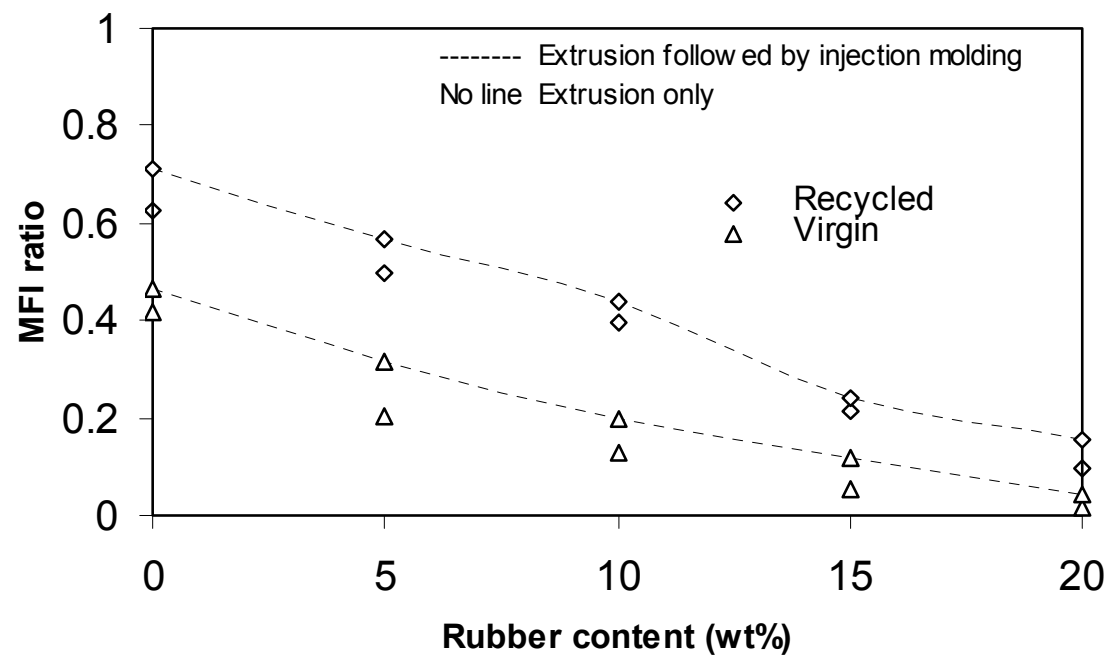

(a)

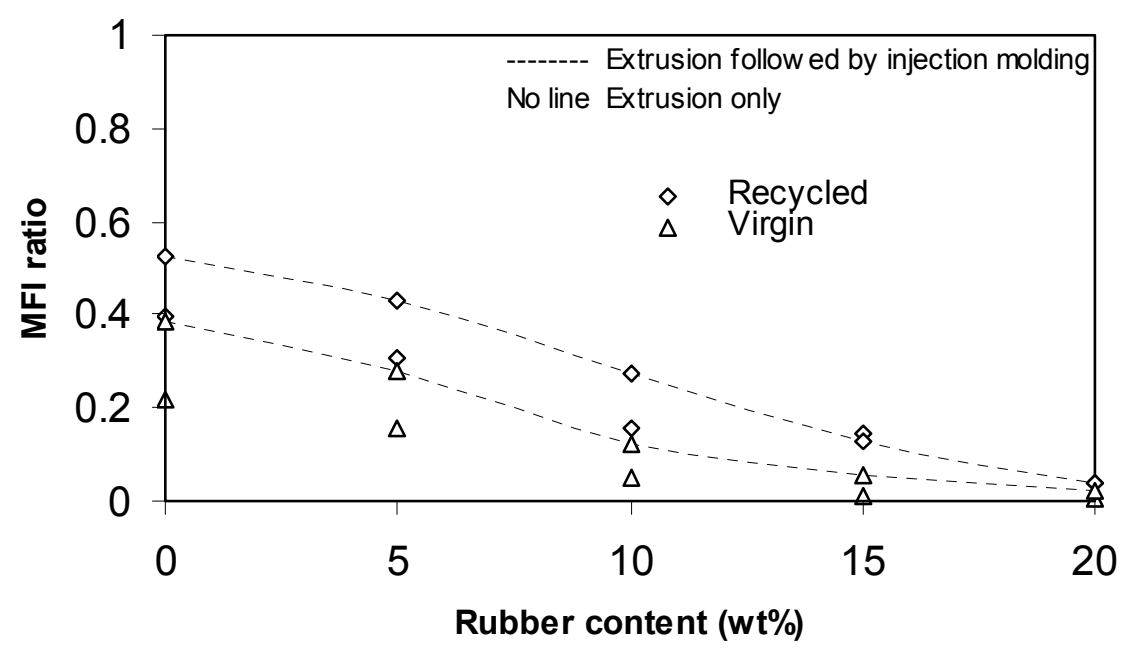

(b)

Figure 4-28 Melt flow rate for the composites vs. EP-g-MA rubber content at different glass fiber loadings: (a) $14.79 \mathrm{wt} \%$, (b) $23.62 \mathrm{wt} \%$. 


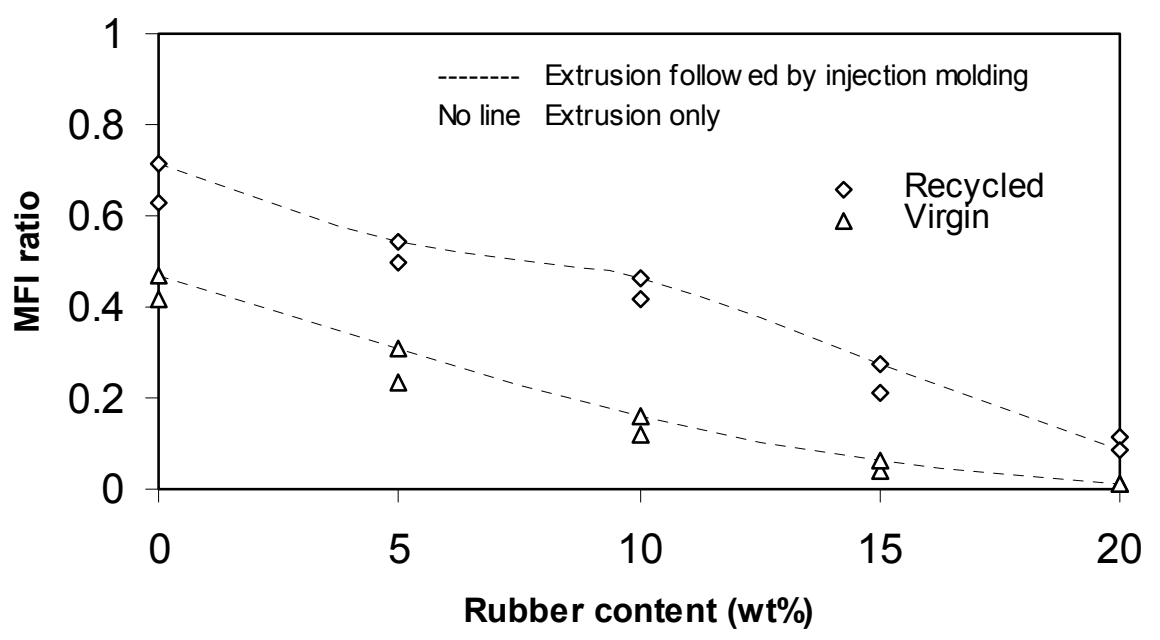

(a)

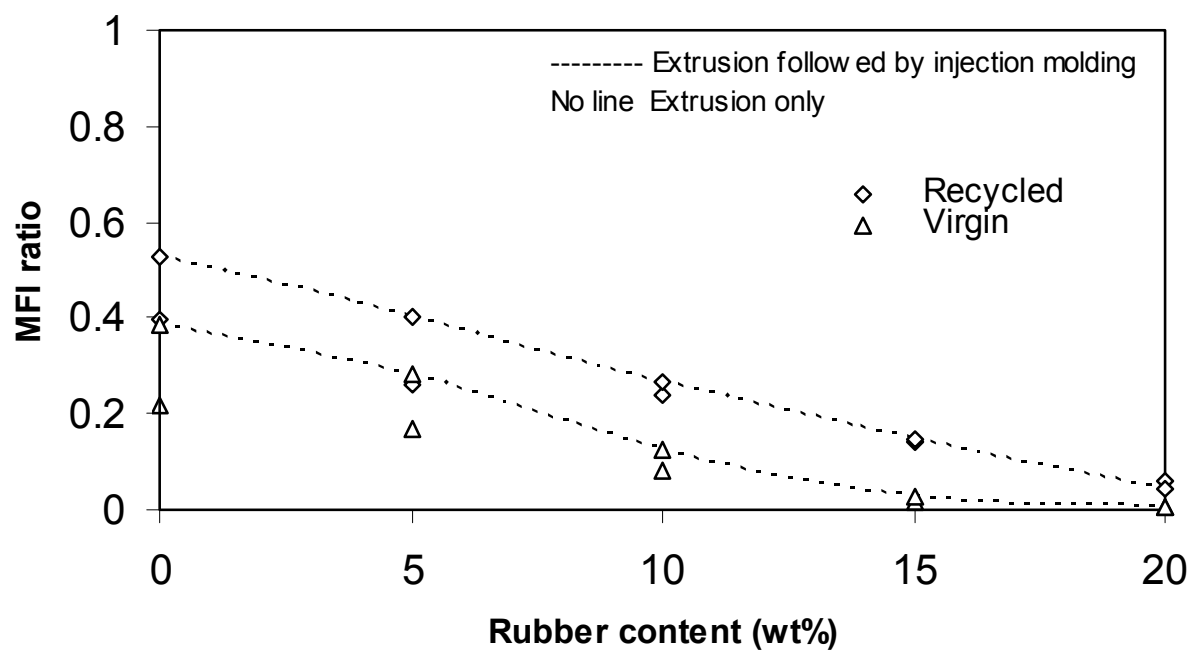

(b)

Figure 4-29 Melt flow rate for the composites vs. SEBS-g-MA rubber content at different glass fiber loadings: (a) $14.79 \mathrm{wt} \%$, (b) $23.62 \mathrm{wt} \%$. 
have smaller glass fiber lengths when compared to those composites prepared by only extrusion (see Tables 4-2 and 4-3).

\subsubsection{Viscosity and shear modulus of the composites}

Figures 4-30 and 4-31 show variations of dynamic viscosities against circular frequency for both recycled and virgin glass-fiber-reinforced nylon 66 toughened with SEBS-g-MA and EP-g-MA. Recycled composites showed lower viscosity than that of virgin composites. This reduction in viscosities of recycled composites is essentially attributed to reduction in molecular weight of recycled nylon 66. Composites with high glass fiber and rubber contents have the highest viscosities. Shear thinning is observed for all composites at high deformation rates. Since the major (matrix) component in all composites is nylon 66 which is a low molecular weight polymer, a Newtonian plateau at low shear rate is observed for all composites except at high glass fiber content. Viscosity vs. temperature relationship for nylon 66 (Zytel $101 \mathrm{~L}$ ) used in this study is given by the following relation:

$\eta=(1 / 126.87) \exp [6500 /(T+273)]$

Where $\mathrm{T}$ is in ${ }^{\circ} \mathrm{C}$. Letting $\mathrm{T}=275^{\circ} \mathrm{C}$, the temperature used in this study, in Eq. 4-7, the viscosity of nylon 66 obtained is $1.117 \times 10^{3}$ poise (p). This value of viscosity is small when compared with blend viscosities at low shear rate in Figures 4-30 and 4-31. The zero shear viscosity, $\eta_{0}$, is an important property in polymer processing. It is the viscosity 


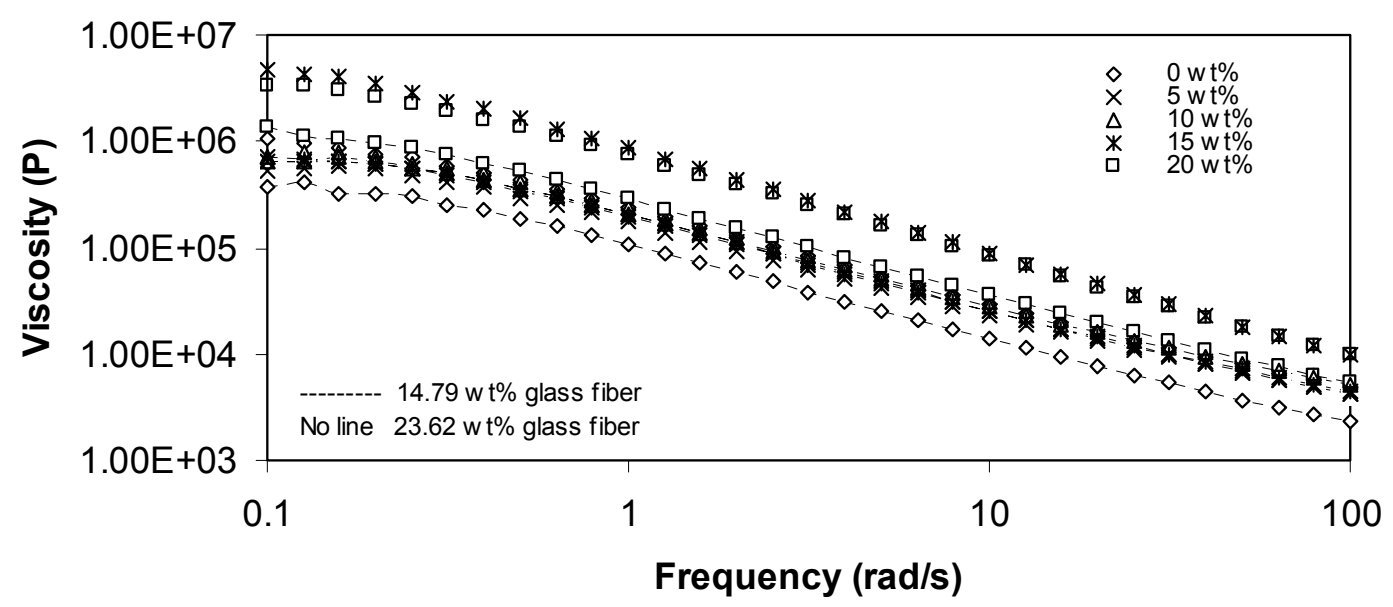

(a)

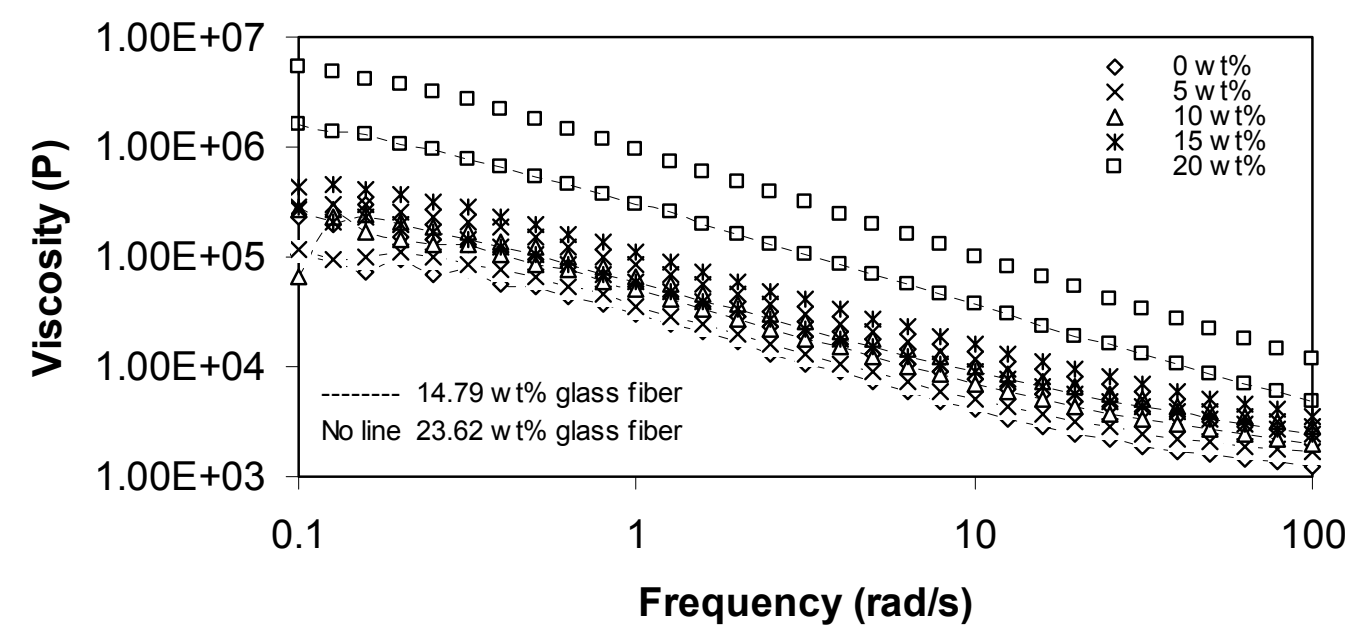

(b)

Figure 4-30 Flow behavior of the glass-fiber-reinforced nylon 66 toughened by different weight percent of SEBE-g-MA: (a) Virgin, (b) Recycled. 


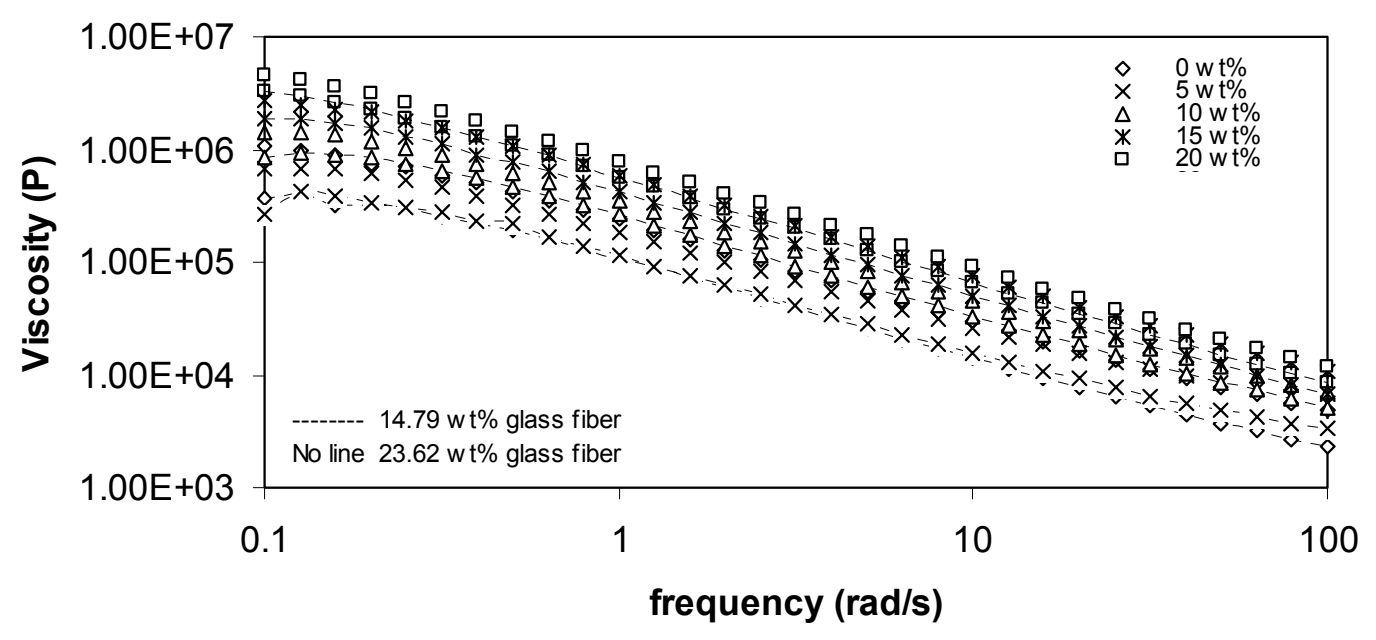

(a)

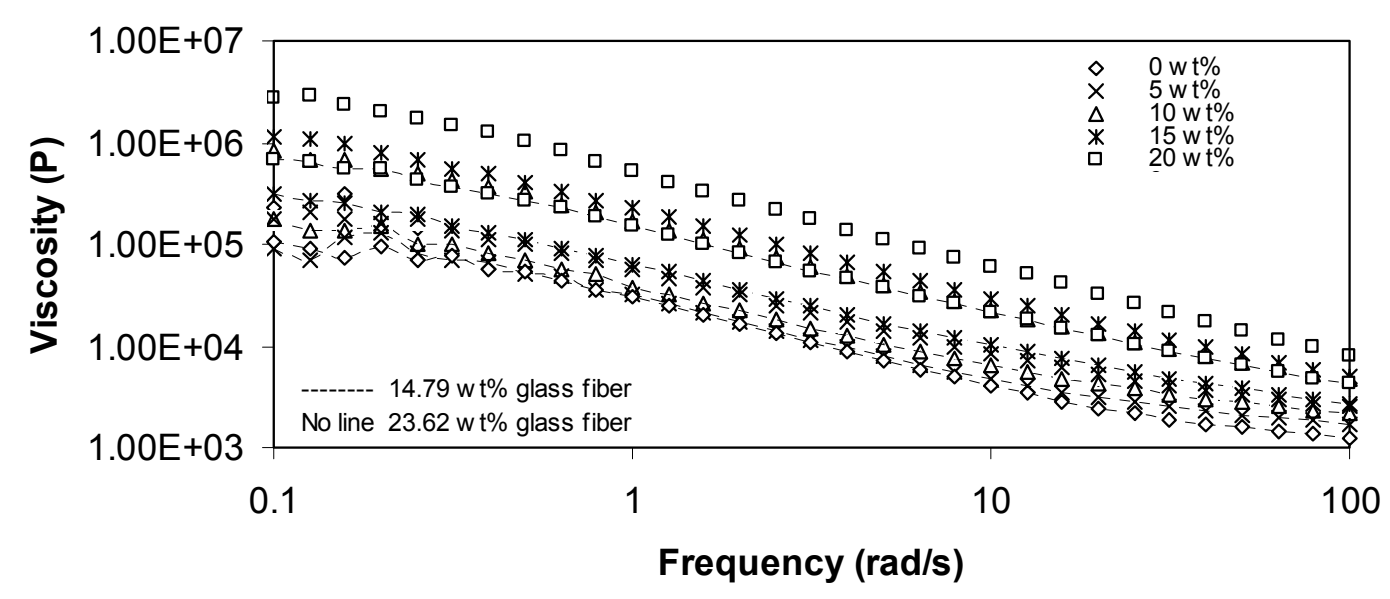

(b)

Figure 4-31 Flow behavior of the glass-fiber-reinforced nylon 66 toughened by different weight percent of EP-g-MA: (a) Virgin, (b) Recycled. 
of a polymer melt when approaching zero shear rate. $\eta_{0}$ of the composites has been estimated by fitting the experimental data to the viscosity-shear rate relationship developed by Carreau (see appendix A for the fitting results). The Carreau model is given by the following relation:

$\left(\eta-\eta_{\infty}\right) /\left(\eta_{0}-\eta_{\infty}\right)=\left[1+(\beta \gamma)^{2}\right]^{(\mathrm{n}-1) / 2}$

Where

$\gamma \quad$ is shear rate

$\eta_{\infty} \quad$ is viscosity at high shear rate

$\eta_{0} \quad$ is viscosity at very low shear rate

$\beta \quad$ is a time constant for the material. It determines the shear rate at which the transition occurs from the zero-shear rate plateau to the power law portion and from power law to high-shear rate plateau $\left(\eta=\eta_{\infty}\right)$

$\mathrm{n} \quad$ is a parameter describes the slope of the rapidly decreasing portion of the viscosity

For a miscible polymer blend system, the viscosity may be predicted by a log additive rule. Generally, polymers tend to deviate from the log additive rule either positively or negatively or both depending on the degree of miscibility between the phases. The log additive rule is given by the following relation [93] 
$\log \eta_{b}=\sum c_{j} \log \eta_{j}$

where
$\eta_{\mathrm{b}}$
is blend viscosity
$c_{j}$ and $\eta_{j}$
are weight fraction and viscosity of the $\mathrm{j}$-th component respectively

Log zero-shear viscosity is plotted against rubber content in Figures 4-32 and 4-33. In the same graphs the behavior expected by the log additive rule is also plotted for comparison. Taking the relative viscosity for SEBS-g-MA and EP-g-MA with respect to nylon 66 to be 0.7 and 6.19 respectively [11] with viscosity of matrix phase being the viscosity of the glass-fiber-reinforced nylon 66 with $0 \mathrm{wt} \%$ of rubber, the dependence of viscosity of the composites in accordance to the $\log$ additive rule has been calculated. Figures 4-32 and 433 clearly show that the composite of glass-fiber- reinforced nylon 66 with EP-g-MA rubber behavior in accordance with the log additive rule up to $5 \mathrm{wt} \%$ of rubber content only. Beyond this concentration a large positive deviation from the log additive rule is observed which indicates an increase in viscosity of the composites. The composites with SEBS-g-MA which are much less viscous than EP-g-MA show two different behaviors. At high glass fiber content, the composites viscosity shows a negative deviation from the $\log$ additive rule for up to $10 \mathrm{wt} \%$ of rubber and then an inversion occurs from negative to positive deviation. On the other hand, at the lower glass fiber content (see Figure 4-32 a) viscosity of the composites shows a positive deviation at all rubber contents. The increase in the zero shear viscosities of the blends which has been underestimated by the $\log$ additive rule may be an indication of physical interaction between the glass fiber phase and the polymer phases. Another possible reason is that the chemical reaction 


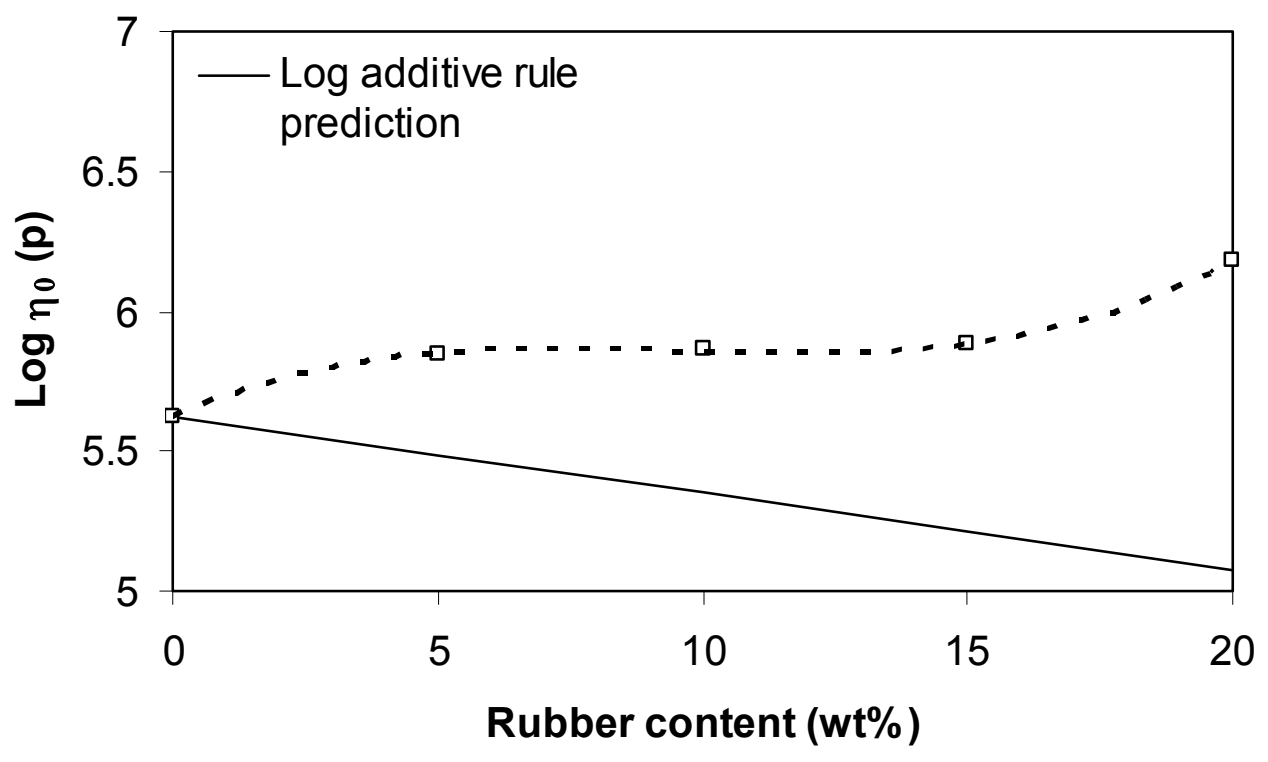

(a)

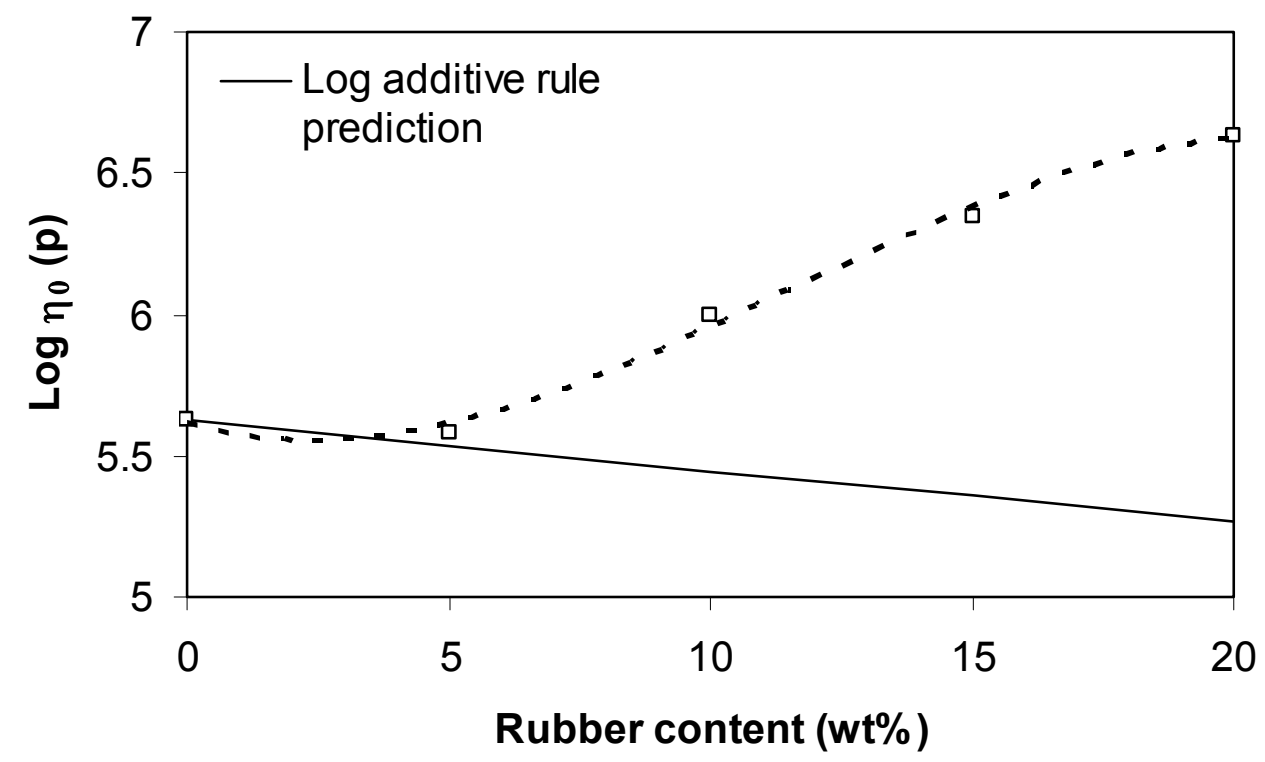

(b)

Figure 4-32 Variation of zero shear viscosity for the virgin composites against rubber weight percent at $14.79 \mathrm{wt} \%$ glass fibers with (a) SEBS-g-MA and (b) EP-g-MA. 


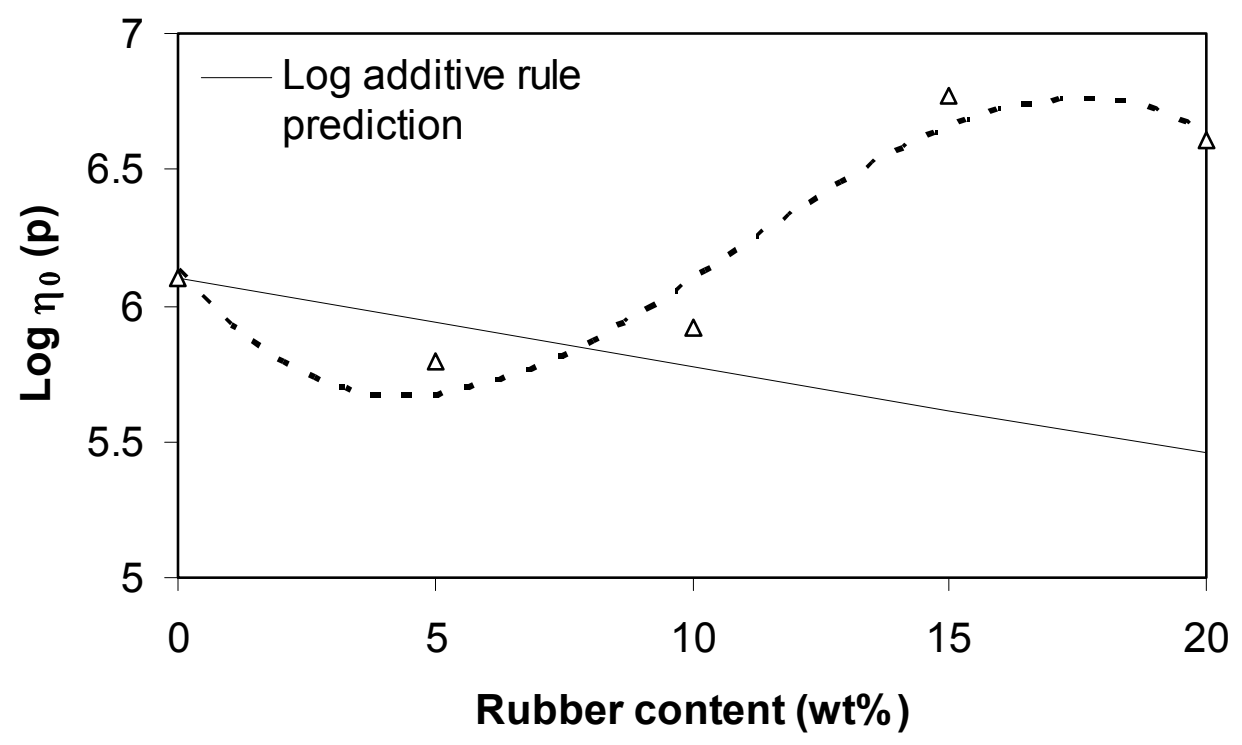

(a)

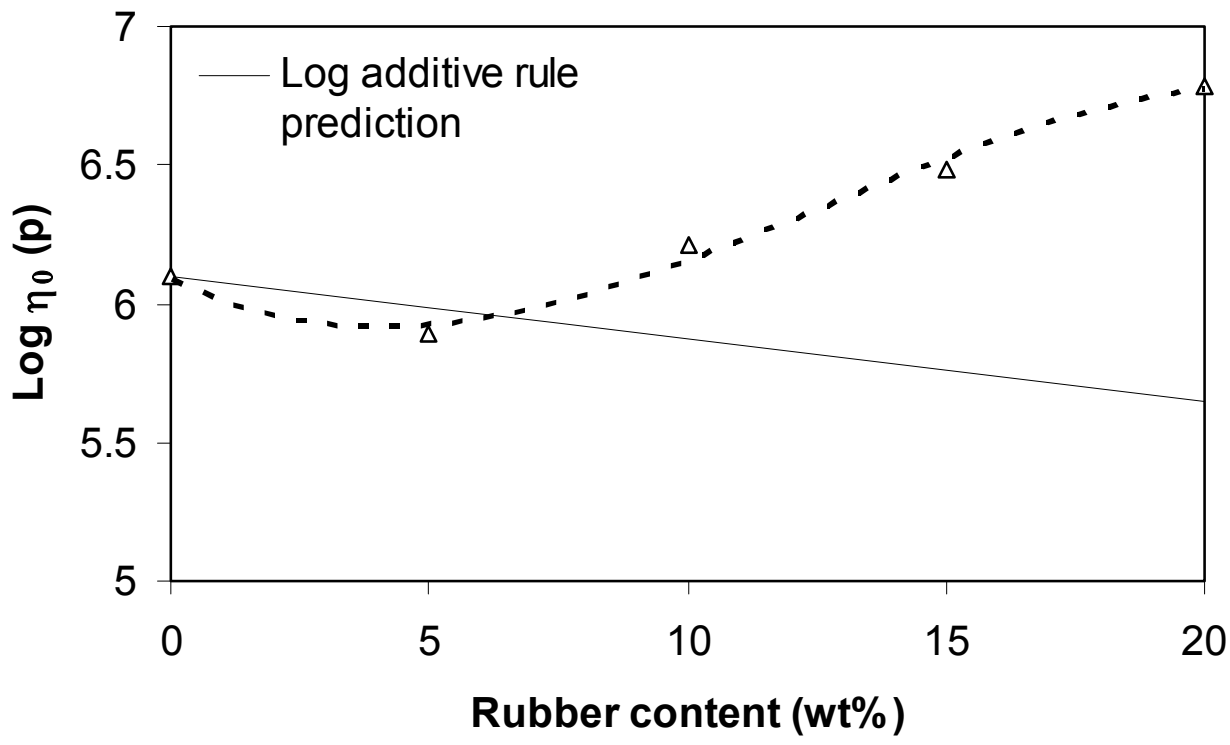

(b)

Figure 4-33 Variation of zero shear viscosity for the virgin composites against rubber weight percent at $23.62 \mathrm{wt} \%$ glass fibers with (a) SEBS-g-MA and (b) EP-g-MA. 
between maleic anhydride group in the rubber and nylon 66 results in an increase in molecular weight which essentially means an increase in viscosity of the composites. Note that the increase in viscosity takes place at high rubber content $(>5 \mathrm{wt} \%)$ as indicated by Figures 4-32 and 4-33.

Shear storage $(G)$ and loss $\left(G^{\prime \prime}\right)$ moduli for the composites have been measured against dynamic shear rate (frequency) as shown in Figures 4-34 through 4-37. The storage modulus which represents energy stored due to elasticity increases with both glass fiber and rubber content; however, it is noticed that in general the variation of G' with frequency is almost flat especially at high glass fiber and rubber content. Perhaps, the flatness in storage modulus of the composites when shear rate is increased is due to the presence of the glass fibers in the composites. Since glass fiber has a high modulus of elasticity, it will dominate the overall storage modulus of the composite. The modulus of elasticity of glass fiber is not expected to be dependent on shear rate. The higher values of $\mathrm{G}^{\prime}$ were observed at high content of glass fiber and rubber (i.e. $23.62 \mathrm{wt} \%$ and $20 \mathrm{wt} \%$ respectively). Recycled glass-fiber-reinforced nylon 66 toughened with both SEBS-g-MA and EP-g-MA exhibited lower values of $\mathrm{G}^{\prime}$ than those of virgin composites with the exception at high glass fiber and rubber content. The shear loss modulus (G") showed different shear rate dependence behavior in contrast with shear storage modulus. G" which represents energy dissipation when polymer deforms increases rapidly with increasing shear rate. Here, unlike the case with storage modulus, glass fibers will not be expected to play a major role since the loss modulus measures the response of viscosity rather than elasticity. This explains the great dependence of the loss modulus, which is dominated by matrix properties, on shear rate. The values of $\mathrm{G}^{\prime \prime}$ increase with increasing 


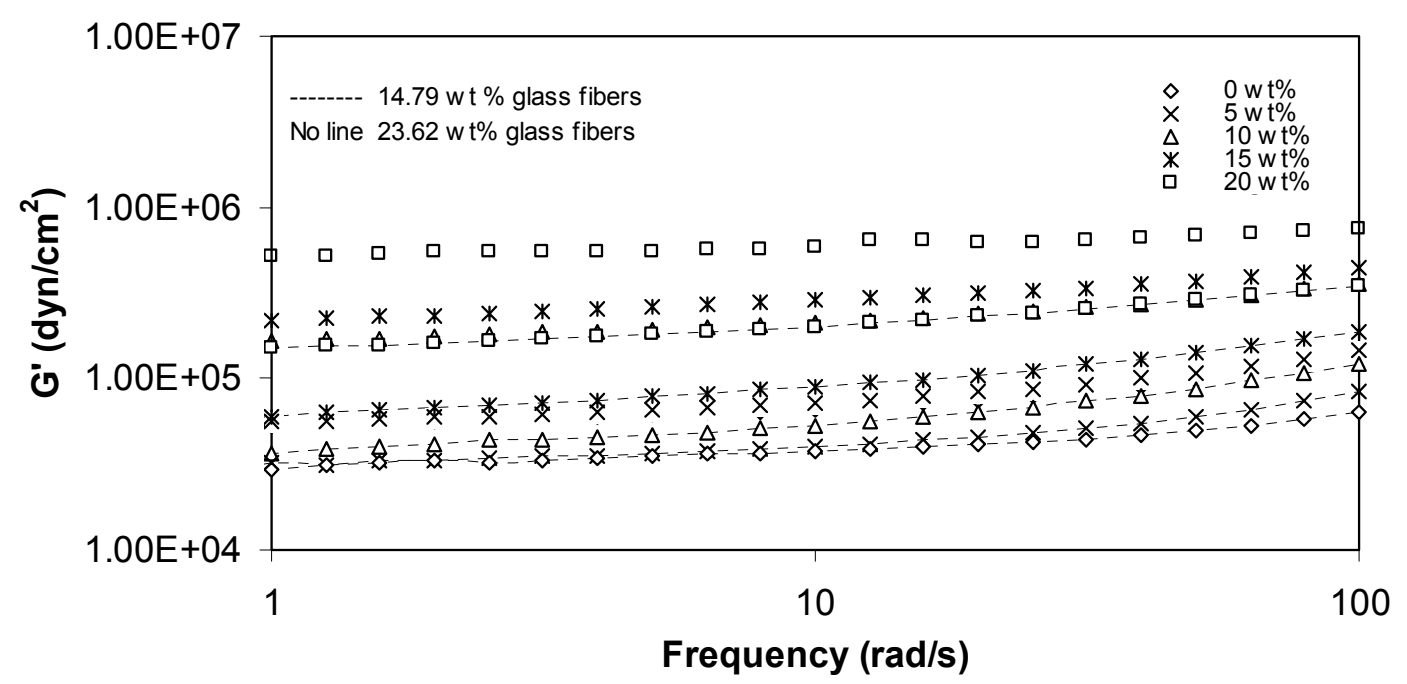

(a)

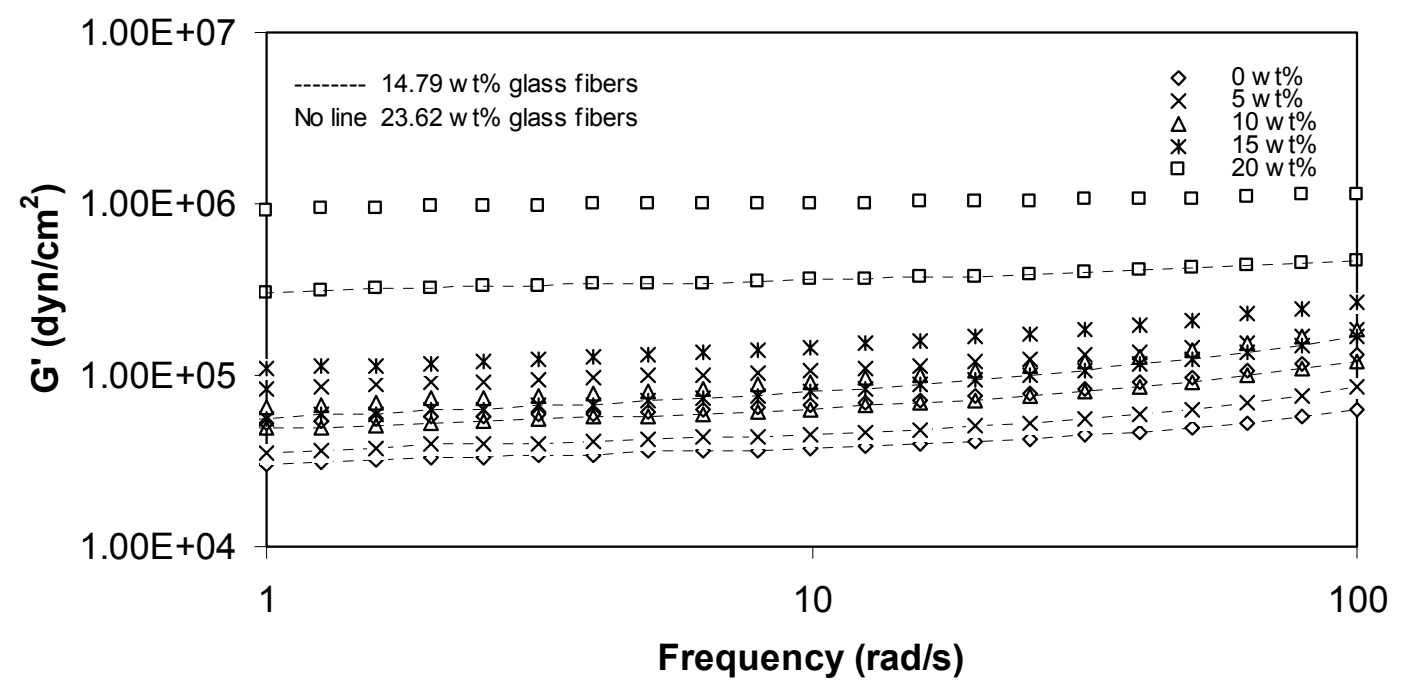

(b)

Figure 4-34 Storage modulus for recycled composites at different rubber contents: (a) EPg-MA, (b) SEBS-g-MA. $\left(\mathrm{T}=275^{\circ} \mathrm{C}\right)$ 


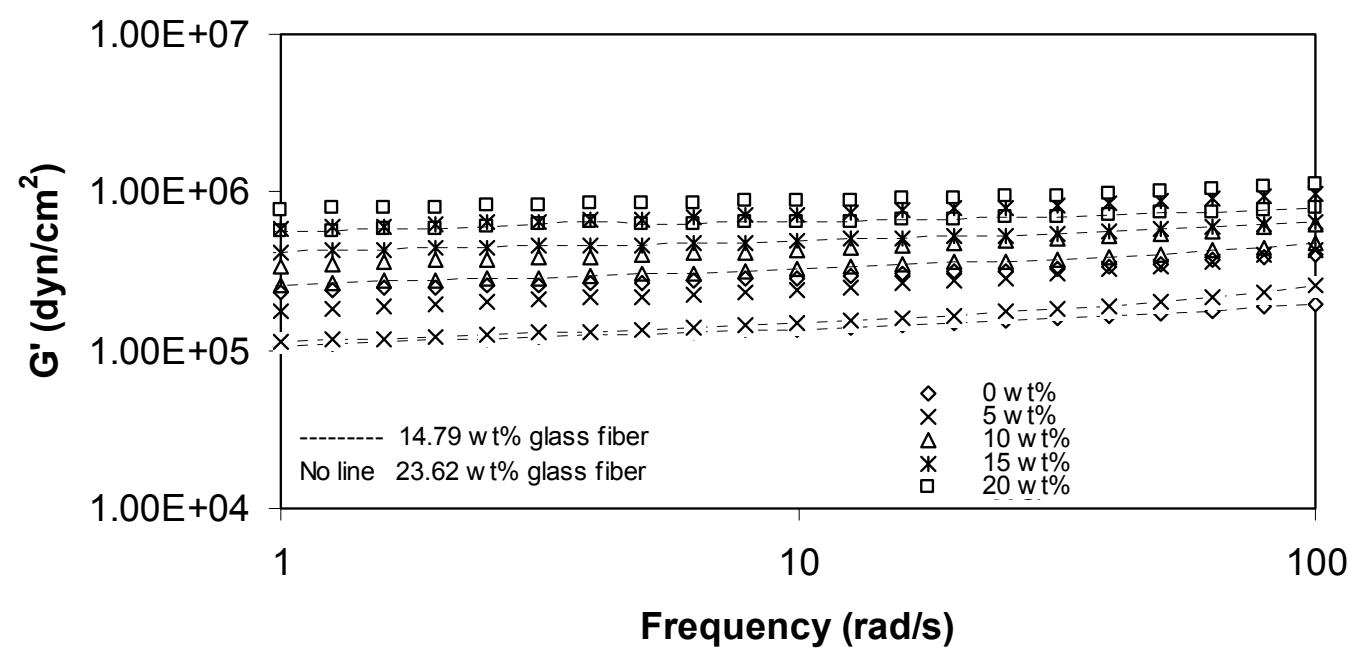

(a)

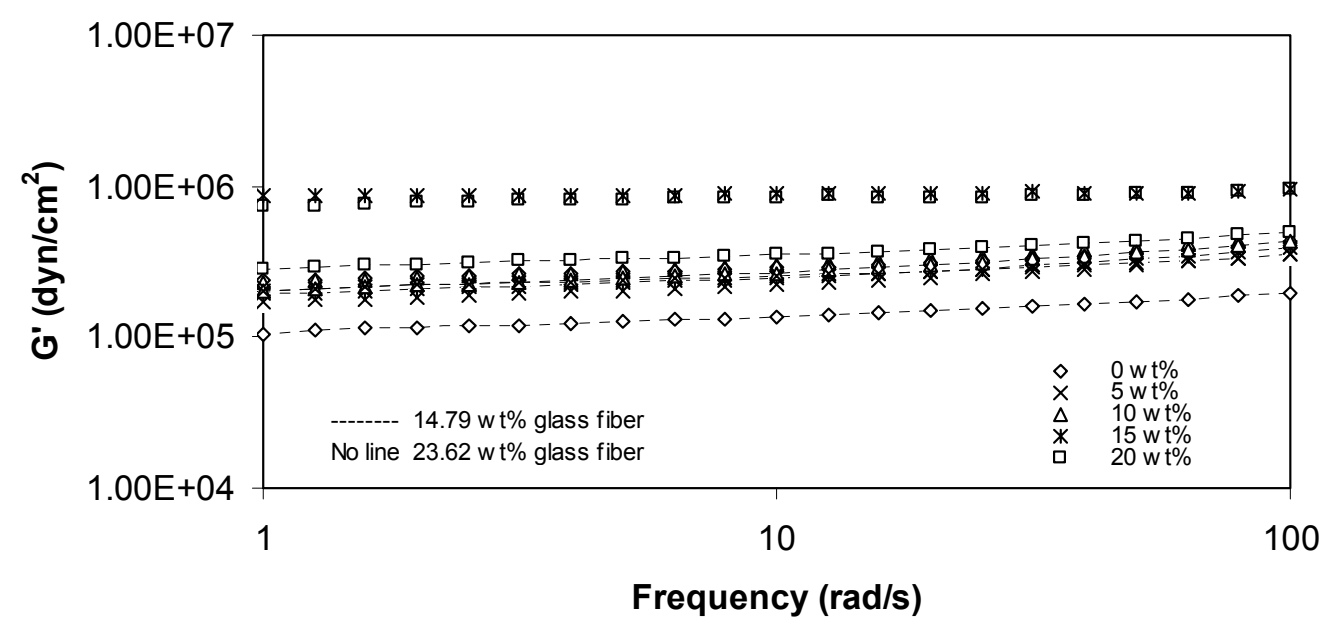

(b)

Figure 4-35 Storage modulus for virgin composites at different rubber contents: (a) EP-gMA, (b) SEBS-g-MA. $\left(T=275^{\circ} \mathrm{C}\right)$ 


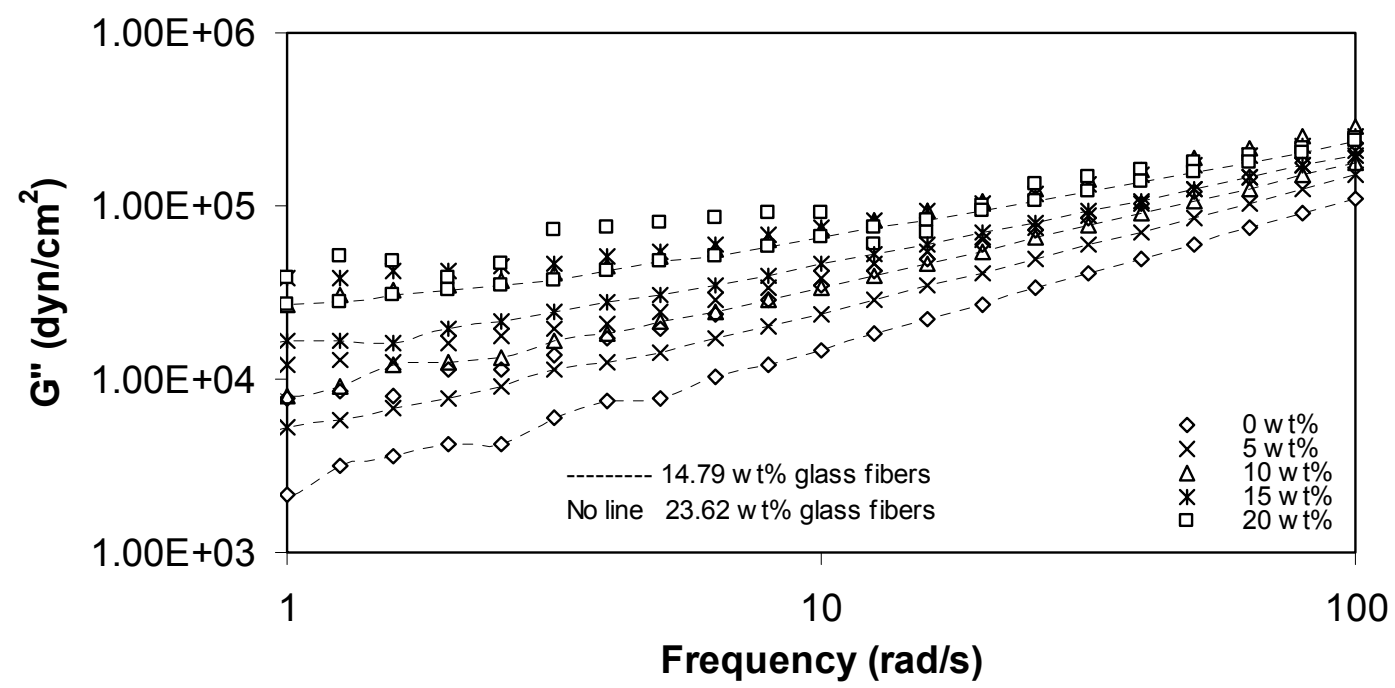

(a)

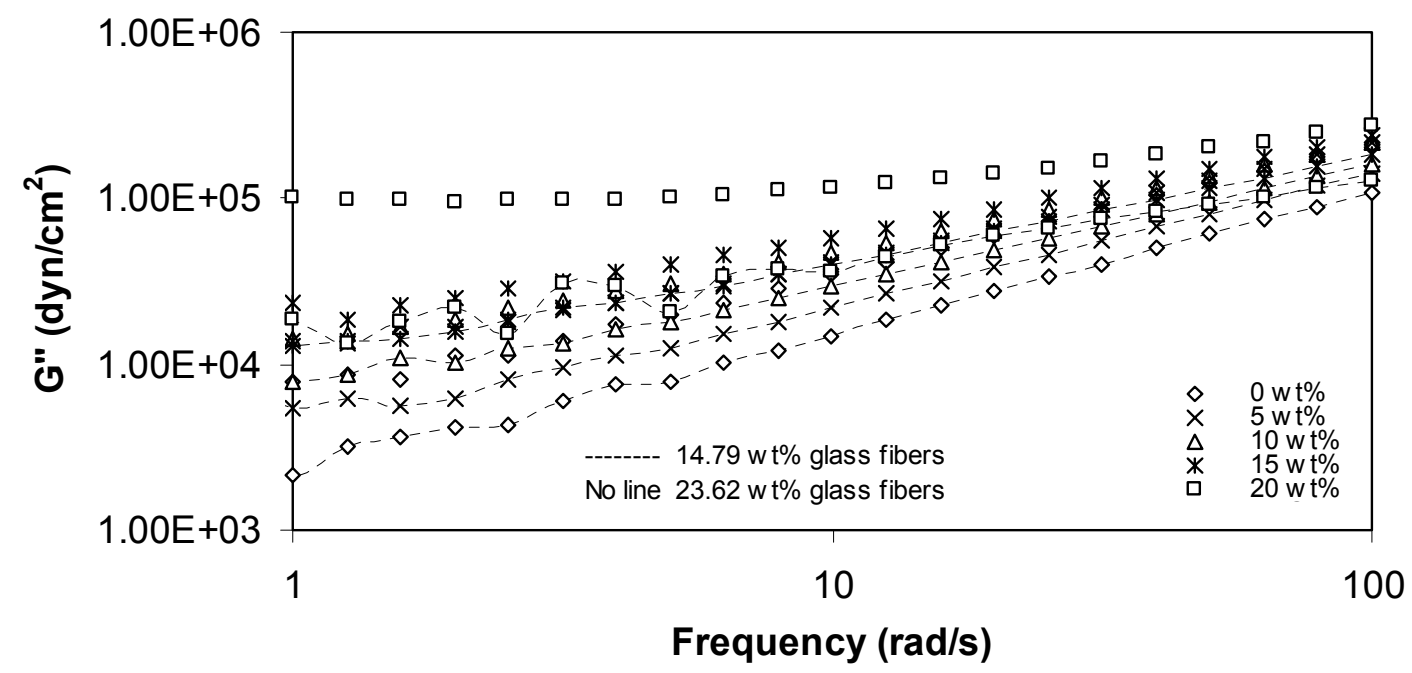

(b)

Figure 4-36 Loss modulus for recycled composites at different rubber contents: (a) EP-gMA, (b) SEBS-g-MA. $\left(T=275^{\circ} \mathrm{C}\right)$ 


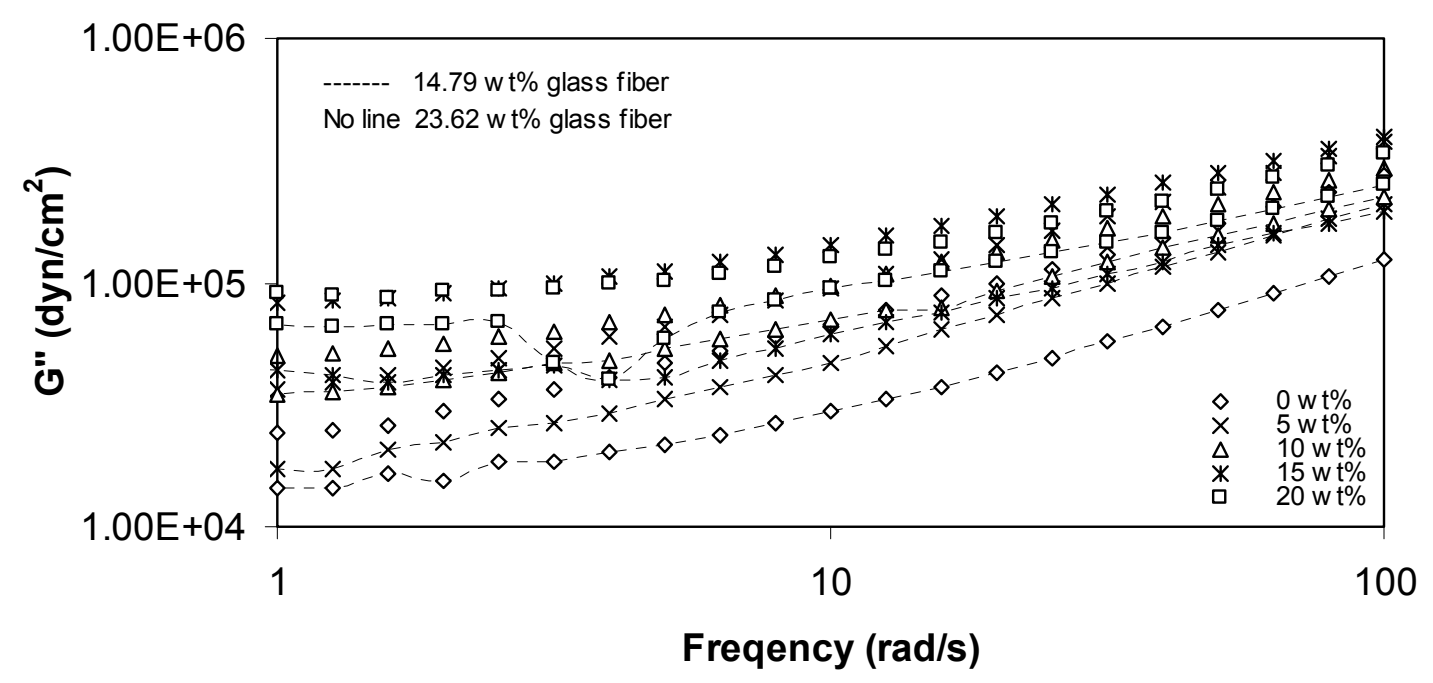

(a)

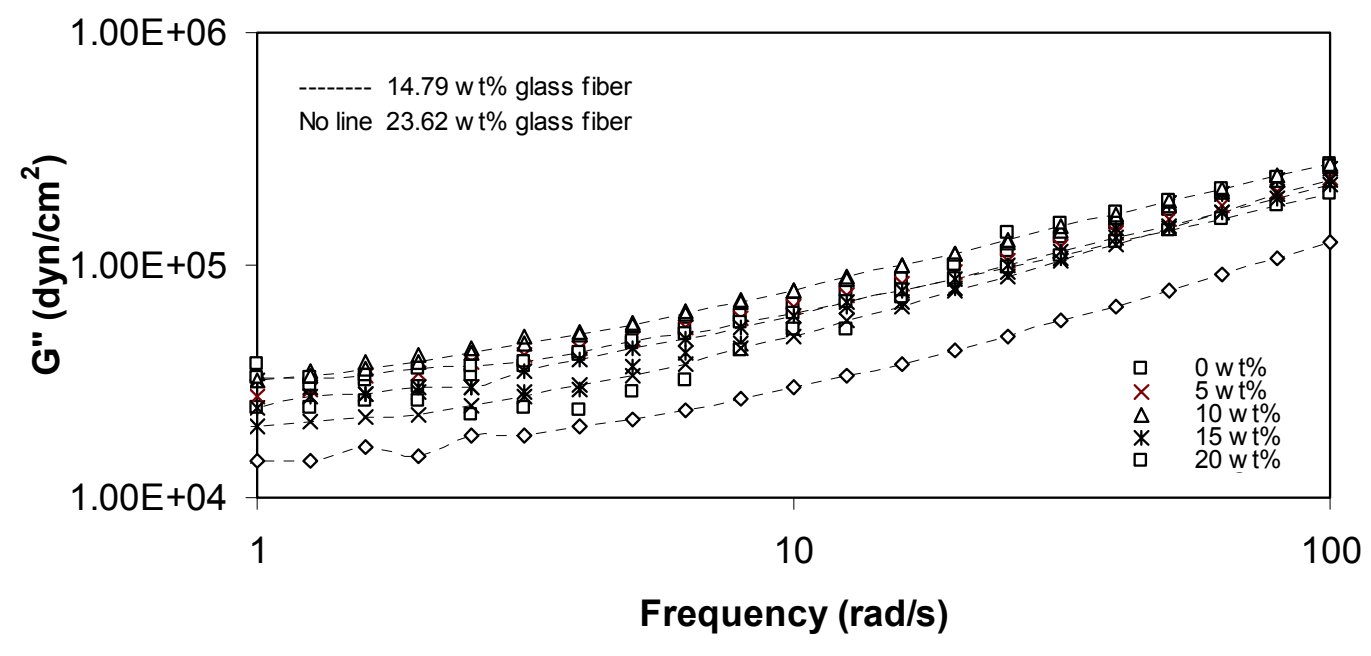

(b)

Figure 4-37 Loss modulus for virgin composites at different rubber content: (a) EP-gMA, (b) SEBS-g-MA. $\left(T=275^{\circ} \mathrm{C}\right)$ 
rubber content at both glass fiber loadings. Similar to what has been observed with values of $\mathrm{G}^{\prime}$, values of $\mathrm{G}^{\prime \prime}$ for recycled composites were less than those of virgin composites. When storage shear modulus is measured against temperature, the modulus goes through a transition at an important property of the material that is the glass transition temperature $\mathrm{T}_{\mathrm{g}}$. For the current study, the variations of shear storage modulus with temperature for glass-fiber-reinforced nylon 66 toughened with SEBS-g-MA and EP-g-MA rubbers at two glass fiber loadings are shown in Figures 4-38 and 4-39. As indicated by these Figures, addition of rubber to glass fiber reinforced nylon 66 causes a reduction in $\mathrm{G}^{\prime}$ as temperature increases. Going from low to high glass fiber contents does not seem to affect values of $G^{\prime}$. The change in $G^{\prime}$ at $T_{g}$ has been observed for all composites. Composites toughened with EP-g-MA have a different behavior at high rubber content (i.e. $\geq 10 \mathrm{wt} \%$ ) than that of composites toughened with SEBS-g-MA. These composites of glass-fiber-reinforced nylon 66 with EP-g-MA at high rubber content exhibit two plateau regions. The temperature at which the transition in $G^{\prime}$ occurs decreases with increasing rubber content. 


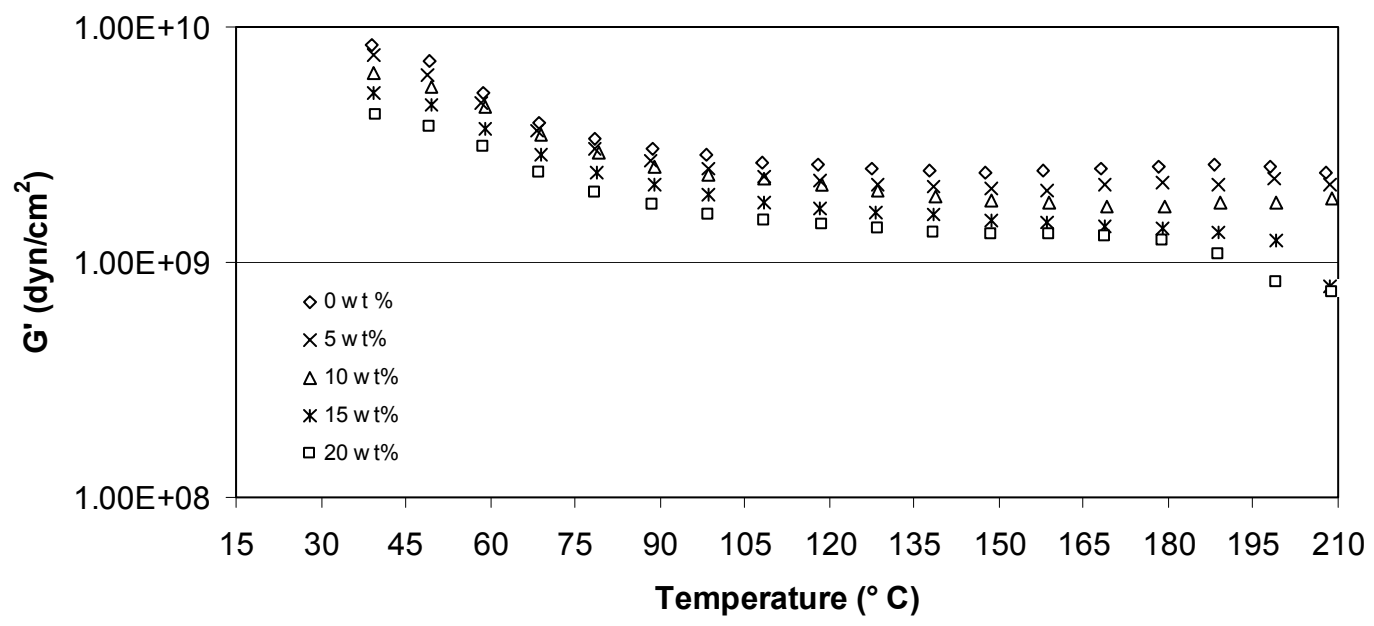

(a)

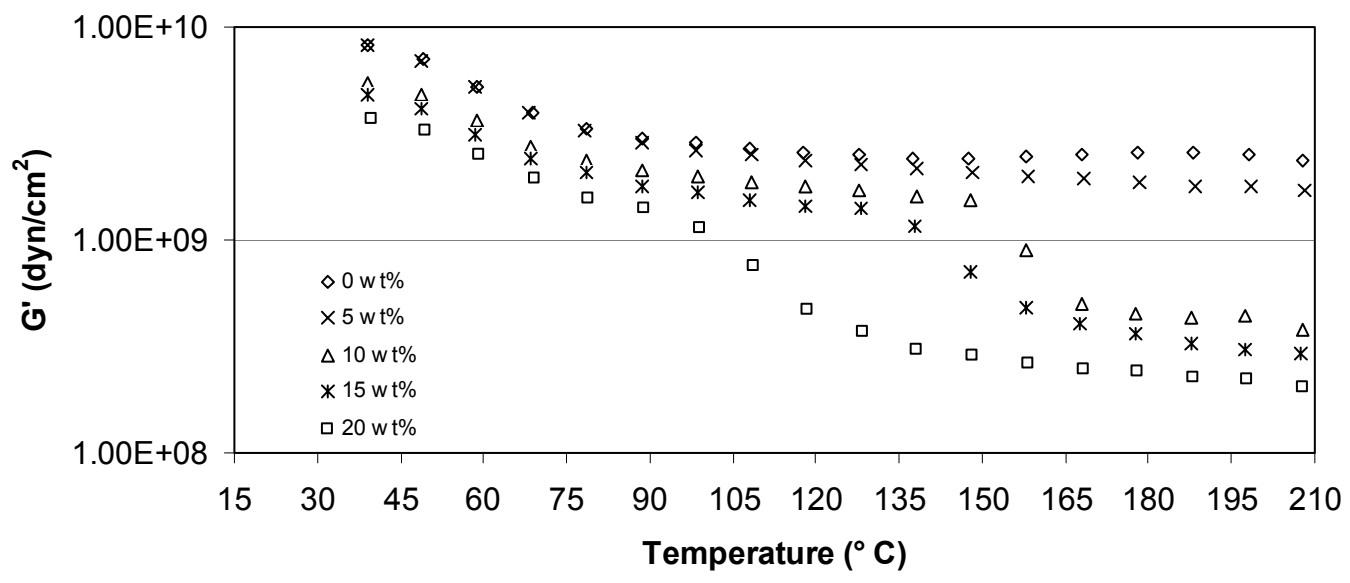

(b)

Figure 4-38 Storage modulus vs. temperature for virgin composites with $14.79 \mathrm{wt} \%$ glass fiber content and different rubber weight percents: (a) SEBS-g-MA, (b) EP-g-MA. 


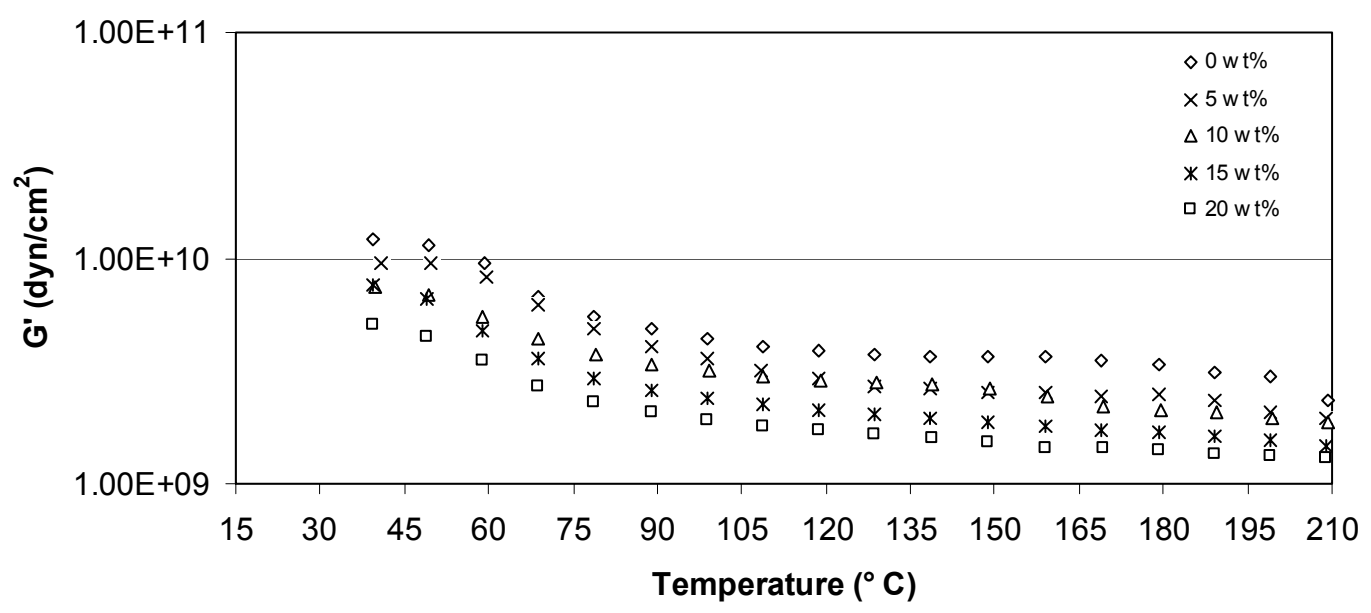

(a)

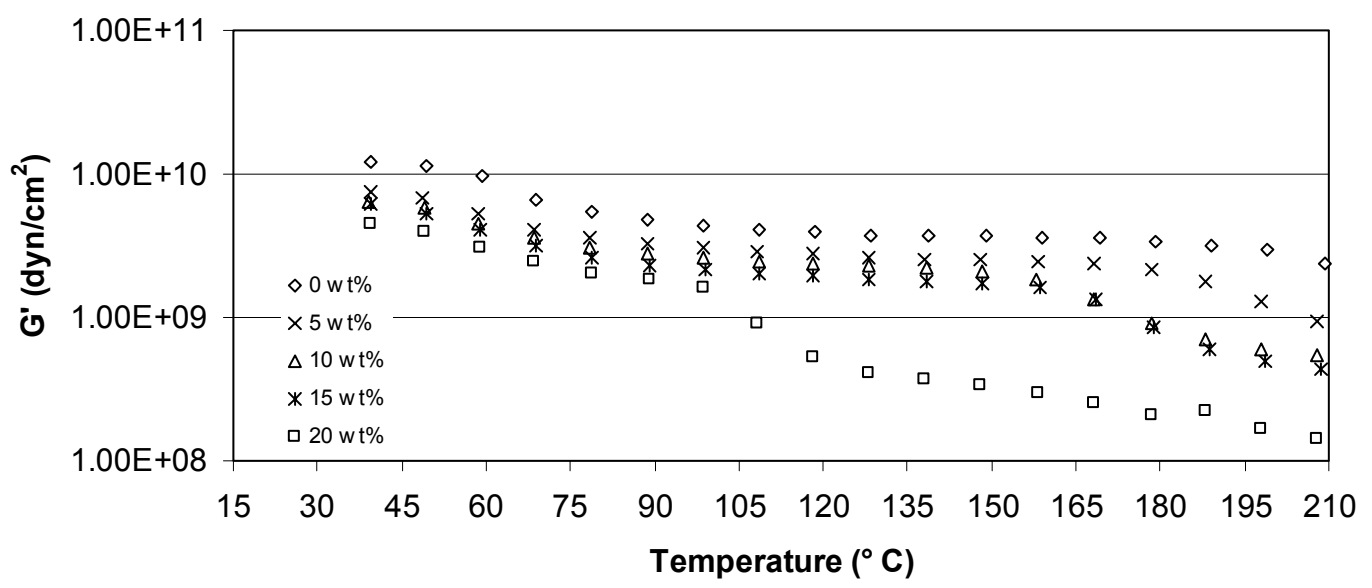

(b)

Figure 4-39 Storage modulus vs. temperature for virgin composites with $23.62 \mathrm{wt} \%$ glass fiber content and different rubber weight percents: (a) SEBS-g-MA, (b) EP-g-MA. 


\section{Chapter 5}

\section{Conclusions and recommendations}

\subsection{Conclusions}

This research has demonstrated the effect of incorporating a ductile rubber phase, i.e. SEBS-g-MA and EP-g-MA, into a semi brittle material, i.e. nylon 66, reinforced with glass fibers on its properties. The approach of combining both reinforcement and tougheners with a thermoplastic is the appropriate way to balance strength and toughness of the material. The results of the current research have shown that both rubbers, i.e. SEBS-g-MA and EP-g-MA, were effective in toughening recycled and virgin glass-fiberreinforced nylon 66. Characterization of the post industrial glass-fiber-reinforced nylon 66 separated from other thermoplastic materials such as PE showed that it had a reasonable molecular weight $(\sim 15,000)$ which is commonly used for injection molding purposes. This was expected since nylon has good melt stability and can retain its molecular weight even after several melting cycles as long as moisture is properly controlled [2]. Mechanical properties of the recycled nylon 66 were comparable to those of the virgin nylon 66. The retention of mechanical properties of the recycled nylon 66 especially tensile and flexural strength (see Figures 4-3 and 4-8) was attributed to the presence of the glass fibers. Tensile test results have shown that as rubber content increases, tensile strength decreases. This is not an unusual finding since the rubber phase acts as a stress concentrator forcing material to yield at lower stress. Elongation at break was found to increase with increasing rubber content. All elongation data were less than $11 \%$ even at high rubber content (i.e. $20 \mathrm{wt} \%$ ); this is perhaps due to the dominant role 
of glass fibers in the blends. This finding is consistent with previous work done by others $[79,85]$. Note that glass fiber typically has a value of elongation at break $~ 5 \%$. Recycled composites exhibited less elongation at break in comparison with the virgin composites. This reduction in the elongation at break is attributed mainly to the possible presence of contaminants in the recycled glass-fiber-reinforced nylon 66. The variation of both tensile and flexural strengths with rubber content was found to obey the behavior given by the rule of mixtures. Although the effective area model developed by Ishai and Cohen was found to underestimate the yield data of this research due to the presence of the glass fibers, a combined equation taken from the work of Ishai and Cohen [44] which accounts for both rubber and reinforcement has been formulated and tested with the data of this research. The experimental data of the yield stress vs. rubber volume fraction was in good agreement with the results predicted theoretically. As expected, impact strength of the composites was found to increase with increasing rubber content. The plot of strength vs. toughness as given by Figure 4-15 has shown that it is possible to optimize strength and toughness of nylon 66 by incorporating both glass fibers and rubber. For example, a composite having $23.62 \mathrm{wt} \%$ glass fiber and $10 \mathrm{wt} \%$ SEBS-g-MA resulted in $28.3 \%$ and $167 \%$ increase in tensile and impact strengths respectively of a neat nylon 66 . Addition of rubber to the glass-fiber-reinforced nylon 66 did not significantly affect the crystallinity of nylon 66 as shown by the heat of fusion data. The melt flow index (MFI) data showed a drastic reduction in MFI when both SEBS-g-MA and EP-g-MA rubbers were added to both recycled and virgin glass-fiber-reinforced nylon 66. The highest reduction in MFI, which implies an increase in viscosity and molecular weight of the composites, was observed at higher rubber content (i.e. $20 \mathrm{wt} \%$ ). This has been supported by the 
measurements of the dynamic viscosity vs. shear rate, which showed an increase in viscosity with increasing rubber content at both glass fiber contents. The experimental viscosity data of the current research were found to comply with the Carraeu model despite the presence of the reinforcement in nylon 66. The zero shear viscosity of the composites was found to generally deviate positively from the log additive rule. This is attributed to the interaction between glass fiber phase and the other polymeric phases, which leads to a noticeable increase in viscosity that was under estimated by the $\log$ additive rule. The morphology of the fractured surfaces was successfully correlated to the mechanical properties of the composites. When rubber content was increased, composites exhibited a great degree of plastic deformation in the form of cavitations and shear bands as revealed by the SEM micrographs, and fiber pull-out was greatly diminished. This allowed the material to absorb much energy before fracture so that impact strength was raised.

Finally, it is noted that the recycled material, glass-fiber-reinforced nylon 66, used in this study has been considered a waste and it ended up in a landfill. However, both molecular weight and mechanical property characterization done by the current research have shown that the post-industrial glass-fiber-reinforced nylon 66 has reasonable properties that would make it suitable to be used in under-the-hood applications in automobiles. The method employed in this research, i.e. combining rubber with the recycled glass-fiber-reinforced nylon 66 , seems to be effective in altering and balancing its properties. The " as received " recycled material had a low value of impact strength; however by incorporating rubber in it, its toughness was enhanced and at the same time, its strength was not drastically reduced due to the presence of glass fibers. This is 
considered a benefit if the recycled material, i.e. glass-fiber-reinforced nylon 66 toughened with rubber, is to be used in under-the-hood applications where parts such as radiator end-tank and cooling fan are subject to repeated impact and shocks.

\subsection{Recommendations}

The following recommendations are suggested for future work:

1. Since the current study has dealt with a post-industrial nylon 66 reinforced with glass fiber at two fixed weight percents (14.79 $\mathrm{wt} \%$ and $23.62 \mathrm{wt} \%)$, the virgin material was adjusted to these two glass fiber loadings in order to compare the properties of recycled to those of the virgin material. It is suggested to vary glass fiber content (e.g. $0 \mathrm{wt} \%$ to $20 \mathrm{wt} \%$ ) in order to have a comprehensive variation of glass fiber content.

2. The mixing order for the current research was that rubber was added to a glassfiber-reinforced nylon 66. For future research, it is suggested that mixing order be changed. Nylon may be blended first with rubber and then the prepared rubbertoughened nylon is reinforced with the glass fibers. Another mixing order is to mix glass fibers with rubber and then mix with nylon. This may make the composite more ductile since a layer of a rubber phase is expected to surround the fiber.

3. As has been discussed in the literature, some studies have suggested that rubber inter-particle distance is a key factor in determining the toughness of the rubbertoughened thermoplastics and another study showed the effect of fiber end to end 
distance on the toughness of glass-fiber-reinforced thermoplastic. Since the current research dealt with both glass fiber and rubber, it is suggested that the influence of the distance between rubber particles and glass fiber on the toughness of the material be investigated.

4. In order to measure the particle size of the rubber used in this study (i.e. SEBS-gMA and EP-g-MA) and hence to measure the distance between a rubber particle and a fiber, a microscope with high resolution such as Transmission Electron Microscope (TEM) or Atomic Force Microscope (AFM) is suggested to be used for future work. Blends of nylon 66 with these two rubbers are expected to be miscible and have a rubber particle size that is in the submicron range.

5. Using high-resolution microscopy will ease the study of morphology of the fractured surfaces where some toughening deformation mechanisms such as crazes may be easily identified.

6. A twin screw extruder was used in this study as a means to blend nylon 66 with rubbers. The maleic anhydride group in the rubbers will react with amine group in nylon 66 and hence form a miscible blend. The twin screw extruder, which was the reactor for this process, can provide only a limited residence time. For future research, it is suggested that the residence time within the extruder be varied by controlling the screw speed (rpm). This will allow studying the effect of the extent of reaction between rubber and nylon 66 on the toughening process. A batch mixer where residence time can be controlled may be used for future work. 


\section{References}

1. Riffat, R; Blackford, J.P.," The impact of plastics recycling on pollution prevention", Proceedings of the thirteenth international conference on solid waste technology and management, Philadelphia, PA. November16-19, 1997.

2. Kohan, M.I.," Nylon plastics handbook", Hanser: New York, 1995.

3. Lubin, G.," Handbook of fiberglass and advanced plastics composites", Van Nostrand Reinhold (VNR): New York, 1969.

4. Miller, E.," Introduction to plastics and composites", Marcel Dekker: New York, 1996.

5. Collyer, A.A.," Rubber toughened engineering plastics", Chapman \& Hall: London, 1994.

6. Bucknall, C.B.," Toughened plastics", Applied Science, London, 1977.

7. Wellinghoff, S.T.; Baer, E.," Microstructure and its relationship to deformation processes in amorphous polymer glasses", J. Appl. Polym. Sci., 22, 2025(1978).

8. Wu, S.," Chain structure, phase morphology, and toughness relationships in polymers and blends", Polym. Eng. Sci., 30, 753(1990).

9. $\quad \mathrm{Wu}, \mathrm{S} ., "$ Impact fracture mechanisms in polymer blends: rubber-toughened nylon", J. Polym. Sci. Polym. Phys., 21, 699(1983).

10. Wu, S.," Phase structure and adhesion in polymer blends: a criterion for rubber toughening", Polymer, 26, 1855-1863(1985).

11. Oshinski, A.J.; Keskkula, H.; Paul, D.R.," Rubber toughening of polyamides with functionalized block copolymers: 2. nylon-6,6", Polymer, 33, 284-293(1992). 
12. Modic, M.J.; Gilmore, D.W.; Kirkpatrick, J.P," Engineering multipolymer blends with styrenic block copolymers", Proceedings of the first international congress on compatibilization and reactive polymer alloying (Compalloy '89), New Orleans, LA, April 5-7 1989.

13. Gelles, B.; Modic, M.; Kirkpatrick, J.," Modification of engineering thermoplastics with functionalized styrenic block copolymers", Soc. Plast. Eng. 46th ANTEC, 513515(1988).

14. Takeda, Y.; Keskkula, H.; Paul, D.R.," Effect of polyamide functionality on the morphology and toughness of blends with a functionalized block copolymer", Polymer, 33, 3173-3181(1992).

15. Kohan, M.I.," Nylon Plastics", John Wiley \& Sons: New York, 1973.

16. Nielsen, L.F.," Mechanical properties of polymers", Van Nostrand Reinhold (VNR): New York, 1962.

17. Matonis, V.A.," Interfacial stresses in particulate composite systems", Polym. Eng. Sci., 9, 100(1969).

18. Lunt, J.M.; Shortall, J.B.," Extrusion compounding of short-glass-fiber-filled nylon 66 blends", Eng. Plast. Rubber Process, 5, 37-44(1980).

19. Muck, D.L.; Ritter, J.R.," Glass microspheres: bubbles and beads as plastics additives", Plast. Compd., 2, 12(1979).

20. Krautz, F.G.," Glass fiber enhances high-temperature performance of thermoplastics", SPE J., 27, 74(1971).

21. Theberge, J.E.; Cloud, P.J.," Elevated temperature resistance of thermoplastic composites", Mod.Plast., 55, 66(1978). 
22. Mallick, P.K.," Fiber-reinforced composites", Marcel Dekker: New York, $2^{\text {nd }}$ ed., 1993.

23. Folkes, M.J.," Short fibre reinforced plastics", Wiley: New York, 1982.

24. Utracki, L.A.," Two phase polymer systems", Hanser: New York, 1991

25. Kelly, A.; Tyson, W.R.," Tensile properties of fiber-reinforced metals: copper/tungsten and copper/molybdenum", J. Mech. Phys. Solids, 13, 329350(1965).

26. Lees, J.K.," A study of the tensile strength of short fiber reinforced plastics", Polym. Eng. Sci., 8, 195-201(1968).

27. Ramsteiner, F.; Theysohn, R.," Tensile and impact strengths of unidirectional, short fiber reinforced thermoplastics", Composites, 111(1979).

28. Blumentritt, B.F.; Vu, B.T.; Cooper, S.L.," The mechanical properties of oriented discontinuous fiber reinforced thermoplastics: I- unidirectional fiber orientation. Polym. Eng. Sci., 14, 633-640(1974).

29. Arridge, R.G.C.," The effect of interlayers on the transverse stresses in fiber composites", Polym. Eng. Sci., 15, 757-760(1975).

30. Peiffer, D.G.," Impact strength of thick-interlayer composites", J. Appl. Polym. Sci., 24, 1451-1455(1979).

31. Bessell, T.; Shortall, J.B.," The crystallization and interfacial bond strength of nylon 6 at carbon and glass fiber surfaces", J. Mat. Sci., 10, 2035-2043(1975).

32. Harris, B.," Engineering composites materials", Institute of Metals, 1986.

33. Cottrell, A.H.," Strong solids", Proc.Roy.Soc., A282, 2-9(1964). 
34. Barlow, C.Y.; Ward, M.V.; Windle, A.H.," The influence of microstructure on the toughness of carbon fibre/plastic composites", Proceeding 6th international conference on deformation yield and fracture of polymers, April (1985).

35. Chai, H.," The characterization of mode I delamination failure in non woven, multidirectional laminates", Composites, 15, 277-290(1984).

36. Wang, S.S.; Suemasu, H.; Zahlan, N.M.," Interlaminar fracture of random short fibre SMG composites", J. Compos. Mat., 18, 574-594(1984).

37. Beahan, P.; Thomas, A.; Bevis, M.," Some observations on the micromorphology of deformed ABS and HIPS rubber-modified materials", J. Mat. Sci., 11, 1207(1976).

38. Bowden, P.B.; Oxborough, R.J.," General critical-strain criterion for crazing in amorphous glassy polymers", Philos. Mag., 28, 547(1973).

39. Kramer, E.J.," Microscopic and molecular fundamentals of crazing", Adv. Polym. Sci., 52, 1-56(1983).

40. Dugdale, D.S.," Yielding of steel sheets containing slits", J. Mech. Phys. Solids, 8, 100-104(1960).

41. Merz, E.H.; Claver, G.C.; Baer, M.," Studies on heterogeneous polymeric systems", J. Polym. Sci., 22, 325(1956).

42. Bucknall, C.B.; Smith, R.R.," Stress-whitening in high impact polystyrene", Polymer, 6, 437(1965).

43. Newman, S.; Strella, S.," Stress-strain behavior of rubber reinforced glassy polymers", J. Appl. Polym. Sci., 9, 2297(1965).

44. Ishai, O.; Cohen, L.J.," Effect of fillers and voids on compressive yield of epoxy composites", J. Compos. Mat., 2, 302-315(1968). 
45. Bucknall, C.B.; Davies, P.; Partridge, I.K.," Rubber toughening of plastics", J. Mat. Sci., 21, 307-313(1986).

46. Ricco, T.; Rink, M.; Caporusso, S.; Pavan, A.," Toughening of plastics II", International Conference, Plastics and Rubber Institute: London, 27, 2(1985).

47. Cigna, G.; Lomellini, P.; Merlotti, M.," Impact thermoplastics: combined role of rubbery phase volume and particle size on toughening efficiency", J. Appl. Polym. Sci., 37, 1527(1989).

48. Wu, S.," A generalized criterion for rubber toughening: the critical matrix ligament thickness", J. Appl. Polym. Sci., 35, 549-561(1988).

49. Margolina, A.; Wu, S.," Percolation model for brittle-tough transition in nylon/rubber blends", Polymer, 29, 2170-2173(1988).

50. Wu, S.; Margolina, A.," Reply to comments on percolation model for brittle-tough transition in nylon/rubber blends", Polymer, 31, 972-974(1990).

51. Dijkstra, K.; Oostenbrink, A.J.; Gaymans, R.J.," Cavitation processes in nylon/rubber blends", Plast. Rubber Inst., Conference on deformation and fracture of polymers, Cambridge, April 1991, pp. 39-1.

52. Oshinski, A.J.; Keskkula, H.; Paul, D.R.," Rubber toughening of polyamides with functionalized block copolymers: 1. nylon-6", Polymer, 33, 268-283(1992).

53. Gilmore, D.; Modic, M.," Modification of polycarbonate with styrenic block copolymers", Soc. Plast. Eng. 47th ANTEC, 1371(1989). 
54. Cimmino, S.; Coppola, F.; D'Orazio, L.;Greco, R.; Maglio, G.; Malianconico, M.; Mancerella, C.; Martuscelli, E.; Ragosta, G.," Ternary nylon-6/rubber/modified rubber blends: effect of the mixing procedure on morphology, mechanical and impact properties", Polymer, 27, 1874(1986).

55. Greco, R.; Malinconico, M.; Martuscelli, E.; Ragosta, G.; Scarinzi, G.," Role of degree of grafting of functionalized ethylene-propylene rubber on the properties of rubber-modified polyamide-6", Polymer, 28, 1185(1987).

56. Cimmino, S.; D'Orazio, L.; Greco, R.; Maglio, G.; Malianconico, M.; Mancerella, C.; Martuscelli, E.; Palumbo, R.; Ragosta, G.," Morphology-properties relationships in binary polyamide 6/rubber blends: influence of the addition of a functionalized rubber", Polym. Eng. Sci., 24, 48(1984).

57. Wu, S.," Formation of dispersed phase in incompatible polymer blends: interfacial and rheological effects", Polym. Eng Sci., 27, 335-343(1987).

58. Borggreve, R.J.M.; Gaymans, R.J.; Schuijer, J.; Ingen Housz, J.F.," Brittle-tough transition in nylon-rubber blends: effect of rubber concentration and particle size", Polymer, 28, 1489-1496(1987).

59. Bragaw, C.G.," Tensile-impact: a simple, meaningful impact test", Mod. Plast., 33, 199-201(1956).

60. British patent 998,439," Thermoplastic compositions", July 14, 1965, DuPont.

61. Seddon, J.D.; Hepworth, S.J.; Priddle, J.E.," Thermoplastic polymer blends", British patent 1,241,361, August 4, 1971, ICI. 
62. Kray, R.J.; Bellet, R.J.," Carboxy terminated graft copolymers of amino-carboxylic acids or lactams on acrylic copolymers", U.S. patent 3,388,186, June 11, 1968, Allied chemical corp.

63. Owens, F.H.; Clovis, J.S.," Acrylic modifiers for polycarbonamides", U.S. patent 3,668,274, June 6, 1972, Rohm and Haas.

64. Epstein, B.N.," Tough thermoplastic nylon compositions", U.S. patent 4,174,358, November 13, 1979, DuPont.

65. Roura, M.J.," Toughened polyamide blends", U.S. patent 4,346,194, August 24, 1982, DuPont.

66. Fukui, T.; Kikuchi, Y.; Inoue, T.," Elastic-plastic analysis of the toughening mechanism in rubber-modified nylon: matrix yielding and cavitation", Polymer, 32, 2367(1991).

67. Hobbs, S.Y.; Dekkers, M.E.J.," Deformation mechanisms in toughened poly(phenylene oxide)- polyamide blends", J. Mat. Sci., 24, 1316(1989).

68. Bucknall, C.B., " The micromechanics of rubber toughening", Makromol. Chem. Macromol. Symp., 20/21, 425-439(1988).

69. Bucknall, C.B.," Fracture resistance in rubber-toughened polymers", Makromol. Chem. Macromol. Symp., 38, 1(1990).

70. Flexman, E.A.," Impact behavior of nylon 66 compositions: ductile-brittle transitions", J. Int. Conf. Toughened Plastics, Plastics and Rubber Institute, London, 1978; pp. 1-8.

71. Flexman, E.A.," Impact behavior of nylon-66 compositions: ductile-brittle transitions", Polym. Eng. Sci., 19, 564(1979). 
72. Narisawa, I.; Ishikawa, M., in" Crazing in polymers", Kausch, H.H. ed., SpringerVerlag: New York, 1990; Vol 2, pp. 375.

73. Borggreve, R.J.M.; Gaymans, R.J.; Luttmer, A.R.," Influence of structure on the impact behavior of nylon-rubber blends", Makromol. Chem. Macromol. Symp., 16, 195-207(1988).

74. Gaymans, R.J.; Borggreve, R.J.M.; Culbertson, B.M.," Contemporary topics of polymer science", Plenum: New York, 1989.

75. Borggreve, R.J.M.," Toughening of polyamide-6 (nylon,rubber)", Ph.D thesis, University of Twente, Netherlands, 1988.

76. Borggreve, R.J.M.; Gaymans, R.J.; Schuijer, J.," Impact behavior of nylon-rubber blends. 5. influence of the mechanical properties of the elastomer", Polymer, 30, 71 (1989).

77. Borggreve, R.J.M.; Gaymans, R.J.; Eichenwald, H.M.," Impact behavior of nylonrubber blends. 6. influence of structure on voiding processes, toughening mechanism", Polymer, 30, 78(1989).

78. Bucknall, C.B.; Heather, P.S.; Lazzeri, A.," Rubber toughening of plastics. Part 12. Deformation mechanisms in toughened nylon 6,6", J. Mat. Sci, 24, 2255(1989).

79. Cho, J.W.; Paul, D.R.," Glass fiber-reinforced polyamide composites toughened with ABS and EPR-g-MA", J. Appl. Polym. Sci., 80, 484-497(2001).

80. Nair, S.V.; Wong, S.C.; Goettler, L.A.," Fracture resistance of polyblends and polyblend matrix composites: Part I unreinforced and fibre-reinforced nylon 6,6/ABS polyblends", J. Mat. Sci, 32, 5335-5346(1997). 
81. Nair, S.V.; Subramaniam, A.; Goettler, L.A.," Fracture resistance of polyblends and polyblend matrix composites: Part II role of the rubber phase in nylon 6,6/ABS alloys", J. Mat. Sci, 32, 5347-5354(1997).

82. Wong, S.C.; Nair, S.V.; Vestergaard, L.H.; Goettler, L.A.; Gustafson, L.A.," Toughening of nylon 6,6/ABS alloys", Plast. Eng., 23 ( January 1995).

83. Nair, S.V.; Subramaniam, A.; Goettler, L.A.," Fracture resistance of polyblends and polyblend matrix composites: Part III role of rubber type and location in nylon 6,6/SAN composites", J. Mat. Sci, 33, 3455-3464(1998).

84. Din, K.J.; Hashemi, S.," Influence of short-fibre reinforcement on the mechanical and fracture behavior of polycarbonate/acrylonitrile butadiene styrene polymer blend", J. Mat. Sci, 32, 375-387(1997).

85. Laura, D.M.; Keskkula, H.; Barlow, J.W.; Paul, D.R.," Effect of glass fiber and maleated ethylene-propylene rubber content on tensile and impact properties of nylon 6", Polymer, 41, 7165-7174(2000).

86. Pecorini, T.J.; Hertzberg, R.W.," The Fracture behavior of rubber-toughened shortfiber composites of nylon 6,6", Polym. Compos., 15, 174-183(1994).

87. Azari, A.; Boss, F.," The effect of impact modification on flexural and impact properties of injection moldable long glass fiber reinforced nylon compounds", SPE ANTEC '96, 54, 3022-3027(1996).

88. Nair, S.V.; Shiao, M.L.," Fracture resistance of a glass-fiber reinforced rubbermodified thermoplastic hybrid composite", J. Mat. Sci, 27, 1085-1100(1992). 
89. Kelnar, I.," The effect of PP and EPR grafted with acrylic acid on the properties and phase structure of polypropylene/elastomer/short glass fibre composites", Angew. Makromol., 189, 207-218(1991).

90. Kinloch, A.J.; Maxwell, D.L.; Young, R.J.," The fracture of hybrid-particulate composites", J. Mat. Sci, 20, 4169-4184(1985).

91. Shiao, M.L.; Nair, S.V.; Garrett, P.D.; Pollard, R.E.," Deformation mechanism and fibre toughening of nylon 6,6", Polymer, 35, 306-314(1994).

92. Sui, G.; Wong, S.-C.; Yue, C.-Y.," Effect of extrusion compounding on the mechanical properties of rubber-toughened polymers containing short glass fibers", J. Mat. Proc. Tech., 113, 167-171(2001).

93. Utracki, L.A.; Kamal, M.R.," Melt rheology of polymer blends", Polym. Eng. Sci., 22, 96-114(1982).

94. Berins, M.L.," Plastics engineering handbook", 5th ed., Chapman \& Hall: New York, 1991. 


\section{Appendix A \\ Glossary}

Table A-1 Definitions of the important terminology used in this research. $[3,94]$

\begin{tabular}{|c|c|c|}
\hline Term & Definition & ASTM \# \\
\hline Compressive strength & $\begin{array}{l}\text { Crushing load at the failure } \\
\text { of a specimen divided by } \\
\text { the original sectional area of } \\
\text { the specimen. }\end{array}$ & D 695 \\
\hline Crazing & $\begin{array}{l}\text { Fine cracks that may extend } \\
\text { in a network on or under the } \\
\text { surface or through a layer of } \\
\text { plastic material. }\end{array}$ & - \\
\hline Creep & $\begin{array}{l}\text { The dimensional change } \\
\text { with time of a material } \\
\text { under load, following the } \\
\text { initial instantaneous elastic } \\
\text { deformation. Creep at room } \\
\text { temperature is sometimes } \\
\text { called cold flow. }\end{array}$ & D 674 \\
\hline Dielectric constant & $\begin{array}{l}\text { The ratio of the capacitance } \\
\text { of an assembly of two } \\
\text { electrodes separated solely } \\
\text { by a plastics insulating } \\
\text { material to its capacitance } \\
\text { when the electrodes are } \\
\text { separated by air. }\end{array}$ & D 150 \\
\hline Elasticity & $\begin{array}{l}\text { That property of a material } \\
\text { by virtue of which it tends } \\
\text { to recover its original size } \\
\text { and shape after } \\
\text { deformation. }\end{array}$ & - \\
\hline Elastomer & $\begin{array}{l}\text { A material that at room } \\
\text { temperature stretches under } \\
\text { low stress to at least twice } \\
\text { its original length and snaps } \\
\text { back to the original length } \\
\text { upon release of stress. }\end{array}$ & - \\
\hline Elongation & The fractional increase in & D 638 \\
\hline
\end{tabular}




\begin{tabular}{|c|c|c|}
\hline & $\begin{array}{l}\text { length of a material stressed } \\
\text { in tension. }\end{array}$ & \\
\hline Extrusion & $\begin{array}{l}\text { Process of compacting and } \\
\text { melting a plastic material } \\
\text { and forcing it through an } \\
\text { orifice in a continuous } \\
\text { fashion. }\end{array}$ & - \\
\hline Fabric & $\begin{array}{l}\text { A material constructed of } \\
\text { interlaced yarns, fibers, or } \\
\text { filaments. }\end{array}$ & - \\
\hline Flexural modulus & $\begin{array}{l}\text { The ratio of stress to strain } \\
\text { for a given material within } \\
\text { its proportional limit under } \\
\text { bending load conditions. }\end{array}$ & D 790 \\
\hline Flexural strength & $\begin{array}{l}\text { Ability of a material to flex } \\
\text { without permanent } \\
\text { distortion or breaking. }\end{array}$ & D 790 \\
\hline Glass transition temperature & $\begin{array}{l}\text { The temperature at which } \\
\text { an amorphous polymer } \\
\text { changes from a hard, brittle } \\
\text { (glassy) condition to a } \\
\text { viscous, elastomeric form. } \\
\text { Also called second-order } \\
\text { transition, gamma } \\
\text { transition, rubber transition, } \\
\text { and rubbery transition. }\end{array}$ & - \\
\hline Hardness & $\begin{array}{l}\text { The resistance of a plastic } \\
\text { material to compression and } \\
\text { indentation. Methods of } \\
\text { testing this property are } \\
\text { Brinell hardness, Rockwell } \\
\text { hardness, and shore } \\
\text { hardness. }\end{array}$ & $\begin{array}{c}\text { Rockwell D } 785 \\
\text { Shore D } 2240\end{array}$ \\
\hline Heat deflection temperature & $\begin{array}{l}\text { The temperature at which a } \\
\text { specimen will deflect a } \\
\text { given distance at a given } \\
\text { load under prescribed } \\
\text { conditions of test. }\end{array}$ & D 648 \\
\hline Impact strength & $\begin{array}{l}\text { The ability of a material to } \\
\text { withstand shock loading. }\end{array}$ & D 256 \\
\hline Mat & $\begin{array}{l}\text { A fabric or felt of glass or } \\
\text { other reinforcing fiber used } \\
\text { in manufacturing plastic } \\
\text { composite parts. }\end{array}$ & - \\
\hline Matrix & The continuous phase of a & - \\
\hline
\end{tabular}




\begin{tabular}{|l|l|c|}
\hline & $\begin{array}{l}\text { composite material; the } \\
\text { resin component in a } \\
\text { reinforced plastics material. }\end{array}$ & \\
\hline Melt index & $\begin{array}{l}\text { The amount, in grams, of a } \\
\text { thermoplastic resin that can } \\
\text { be forced through an orifice } \\
\text { when subjected to load and } \\
\text { temperature in 10 minutes. }\end{array}$ & D 1238 \\
\hline Modulus of elasticity & $\begin{array}{l}\text { The ratio of stress to strain } \\
\text { in a material that is } \\
\text { elastically deformed. }\end{array}$ & D 790 \\
\hline Plasticizer & $\begin{array}{l}\text { A material incorporated in a } \\
\text { plastic to increase its } \\
\text { workability and flexibility } \\
\text { or distensibility. The } \\
\text { addition of a plasticizer may } \\
\text { lower melt viscosity, glass } \\
\text { transition temperature, or } \\
\text { elastic modulus. }\end{array}$ & \\
\hline Rheology & $\begin{array}{l}\text { The study of material flow } \\
\text { under varying conditions of } \\
\text { heat and pressure. }\end{array}$ & \\
\hline Roving & $\begin{array}{l}\text { A form of fibrous glass in } \\
\text { which spun strands are } \\
\text { woven into a tubular rope. }\end{array}$ & \\
\hline Strain & $\begin{array}{l}\text { Any elastomer capable of } \\
\text { rapid elastic recovery after } \\
\text { being stretched to at least } \\
\text { twice its length at } \\
\text { temperatures from 0 to 150 } \\
\text { oF. }\end{array}$ & \\
\hline Rubber & $\begin{array}{l}\text { The stress at which a } \\
\text { material fails under a shear } \\
\text { loading condition. }\end{array}$ & \\
\hline coefficient & $\begin{array}{l}\text { Elastic deformation caused } \\
\text { by stress measured as } \\
\text { change in length per unit of } \\
\text { length. }\end{array}$ & D \\
\hline $\begin{array}{l}\text { The pulling stress, in psi, } \\
\text { required to break a given } \\
\text { specimen. }\end{array}$ & D \\
\hline $\begin{array}{l}\text { The fractional change in } \\
\text { dimension (sometimes } \\
\text { volume) specified, of a } \\
\text { material for a unit change in } \\
\text { temperature. Values for }\end{array}$ & - \\
\hline
\end{tabular}




\begin{tabular}{|l|l|c|}
\hline & $\begin{array}{l}\text { plastics range from } 0.01 \text { to } \\
0.2 /{ }^{\circ} \mathrm{C} .\end{array}$ & \\
\hline Thermoplastic & $\begin{array}{l}\text { A material that will } \\
\text { repeatedly soften when } \\
\text { heated and harden when } \\
\text { cooled. }\end{array}$ & - \\
\hline Woven roving & $\begin{array}{l}\text { Similar to fabric but heavier } \\
\text { since rovings are thicker } \\
\text { than yarns. }\end{array}$ & \\
\hline
\end{tabular}


Appendix B

Fitting the experimental viscosity data to Carreau model

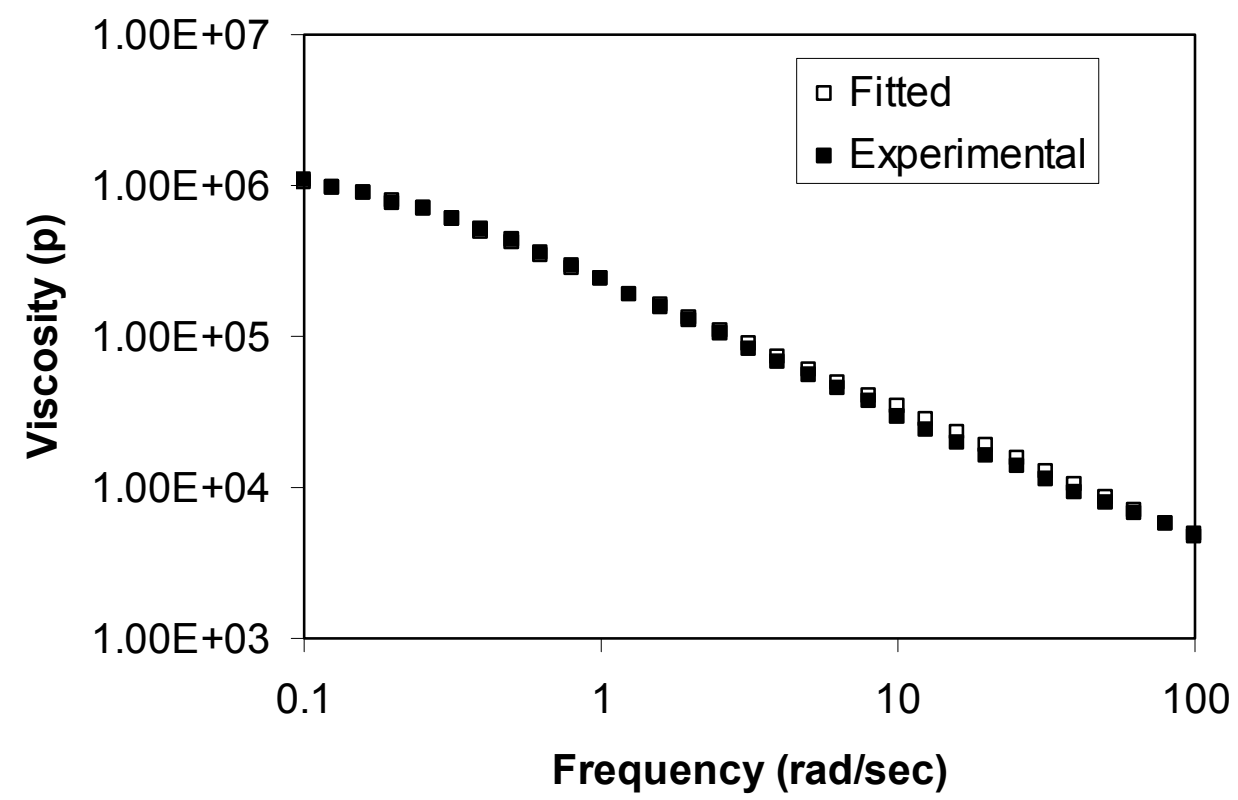

(a)

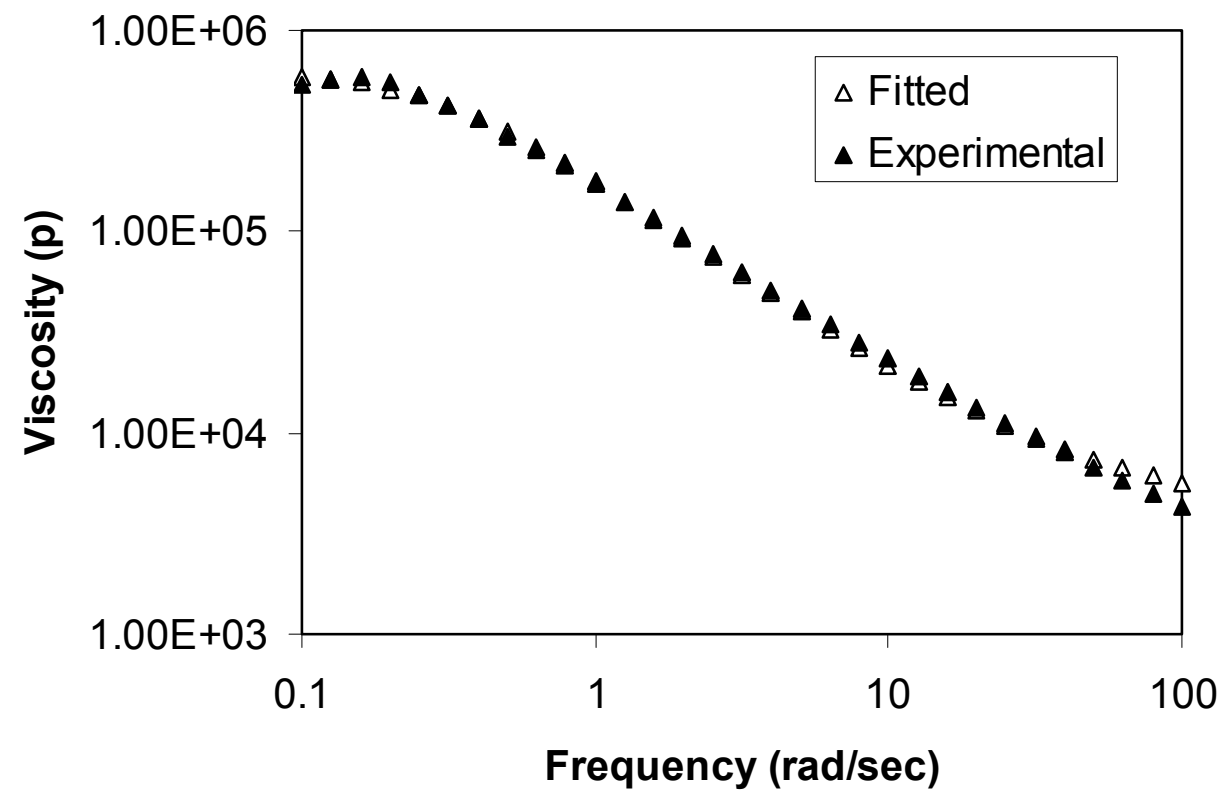

(b)

Figure B-1 Fitting viscosity vs. shear rate to Carreau model for the $23.62 \mathrm{wt} \%$ glass fiber toughened with various weight percent of SEBS-g-MA: (a) $0 \%$; (b) $5 \%$. 


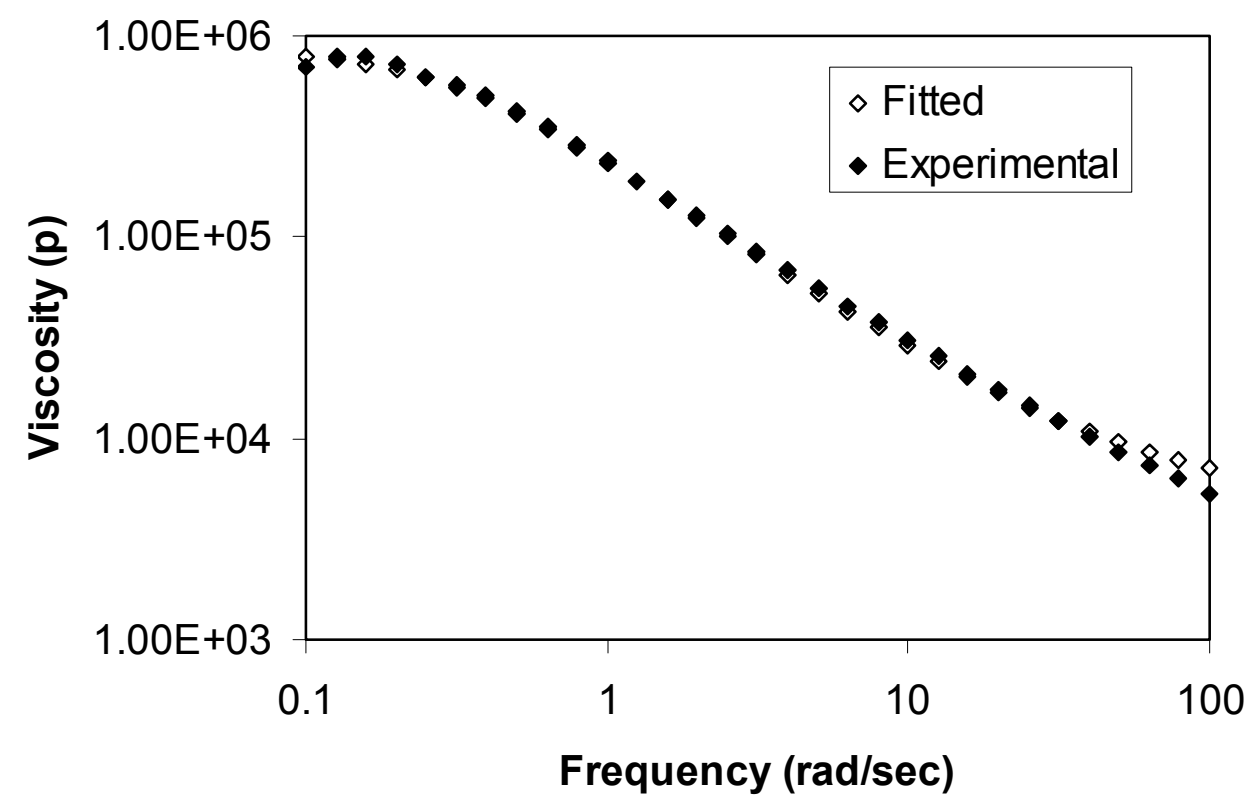

(a)

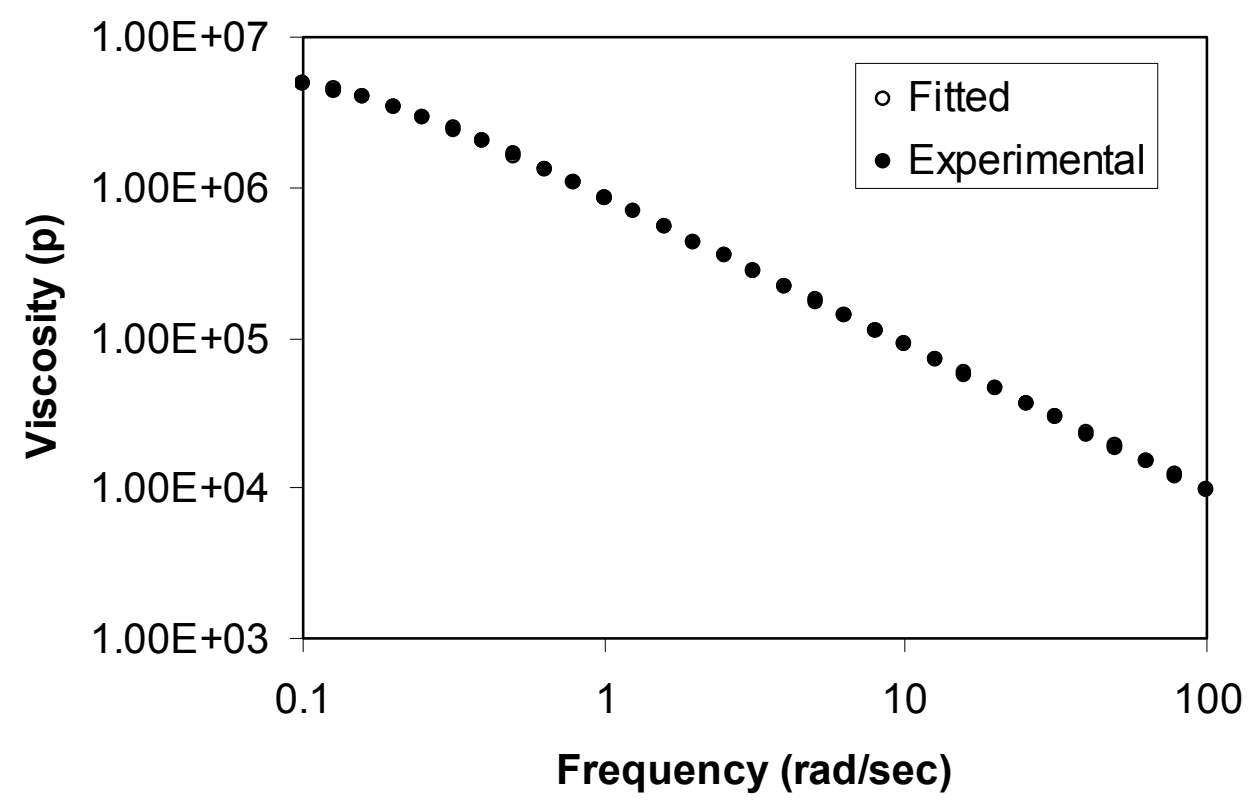

(b)

Figure B-2 Fitting viscosity vs. shear rate to Carreau model for the $23.62 \mathrm{wt} \%$ glass fiber toughened with various weight percent of SEBS-g-MA: (a) 10\%; (b) 15\%. 


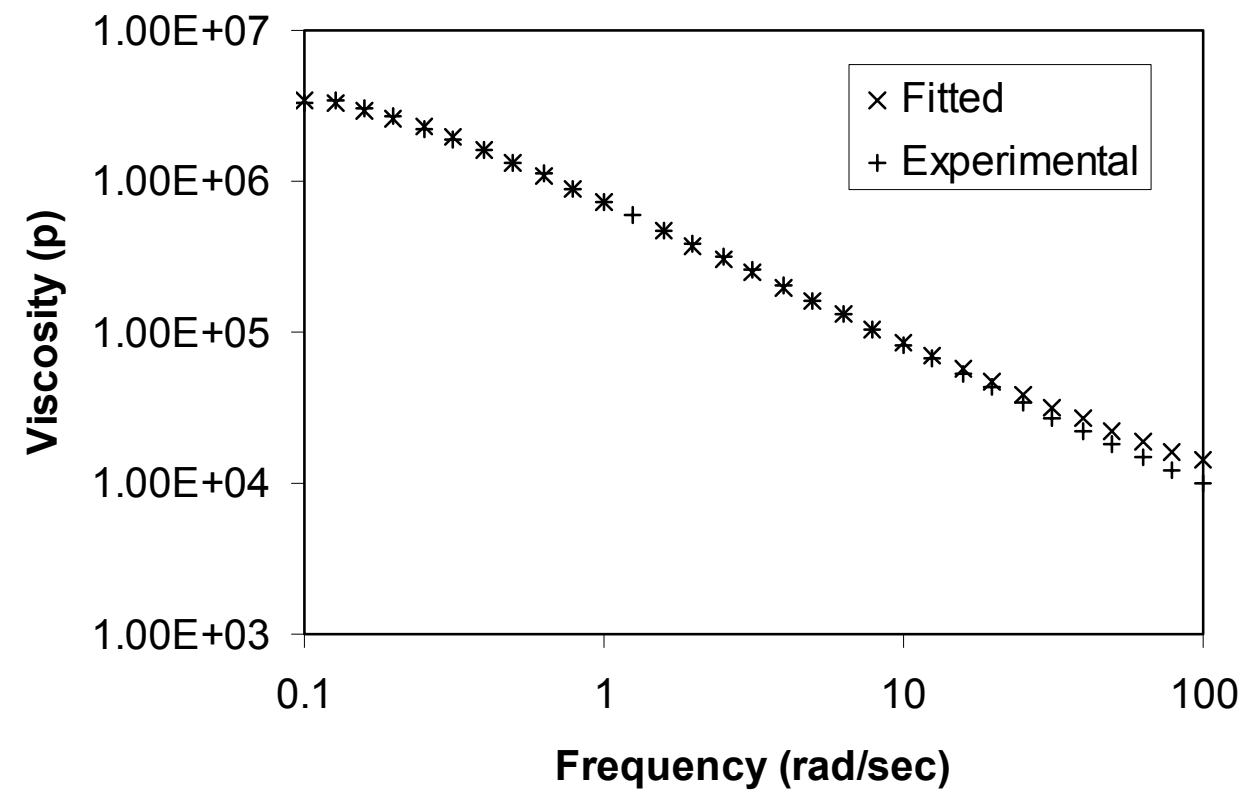

Figure B-3 Fitting viscosity vs. shear rate to Carreau model for the $23.62 \mathrm{wt} \%$ glass fiber toughened with $20 \mathrm{wt} \%$ SEBS-g-MA. 


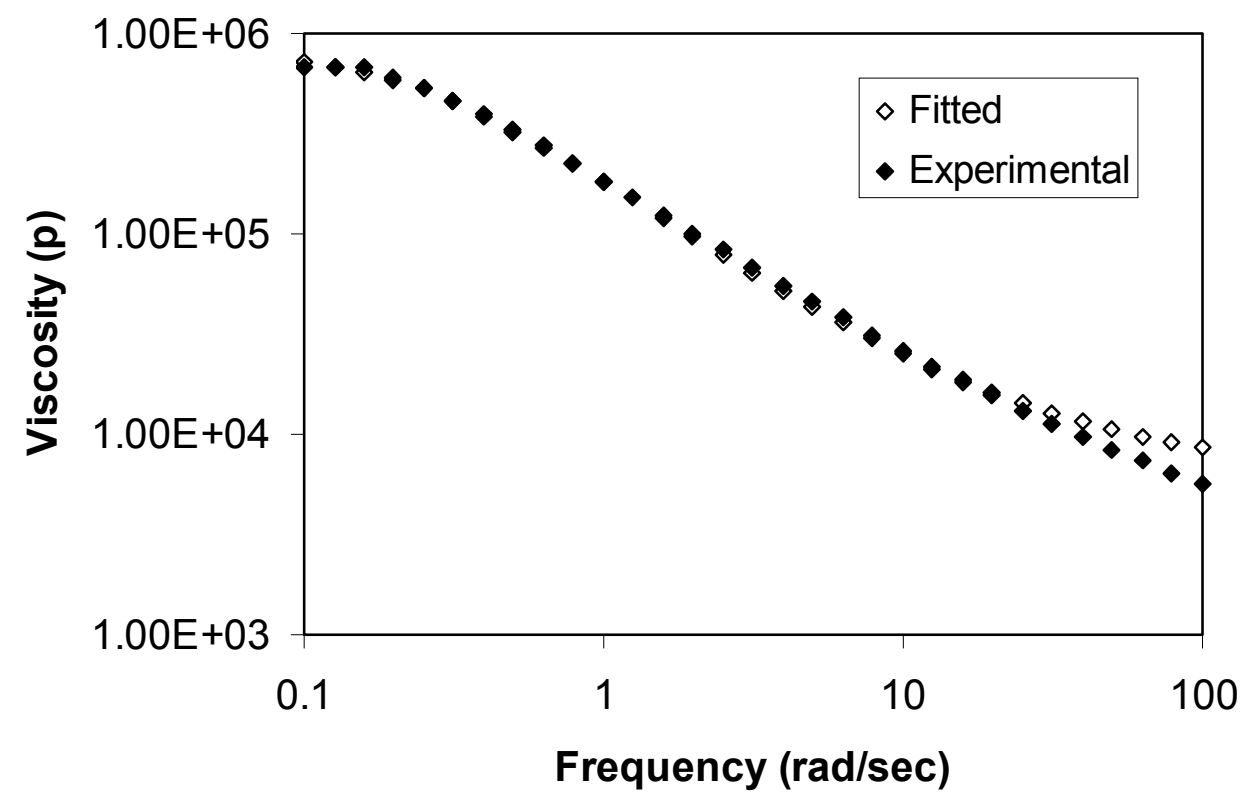

(a)

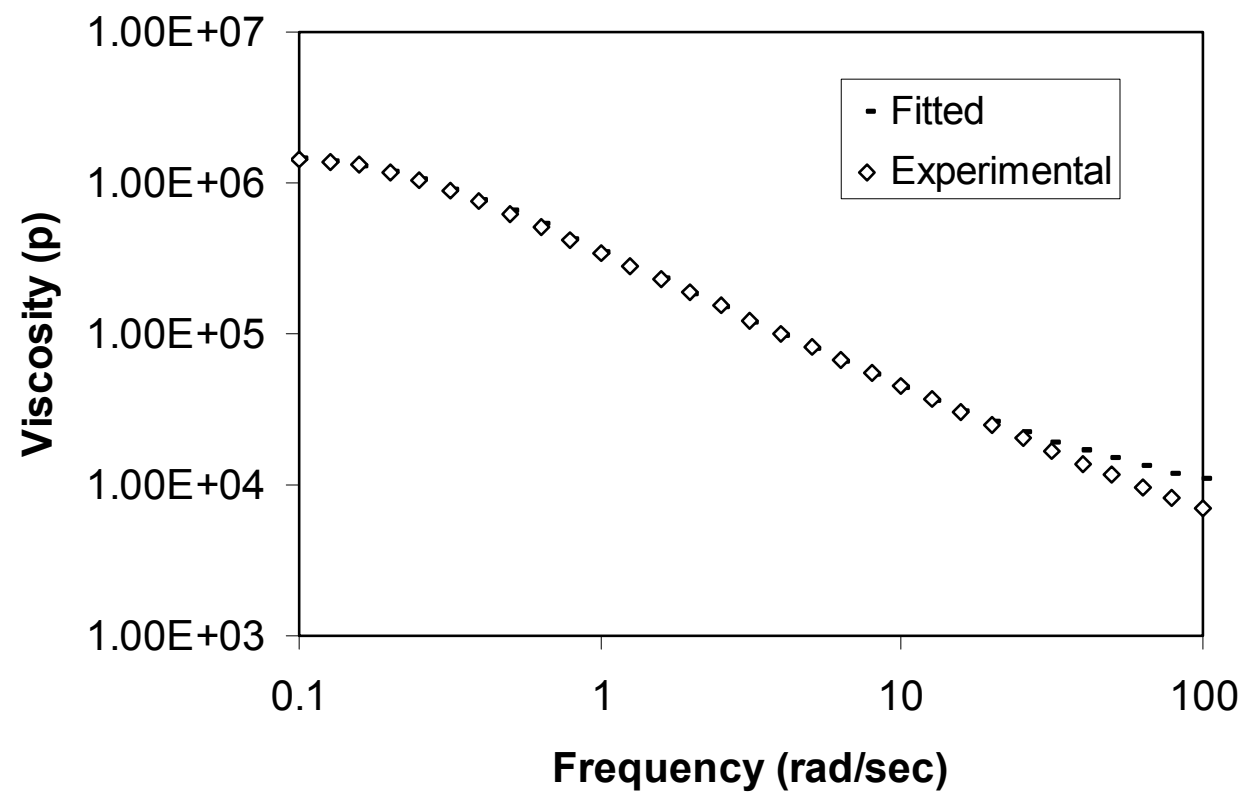

(b)

Figure B-4 Fitting viscosity vs. shear rate to Carreau model for the $23.62 \mathrm{wt} \%$ glass fiber toughened with various weight percent of EP-g-MA: (a) 5\%; (b) $10 \%$. 


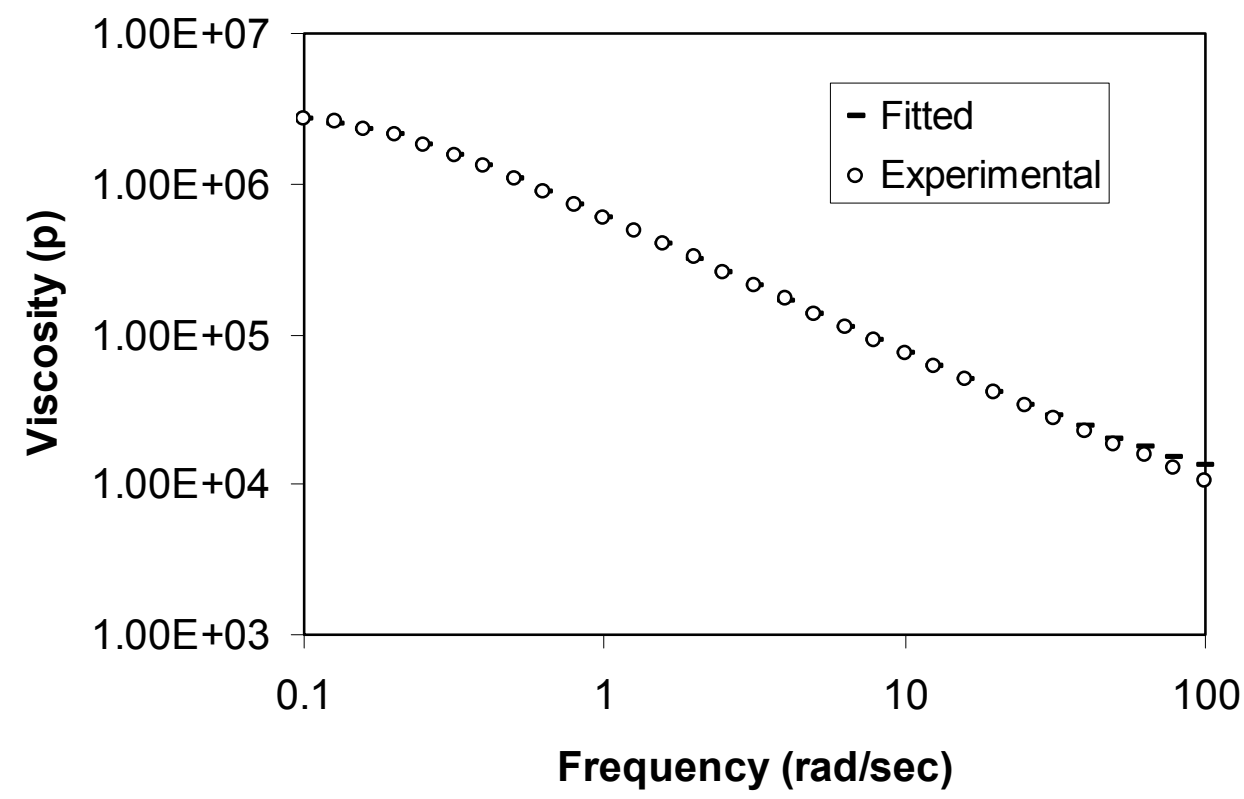

(a)

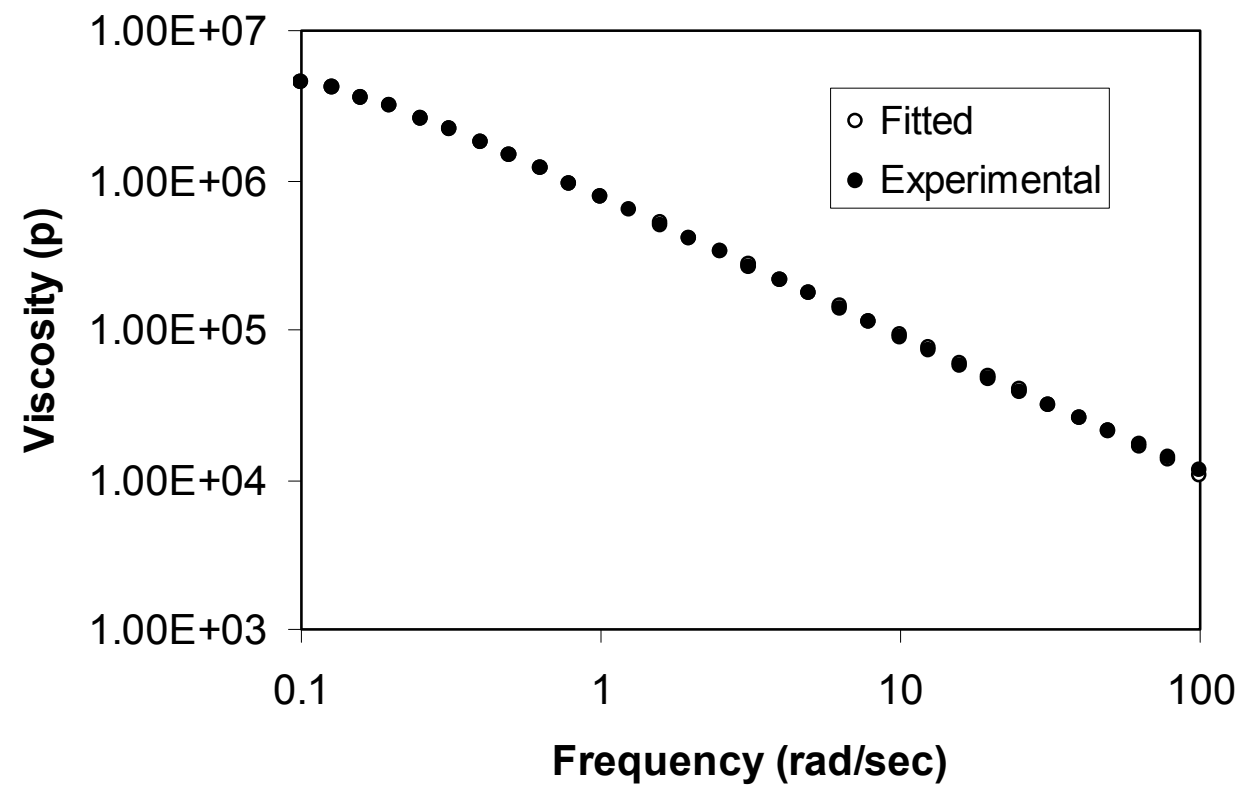

(b)

Figure B-5 Fitting viscosity vs. shear rate to Carreau model for the $23.62 \mathrm{wt} \%$ glass fiber toughened with various weight percent of EP-g-MA: (a) $15 \%$; (b) $20 \%$. 


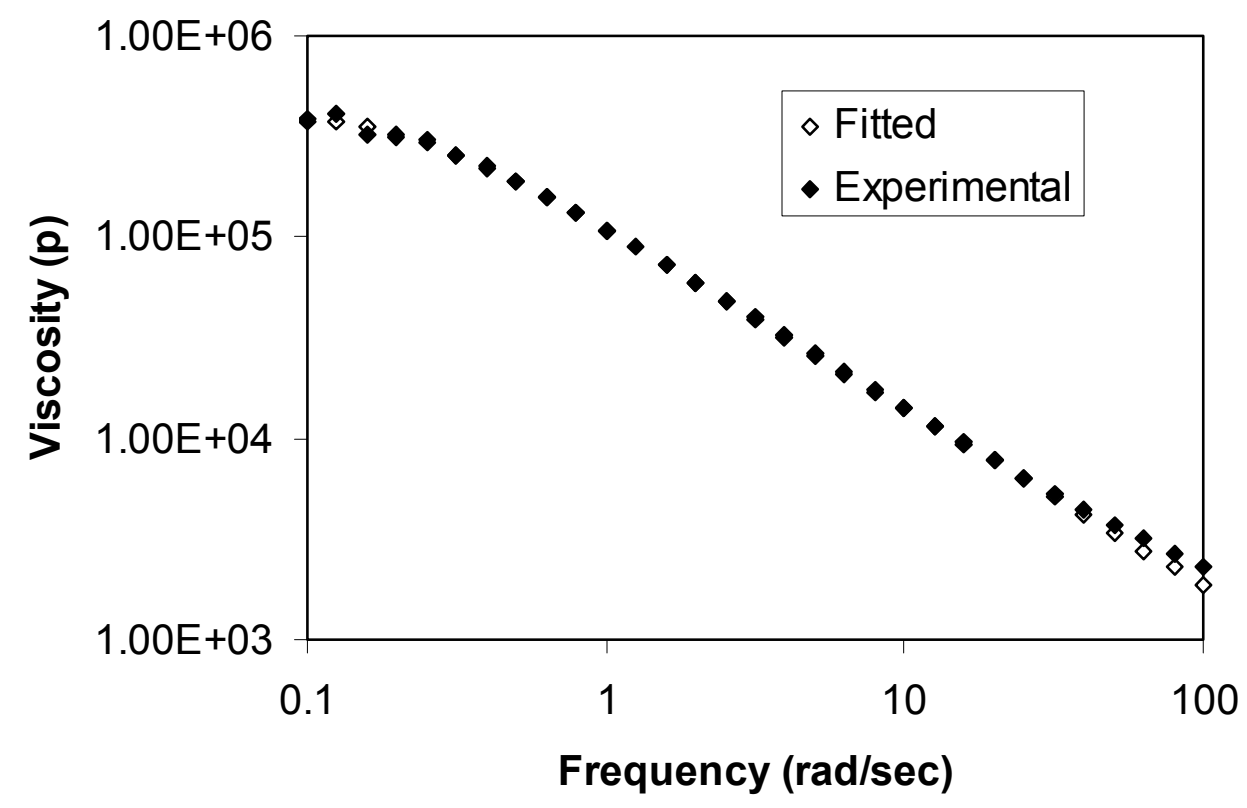

(a)

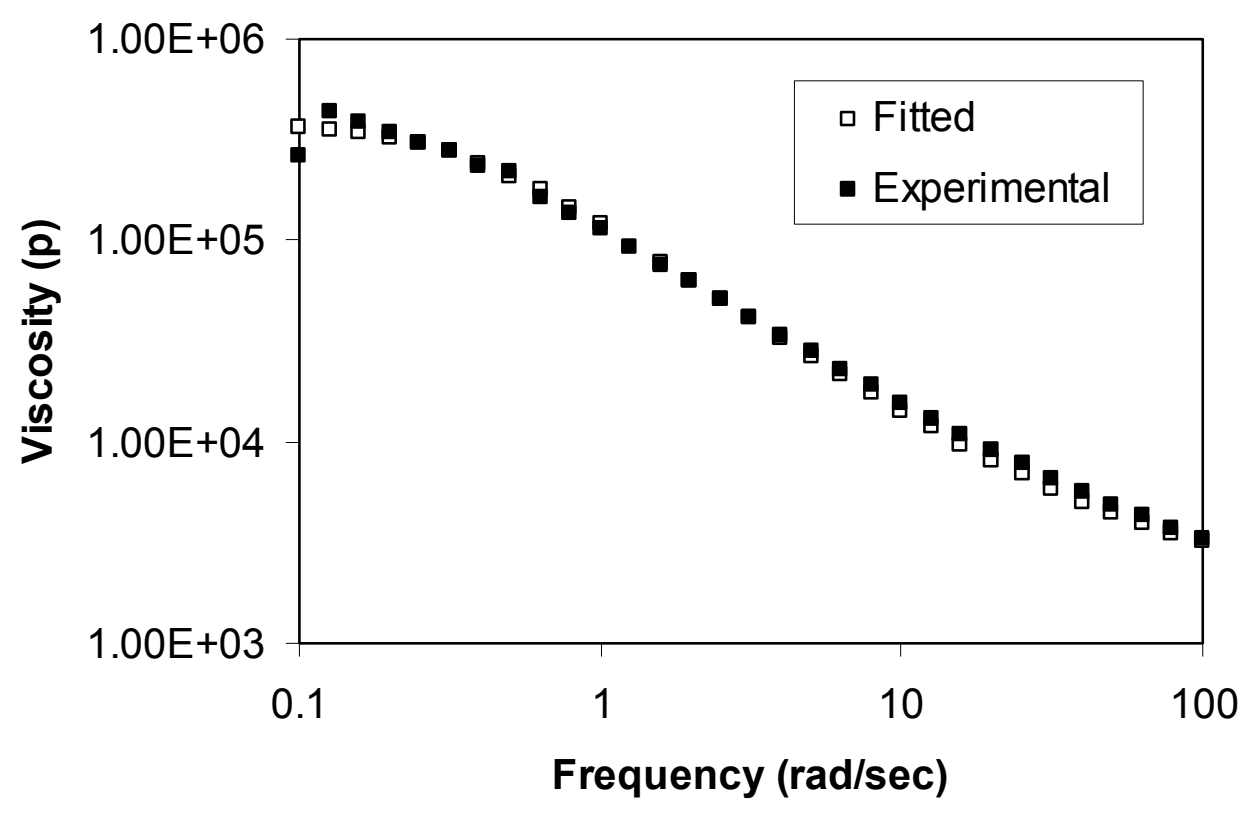

(b)

Figure B-6 Fitting viscosity vs. shear rate to Carreau model for the $14.79 \mathrm{wt} \%$ glass fiber toughened with various weight percent of EP-g-MA: (a) $0 \%$; (b) $5 \%$. 


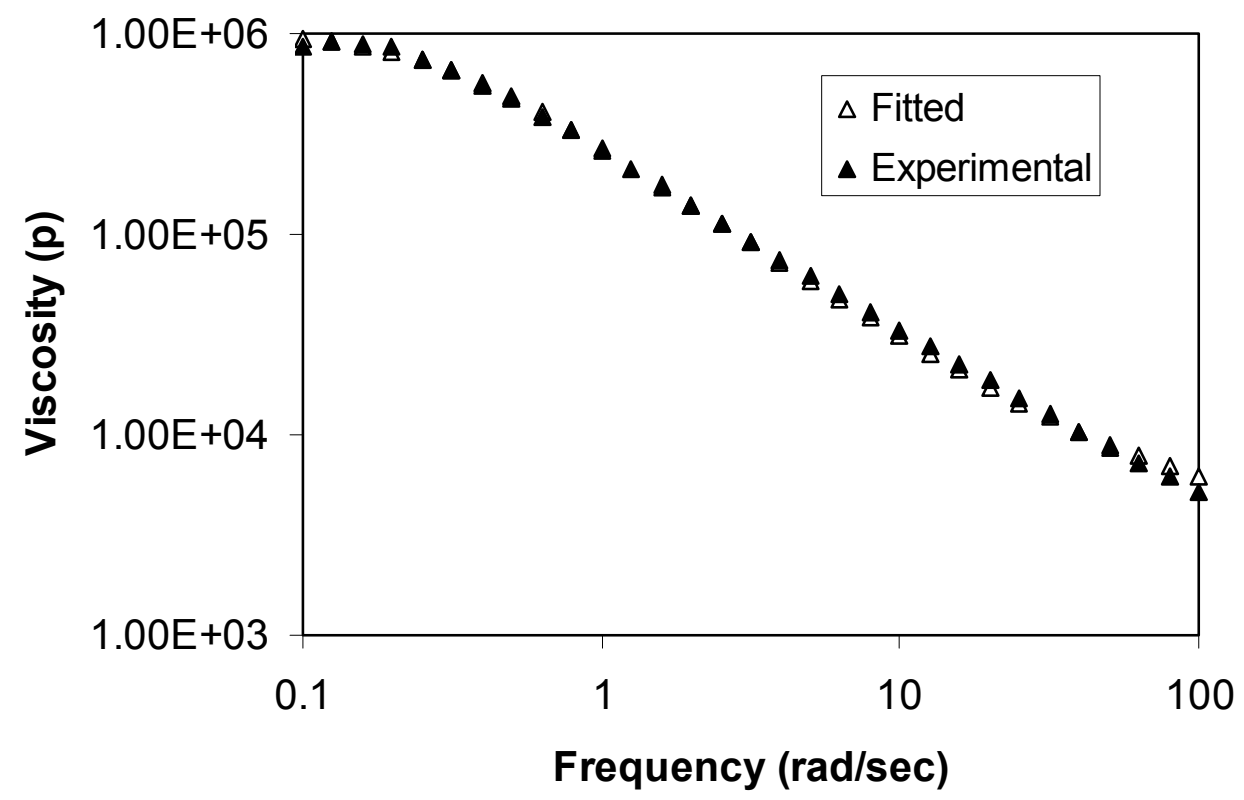

(a)

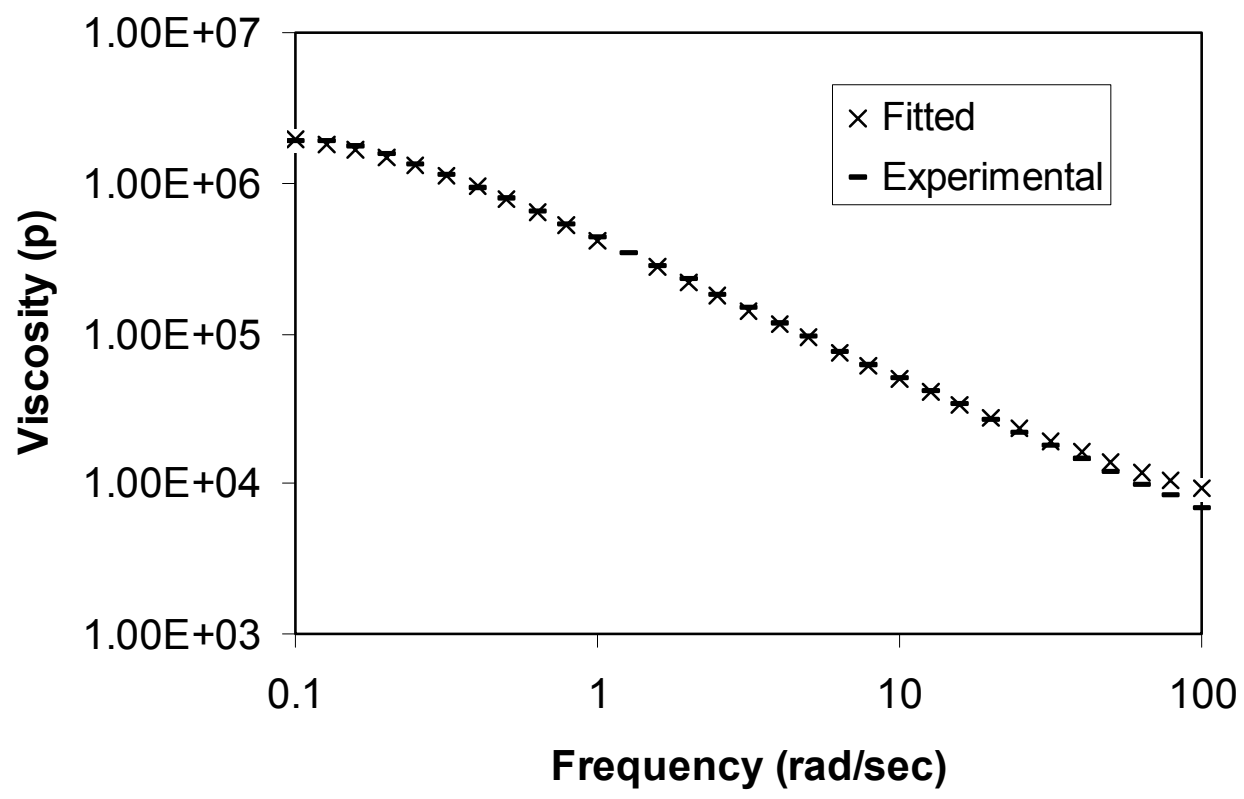

(b)

Figure B-7 Fitting viscosity vs. shear rate to Carreau model for the $14.79 \mathrm{wt} \%$ glass fiber toughened with various weight percent of EP-g-MA: (a) $10 \%$; (b) $15 \%$. 


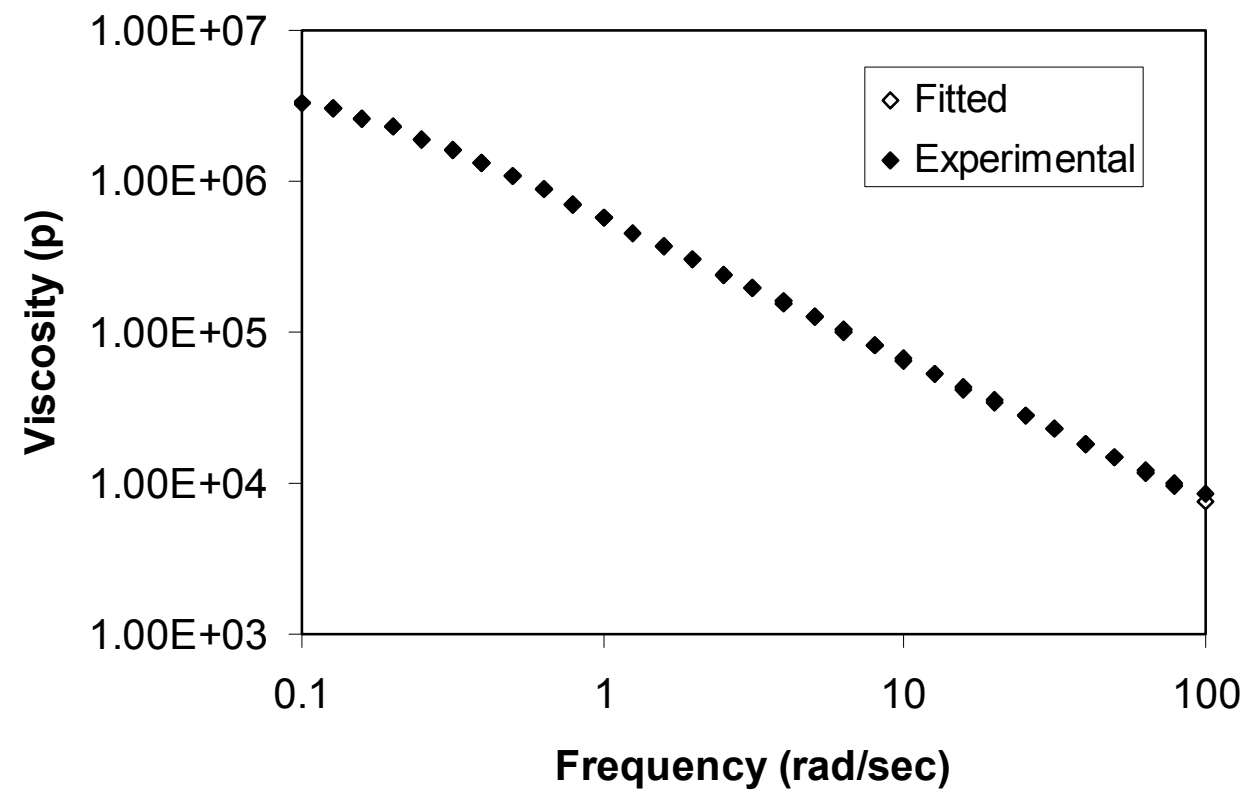

Figure B-8 Fitting viscosity vs. shear rate to Carreau model for the $14.79 \mathrm{wt} \%$ glass fiber toughened with $20 \mathrm{wt} \%$ EP-g-MA. 


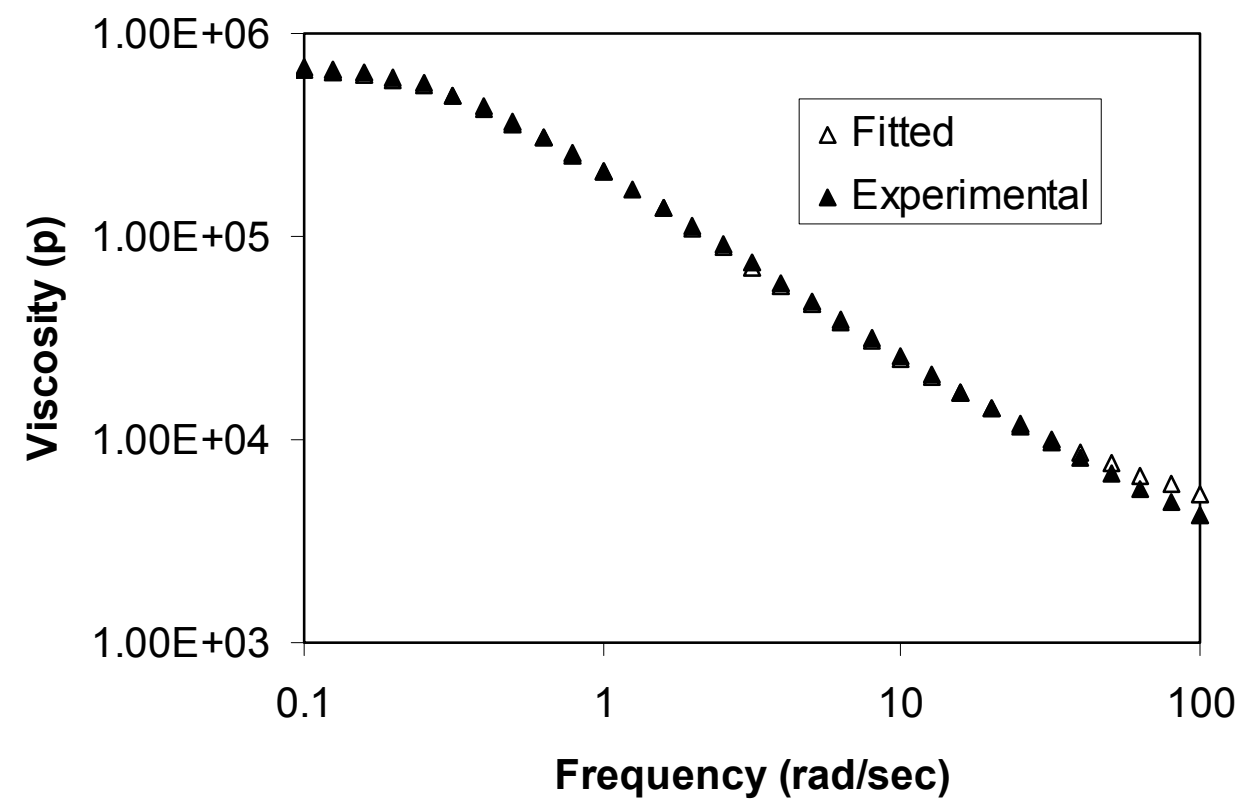

(a)

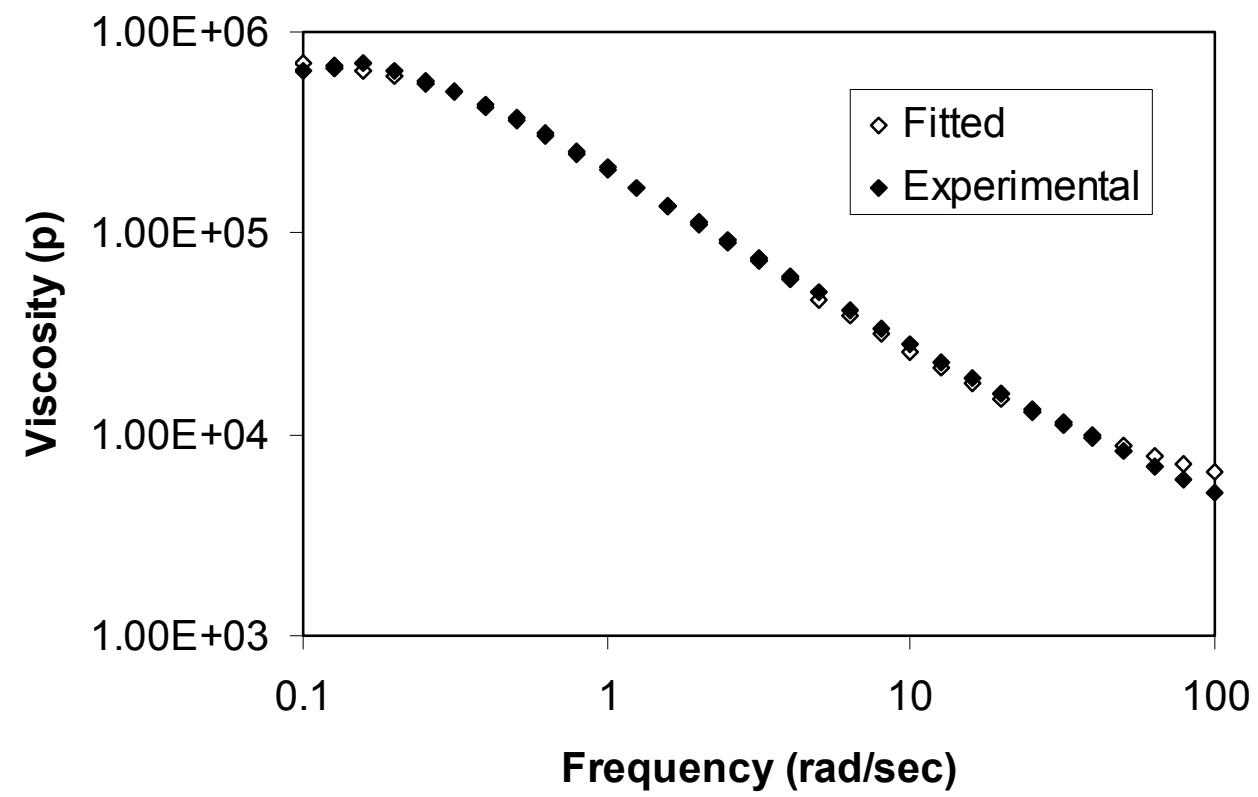

(b)

Figure B-9 Fitting viscosity vs. shear rate to Carreau model for the $14.79 \mathrm{wt} \%$ glass fiber toughened with various weight percent of SEBS-g-MA: (a) 5\%; (b) 10\%. 


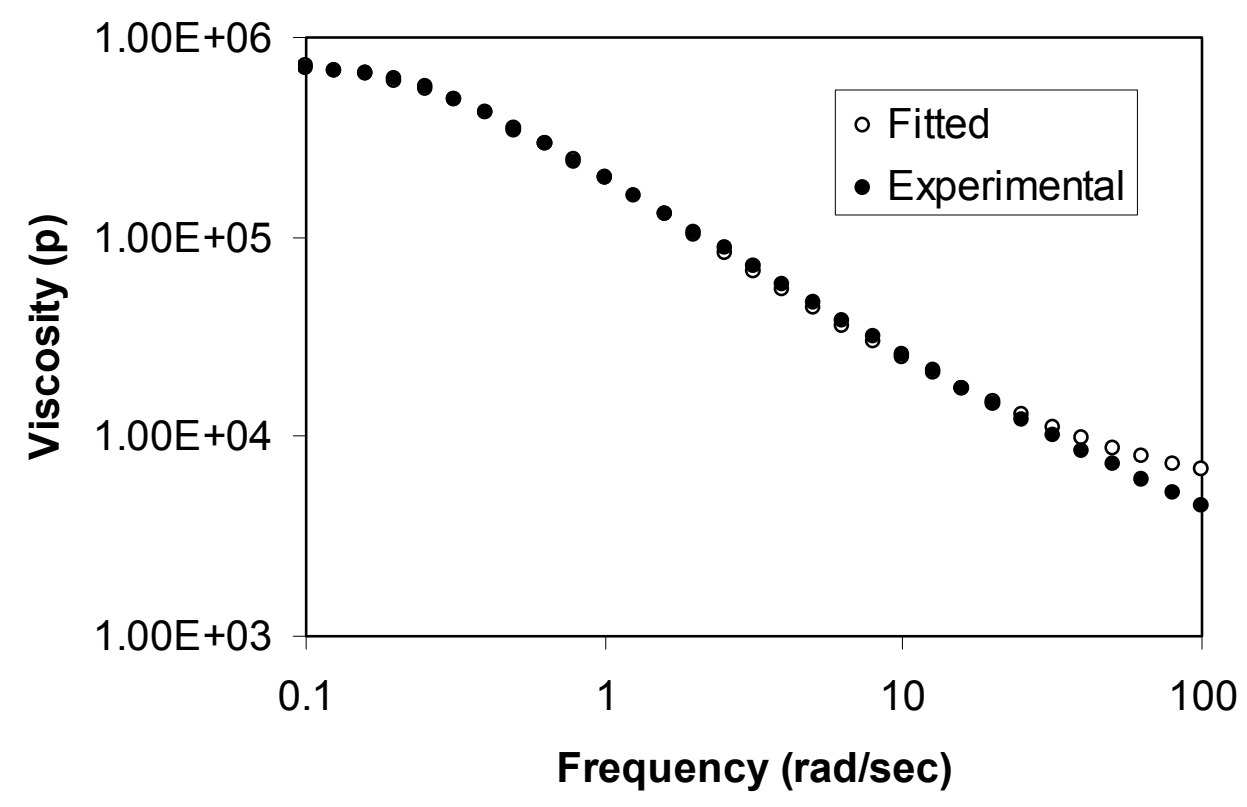

(a)

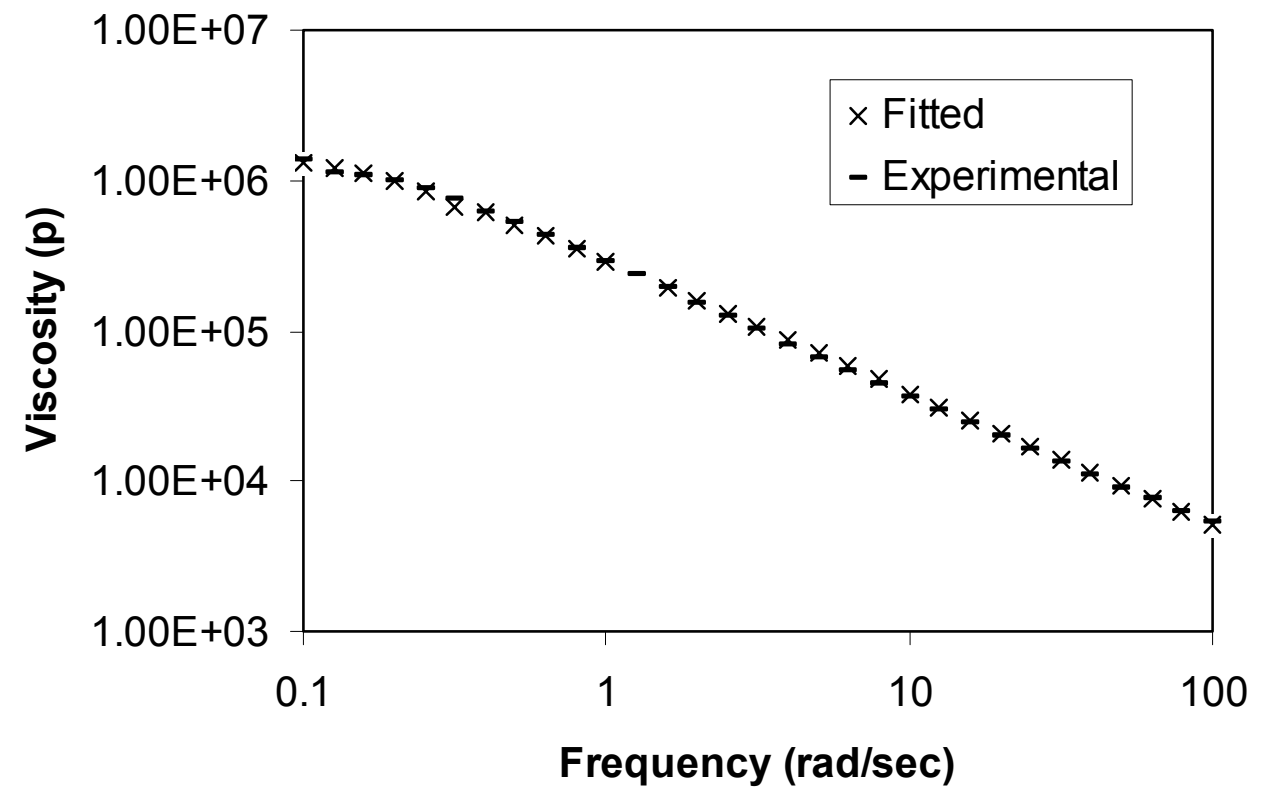

(b)

Figure B-10 Fitting viscosity vs. shear rate to Carreau model for the $14.79 \mathrm{wt} \%$ glass fiber toughened with various weight percent of SEBS-g-MA: (a) 15\%; (b) 20\%. 
Appendix C

Mechanical properties of the composites

Table C-1 Tensile strength (kpsi) data for the recycled composites.

\begin{tabular}{|l|ll|ll|l|l|}
\hline & \multicolumn{3}{|l|}{ Recycled \& EP-g-MA } & \multicolumn{3}{l|}{ Recycled \& SEBS-g-MA } \\
\hline Rubber & $\begin{array}{l}23.62 \\
\mathrm{wt} \%\end{array}$ & $\mathrm{wt} \%$ & $\begin{array}{l}14.79 \\
\text { glass }\end{array}$ & $\mathrm{wt} \%$ & $23.62 \quad \mathrm{wt} \%$ & $14.79 \quad \mathrm{wt} \%$ \\
glass & glass & glass \\
\hline 0 & 18.194 & 14.306 & 18.194 & 14.306 \\
\hline 5 & 16.082 & 13.674 & 17.511 & 14.302 \\
\hline 10 & 14.558 & 11.7 & 15.246 & 12.353 \\
\hline 15 & 11.909 & 10.072 & 12.79 & 10.562 \\
\hline 20 & 10.302 & 8.839 & 11.324 & 8.486 \\
\hline
\end{tabular}

Table C-2 Tensile strength (kpsi) data for the virgin composites.

\begin{tabular}{|l|ll|ll|ll|l|}
\hline & \multicolumn{3}{|l|}{ Virgin \& SEBS-g-MA } & \multicolumn{3}{l|}{ Virgin \& EP-g-MA } \\
\hline Rubber & 23.62 & wt\% & 14.79 & wt\% & $23.62 \quad$ wt\% & $14.79 \quad$ wt\% \\
wt\% & glass & glass & glass & glass \\
\hline 0 & 19.458 & 14.255 & 19.458 & 14.255 \\
\hline 5 & 17.177 & 13.799 & 16.038 & 13.581 \\
\hline 10 & 14.879 & 12.176 & 14.04 & 11.626 \\
\hline 15 & 13.342 & 11.103 & 12.254 & 10.394 \\
\hline 20 & 11.422 & 9.793 & 10.264 & 8.758 \\
\hline
\end{tabular}


Table C-3 Elongation at break (\%) data for the recycled composites.

\begin{tabular}{|l|ll|ll|ll|l|}
\hline & \multicolumn{3}{|l|}{ Recycled \& EP-g-MA } & \multicolumn{3}{l|}{ Recycled \& SEBS-g-MA } \\
\hline Rubber & 23.62 & wt\% & 14.79 & wt\% & 23.62 & wt\% & $14.79 \quad$ wt $\%$ \\
wt\% & glass & glass & glass & & glass \\
\hline 0 & 4.283 & 3.849 & 4.283 & 3.849 \\
\hline 5 & 5.269 & 5.311 & 5.158 & 5.292 \\
\hline 10 & 5.438 & 5.584 & 5.151 & 5.276 \\
\hline 15 & 5.936 & 5.799 & 5.751 & 5.812 \\
\hline 20 & 6.48 & 5.93 & 6.836 & 7.359 \\
\hline
\end{tabular}

Table C-4 Elongation at break (\%) data for the virgin composites.

\begin{tabular}{|c|c|c|c|c|}
\hline & Virgin \& SEB & S-g-MA & Virgin \& EP- & -MA \\
\hline $\begin{array}{l}\text { Rubber } \\
\text { wt } \%\end{array}$ & $\begin{array}{ll}23.62 & \mathrm{wt} \% \\
\text { glass } & \end{array}$ & $\begin{array}{ll}14.79 & \mathrm{wt} \% \\
\text { glass } & \end{array}$ & $\begin{array}{ll}23.62 & \mathrm{wt} \% \\
& \\
\text { glass } & \end{array}$ & $\begin{array}{ll}14.79 & \mathrm{wt} \% \\
\text { glass } & \end{array}$ \\
\hline 0 & 5.736 & 3.766 & 5.736 & 3.766 \\
\hline 5 & 6.099 & 6.524 & 6.349 & 5.942 \\
\hline 10 & 6.801 & 7.361 & 6.381 & 6.169 \\
\hline 15 & 7.392 & 8.311 & 6.835 & 7.507 \\
\hline 20 & 9.488 & 10.57 & 7.618 & 7.588 \\
\hline
\end{tabular}


Table C-5 Flexural strength (kpsi) data for the recycled composites.

\begin{tabular}{|l|ll|l|l|l|}
\hline & EP-g-MA & \multicolumn{3}{|l|}{ SEBS-g-MA } \\
\hline Rubber & $23.62 \quad \mathrm{wt} \%$ & $14.79 \quad \mathrm{wt} \%$ & $23.62 \quad \mathrm{wt} \%$ & $14.79 \quad \mathrm{wt} \%$ \\
& glass $\%$ & glass & glass & glass \\
\hline 0 & 28.31 & 21.77 & 28.31 & 21.77 \\
\hline 5 & 24.95 & 20.27 & 25.28 & 20.02 \\
\hline 10 & 20.92 & 16.84 & 23.25 & 17.52 \\
\hline 15 & 16.98 & 13.94 & 19.04 & 15.17 \\
\hline 20 & 14.19 & 12.53 & 16.47 & 11.92 \\
\hline
\end{tabular}

Table C-6 Flexural strength (kpsi) data for the virgin composites.

\begin{tabular}{|c|c|c|c|c|}
\hline & SEBS-g-MA & & EP-g-MA & \\
\hline $\begin{array}{l}\text { Rubber } \\
\mathrm{wt} \%\end{array}$ & $\begin{array}{l}23.62 \quad \mathrm{wt}^{0} \% \\
\text { glass }\end{array}$ & $\begin{array}{l}14.79 \mathrm{wt}^{0} \% \\
\text { glass }\end{array}$ & $\begin{array}{ll}23.62 \quad \mathrm{wt} \% \\
\text { glass }\end{array}$ & $\begin{array}{l}14.79 \mathrm{wt} \% \\
\text { glass }\end{array}$ \\
\hline 0 & 28.41 & 22.13 & 28.41 & 22.13 \\
\hline 5 & 25.13 & 18.85 & 23.43 & 18.96 \\
\hline 10 & 21.05 & 17.22 & 19.4 & 15.78 \\
\hline 15 & 18.72 & 14.43 & 17.69 & 14.22 \\
\hline 20 & 15.6 & 13.61 & 13.67 & 12.03 \\
\hline
\end{tabular}


Table C-7 Impact strength (ft-lb/in) data for the recycled composites.

\begin{tabular}{|l|ll|ll|ll|l|}
\hline & EP-g-MA & & & \multicolumn{3}{|l|}{ SEBS-g-MA } \\
\hline Rubber & 23.62 & wt\% & 14.79 & wt\% & 23.62 & wt\% & $14.79 \quad$ wt $\%$ \\
wt\% & glass & glass & & glass & & glass \\
\hline 0 & 1.2 & 0.71 & 1.2 & 0.71 \\
\hline 5 & 2.09 & 1.26 & 2.11 & 0.93 \\
\hline 10 & 2.39 & 1.96 & 2.26 & 1.96 \\
\hline 15 & 3.25 & 2.32 & 3 & 2.4 \\
\hline 20 & 4.31 & 3.29 & 4.07 & 4.36 \\
\hline
\end{tabular}

Table C-8 Impact strength (ft-lb/in) data for the virgin composites.

\begin{tabular}{|c|c|c|c|c|}
\hline & EP-g-MA & & SEBS-g-MA & \\
\hline $\begin{array}{l}\text { Rubber } \\
\text { wt } \%\end{array}$ & $\begin{array}{ll}23.62 & \mathrm{wt} \% \\
\text { glass } & \end{array}$ & $\begin{array}{ll}14.79 & \mathrm{wt} \% \\
\text { glass } & \end{array}$ & $\begin{array}{ll}23.62 & \mathrm{wt} \% \\
& \\
\text { glass } & \end{array}$ & $\begin{array}{ll}14.79 & \mathrm{wt} \% \\
& \\
\text { glass } & \end{array}$ \\
\hline 0 & 1.22 & 0.76 & 1.22 & 0.76 \\
\hline 5 & 2.23 & 1.65 & 2.18 & 2.06 \\
\hline 10 & 2.95 & 2.61 & 2.67 & 2.49 \\
\hline 15 & 4.05 & 2.97 & 3.46 & 3.23 \\
\hline 20 & 5.34 & 4.97 & 4.7 & 4.51 \\
\hline
\end{tabular}

